\title{
Determinants of health status in COPD
}

\author{
Citation for published version (APA):
}

Wilke, S. (2016). Determinants of health status in COPD. [Doctoral Thesis, Maastricht University]. Datawyse / Universitaire Pers Maastricht. https://doi.org/10.26481/dis.20160203sw

Document status and date:

Published: 01/01/2016

DOI:

10.26481/dis.20160203sw

Document Version:

Publisher's PDF, also known as Version of record

\section{Please check the document version of this publication:}

- A submitted manuscript is the version of the article upon submission and before peer-review. There can be important differences between the submitted version and the official published version of record.

People interested in the research are advised to contact the author for the final version of the publication, or visit the DOI to the publisher's website.

- The final author version and the galley proof are versions of the publication after peer review.

- The final published version features the final layout of the paper including the volume, issue and page numbers.

Link to publication

\footnotetext{
General rights rights.

- You may freely distribute the URL identifying the publication in the public portal. please follow below link for the End User Agreement:

www.umlib.nl/taverne-license

Take down policy

If you believe that this document breaches copyright please contact us at:

repository@maastrichtuniversity.nl

providing details and we will investigate your claim.
}

Copyright and moral rights for the publications made accessible in the public portal are retained by the authors and/or other copyright owners and it is a condition of accessing publications that users recognise and abide by the legal requirements associated with these

- Users may download and print one copy of any publication from the public portal for the purpose of private study or research.

- You may not further distribute the material or use it for any profit-making activity or commercial gain

If the publication is distributed under the terms of Article $25 \mathrm{fa}$ of the Dutch Copyright Act, indicated by the "Taverne" license above, 
Copyright @ Sarah Wilke, Maastricht 2016

ISBN: $\quad 9789461595102$

Layout: Datawyse / Universitaire Pers Maastricht

Cover: $\quad$ KATHARINA SCHMIDT | Graphic Design

Production: Datawyse | Universitaire Pers Maastricht

This thesis was financially supported by the Lung Foundation Netherlands, Amersfoort, the Netherlands (Grant 3.4.10.015) and GlaxoSmithKline B.V., Zeist, the Netherlands (Grant SC0115406).

Printing and distribution of this thesis was financially supported by CIRO, Horn, the Netherlands; Lung Foundation Netherlands, Amersfoort, the Netherlands; Stichting Astmabestrijding, Amsterdam, the Netherlands; Boehringer Ingelheim B.V., Alkmaar, the Netherlands and Chiesi Pharmaceuticals B.V., Rijswijk, the Netherlands. 


\title{
Determinants of Health Status in COPD
}

\author{
PROEFSCHRIFT
}

ter verkrijging van de graad van doctor aan de Universiteit Maastricht, op gezag van de Rector Magnificus, Prof. dr. L.L.G. Soete, volgens het besluit van het College van Decanen,

in het openbaar te verdedigen op

woensdag, 3 februari 2016, om 10:00 uur

door

Sarah Wilke

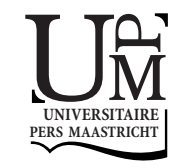


Promotor

Prof. dr. E.F.M. Wouters

Copromotores

Dr. F.M.E. Franssen

Dr. M.A. Spruit

Beoordelingscommissie

Prof. dr. H.J.G.M. Crijns (voorzitter)

Prof. dr. F. Blasi (Universiteit van Milaan, Italië)

Prof. dr. J.P. Kooman

Prof. dr. N.M. Siafakas (Universiteit van Kreta, Griekenland)

Prof. dr. F.W.M.J. Smeenk 


\section{TABLE OF CONTENTS}

CHAPTER 1 General Introduction

CHAPTER 2 Correlations between disease-specific and generic health status questionnaires in patients with advanced COPD:

a one-year observational study

CHAPTER 3 Determinants of one-year changes in disease-specific health status in patients with advanced chronic obstructive pulmonary disease: a one-year observational study

CHAPTER 4 One-year change in health status and subsequent outcomes in chronic obstructive pulmonary disease

CHAPTER 5 The 2014 updated GOLD strategy: a comparison of the various scenarios

CHAPTER 6 Impact of symptoms of anxiety and depression on COPD Assessment Test (CAT) scores

CHAPTER 7 Prevalence of peripheral artery disease and its impact in patients with COPD in the COSYCONET study

CHAPTER 8 Echocardiographic abnormalities and their impact on health status in patients with COPD

CHAPTER 9 General Discussion

Summary

Samenvatting

Zusammenfassung

Valorization

Acknowledgements

Curriculum vitae 



\section{CHAPTER 1}

General Introduction 



\section{CHRONIC OBSTRUCTIVE PULMONARY DISEASE}

The Global initiative for chronic Obstructive Pulmonary Disease (GOLD) guidelines define chronic obstructive pulmonary disease (COPD) as "a common preventable and treatable disease, which is characterized by persistent airflow limitation that is usually progressive and associated with an enhanced chronic inflammatory response in the airways and the lungs to noxious particles or gases." COPD is an umbrella term for chronic bronchitis and pulmonary emphysema, both chronic illnesses impairing the airflow in the lungs. Patients with COPD suffer from symptoms like chronic cough, sputum production and/or dyspnoea and frequently experience exacerbations, characterized by acute worsening of disease symptoms [1]. Accordingly, they often experience lack of energy or fatigue, sleeplessness and difficulties of daily activities [2, 3]. Although COPD is a heterogeneous multisystem disease, it is still primarily diagnosed by the degree of airflow obstruction into mild, moderate, severe and very severe COPD. Tobacco smoke has yet been identified as a major risk factor for COPD [1]. However, although COPD develops over decades and is mostly diagnosed at the age of $40-50$, there is still more evidence that it already develops before birth or in early childhood [4].

\section{A SERIOUS PUBLIC HEALTH PROBLEM}

COPD belongs to the leading contributors to disease burden in older people [5]. Worldwide, the prevalence of COPD is approximately $10 \%$ with highest prevalence in older ages; i.e. $19-47 \%$ and $6-33 \%$ for men and women, respectively, aged 70 years or older [6]. However, Vanfleteren and colleagues recently reported a prevalence of COPD of $24 \%$ in a sample of a Dutch population [7]. In 2005, more than 3 million people died of COPD which is estimated to double the next years: COPD is expected to be the fourth leading cause of death in 2030 [8].

The economic burden of COPD is substantial: hospitalizations are the major direct cost drivers of this disease which continue to increase [9-11]. In Europe, health care costs per patient per year vary between $€ 900$ and $€ 3900$, dependent on the country and severity of the disease [12]. In 2007, the costs for COPD were $€ 415$ million in the Netherlands. Although most cases of COPD are preventable, the disease cannot be cured. Appropriate pharmacological as well as non-pharmacological treatment (i.e., pulmonary rehabilitation) can reduce COPD symptoms and improve health status as well as exercise tolerance $[1,13]$. 


\section{IMPACT ON HEALTH STATUS}

Beyond the economic dimension of the disease, COPD has an important impact on a patient's life. Patients with COPD report an impaired health status irrespective of the degree of airflow obstruction [14]. Health status can be defined as "the impact of health on a person's ability to perform and derive fulfilment from the activities of daily life". Accordingly, self-reported health status includes health-related quality of life and functional status [15]. Poor health status in COPD is multi-factorial and associated with higher levels of dyspnoea [16], reduced exercise capacity [17], symptoms of anxiety and depression [18] and frequent exacerbations and mortality [19].

Given the importance of health status in COPD, numerous questionnaires were developed in order to assess this outcome. These questionnaires address emotional, psychological and physical effects of the disease, but most of their items usually concern practical aspects of disturbance to daily life [20]. Health status can be assessed using generic (i.e., intended for general use, irrespective of the underlying disease) or disease-specific health status questionnaires (i.e., related to a specific condition or group). Since generic and disease-specific questionnaires cover different aspects of health status, it is important to understand the association and agreement of both questionnaires. Previous cross-sectional studies showed a moderate to strong association between disease-specific and generic health status questionnaires in patients with COPD [21-23]. To understand causal relationships between disease-specific and generic questionnaires, longitudinal studies assessing the association between changes in disease-specific as well as generic health status questionnaires are required.

In COPD studies, health status is often assessed by the disease-specific St. George's Respiratory Questionnaire (SGRQ) [24]. The SGRQ has primarily been used to measure a specific effect of a certain pharmacological or nonpharmacological intervention [25-27] or the impact of several clinical characteristics $[16,28,29]$ on health status. However, knowledge about determinants of change in SGRQ score is scarce. Understanding determinants of health status in patients with COPD is crucial to successfully manage COPD and consequently improve health status. Additionally, the impact of clinically relevant changes in health status on outcomes is not known yet.

To date, airflow limitation is largely used as single measure for COPD diagnoses and classification [1]. However, this parameter is only poorly-to-moderately associated with disease activity and progression, extra-pulmonary features, comorbidities and prognosis in COPD patients [30-32]. Therefore, the GOLD 
document recommends to include the assessment of health status as an objective in disease diagnosis and follow up. Accordingly, the 2011 GOLD strategy started classifying patients in four new groups (GOLD groups $A$ to $D$ ) based on the combination of the degree of airflow limitation and the number of exacerbations in the past 12 months and the severity of symptoms or impaired health status (Figure 1) [1]. To assess the severity of symptoms, the GOLD strategy recommends several simple and reliable assessment tools which might impact patient assignment [33].

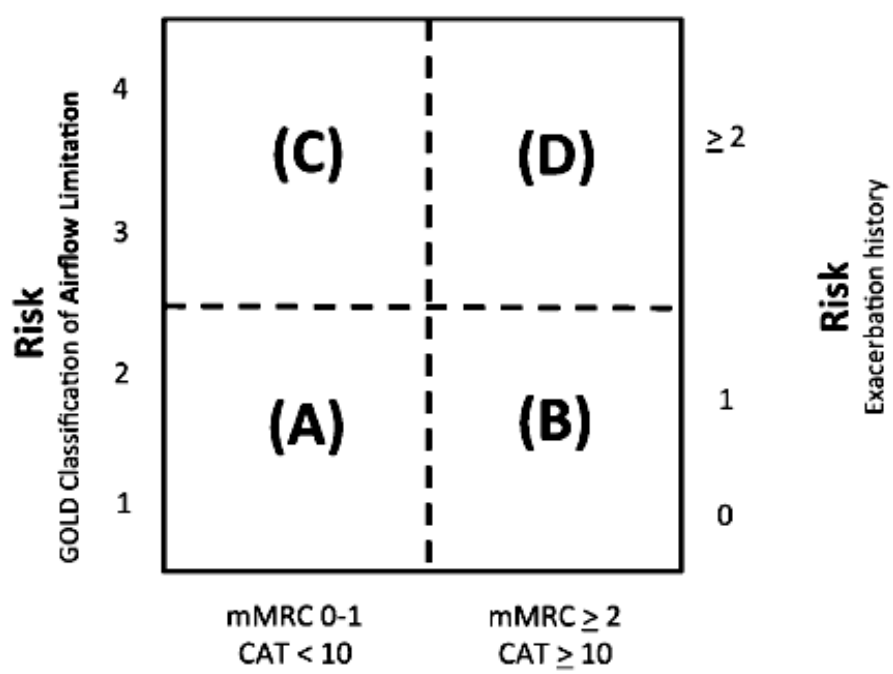

\section{Symptoms \\ (mMRC or CAT score)}

FIGURE 1. Combined COPD Assessment as introduced by the GOLD 2011 guidelines [1]. CAT, COPD Assessment Test; mMRC, modified Medical Research Council dyspnoea scale.

\section{COPD, COMORBIDITIES AND HEALTH STATUS}

Beyond respiratory impairment, patients with COPD often suffer from multiple comorbidities which substantially contribute to the burden of the disease. Comorbidities are defined as the coexistence of any other medical conditions alongside COPD [1]. The majority of patients (up to 98\%) have one or more comorbidities [30,34]. Patients with COPD use a disproportionate amount of health services for comorbid diseases, showing an important burden of comorbidities in patients with COPD on the healthcare system [35]. In addition, comorbidities are associated with reduced survival, underlying the importance to appropriately detect and consequently treat patients with COPD and concurrent diseases [1]. Health status in patients with COPD can be worsened by the 
presence of co-morbidities [30,36]. For instance, in a large European primary care study, patients with three or more comorbidities had a worse health status compared to those with no or one or two comorbidities [36]. However, the magnitude of the impact of comorbidities on health status depends on the comorbidity studied [30].

Around one third of patients with COPD experience symptoms of anxiety and depression [37] while anxiety was even associated with an increased risk for death [38]. Previous studies showed an association between symptoms of anxiety and depression and SGRQ scores $[39,40]$. To date, the impact of symptoms of anxiety and depression on health status as assessed with the short and simple COPD Assessment Test remains unknown. Furthermore, the distribution of patients with symptoms of anxiety and depression across the updated GOLD classification remains currently unknown. Sillen and colleagues reported a prevalence of symptoms of anxiety and depression of $38 \%$ and $32 \%$ in COPD patients with GOLD D, respectively [41]. Previously, it has been shown that clinically relevant symptoms of anxiety and depression are more common in patients with very severe COPD compared to those with mild or moderate COPD [39].

Because of their direct impact on survival [42-44], vascular and cardiovascular diseases are probably the most important coexisting diseases which occur frequently in COPD [1]. Peripheral artery disease (PAD), an atherosclerotic process that refers to the occlusion of the arteries in the lower limbs [45], is a risk factor for cardiovascular diseases and often described as a "silent killer": a high prevalence of persons with PAD are asymptomatic and accordingly unaware of the disease [46]. Currently, there is no established indicator of cardiovascular risk in patients with COPD, which is simple and accurate to be included in routine clinical practice. The ankle-brachial index $(A B I)$ is the ratio of the systolic blood pressure measured at the ankle to that measured at the brachial artery and is commonly used as a non-invasive diagnostic measure for PAD [47]. Knowledge about the impact of PAD and its impact on health status and functional capacity in patients with COPD in a large cohort of patients with COPD is scarce.

Probably due to shared pathophysiological mechanisms, cardiac diseases also often remain unrecognized in patients with COPD [48]. For instance, Rutten and colleagues reported a prevalence of $20 \%$ for previously undiagnosed heart failure in primary care patients with COPD [49]. Accordingly, the GOLD document recommends to diagnose and treat cardiac diseases in patients with COPD appropriately [1]. The frequency of cardiac diseases as objectively assessed by echocardiography in patients referred for a comprehensive pulmonary rehabilitation program is currently unknown. Furthermore, patients with cardiac diseas- 
es $[50,51]$ as well as patients with COPD $[14,16]$ report an impaired health status. Therefore, it is reasonable to hypothesize that patients with COPD and concurrent cardiac diseases report a worse health status compared to those without cardiac diseases. In addition, since it has previously been suggested that self-reported comorbidities may impact outcomes of pulmonary rehabilitation [52], it is important to detect, treat and monitor these diseases to consequently understand their clinical effects and to ensure patients' safety during their pulmonary rehabilitation programme.

\section{AIMS OF THIS THESIS}

Health status and comorbidities are complex concepts in patients with COPD. A better understanding of these concepts will encourage integrated disease management. Therefore, the aims of this thesis are:

- To determine whether and to what extent a disease-specific health status questionnaire correlates with three generic health status questionnaires in patients with advanced COPD; and to determine the correlation between changes in these health status questionnaires.

- To identify baseline and longitudinal determinants of change in SGRQ total score in patients with advanced COPD.

- To explore the impact of clinically relevant changes in disease-specific health status on the likelihood of having an exacerbation, hospitalization or dying in a large cohort of patients with COPD.

- To investigate the impact of four different assessment tools for symptoms and different definitions of future risk on the frequency distribution of the new GOLD classification; and to study differences in clinical characteristics between the GOLD groups using these different scenarios.

- To assess the impact of symptoms of anxiety and depression on diseasespecific health status in patients with COPD; and to investigate the relationship between the updated GOLD classification and symptoms of anxiety and depression.

- To investigate the frequencies of cardiac diseases as assessed with echocardiography in patients with COPD referred for pulmonary rehabilitation; to study the rates of previous under-diagnosis and under-treatment of these abnormalities; and to examine the impact of echocardiographic abnormalities on disease-specific health status.

- To determine the prevalence of PAD and its impact on disease-specific as well as generic health status and functional capacity in a large cohort of patients with COPD. 
An overview of the questionnaires used in this thesis can be found in the appendix of this chapter.

\section{OUTLINE OF THIS THESIS}

First, this thesis will give an overview of health status measurement as well as determinants of health status and its impact on outcomes in patients with COPD. Further, this thesis will focus on the impact of comorbidities on health status in patients with COPD.

Longitudinal studies analysing the correlations between disease-specific and generic health status questionnaires at different time points in patients with advanced COPD are lacking. Chapter 2 shows the correlation between a disease-specific (SGRQ) and generic health status questionnaires (EuroQol-5Dimensions, EQ-5D; Assessment of Quality of Life instrument, AQoL; Medical Outcomes Study 36-Item Short-Form Health Survey, SF-36) at four different time points in patients with advanced COPD and discusses the correlation between changes in these health status questionnaires during one-year follow-up. Further, chapter 3 describes baseline and longitudinal determinants of one-year changes in disease-specific health status as assessed with SGRQ in patients with advanced COPD. To date, it remains unknown whether and to what extent clinically relevant changes in disease-specific health status may affect morbidity and mortality in patients with COPD. Chapter 4 explores the impact of clinically relevant one-year changes in SGRQ total scores on the likelihood of having an exacerbation, hospitalisation or dying in a large cohort of patients with COPD enrolled in the Evaluation of COPD Longitudinally to Identify Predictive Surrogate Endpoints (ECLIPSE) study. Since health status plays an important role in COPD assessment and management, chapter 5 describes the impact of several GOLD-recommended assessment methods to classify COPD on the frequency distribution of GOLD groups $A$ to $D$ as well as their clinical characteristics (i.e., health status, functional mobility, symptoms of anxiety and depression and selfreported comorbidities).

Comorbidities occur frequently in patients with COPD and may worsen patients' health status. Chapter 6 discusses the impact of symptoms of anxiety and depression on health status as assessed with the COPD Assessment Test (CAT) in patients with COPD entering pulmonary rehabilitation at CIRO, Netherlands, and LHL Health Röros, Norway. Furthermore, this chapter investigates the relationship between the updated GOLD classification and symptoms of anxiety and depression. In chapter 7, the prevalence and impact of PAD on disease- 
specific as well as generic health status and functional capacity in a large cohort of patients with COPD enrolled in the German COPD and Systemic Consequences-Comorbidities Network (COSYCONET) cohort study are described. Chapter 8 demonstrates the prevalence and impact of cardiac diseases as objectively assessed with echocardiography on disease-specific health status in patients with COPD referred for pulmonary rehabilitation. Finally, chapter 9 generally discusses previous chapters in a broader perspective and gives future directions for research. 


\section{REFERENCES}

1. Vestbo J, Hurd SS, Agusti AG, Jones PW, Vogelmeier C, Anzueto A, Barnes PJ, Fabbri LM, Martinez FJ, Nishimura M, et al: Global strategy for the diagnosis, management, and prevention of chronic obstructive pulmonary disease: GOLD executive summary. Am J Respir Crit Care Med 2013, 187:347-365.

2. Vaes AW, Wouters EF, Franssen FM, Uszko-Lencer NH, Stakenborg KH, Westra M, Meijer K, Schols AM, Janssen PP, Spruit MA: Task-related oxygen uptake during domestic activities of daily life in patients with COPD and healthy elderly subjects. Chest 2011, 140:970-979.

3. Janssen DJ, Spruit MA, Uszko-Lencer NH, Schols JM, Wouters EF: Symptoms, comorbidities, and health care in advanced chronic obstructive pulmonary disease or chronic heart failure. $J$ Palliat Med 2011, 14:735-743.

4. Postma DS, Bush A, van den Berge M: Risk factors and early origins of chronic obstructive pulmonary disease. Lancet 2015, 385:899-909.

5. Prince MJ, Wu F, Guo Y, Gutierrez Robledo LM, O'Donnell M, Sullivan R, Yusuf S: The burden of disease in older people and implications for health policy and practice. Lancet 2015, 385:549562.

6. Buist AS, McBurnie MA, Vollmer WM, Gillespie S, Burney P, Mannino DM, Menezes AM, Sullivan $\mathrm{SD}$, Lee TA, Weiss KB, et al: International variation in the prevalence of COPD (the BOLD Study): a population-based prevalence study. Lancet 2007, 370:741-750.

7. Vanfleteren LE, Franssen FM, Wesseling G, Wouters EF: The prevalence of chronic obstructive pulmonary disease in Maastricht, the Netherlands. Respir Med 2012, 106:871-874.

8. Mathers CD, Loncar D: Projections of global mortality and burden of disease from 2002 to 2030. PLoS Med 2006, 3:e442.

9. Teo WS, Tan WS, Chong WF, Abisheganaden J, Lew YJ, Lim TK, Heng BH: Economic burden of chronic obstructive pulmonary disease. Respirology 2012, 17:120-126.

10. Blanchette CM, Dalal AA, Mapel D: Changes in COPD demographics and costs over 20 years. $J$ Med Econ 2012, 15:1176-1182.

11. Bustacchini S, Chiatti C, Furneri G, Lattanzio F, Mantovani LG: The economic burden of chronic obstructive pulmonary disease in the elderly: results from a systematic review of the literature. Curr Opin Pulm Med 2011, 17 Suppl 1:S35-41.

12. Chapman KR, Mannino DM, Soriano JB, Vermeire PA, Buist AS, Thun MJ, Connell C, Jemal A, Lee TA, Miravitlles M, et al: Epidemiology and costs of chronic obstructive pulmonary disease. Eur Respir J 2006, 27:188-207.

13. Spruit MA, Singh SJ, Garvey C, Zuwallack R, Nici L, Rochester C, Hill K, Holland AE, Lareau SC, Man WD, et al: An official american thoracic society/european respiratory society statement: key concepts and advances in pulmonary rehabilitation. Am J Respir Crit Care Med 2013, 188:e13-64.

14. Jones PW, Brusselle G, Dal Negro RW, Ferrer M, Kardos P, Levy ML, Perez T, Soler-Cataluna JJ, van der Molen T, Adamek L, Banik N: Health-related quality of life in patients by COPD severity within primary care in Europe. Respir Med 2011, 105:57-66.

15. Curtis JR, Patrick DL: The assessment of health status among patients with COPD. Eur Respir $J$ Supp/2003, 41:36s-45s.

16. Janssen DJ, Franssen FM, Wouters EF, Schols JM, Spruit MA: Impaired health status and care dependency in patients with advanced COPD or chronic heart failure. Qual Life Res 2011, 20:1679-1688.

17. Spruit MA, Watkins ML, Edwards LD, Vestbo J, Calverley PM, Pinto-Plata V, Celli BR, Tal-Singer R, Wouters EF: Determinants of poor 6-min walking distance in patients with COPD: the ECLIPSE cohort. Respir Med 2010, 104:849-857. 
18. Blakemore A, Dickens C, Guthrie E, Bower P, Kontopantelis E, Afzal C, Coventry PA: Depression and anxiety predict health-related quality of life in chronic obstructive pulmonary disease: systematic review and meta-analysis. Int J Chron Obstruct Pulmon Dis 2014, 9:501-512.

19. Domingo-Salvany A, Lamarca R, Ferrer M, Garcia-Aymerich J, Alonso J, Felez M, Khalaf A, Marrades RM, Monso E, Serra-Batlles J, Anto JM: Health-related quality of life and mortality in male patients with chronic obstructive pulmonary disease. Am J Respir Crit Care Med 2002, 166:680-685.

20. Jones PW: Health status measurement in chronic obstructive pulmonary disease. Thorax 2001, 56:880-887.

21. Maly $\mathrm{M}$, Vondra V: Generic versus disease-specific instruments in quality-of-life assessment of chronic obstructive pulmonary disease. Methods Inf Med 2006, 45:211-215.

22. Pickard AS, Yang Y, Lee TA: Comparison of health-related quality of life measures in chronic obstructive pulmonary disease. Health Qual Life Outcomes 2011, 9:26.

23. Mazur W, Kupiainen H, Pitkaniemi J, Kilpelainen M, Sintonen H, Lindqvist A, Kinnula VL, Laitinen $\mathrm{T}$ : Comparison between the disease-specific Airways Questionnaire 20 and the generic 15D instruments in COPD. Health Qual Life Outcomes 2011, 9:4.

24. Jones PW, Quirk FH, Baveystock CM, Littlejohns P: A self-complete measure of health status for chronic airflow limitation. The St. George's Respiratory Questionnaire. Am Rev Respir Dis 1992, 145:1321-1327.

25. Eskander A, Waddell TK, Faughnan ME, Chowdhury N, Singer LG: BODE index and quality of life in advanced chronic obstructive pulmonary disease before and after lung transplantation. $J$ Heart Lung Transplant 2011, 30:1334-1341.

26. Hanania NA, Sharafkhaneh A, Celli B, Decramer M, Lystig T, Kesten S, Tashkin D: Acute bronchodilator responsiveness and health outcomes in COPD patients in the UPLIFT trial. Respir Res 2011, 12:6.

27. Sillen MJ, Franssen FM, Delbressine JM, Vaes AW, Wouters EF, Spruit MA: Efficacy of lowerlimb muscle training modalities in severely dyspnoeic individuals with COPD and quadriceps muscle weakness: results from the DICES trial. Thorax 2014, 69:525-531.

28. Burgel PR, Escamilla R, Perez T, Carre P, Caillaud D, Chanez P, Pinet C, Jebrak G, Brinchault G, Court-Fortune I, et al: Impact of comorbidities on COPD-specific health-related quality of life. Respir Med 2013, 107:233-241.

29. Sant'Anna CA, Stelmach R, Zanetti Feltrin MI, Filho WJ, Chiba T, Cukier A: Evaluation of healthrelated quality of life in low-income patients with COPD receiving long-term oxygen therapy. Chest 2003, 123:136-141.

30. Vanfleteren LE, Spruit MA, Groenen M, Gaffron S, van Empel VP, Bruijnzeel PL, Rutten EP, Op 't Roodt J, Wouters EF, Franssen FM: Clusters of comorbidities based on validated objective measurements and systemic inflammation in patients with chronic obstructive pulmonary disease. Am J Respir Crit Care Med 2013, 187:728-735.

31. Spruit MA, Polkey MI, Celli B, Edwards LD, Watkins ML, Pinto-Plata V, Vestbo J, Calverley PM, Tal-Singer R, Agusti A, et al: Predicting outcomes from 6-minute walk distance in chronic obstructive pulmonary disease. J Am Med Dir Assoc 2012, 13:291-297.

32. Graat-Verboom L, van den Borne BE, Smeenk FW, Spruit MA, Wouters EF: Osteoporosis in COPD outpatients based on bone mineral density and vertebral fractures. $J$ Bone Miner Res 2011, 26:561-568.

33. Jones PW, Adamek L, Nadeau G, Banik N: Comparisons of health status scores with MRC grades in COPD: implications for the GOLD 2011 classification. Eur Respir J2013, 42:647-654.

34. Schnell K, Weiss CO, Lee T, Krishnan JA, Leff B, Wolff JL, Boyd C: The prevalence of clinicallyrelevant comorbid conditions in patients with physician-diagnosed COPD: a cross-sectional study using data from NHANES 1999-2008. BMC Pulm Med 2012, 12:26.

35. Gershon AS, Mecredy GC, Guan J, Victor JC, Goldstein R, To T: Quantifying comorbidity in individuals with COPD: a population study. Eur Respir J 2015, 45:51-59. 
36. Jones PW, Brusselle G, Dal Negro RW, Ferrer M, Kardos P, Levy ML, Perez T, Soler Cataluna JJ, van der Molen T, Adamek L, Banik N: Properties of the COPD assessment test in a crosssectional European study. Eur Respir J 2011, 38:29-35.

37. Panagioti M, Scott C, Blakemore A, Coventry PA: Overview of the prevalence, impact, and management of depression and anxiety in chronic obstructive pulmonary disease. Int J Chron Obstruct Pulmon Dis 2014, 9:1289-1306.

38. Divo M, Cote C, de Torres JP, Casanova C, Marin JM, Pinto-Plata V, Zulueta J, Cabrera C, Zagaceta J, Hunninghake G, Celli B: Comorbidities and risk of mortality in patients with chronic obstructive pulmonary disease. Am J Respir Crit Care Med 2012, 186:155-161.

39. Janssen DJ, Spruit MA, Leue C, Gijsen C, Hameleers H, Schols JM, Wouters EF: Symptoms of anxiety and depression in COPD patients entering pulmonary rehabilitation. Chron Respir Dis 2010, 7:147-157.

40. Lou P, Zhu Y, Chen P, Zhang P, Yu J, Zhang N, Chen N, Zhang L, Wu H, Zhao J: Prevalence and correlations with depression, anxiety, and other features in outpatients with chronic obstructive pulmonary disease in China: a cross-sectional case control study. BMC Pulm Med 2012, 12:53.

41. Sillen MJ, Franssen FM, Delbressine JM, Uszko-Lencer NH, Vanfleteren LE, Rutten EP, Wouters EF, Spruit MA: Heterogeneity in clinical characteristics and co-morbidities in dyspneic individuals with COPD GOLD D: Findings of the DICES trial. Respir Med 2013, 107:1186-1194.

42. Mullerova H, Agusti A, Erqou S, Mapel DW: Cardiovascular comorbidity in COPD: systematic literature review. Chest 2013, 144:1163-1178.

43. Macchia A, Rodriguez Moncalvo JJ, Kleinert M, Comignani PD, Gimeno G, Arakaki D, Laffaye N, Fuselli JJ, Massolin HP, Gambarte J, et al: Unrecognised ventricular dysfunction in COPD. Eur Respir J 2012, 39:51-58.

44. Sibila O, Mortensen EM, Anzueto A, Laserna E, Restrepo MI: Prior cardiovascular disease increases long-term mortality in COPD patients with pneumonia. Eur Respir J 2014, 43:36-42.

45. Gillum RF: Peripheral arterial occlusive disease of the extremities in the United States: hospitalization and mortality. Am Heart J 1990, 120:1414-1418.

46. Dhaliwal G, Mukherjee D: Peripheral arterial disease: Epidemiology, natural history, diagnosis and treatment. Int J Angio/2007, 16:36-44.

47. Aboyans V, Criqui MH, Abraham P, Allison MA, Creager MA, Diehm C, Fowkes FG, Hiatt WR, Jonsson $B$, Lacroix $P$, et al: Measurement and interpretation of the ankle-brachial index: a scientific statement from the American Heart Association. Circulation 2012, 126:2890-2909.

48. Huiart L, Ernst P, Suissa S: Cardiovascular morbidity and mortality in COPD. Chest 2005, 128:2640-2646.

49. Rutten FH, Cramer MJ, Grobbee DE, Sachs AP, Kirkels JH, Lammers JW, Hoes AW: Unrecognized heart failure in elderly patients with stable chronic obstructive pulmonary disease. Eur Heart J 2005, 26:1887-1894.

50. Wu JR, Lennie TA, Frazier SK, Moser DK: Health-Related Quality of Life, Functional Status, and Cardiac Event-Free Survival in Patients With Heart Failure. J Cardiovasc Nurs 2015.

51. Bainey KR, Norris CM, Gupta M, Southern D, Galbraith D, Knudtson ML, Graham MM: Altered health status and quality of life in South Asians with coronary artery disease. Am Heart J2011, 162:501-506.

52. Crisafulli E, Gorgone P, Vagaggini B, Pagani M, Rossi G, Costa F, Guarriello V, Paggiaro P, Chetta A, de Blasio F, et al: Efficacy of standard rehabilitation in COPD outpatients with comorbidities. Eur Respir J 2010, 36:1042-1048. 


\section{APPENDIX}

\section{GENERIC HEALTH STATUS}

Generic health status questionnaires are intended for general use, irrespective of the underlying disease. They address a wide range of disorders across a range of conditions [1].

\section{Assessment of Quality of Life instrument (AQoL)}

AQoL consists of 15 items divided into five domains: illness, independent living, social relationships, physical senses, and psychological well-being [2]. The total score ranges from -0.04 to 1.00 while higher scores represent better health status. The minimum clinically important difference (MCID) for the AQoL has not been established yet but has generally been suggested to be 0.06 points [3].

\section{EuroQol-5-Dimensions (EQ-5D)}

EQ-5D consists of five items (mobility, self-care, usual activity, pain/discomfort, and anxiety/depression) with three levels (no problems, some problems and extreme problems) and a visual analogue scale (VAS) for valuing health on a rating scale from 0 (worst imaginable health state) to 100 (best imaginable health state). An index score is provided which ranges from -0.59 (worst) to 1.0 (best) [4]. An MCID of 8 points for the EQ-5D VAS has been proposed for patients with moderate-to-severe COPD [5]. In chapter 7, the German TTO tariff is described to calculate utility scores ranging from 0 to 1 with higher values indicating better health [6]. A MCID has not been established yet but may range between 0.08 and 0.10 points according to previous studies in non-COPD patients [7-9].

\section{Study 36-Item Short-Form Health Survey (SF-36)}

SF-36 consists of 36 items divided into eight domains: physical functioning, role-physical, bodily pain, general health, vitality, social functioning, roleemotional, and mental health. For each domain, scores range from 0 (worst) to 100 points (best) [10]. A Physical Component Summary measure (PCS) and a Mental Component Summary measure (MCS) are provided using norm-based methods with scores from a Dutch general population [11]. These summary measure scores are transformed to create a minimum and maximum possible score of 0 and 100 points while higher scores represent better health status. All scores below 50 points can be interpreted as below the general population 
norm [10]. General suggestions for an MCID for the SF-36 range between 3 and 5 points [12].

\section{DISEASE-SPECIFIC HEALTH STATUS}

In contrast to generic health status questionnaires, disease-specific health status questionnaires are narrow in focus and related to a specific condition or group [1].

\section{COPD Assessment Test (CAT)}

CAT consists of eight items regarding symptoms, energy, sleep and activity ranging from 0 to 5 . Accordingly, it provides a total score ranging from 0 to 40 while higher scores represent worse disease-specific health status [13]. The MCID of the CAT has been suggested to be 2 points for patients with COPD [14].

\section{Clinical COPD Questionnaire (CCQ)}

CCQ consists of ten items and provides three domain scores (symptoms, functional and mental state) and an overall score ranging from 0 to 6 points [15] with higher scores representing worse health status scores. A difference of 0.4 points has been suggested as MCID [16].

\section{St. George's Respiratory Questionnaire (SGRQ)}

SGRQ contains 50 items with 76 weighted responses divided into three domain scores (symptoms, activity and impact) and a total score [17]. More recently, the COPD-specific version of the SGRQ (SGRQ-C) has been developed consisting of 40 items [18]. Domain as well as total scores range from 0 (optimal) to 100 points (worst) for both versions. A change of 4 units is considered as the MCID [19]. 


\section{REFERENCES}

1. Maly $\mathrm{M}$, Vondra V: Generic versus disease-specific instruments in quality-of-life assessment of chronic obstructive pulmonary disease. Methods Inf Med 2006, 45:211-215.

2. Hawthorne G, Richardson J, Osborne R: The Assessment of Quality of Life (AQoL) instrument: a psychometric measure of health-related quality of life. Qual Life Res 1999, 8:209-224.

3. Hawthorne G, Osborne R: Population norms and meaningful differences for the Assessment of Quality of Life (AQoL) measure. Aust N Z J Public Health 2005, 29:136-142.

4. Dolan P: Modeling valuations for EuroQol health states. Med Care 1997, 35:1095-1108.

5. Zanini A, Aiello M, Adamo D, Casale S, Cherubino F, Della Patrona S, Raimondi E, Zampogna E, Chetta A, Spanevello A: Estimation of minimal clinically important difference in EQ-5D visual analog scale score after pulmonary rehabilitation in subjects with COPD. Respir Care 2015, 60:88-95.

6. Greiner W, Claes C, Busschbach JJ, von der Schulenburg JM: Validating the EQ-5D with time trade off for the German population. Eur J Health Econ 2005, 6:124-130.

7. Kim SK, Kim SH, Jo MW, Lee SI: Estimation of minimally important differences in the EQ-5D and SF-6D indices and their utility in stroke. Health Qual Life Outcomes 2015, 13:227.

8. Kwakkenbos L, Fransen J, Vonk MC, Becker ES, Jeurissen M, van den Hoogen FH, van den Ende $\mathrm{CH}$ : A comparison of the measurement properties and estimation of minimal important differences of the EQ-5D and SF-6D utility measures in patients with systemic sclerosis. Clin Exp Rheumato/2013, 31:50-56.

9. Pickard AS, Neary MP, Cella D: Estimation of minimally important differences in EQ-5D utility and VAS scores in cancer. Health Qual Life Outcomes 2007, 5:70.

10. Ware JE, Snow KK, Kosinski M: SF-36 health survey manual and interpretation guide. Boston, MA: The Health Institute, New England Medical Center Hospitals; 1993.

11. Kruijshaar ME, Hoeymans N, Bijl RV, Spijker J, Essink-Bot ML: Levels of disability in major depression: findings from the Netherlands Mental Health Survey and Incidence Study (NEMESIS). J Affect Disord 2003, 77:53-64.

12. Hays RD, Morales LS: The RAND-36 measure of health-related quality of life. Ann Med 2001, 33:350-357.

13. Jones PW, Harding G, Berry P, Wiklund I, Chen WH, Kline Leidy N: Development and first validation of the COPD Assessment Test. Eur Respir J2009, 34:648-654.

14. Kon SS, Canavan JL, Jones SE, Nolan CM, Clark AL, Dickson MJ, Haselden BM, Polkey MI, Man WD: Minimum clinically important difference for the COPD Assessment Test: a prospective analysis. Lancet Respir Med 2014, 2:195-203.

15. van der Molen T, Willemse BW, Schokker S, ten Hacken NH, Postma DS, Juniper EF: Development, validity and responsiveness of the Clinical COPD Questionnaire. Health Qual Life Outcomes $2003,1: 13$.

16. Kocks JW, Tuinenga MG, Uil SM, van den Berg JW, Stahl E, van der Molen T: Health status measurement in COPD: the minimal clinically important difference of the clinical COPD questionnaire. Respir Res 2006, 7:62.

17. Jones PW, Quirk FH, Baveystock CM, Littlejohns P: A self-complete measure of health status for chronic airflow limitation. The St. George's Respiratory Questionnaire. Am Rev Respir Dis 1992, 145:1321-1327.

18. Meguro M, Barley EA, Spencer S, Jones PW: Development and Validation of an Improved, COPD-Specific Version of the St. George Respiratory Questionnaire. Chest 2007, 132:456-463.

19. Jones PW: Interpreting thresholds for a clinically significant change in health status in asthma and COPD. Eur Respir J 2002, 19:398-404. 



\section{CHAPTER 2}

Correlations between disease-specific and generic health status questionnaires in patients with advanced COPD: a one-year observational study

Sarah Wilke, Daisy, J.A. Janssen, Emiel F.M. Wouters, Jos M.G.A. Schols, Frits M.E. Franssen, and Martijn A. Spruit

Health and Quality of Life Outcomes 2012, 10, 98 



\section{ABSTRACT}

\section{BACKGROUND}

Longitudinal studies analyzing the correlations between disease-specific and generic questionnaires at different time points in patients with advanced COPD are lacking. The aim of this study was to determine whether and to what extent a disease-specific health status questionnaire (Saint George's Respiratory Questionnaire, SGRQ) correlates with generic health status questionnaires (EuroQol-5-Dimensions, EQ-5D; Assessment of Quality of Life instrument, AQoL; Medical Outcomes Study 36-Item Short-Form Health Survey, SF-36) at four different time points in patients with advanced COPD; and to determine the correlation between the changes in these questionnaires during one-year follow-up.

\section{METHODS}

Demographic and clinical characteristics were assessed in 105 outpatients with advanced COPD at baseline. Disease-specific health status (SGRQ) and generic health status (EQ-5D, AQoL, SF-36) were assessed at baseline, four, eight, and 12 months. Correlations were determined between SGRQ and EQ-5D, AQoL, and SF-36 scores and changes in these scores. Agreement in direction of change was assessed.

\section{RESULTS}

Eighty-four patients (80\%) completed one-year follow-up and were included for analysis. SGRQ total score and EQ-5D index score, AQoL total score and SF-36 Physical Component Summary measure (SF-36 PCS) score were moderately to strongly correlated. The correlation of the changes between the SGRQ total score and EQ-5D index score, AQoL total score, SF-36 PCS, and SF-36 Mental Component Summary measure (SF-36 MCS) score were weak or absent. The direction of changes in SGRQ total scores agreed slightly with the direction of changes in EQ-5D index score, AQoL total score, and SF-36 PCS score.

\section{CONCLUSIONS}

At four, eight and 12 months after baseline, SGRQ total scores and EQ-5D index scores, AQoL total scores and SF-36 PCS scores were moderately to strongly correlated, while SGRQ total scores were weakly correlated with SF-36 MCS scores. The correlations between changes over time were weak or even absent. Disease-specific health status questionnaires and generic health status questionnaires should be used together to gain complete insight in health status and changes in health status over time in patients with advanced COPD. 


\section{INTRODUCTION}

Chronic obstructive pulmonary disease (COPD) is a highly prevalent chronic disease, characterized by expiratory airflow limitation, which is not fully reversible and usually progressive [1]. The Global initiative for chronic Obstructive Lung Disease (GOLD) classified the severity of COPD in mild (stage I), moderate (stage II), severe (stage III), or very severe (stage IV) according to the severity of airway obstruction and the presence of respiratory failure [1]. Despite optimal medical treatment, patients experience symptoms such as dyspnea, fatigue, and/or chronic cough [2]. Consequently, patients have a poor exercise capacity and limited performance in daily life activities $[3,4]$.

Health status can be defined as "the impact of health on a person's ability to perform and derive fulfillment from the activities of daily life" [5]. A patient's self-reported health status thus includes health-related quality of life and functional status [5]. Patients suffering from COPD in all GOLD stages report an impaired health status, with worst scores reported by GOLD stage IV patients [68]. Therefore, improvement of health status is an important component in COPD management, including pulmonary rehabilitation [9-12].

A careful assessment of patient's health status is necessary to identify targets for (non-) pharmacological interventions, as well as to evaluate the effects of these interventions [13]. Disease-specific health status questionnaires (i.e., related to a specific condition or group) or generic health status questionnaires (i.e., intended for general use, irrespective of the underlying disease) can be used as instruments to assess health status [14]. For instance, the Saint George's Respiratory Questionnaire (SGRQ) is a commonly used instrument measuring disease-specific health status among patients with COPD [15-20], while the European Quality of Life-5 dimensions (EQ-5D) [18, 19, 21], Assessment of Quality of Life Instrument (AQoL) [22, 23], and Medical Outcome Study 36-Item Short-Form Health Survey (SF-36) $[15,17,24-26]$ are used to assess generic health status.

Previous cross-sectional studies found that disease-specific and generic health status questionnaires are moderately to strongly correlated in patients with COPD $[17,19,27]$. A longitudinal study among patients with newly detected COPD suggested that changes in a disease-specific health status questionnaire (Chronic Respiratory Disease Questionnaire, CRQ) are significantly correlated with the changes in several sections of a generic health status questionnaire (Nottingham Health Profile, NHP) [28]. However, longitudinal studies analyzing the correlations between disease-specific and generic questionnaires at differ- 
ent time points in patients with advanced COPD are lacking. Therefore, the aims of the current longitudinal observational study were: (1) to determine whether and to what extent a disease-specific questionnaire (SGRQ) correlates with generic health status questionnaires (EQ-5D, AQoL and SF-36) at four different time points in patients with advanced COPD; and (2) to determine the correlation between changes in these health status questionnaires during one-year follow-up.

\section{METHODS}

This study is an analysis of a longitudinal observational study concerning symptoms and care needs of patients with advanced chronic organ failure [29]. Methodological details of this study and cross-sectional data about health status, symptom distress, family caregiving and advance care planning in patients with advanced COPD were published before [29-34].

\section{Study population}

Patients with advanced COPD were recruited by their chest physician at the outpatient clinic of one academic and two general hospitals in The Netherlands between January 2008 and June 2009. Patients were included if they had a physician-confirmed diagnosis of severe to very severe COPD (GOLD stages III and IV). Patients were excluded if they were not clinically stable for at least four weeks preceding enrolment (no hospital admission or major change in medication, according to the treating chest physician), if their pharmacological therapy was not optimal (according to the current available guidelines) and stable for at least two months preceding enrolment and if patients lived in a nursing home. All participating patients gave written informed consent. The Medical Ethical Committee of the Maastricht University Medical Centre+ (MUMC+), Maastricht, the Netherlands, approved this study (MEC 07-3-054). The study was registered at the Dutch Trial Register (NTR 1552).

\section{Instruments}

Patients were visited by a member of the research team in their home environment. The following outcomes were assessed at baseline: demographics, weight and height, smoking status, current self-reported comorbidities (Charlson Comorbidity Index) [35], long-term oxygen therapy (LTOT), self-perceived mobility problems, dependency in personal care, and forced expiratory volume in the first second $\left(\mathrm{FEV}_{1}\right)$. FEV 1 was calculated from the flow-volume curve 
measured by a handheld pulmonary spirometer [36]. Severity of dyspnoea was measured using the modified Borg scale (range 0 [nothing at all] to 10 [maximal]) [37]. Symptoms of anxiety and depression were studied using the Hospital Anxiety and Depression scale (HADS), which is divided into an anxiety subscale (HADS-A) and a depression subscale (HADS-D) [38]. Total scores for each subscale range from 0 (optimal) to 21 points (worst). Patients were visited at baseline, and four, eight, and 12 months after baseline to assess disease-specific and generic health status using the questionnaires as described below.

\section{Disease-specific health status}

Disease-specific health status was assessed using the SGRQ which consists of 76 items. The SGRQ provides three domain scores (symptoms, activity and impact) and a total score, ranging from 0 (optimal) to 100 points (worst) [39]. A recall period of three months was used.

\section{Generic health status}

Generic health status was assessed using the self-administered questionnaires EQ-5D [21], AQoL [22] and the SF-36 [24].

EQ-5D is a five-item questionnaire consisting of several items: mobility, selfcare, usual activity, pain/discomfort, and anxiety/depression [21]. Each item has three levels: no problems (1), some problems (2), and extreme problems (3). Higher scores on the several items indicate more severe problems. An index score is provided which ranges from -0.59 (worst) to 1.0 (best) [21]. In addition, patients rated their current health using a visual analogue scale (VAS). VAS score ranges from 0 (death or worst possible health) to 100 (best possible health).

AQoL consists of 15 items divided into five domains: illness, independent living, social relationships, physical senses, and psychological well-being [22]. Total score ranges from -0.04 (worst) to 1.00 (best) [40].

SF-36 consists of 36 items divided into eight domains: physical functioning, role-physical, bodily pain, general health, vitality, social functioning, roleemotional, and mental health. For each domain, scores range from 0 (worst) to 100 points (best) [24]. A Physical Component Summary measure (PCS) and a Mental Component Summary measure (MCS) are provided using norm-based methods with scores from a Dutch general population [41]. These summary measure scores are transformed to create a minimum and maximum possible 
score of 0 and 100 points. All scores below 50 points can be interpreted as below the general population norm [24].

\section{Statistics}

Categorical variables were described as frequencies. Continuous variables were tested for normality and were described as mean and standard deviation (SD). Only patients who completed all four visits were included in the analyses. To compare baseline characteristics between patients who completed the study and those who withdrew from the study, an independent sample t-test or MannWhitney U test was used, as appropriate. For categorical variables, a Chi square test was used. Depending on the variable distribution, a paired sample t-test or Wilcoxon Signed-Rank test was performed to compare the baseline scores of the health status questionnaires with the follow up scores at four, eight, and 12 months. To visualize the correlations between the SGRQ total score and the EQ5D index score, AQoL total score, and SF-36 PCS and MCS score at baseline, scatterplots were constructed. Furthermore, correlations of the changes in SGRQ total score and EQ-5D index score, AQoL total score, and SF-36 PCS and MCS score and the correlations of the changes in generic health status questionnaires between baseline and four months, four and eight months, and eight and 12 months were shown using scatterplots. To illustrate the correlations of the baseline EQ-5D, AQoL, SF-36 PCS and MCS scores and the correlations of the changes between these generic health status questionnaires, scatterplots were constructed. Additionally, bivariate correlations (Pearson's productmoment correlation) were performed. Strength of correlation was classified as follows: absent $(< \pm 0.20)$, weak $( \pm 0.20$ to \pm 0.34$)$, moderate $( \pm 0.35$ to \pm 0.50$)$, and strong $(> \pm 0.50)[19,42]$. The agreement in the direction of change in SGRQ total score and EQ-5D index score, AQoL total score, and SF-36 PCS and MCS score was determined. The four-months changes were classified into: no change, improvement and deterioration. For generic questionnaires, improvement is defined as a change $>0+(1.96 * \mathrm{SE}$ of mean change), deterioration is defined as a change $<0-(1.96 * \mathrm{SE}$ of mean change), otherwise no change. For SGRQ improvement is defined as a change $<0-(1.96 * \mathrm{SE}$ of mean change), deterioration is defined as a change $>0+\left(1.96^{\star} \mathrm{SE}\right.$ of mean change), otherwise no change. Cohen's Kappa was used to test agreement. Kappa values were categorized as poor $(<0.0)$, slight $(0.00-0.20)$, fair $(0.21-0.40)$, moderate $(0.41-0.60)$, substantial $(0.61-0.80)$, and almost perfect (0.81-1.00) agreement [43]. A $p$-value $\leq 0.05$ was interpreted as statistically significant [44]. All statistical analyses were performed using SPSS for Windows, Version 19.0. 


\section{RESULTS}

\section{Baseline characteristics}

In total, 105 COPD patients were included (Table 1). Most patients had very severe COPD (GOLD stage IV: $n=77,73.3 \%$ ). Fifty-nine percent of the patients used long-term oxygen therapy. Patients were generally slightly overweight, and $85 \%$ of the patients experienced mobility problems. Patients who withdrew from the study were more frequently dependent in personal care than patients who completed the study.

TABLE 1. Baseline Patient Characteristics

\begin{tabular}{|c|c|c|c|c|}
\hline & $\begin{array}{c}\text { Total sample } \\
\quad(\mathrm{n}=105)\end{array}$ & $\begin{array}{l}\text { Study completed } \\
\qquad(\mathrm{n}=86)\end{array}$ & $\begin{array}{l}\text { Dropout } \\
(\mathrm{n}=19)\end{array}$ & $p$-value ${ }^{c}$ \\
\hline Male, n (\%) & $65(61.9)$ & $54(62.8)$ & $11(57.9)$ & 0.69 \\
\hline Age, years & $66.3(9.2)$ & $65.7(9.3)$ & $68.8(8.2)$ & 0.18 \\
\hline $\mathrm{BMI}, \mathrm{kg} / \mathrm{m}^{2 \mathrm{~d}}$ & $26.3(6.7)$ & $26.5(6.9)$ & $25.5(5.4)$ & 0.99 \\
\hline Current smokers, n (\%) & $26(24.8)$ & $23(26.7)$ & $3(15.8)$ & 0.69 \\
\hline $\mathrm{FEV}_{1}, \%$ predicted $^{\mathrm{d}}$ & $34.1(13.5)^{\mathrm{a}}$ & $34.4(13.6)^{b}$ & $32.7(13.1)$ & 0.60 \\
\hline Charlson Comorbidity index, points & $2.5(1.7)$ & $2.4(1.7)$ & $2.7(1.7)$ & 0.50 \\
\hline Long-term oxygen therapy, n (\%) & $62(59.0)$ & $53(61.6)$ & $9(47.4)$ & 0.26 \\
\hline Borg scale (dyspnea), points & $4.8(2.0)$ & $4.8(2.0)$ & $4.9(2.1)$ & 0.79 \\
\hline Borg scale (fatigue), points & $4.6(2.5)$ & $4.4(2.4)$ & $5.3(2.8)$ & 0.15 \\
\hline HADS-A score, points & $5.9(4.5)$ & $5.5(4.2)$ & $7.5(5.6)$ & 0.16 \\
\hline HADS-D score, points & $6.3(4.0)$ & $6.0(4.0)$ & $7.7(3.4)$ & 0.10 \\
\hline Self-perceived mobility problems, n (\%) & $89(84.8)$ & $72(83.8)$ & $17(89.5)$ & 0.33 \\
\hline Dependent in personal care, $\mathrm{n}(\%)$ & $47(44.8)$ & $33(38.4)$ & $14(73.6)$ & 0.009 \\
\hline
\end{tabular}

Abbreviations: BMI, body mass index; $\mathrm{FEV}_{1}$, forced expiratory volume in the first second; HADS-A, Hospital Anxiety and Depression Scale, Anxiety subscale; HADS-D, Hospital Anxiety and Depression Scale, Depression subscale. ${ }^{a} n=102 ;{ }^{b} n=83 ;{ }^{c}$ comparison between patients who completed the study and patients who withdrew from the study; ${ }^{\mathrm{d}}$ non parametric statistic tests were used because of skewed data

\section{Health status}

At baseline, patients generally had an impaired disease-specific and generic health status (Table 2). Patients who withdrew from the study reported worse scores on the SGRQ impact domain, several domains of the EQ-5D and AQoL, the EQ-5D index score and AQoL total score compared to patients who completed all four visits. 
TABLE 2. Baseline Health Status

\begin{tabular}{|c|c|c|c|c|c|}
\hline Questionnaire & Domain & $\begin{array}{c}\text { Total sample } \\
\quad(n=105)\end{array}$ & $\begin{array}{c}\text { Study } \\
\text { completed } \\
(\mathrm{n}=86)\end{array}$ & $\begin{array}{l}\text { Dropout } \\
(n=19)\end{array}$ & $p$-value ${ }^{c}$ \\
\hline \multirow[t]{7}{*}{ EQ-5D } & Mobility $^{d}$ & $1.87(0.39)$ & $1.85(0.39)$ & $1.95(0.40)$ & 0.33 \\
\hline & Self-Care & $1.70(0.66)$ & $1.60(0.62)$ & $2.16(0.69)$ & 0.001 \\
\hline & Usual activities & $2.08(0.65)$ & $1.99(0.60)$ & $2.47(0.70)$ & 0.01 \\
\hline & Pain/discomfort & $1.55(0.66)$ & $1.56(0.64)$ & $1.53(0.77)$ & 0.85 \\
\hline & Anxiety/depression & $1.50(0.67)$ & $1.47(0.66)$ & $1.68(0.67)$ & 0.20 \\
\hline & Index score & $0.51(0.33)$ & $0.55(0.30)$ & $0.33(0.37)$ & 0.008 \\
\hline & VAS & $62.6(14.0)$ & $64.1(13.2)$ & $55.8(15.9)$ & 0.02 \\
\hline \multirow[t]{6}{*}{ AQoL } & Illness $^{d}$ & $0.17(0.17)$ & $0.18(0.16)$ & $0.12(0.19)$ & 0.04 \\
\hline & Independent living & $0.58(0.30)$ & $0.63(0.27)$ & $0.36(0.31)$ & $<0.0005$ \\
\hline & Social relationships $^{d}$ & $0.83(0.20)$ & $0.85(0.20)$ & $0.77(0.20)$ & 0.06 \\
\hline & Physical senses $^{d}$ & $0.92(0.11)$ & $0.93(0.09)$ & $0.86(0.18)$ & 0.17 \\
\hline & Psychological wellbeing & $0.87(0.13)$ & $0.97(0.13)$ & $0.85(0.15)$ & 0.50 \\
\hline & Total & $0.46(0.28)$ & $0.50(0.27)$ & $0.29(0.30)$ & 0.005 \\
\hline \multirow[t]{10}{*}{ SF-36 } & Physical Functioning $^{d}$ & $21.0(21.1)$ & $22.3(20.8)$ & $15.5(22.4)$ & 0.07 \\
\hline & Role-physical $^{d}$ & $37.1(42.8)$ & $38.4(43.2)$ & $31.6(41.5)$ & 0.61 \\
\hline & Bodily pain $^{d}$ & $70.9(29.5)$ & $72.8(28.3)$ & $62.3(34.0)$ & 0.23 \\
\hline & General health & $29.7(19.1)$ & $30.1(19.2)$ & $28.2(19.3)$ & 0.70 \\
\hline & Vitality & $51.1(18.9)$ & $51.3(19.1)$ & $50.3(18.7)$ & 0.83 \\
\hline & Social functioning & $65.0(26.1)$ & $67.0(25.7)$ & $55.9(27.1)$ & 0.10 \\
\hline & Role-emotional $^{\mathrm{d}}$ & $62.9(44.9)$ & $63.6(44.7)$ & $59.7(46.6)$ & 0.80 \\
\hline & Mental health & $68.6(19.9)$ & $69.7(19.3)$ & $63.8(22.2)$ & 0.25 \\
\hline & $\operatorname{PCS}^{d}$ & $22.4(9.6)$ & $22.9(9.2)$ & $19.8(11.3)$ & 0.08 \\
\hline & MCS & $47.3(14.1)$ & $47.7(14.4)$ & $45.1(15.4)$ & 0.48 \\
\hline \multirow[t]{4}{*}{ SGRQ } & Symptoms & $58.6(22.5)^{\mathrm{a}}$ & $59.3(22.9)^{\mathrm{b}}$ & $55.4(25.5)$ & 0.52 \\
\hline & Activity $^{d}$ & $74.8(21.9)^{\mathrm{a}}$ & $73.6(21.3)^{\mathrm{b}}$ & $80.1(24.3)$ & 0.06 \\
\hline & Impact & $45.2(18.5)^{\mathrm{a}}$ & $43.6(17.7)^{b}$ & $52.7(20.4)$ & 0.04 \\
\hline & Total $^{d}$ & $56.5(21.8)^{a}$ & $55.3(16.0)^{\mathrm{b}}$ & $61.5(19.7)$ & 0.09 \\
\hline
\end{tabular}

Values expressed in points as mean (standard deviation [SD]). Bold printed numbers show significant $(\mathrm{p} \leq 0.05)$ results. Abbreviations. EQ-5D, European Quality of Life- 5 dimensions; VAS, Visual Analogue Scale; AQoL, Assessment of Quality of Life instrument; SF-36, Short Form 36-item health survey; PCS, Physical Component Summary measure; MCS, Mental Component Summary measure; SGRQ, St. George Respiratory Questionnaire. ${ }^{a} n=103 ;{ }^{b} n=84 ;{ }^{c}$ comparison between patients who completed the study and patients who withdrew from the study; ${ }^{d}$ non parametric statistic tests were used because of skewed data

On average, patients who completed the study reported 3.1 (2.3) exacerbations during 12 months follow-up $(n=83)$. Generic and disease-specific health status scores at baseline were comparable between patients who had less than two exacerbations during 12 months follow up $(n=25)$ and those who had two or more exacerbations $(n=58)(p>0.05)$. Patients who experienced two or more exacerbations during 12 months reported a worse AQoL total score $(0.41(0.24)$ 
points) and SF-36 PCS score (20.83 (9.88) points) compared to patients who had less than two exacerbations during 12 months (AQoL total score: 0.54 (0.21) points, $p=0.03$; SF-36 PCS score (26.76 (10.70) points, $p=0.02)$.

Table 3 shows the changes in health status over time. SGRQ total score, EQ-5D index score, and SF-36 PCS and MCS scores remained stable over time. Patients reported worse AQoL total scores at eight and 12 months compared to baseline.

TABLE 3. Health Status at baseline, 4,8 and 12 months

\begin{tabular}{|c|c|c|c|c|c|}
\hline Questionnaire & Domain & Baseline & 4 months & 8 months & 12 months \\
\hline \multirow[t]{7}{*}{ EQ-5D } & Mobility $^{\mathrm{C}}$ & $1.85(0.39)$ & $1.83(0.44)$ & $1.90(0.41)$ & $1.97(0.32)^{\mathrm{b}}$ \\
\hline & Self-Care & $1.60(0.62)$ & $1.67(0.68)$ & $1.78(0.66)^{b}$ & $1.76(0.68)^{b}$ \\
\hline & Usual activities & $1.99(0.60)$ & $2.15(0.58)^{b}$ & $2.14(0.58)^{b}$ & $2.13(0.70)$ \\
\hline & Pain/discomfort & $1.56(0.64)$ & $1.40(0.60)^{b}$ & $1.55(0.66)$ & $1.47(0.61)$ \\
\hline & Anxiety/depression & $1.47(0.66)$ & $1.35(0.63)^{b}$ & $1.41(0.62)$ & $1.33(0.61)^{\mathrm{b}}$ \\
\hline & Index score & $0.55(0.30)$ & $0.57(0.31)$ & $0.52(0.32)$ & $0.51(0.31)$ \\
\hline & VAS & $64.1(13.2)$ & $61.7(15.1)$ & $61.9(14.5)$ & $60.6(13.4)^{\mathrm{b}}$ \\
\hline \multirow[t]{6}{*}{ AQoL } & Illness & $0.18(0.16)$ & $0.23(0.16)^{b}$ & $0.24(0.16)^{b}$ & $0.24(0.17)^{\mathrm{b}}$ \\
\hline & Independent living & $0.63(0.27)$ & $0.59(0.28)$ & $0.54(0.28)^{b}$ & $0.53(0.29)^{b}$ \\
\hline & Social relationships $^{c}$ & $0.85(0.20)$ & $0.82(0.21)$ & $0.81(0.21)$ & $0.84(0.18)$ \\
\hline & Physical senses & $0.93(0.09)$ & $0.94(0.08)$ & $0.93(0.09)$ & $0.94(0.08)$ \\
\hline & Psychological wellbeing & $0.97(0.13)$ & $0.90(0.12)^{b}$ & $0.90(0.14)$ & $0.91(0.11)^{\mathrm{b}}$ \\
\hline & Total & $0.50(0.27)$ & $0.48(0.26)$ & $0.44(0.26)^{b}$ & $0.45(0.24)^{\mathrm{b}}$ \\
\hline \multirow[t]{10}{*}{ SF-36 } & Physical Functioning & $22.3(20.8)$ & $19.9(20.0)$ & $21.6(20.2)$ & $20.3(21.4)$ \\
\hline & Role-physical $^{c}$ & $38.4(43.2)$ & $37.8(45.0)$ & $48.8(46.8)$ & $41.9(46.9)$ \\
\hline & Bodily pain & $72.8(28.3)$ & $75.2(29.0)$ & $72.0(30.4)$ & $76.5(28.9)$ \\
\hline & General health & $30.1(19.2)$ & $27.6(18.2)$ & $28.5(16.7)$ & $28.2(19.9)$ \\
\hline & Vitality & $51.3(19.1)$ & $53.9(17.9)$ & $53.4(17.0)$ & $52.7(18.3)$ \\
\hline & Social functioning & $67.0(25.7)$ & $67.6(26.7)$ & $62.7(28.6)$ & $63.2(28.7)$ \\
\hline & Role-emotional $^{c}$ & $63.6(44.8)$ & $67.8(42.9)$ & $67.1(45.0)$ & $70.2(43.7)$ \\
\hline & Mental health & 69.7 (19.3) & $70.6(19.7)$ & $69.4(18.6)$ & $69.4(17.6)$ \\
\hline & PCS & $22.9(9.2)$ & $21.8(9.6)$ & $23.4(10.5)$ & $22.6(10.4)$ \\
\hline & MCS & $47.7(14.4)$ & $49.5(14.6)$ & 47. $6(14.4)$ & $48.5(13.2)$ \\
\hline \multirow[t]{4}{*}{$\mathrm{SGRQ}^{\mathrm{a}}$} & Symptoms & $59.3(22.9)$ & $56.4(20.9)$ & $57.2(19.4)$ & $58.2(18.2)$ \\
\hline & Activity & $73.6(21.3)$ & $77.1(18.2)$ & $74.1(22.1)$ & 76.8 (19.7) \\
\hline & Impact & $43.6(17.7)$ & $43.6(16.0)$ & $42.3(17.0)$ & $43.3(17.5)$ \\
\hline & Total & $55.3(16.0)$ & $55.9(14.5)$ & $54.3(16.2)$ & $56.3(15.2)$ \\
\hline
\end{tabular}

Values expressed in points as mean (standard deviation [SD]). Bold printed numbers show significant $(p \leq 0.05)$ results. Abbreviations. please see legend table $2 .{ }^{a} n=84 ;{ }^{b} p=\leq 0.05$ vs. baseline; ${ }^{c}$ non parametric statistic tests were used because of skewed data 


\section{Correlations}

Correlations between SGRQ total scores and the EQ-5D index score, AQOoL total score, and SF-36 PCS and MCS scores were weak to strong at the four different time points (Table 4).

TABLE 4. Correlations between SGRQ total score and generic health status questionnaires

\begin{tabular}{lllll}
\hline & Baseline & 4 months & 8 months & 12 months \\
\hline EQ-5D index score & -0.536 & -0.439 & -0.487 & -0.421 \\
AQoL total score & -0.617 & -0.547 & -0.587 & -0.496 \\
SF-36, PCS score & -0.679 & -0.469 & -0.464 & -0.559 \\
SF-36, MCS score & -0.489 & -0.296 & -0.314 & -0.285 \\
\hline
\end{tabular}

$\mathrm{n}=84$, all correlation: $\mathrm{p} \leq 0.01$ Abbreviations. Please see legend table 2 .

Figures $1 \mathrm{a}$ to $1 \mathrm{~h}$ show the correlations between the SGRQ total scores and EQ5D index scores, AQoL total scores and SF-36 PCS and MCS scores at all time points, and the correlations between the changes in SGRQ total scores and the changes in EQ-5D index scores, AQoL total scores and SF-36 PCS and MCS scores. At baseline, disease-specific and generic health status questionnaires were moderately to strongly correlated, while the correlations between the changes were weak or absent.

Furthermore, at baseline, generic health status questionnaires were moderately to strongly correlated. The correlations between the changes were weak to moderate while the changes in AQoL total score were not correlated with the changes in SF-36 PCS score (Figures 2a to 2j). 
a)
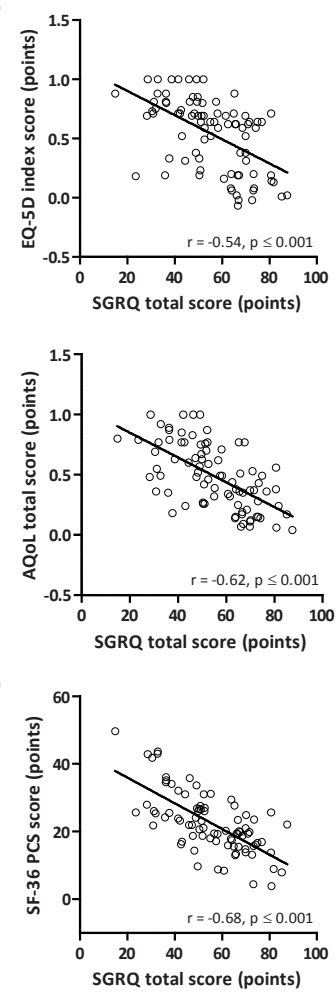

g)

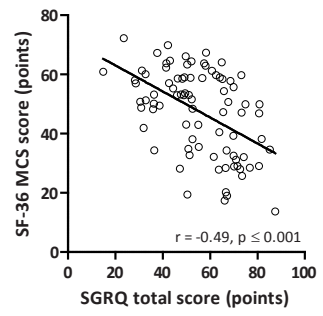

b)

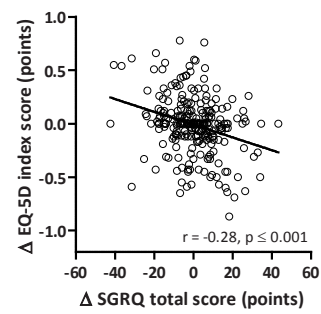

d)

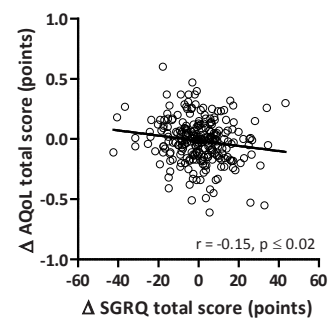

f)

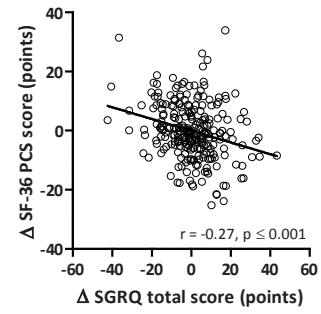

h)

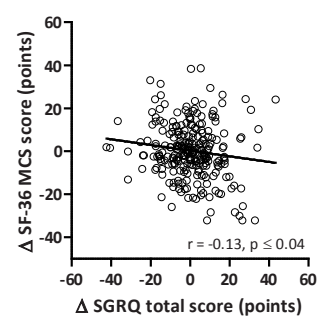

FIGURE 1. Correlation between SGRQ total score and EQ-5D index score (a), AQoL total score (c), SF-36 PCS score (e) and SF-36 MCS score (g) at baseline and correlation between changes between 0-4 months, 4-8 months and 8-12 months of SGRQ total score and changes of EQ-5D index score (b), AQoL total score (d), SF-36 PCS (f) and SF-36 MCS score (h) (all data points together); $\mathrm{n}=84 ; \Delta$, change in 
a)
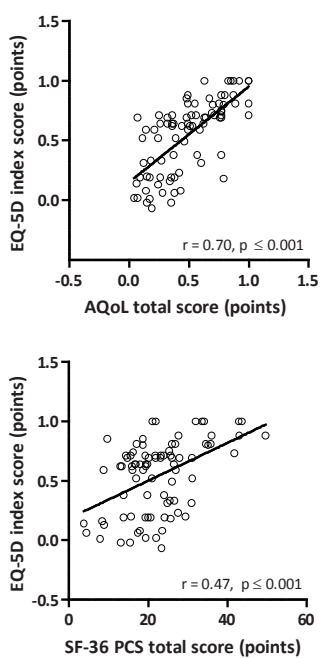

e)
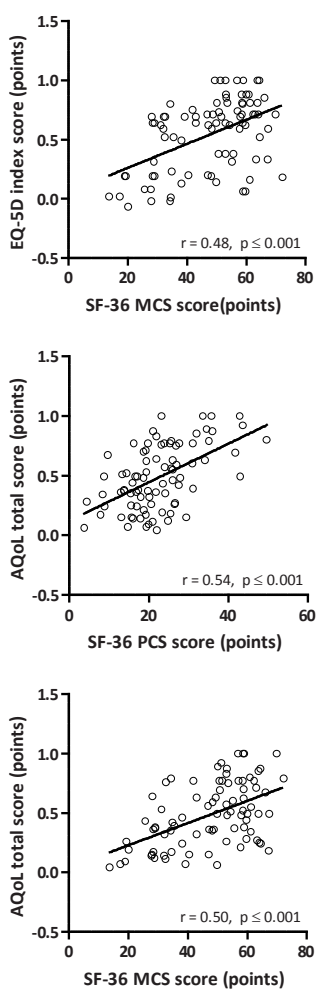

b)

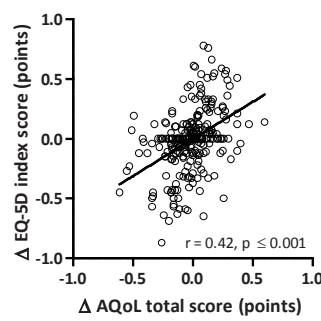

d)
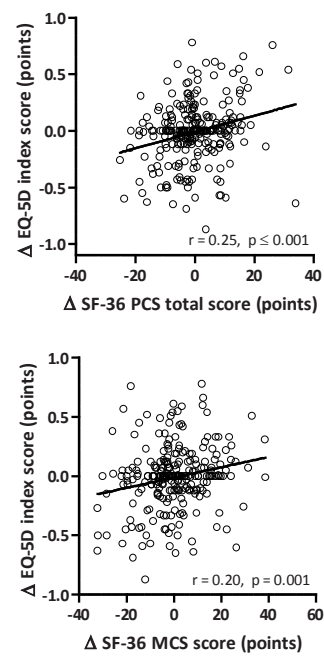

h)

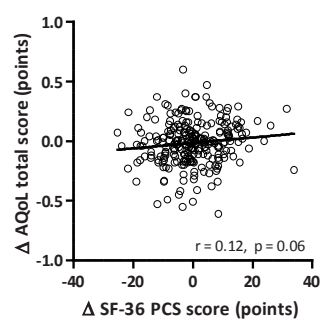

j)

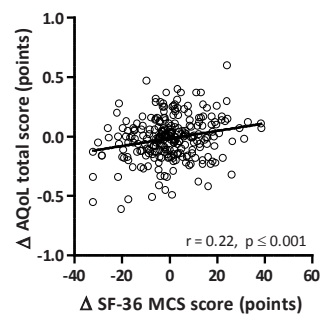

FIGURE 2. Correlation between EQ-5D index score and AQoL total score (a), SF-36 PCS score (c), SF-36 MCS score (e) and correlation between AQoL total score and SF-36 PCS score (g) and SF-36 MCS score (i) at baseline and correlation between changes from 0-4 months, 4-8 months and 8-12 months of EQ-5D index score and changes of AQoL total score (b), SF-36 PCS score (d), SF-36 MCS score (f) and changes of AQoL total score and SF-36 PCS score (h) and SF-36 MCS score (j) (all data points together); $\mathrm{n}=84 ; \Delta$, change in 


\section{Agreement}

Table 5 shows the agreement of the direction of changes in SGRQ total scores with the direction of changes in EQ-5D index score, AQoL total score, SF-36 PCS and SF-36 MCS scores. The direction of changes in SGRQ total scores agreed slightly (Kappa ranged from 0.12 to $0.18, p<0.05$ ) with the direction of changes in EQ-5D index score, AQoL total score and SF-36 PCS score.

TABLE 5. Direction of 4-months changes in SGRQ total score and EQ-5D index score, AQoL total score, SF-36 PCS and SF-36 MCS

\begin{tabular}{|c|c|c|c|c|}
\hline & & $\begin{array}{l}\text { SGRQ total score } \\
\text { No change }\end{array}$ & Improvement & Deterioration \\
\hline change in EQ-5D & No change & $12(4.8 \%)$ & $23(9.1 \%)$ & $24(9.5 \%)$ \\
\hline index score & Improvement & $10(4.0 \%)$ & $52(20.6 \%)$ & $31(12.3 \%)$ \\
\hline$(K \approx 0.18)$ & Deterioration & $12(4.8 \%)$ & 32 (12.7\%) & $56(22.2 \%)$ \\
\hline change in AQoL & No change & $5(2.0 \%)$ & $6(2.4 \%)$ & $14(5.6 \%)$ \\
\hline total score & Improvement & $14(5.6 \%)$ & 54 (21.4\%) & 38 (15.1\%) \\
\hline$(\mathrm{K} \approx 0.11)$ & Deterioration & $15(6.0 \%)$ & 47 (18.7\%) & 59 (23.4\%) \\
\hline change in & No change & $7(2.8 \%)$ & $19(7.5 \%)$ & $12(4.8 \%)$ \\
\hline SF-36 PCS score & Improvement & $10(4.0 \%)$ & 48 (19.0\%) & $38(15.1 \%)$ \\
\hline$(K \approx 0.12)$ & Deterioration & 17 (6.7\%) & 40 (15.9\%) & $61(24.2 \%)$ \\
\hline change in & No change & $7(2.8 \%)$ & $9(3.6 \%)$ & $10(4.0 \%)$ \\
\hline SF-36 MCS score & Improvement & 17 (6.7\%) & 49 (19.4\%) & $43(17.1 \%)$ \\
\hline$(K \approx 0.08)$ & Deterioration & $10(4.0 \%)$ & 49 (19.4\%) & $58(23.0 \%)$ \\
\hline
\end{tabular}

Abbreviations. please see legend table 2.

$K$, Cohen's Kappa; bold printed numbers show significant $(p \leq 0.05)$ results.

The direction of changes in EQ-5D index score agreed fairly with the direction of changes in AQoL total score and SF-36 PCS score (Kappa ranged from 0.21 to $0.34, p<0.05)$. The direction of changes in AQoL total score agreed moderately with the direction of changes in SF-36 PCS score $(K=0.41, p<0.001)$. There was no agreement between the direction of changes in SF-36 PCS score and the direction of changes in EQ-5D index score $(K=0.17, p=0.07)$ and $A Q o L$ total score $(K=0.15, p=0.17)$.

\section{DISCUSSION}

The current study shows that the SGRQ total score and the EQ-5D index score, AQoL total score, and SF-36 PCS score were moderately to strongly correlated at four consecutive time points in patients with advanced COPD, while SGRQ total scores were weakly correlated with SF-36 MCS scores at four, eight and 12 
months after baseline. The correlations between changes over time were weak or even absent. This is probably due to a poor or absent agreement in the direction of changes in the different health status questionnaires.

Previous cross-sectional studies found moderate to strong correlations between disease-specific and generic health status questionnaires in patients with COPD $[19,27]$. The current longitudinal study extends these findings and shows that SGRQ total scores were moderately to strongly correlated with the EQ-5D index score, AQoL total score, and SF-36 PCS score at four consecutive time points during one year follow-up. SGRQ total scores were weakly correlated with SF-36 MCS scores at four, eight, and 12 months. This can be explained by the fact that the SF-36 MCS focusses on mental aspects of health status, while the SGRQ total score includes several components of disease-specific health status. These findings are in line with Katsura et al. who reported even no correlation $(r=0.19)$ between the SGRQ total score and SF-36 MCS score in elderly patients with COPD [45].

Generic health status questionnaires were moderately to strongly correlated, while the correlations between the changes were weak to moderate. Pickard et al. found similar data in a cross-sectional study including inpatients and outpatients diagnosed with COPD concerning the EQ-5D index score and SF-36 PCS and MCS score [19]. EQ-5D index score showed the best correlation with AQoL total score, at baseline and between changes over time. Holland et al. compared the AQoL and EQ-5D in elderly patients admitted to an acute hospital and found a comparable correlation of the baseline scores and changes between these two questionnaires as in the present study [46]. Thus, even the generic health status questionnaires lack correlation. Researchers and clinicians should consider carefully which questionnaire is in line with their individual study objectives and study population. To the best of our knowledge, the AQoL has not been used as generic health status questionnaire in patients with COPD before. The current findings may suggest that the AQoL can be used to assess health status in outpatients with advanced COPD. However, future research is needed to support these results.

To the best of our knowledge, this is the first longitudinal study exploring the correlations (at four consecutive time points as well as the changes between these time points) between the SGRQ and the EQ-5D, AQoL, and SF-36 in patients with advanced COPD. Previously, improved health status (measured by SGRQ and SF36) was found in patients with COPD who followed pulmonary rehabilitation or received home care [47-49]. Thus, it seemed reasonable to hypothesize that changes in disease-specific and generic health status questionnaires were somehow correlated. However, in the present study, the correlations between the changes in SGRQ total scores and in AQoL total scores as well as SF-36 MCS 
scores were absent. The changes in SGRQ total score and EQ-5D index score and SF-36 PCS scores were weakly correlated. These weak or absent correlations can be explained by the fact that the direction of changes in SGRQ total scores and EQ-5D index score, AQoL total scores and SF-36 PCS score just slightly agree. There was even no agreement on the direction of change in SGRQ total score and SF-36 MCS score. The agreement on the direction of change in disease-specific and generic health status was about $45 \%$, while in 25 to $35 \%$ of the patients the observed four months changes were in opposite direction (table 5). Ritva et al. compared the changes measured by SGRQ and 15D, a 15 dimensional generic health status questionnaire, among asthmatic patients and concluded that these instruments agreed on direction of change in health status in $64.8 \%$ of patients. In $15.8 \%$ of the cases the changes were in an opposite direction. In the remaining patients, health status changed according to one questionnaire [50]. However, Ritva et al. assessed changes in health status during three years [50], while we studied changes in health status during one year.

The current results support that healthcare professionals should use diseasespecific as well as generic instruments to gain insight into the disease-specific and general impact of the disease and to get an in depth understanding of patients' health status. Indeed, disease-specific questionnaires include relevant questions related to the patient's disease and may generally be more sensitive to the disease and small changes in health status [17]. Generic health status questionnaires are intended for general use and are universally applicable: they tend to cover a broad variety of aspects (e.g. functional states, perceptions, social opportunities) $[14,17]$. Indeed, disease-specific instruments may be more responsive to change in clinical status or more sensitive in distinguishing patients with different disease severities while generic measures may be more likely to detect unexpected events which are probably not related to the disease and detect effects of diverse aspects on a disease [5]. However, in the current study, the SGRQ did not detect differences between patients who experiences two or more exacerbations during 12 months compared to patients who had less than two exacerbations during 12 months while the AQoL and SF-36 PCS did. In contrast to previous studies, these results do not support the diseasespecific qualities of the SGRQ in detecting differences in clinical status in patients with advanced COPD. Further, the AQoL showed changes over one year in total score and several domain scores (e.g., "independent living" or "illness") while the SGRQ did not show changes over one year. This underlines the fact that generic and disease-specific instruments measure different aspects and cannot replace each other. Combining both types of questionnaires allows healthcare professionals to identify targets for interventions as well as to evaluate the effects of these interventions [13]. 
Recently, Pakhale et al. constructed a new questionnaire (McGill-COPD Quality of Life Questionnaire) by combining items of a disease-specific questionnaire with qualities of a generic questionnaire to measure health status in COPD patients [51]. Combining items of different measures can reduce patients' load and increase their attention and participation. But it is still not clear which questionnaires or items in terms of psychometric properties (e.g. validity, reliability, sensitivity to change) are most suitable to use for combination. The McGillCOPD Quality of Life Questionnaire suggests possibilities. However, this questionnaire needs to be validated before it can be used in clinical practice or further research.

Interestingly, participants in the present study reported a better generic health status over time according to the AQoL illness domain, while the AQoL total score showed worse generic health status. This was also true for some EQ-5D domains and the EQ-5D VAS score (table 3). These findings show that domain scores as well as total scores should be examined to achieve a correct understanding of patients' health status. Furthermore, our results may suggest that the AQoL is more sensitive to detect changes than the SF-36 or SGRQ. However, the current study did not focus on sensitivity of health status questionnaires. A lack of previous studies using the AQoL as generic health status measure underlines the importance of further research in this field.

The present study has some methodological considerations that should be considered in interpreting the results. First, the study population consists of a convenience sample of patients with advanced COPD. Thus, it remains unknown whether these data are applicable for patients with GOLD stage I or II. Second, about $20 \%$ of the baseline study sample withdrew from the study during one year follow-up. These patients were more dependent in personal care and reported a worse baseline generic health status than patients who completed the study. It may be possible that changes in disease-specific and generic health status were different among patients who completed the study and patients who withdrew from the study. However, total scores of the diseasespecific questionnaire SGRQ were comparable with findings from previous studies $[6,19]$. Third, the duration of the follow-up period is limited. However, longitudinal studies among elderly with advanced chronic diseases are scarce and recruitment and sustained participation is challenging in this population $[52,53]$. Fourth, ceiling effects and floor effects in longitudinal studies can limit the results because changes cannot be adequately detected. However, the proportion of patients reporting the highest possible score on the disease-specific and generic questionnaires ranged from $1.2-8.3 \%$ for all data points, while none of the patients reported the lowest possible score on any of the disease-specific and 
generic health status questionnaires on any of the data points. Because ceiling effects and floor effects are considered to be present if more than $15 \%$ of the subjects score the highest or lowest possible value, respectively [54], the influence of ceiling effects and floor effects seems to be limited in the current study. Fifth, the current findings need to be interpreted in the light of the number of comparisons that were made in the present study. Nonetheless, multiple findings in the same direction, rather than a single statistically significant result, suggest that these are not due to chance alone. Moreover, 'Bonferoni adjustments are at best, unnecessary and, at worst, deleterious to sound statistical inference' [55].

\section{CONCLUSION}

The current study suggests that health care professionals should use diseasespecific as well as generic instruments to gain insight into the disease-specific and general impact of the disease. This is necessary to identify targets for interventions with the aim to improve disease-specific and generic health status and to evaluate the effects of interventions. Future research is required to compare disease-specific and generic health status questionnaires in a broader population. In addition, the possibilities and characteristics of a combined instrument measuring health status in patients with advanced COPD should be studied. 


\section{REFERENCES}

1. Rabe KF, Hurd S, Anzueto A, Barnes PJ, Buist SA, Calverley P, Fukuchi Y, Jenkins C, RodriguezRoisin R, van Weel C, Zielinski J: Global strategy for the diagnosis, management, and prevention of chronic obstructive pulmonary disease: GOLD executive summary. Am J Respir Crit Care Med 2007, 176:532-555.

2. Kessler R, Partridge MR, Miravitlles M, Cazzola M, Vogelmeier C, Leynaud D, Ostinelli J: Symptom variability in patients with severe COPD: a pan-European cross-sectional study. Eur Respir J2011, 37:264-272.

3. Vaes AW, Wouters EF, Franssen FM, Uszko-Lencer NH, Stakenborg KH, Westra M, Meijer K, Schols AM, Janssen PP, Spruit MA: Task-related oxygen uptake during domestic activities of daily life in patients with COPD and healthy elderly subjects. Chest 2011, 140:970-979.

4. Annegarn J, Meijer K, Passos VL, Stute K, Wiechert J, Savelberg HH, Schols AM, Wouters EF, Spruit MA: Problematic Activities of Daily Life are Weakly Associated With Clinical Characteristics in COPD. J Am Med Dir Assoc 2012, 13:284-290.

5. Curtis JR, Patrick DL: The assessment of health status among patients with COPD. Eur Respir J Supp/2003, 41:36s-45s.

6. Jones PW, Brusselle G, Dal Negro RW, Ferrer M, Kardos P, Levy ML, Perez T, Soler-Cataluna JJ, van der Molen T, Adamek L, Banik N: Health-related quality of life in patients by COPD severity within primary care in Europe. Respir Med2011, 105:57-66.

7. Janssen DJ, Spruit MA, Leue C, Gijsen C, Hameleers H, Schols JM, Wouters EF: Symptoms of anxiety and depression in COPD patients entering pulmonary rehabilitation. Chron Respir Dis 2010, 7:147-157.

8. Spruit MA, Pennings HJ, Janssen PP, Does JD, Scroyen S, Akkermans MA, Mostert R, Wouters EF: Extra-pulmonary features in COPD patients entering rehabilitation after stratification for MRC dyspnea grade. Respir Med 2007, 101:2454-2463.

9. Dodd JW, Hogg L, Nolan J, Jefford H, Grant A, Lord VM, Falzon C, Garrod R, Lee C, Polkey MI, et al: The COPD assessment test (CAT): response to pulmonary rehabilitation. A multicentre, prospective study. Thorax 2011, 66:425-429.

10. Moullec G, Laurin C, Lavoie KL, Ninot G: Effects of pulmonary rehabilitation on quality of life in chronic obstructive pulmonary disease patients. Curr Opin Pulm Med2011, 17:62-71.

11. Nici L, ZuWallack R, Wouters E, Donner CF: On pulmonary rehabilitation and the flight of the bumblebee: the ATS/ERS Statement on Pulmonary Rehabilitation. Eur Respir J2006, 28:461-462.

12. Spruit MA, Vanderhoven-Augustin I, Janssen PP, Wouters EF: Integration of pulmonary rehabilitation in COPD. Lancet 2008, 371:12-13.

13. Cazzola M, MacNee W, Martinez FJ, Rabe KF, Franciosi LG, Barnes PJ, Brusasco V, Burge PS, Calverley PM, Celli BR, et al: Outcomes for COPD pharmacological trials: from lung function to biomarkers. Eur Respir J 2008, 31:416-469.

14. Patrick DL, Deyo RA: Generic and disease-specific measures in assessing health status and quality of life. Med Care 1989, 27:S217-232.

15. Esteban C, Quintana JM, Aburto M, Moraza J, Egurrola M, Perez-Izquierdo J, Aizpiri S, Aguirre U, Capelastegui A: Impact of changes in physical activity on health-related quality of life among patients with COPD. Eur Respir J2010, 36:292-300.

16. Habraken JM, van der Wal WM, Ter Riet G, Weersink EJ, Toben F, Bindels PJ: Health-related quality of life and functional status in end-stage COPD: a longitudinal study. Eur Respir J2011, 37:280-288.

17. Maly M, Vondra V: Generic versus disease-specific instruments in quality-of-life assessment of chronic obstructive pulmonary disease. Methods Inf Med2006, 45:211-215.

18. Menn $P$, Weber N, Holle R: Health-related quality of life in patients with severe COPD hospitalized for exacerbations - comparing EQ-5D, SF-12 and SGRQ. Health Qual Life Outcomes 2010, 8:39. 
19. Pickard AS, Yang Y, Lee TA: Comparison of health-related quality of life measures in chronic obstructive pulmonary disease. Health Qual Life Outcomes 2011, 9:26.

20. Singh SJ, Sodergren SC, Hyland ME, Williams J, Morgan MD: A comparison of three diseasespecific and two generic health-status measures to evaluate the outcome of pulmonary rehabilitation in COPD. Respir Med 2001, 95:71-77.

21. Dolan P: Modeling valuations for EuroQol health states. Med Care 1997, 35:1095-1108.

22. Hawthorne G, Richardson J, Osborne R: The Assessment of Quality of Life (AQoL) instrument: a psychometric measure of health-related quality of life. Qual Life Res 1999, 8:209-224.

23. Moore RP, Berlowitz DJ, Denehy L, Pretto JJ, Brazzale DJ, Sharpe K, Jackson B, McDonald CF: A randomised trial of domiciliary, ambulatory oxygen in patients with COPD and dyspnoea but without resting hypoxaemia. Thorax 2011, 66:32-37.

24. Ware JE, Snow KK, Kosinski M: SF-36 health survey manual and interpretation guide. Boston, MA: The Health Institute, New England Medical Center Hospitals; 1993.

25. Benzo R, Flume PA, Turner D, Tempest M: Effect of pulmonary rehabilitation on quality of life in patients with COPD: the use of SF-36 summary scores as outcomes measures. J Cardiopulm Rehabil2000, 20:231-234.

26. Mahler DA, Mackowiak JI: Evaluation of the short-form 36-item questionnaire to measure health-related quality of life in patients with COPD. Chest 1995, 107:1585-1589.

27. Mazur W, Kupiainen H, Pitkaniemi J, Kilpelainen M, Sintonen H, Lindqvist A, Kinnula VL, Laitinen T: Comparison between the disease-specific Airways Questionnaire 20 and the generic 15D instruments in COPD. Health Qual Life Outcomes 2011, 9:4.

28. Tsukino M, Nishimura K, McKenna SP, Ikeda A, Hajiro T, Zhang M, Izumi T: Change in generic and disease-specific health-related quality of life during a one-year period in patients with newly detected chronic obstructive pulmonary disease. Respiration 2002, 69:513-520.

29. Janssen DJ, Wouters EF, Schols JM, Spruit MA: Self-perceived symptoms and care needs of patients with severe to very severe chronic obstructive pulmonary disease, congestive heart failure or chronic renal failure and its consequences for their closest relatives: the research protocol. BMC Palliat Care 2008, 7:5.

30. Janssen DJ, Franssen FM, Wouters EF, Schols JM, Spruit MA: Impaired health status and care dependency in patients with advanced COPD or chronic heart failure. Qual Life Res 2011, 20:1679-1688.

31. Janssen DJ, Spruit MA, Schols JM, Cox B, Nawrot TS, Curtis JR, Wouters EF: Predicting changes in preferences for life-sustaining treatment among patients with advanced chronic organ failure. Chest 2012, 141:1251-1259.

32. Janssen DJ, Spruit MA, Uszko-Lencer NH, Schols JM, Wouters EF: Symptoms, comorbidities, and health care in advanced chronic obstructive pulmonary disease or chronic heart failure. $J$ Palliat Med 2011, 14:735-743.

33. Janssen DJ, Spruit MA, Schols JM, Wouters EF: A call for high-quality advance care planning in outpatients with severe COPD or chronic heart failure. Chest 2011, 139:1081-1088.

34. Janssen DJ, Spruit MA, Wouters EF, Schols JM: Family caregiving in advanced chronic organ failure. J Am Med Dir Assoc 2012, 13:394-399.

35. Charlson ME, Pompei P, Ales KL, MacKenzie CR: A new method of classifying prognostic comorbidity in longitudinal studies: development and validation. J Chronic Dis 1987, 40:373-383.

36. Standardization of Spirometry, 1994 Update. American Thoracic Society. American Journal of Respiratory and Critical Care Medicine 1995, 152:1107-1136.

37. Wilson RC, Jones PW: A comparison of the visual analogue scale and modified Borg scale for the measurement of dyspnoea during exercise. Clin Sci (Lond) 1989, 76:277-282.

38. Zigmond AS, Snaith RP: The hospital anxiety and depression scale. Acta Psychiatr Scand 1983, 67:361-370.

39. Jones PW, Quirk FH, Baveystock CM, Littlejohns P: A self-complete measure of health status for chronic airflow limitation. The St. George's Respiratory Questionnaire. Am Rev Respir Dis $1992,145: 1321-1327$. 
40. Hawthorne G, Osborne R: Population norms and meaningful differences for the Assessment of Quality of Life (AQoL) measure. Aust N Z J Public Health 2005, 29:136-142.

41. Kruijshaar ME, Hoeymans N, Bijl RV, Spijker J, Essink-Bot ML: Levels of disability in major depression: findings from the Netherlands Mental Health Survey and Incidence Study (NEMESIS). J Affect Disord 2003, 77:53-64.

42. Juniper E, Guyatt G, Jaeschke R: How to develop and validate a new health-related quality of life instrument. In Quality of life and pharmacoeconomics in Clinical Trials. 2 edition. Edited by Spiker B. Philadelphia: Lippincott-Raven; 1996: 49-56

43. Landis JR, Koch GG: The measurement of observer agreement for categorical data. Biometrics 1997, 33:159-174.

44. Altman DG, Bland JM: Statistics notes: the normal distribution. BMJ1995, 310:298.

45. Katsura $\mathrm{H}$, Yamada $\mathrm{K}$, Kida $\mathrm{K}$ : Usefulness of a linear analog scale questionnaire to measure health-related quality of life in elderly patients with chronic obstructive pulmonary disease. $J$ Am Geriatr Soc 2003, 51:1131-1135.

46. Holland R, Smith RD, Harvey I, Swift L, Lenaghan E: Assessing quality of life in the elderly: a direct comparison of the EQ-5D and AQoL. Health Econ 2004, 13:793-805.

47. Coultas D, Frederick J, Barnett B, Singh G, Wludyka P: A randomized trial of two types of nurseassisted home care for patients with COPD. Chest 2005, 128:2017-2024.

48. Elci A, Borekci S, Ovayolu N, Elbek O: The efficacy and applicability of a pulmonary rehabilitation programme for patients with COPD in a secondary-care community hospital. Respirology 2008, 13:703-707.

49. Katsura H, Yamada K, Kida K: Both generic and disease specific health-related quality of life are deteriorated in patients with underweight COPD. Respir Med 2005, 99:624-630.

50. Ritva K, Pekka R, Harri S: Agreement between a generic and disease-specific quality-of-life instrument: the 15D and the SGRQ in asthmatic patients. Qual Life Res 2000, 9:997-1003.

51. Pakhale S, Wood-Dauphinee S, Spahija J, Collet JP, Maltais F, Bernard S, Baltzan M, Rouleau M, Bourbeau J: Combining Both Generic and Disease-Specific Properties: Development of the McGill COPD Quality of Life Questionnaire. COPD: Journal of Chronic Obstructive Pulmonary Disease 2011, 8:255-263.

52. Barnes S, Gott M, Payne S, Parker C, Seamark D, Gariballa S, Small N: Recruiting older people into a large, community-based study of heart failure. Chronic IIIn 2005, 1:321-329.

53. Steinhauser KE, Clipp EC, Hays JC, Olsen M, Arnold R, Christakis NA, Lindquist JH, Tulsky JA: Identifying, recruiting, and retaining seriously-ill patients and their caregivers in longitudinal research. Palliat Med 2006, 20:745-754.

54. McHorney CA, Tarlov AR: Individual-patient monitoring in clinical practice: are available health status surveys adequate? Qual Life Res 1995, 4:293-307.

55. Perneger TV: What's wrong with Bonferroni adjustments. BMJ1998, 316:1236-1238. 



\section{CHAPTER 3}

Determinants of one-year changes in disease-specific health status in patients with advanced chronic obstructive pulmonary disease: a one-year observational study

Sarah Wilke, Martijn A. Spruit, Emiel F.M. Wouters, Jos M.G.A. Schols, Frits M.E. Franssen, and Daisy J.A. Janssen

International Journal of Nursing Practice 2015; 21: 239-248 



\section{ABSTRACT}

We aimed to identify baseline and longitudinal determinants of change in disease-specific health status in patients with advanced COPD. Demographic and clinical characteristics as well as disease-specific health status (Saint George Respiratory Questionnaire, SGRQ) were assessed in 105 outpatients with advanced COPD at baseline, four, eight, and 12 months. Eighty-five patients (81.0\%) had complete SGRQ data at baseline and 12 months and were included for analyses. Stepwise multiple regression analysis revealed that lower SGRQ total score, higher depression scores and more time needed to complete the Timed 'Up and Go' (TUG) test at baseline, as well as an increase in time needed to complete the TUG test and an increase in dyspnoea during one-year follow-up were predictors of deterioration in disease-specific health status. The current study reinforces the stimulation of physical mobility and targeting dyspnoea as components for treatment programs to optimize disease-specific health status in patients with advanced COPD. 


\section{INTRODUCTION}

Chronic obstructive pulmonary disease (COPD) is characterized by chronic inflammation of the lungs, resulting in persistent airflow limitation. It is a major cause of worldwide morbidity and mortality [1]. In addition to respiratory symptoms, patients with moderate to very severe COPD have an impaired diseasespecific health status [2-4], which may deteriorate over time [5]. Impairment in health status has been suggested to be associated with increased mortality in elderly COPD patients [6].

Previous studies have shown that baseline characteristics, such as male gender, older age, lower level of education, lower body weight, more respiratory symptoms, severe airflow limitation, and symptoms of anxiety and depression are related to deterioration in generic and disease-specific health status in patients with COPD [7-12]. In addition, frequent exacerbations during follow-up have been shown to be related to deterioration in disease-specific health status [13]. Previous authors suggested that the rate of decline in Forced Expiratory Volume in the first second $\left(\mathrm{FEV}_{1}\right)$ is related to the rate of increase in Saint George's Respiratory Questionnaire (SGRQ) score [7, 9]. Other authors indicate a moderate correlation between deterioration in disease-specific health status and increase in dyspnoea and psychological symptoms [14]. However, knowledge about the association between changes in clinical characteristics and change in disease-specific health status in patients with advanced COPD is lacking. For example, a cross-sectional study has shown a relationship between the level of care dependency and impairment in disease-specific health status in patients with advanced COPD [15]. To date, it remains unknown whether and to what extent changes in care dependency are related to changes in diseasespecific health status in COPD. Assessing the relationship between changes in patient characteristics and changes in disease-specific health status is necessary to understand causal relationships.

Therefore, the aim of the present longitudinal study was to identify baseline and longitudinal determinants of change in SGRQ total score in patients with advanced COPD. The present authors hypothesized that, amongst other clinical characteristics, an increase in care dependency is associated with deterioration in disease-specific health status over one year as assessed by SGRQ. 


\section{METHODS}

This study is a secondary analysis of a longitudinal observational study concerning symptoms and care needs of patients with advanced chronic organ failure [16]. Methodological details of this study and cross-sectional data about impaired health status, symptom distress, family caregiving, advance care planning and longitudinal data about the preferences for site of death and correlations between disease-specific and generic health status questionnaires in patients with advanced COPD were published before [15-22].

\section{Study population}

A total of 105 patients with advanced COPD were recruited by their chest physician at the outpatient clinic of one academic and two general hospitals in the Netherlands between January 2008 and June 2009. Patients were eligible if they were clinically stable for at least four weeks preceding enrolment (no hospital admission or major change in medication, according to the treating chest physician), and if they had a diagnosis of severe to very severe COPD (Global initiative for chronic Obstructive Lung Disease [1] stage III or IV). All participating patients gave written informed consent. The Medical Ethical Committee of the Maastricht University Medical Centre+ (MUMC+), Maastricht, the Netherlands, approved this study (MEC 07-3-054). The study was registered at the Dutch Trial Register (NTR 1552).

\section{Instruments}

Patients were visited by a member of the research team in their home environment at baseline and four, eight, and 12 months after baseline. The following outcomes were assessed: demographics, weight and height, smoking status, current self-reported comorbidities (Charlson Comorbidity Index) [23] and longterm oxygen therapy (LTOT). FEV 1 was assessed at baseline and calculated from the flow-volume curve measured by a handheld pulmonary spirometer. Severity of dyspnoea and fatigue was measured using a numeric rating scale (NRS) (range 0 [nothing at all] to 10 [maximal]). A recall period of two weeks was used.

Symptoms of anxiety and depression were studied using the Hospital Anxiety and Depression scale (HADS), which is divided into an anxiety subscale (HADSA) and a depression subscale (HADS-D). Total scores for each subscale range from 0 (optimal) to 21 points (worst) [24]. 
The Care Dependency Scale (CDS) was used to assess care dependency. The CDS consists of 15 items regarding basic daily activities, like personal care and household activities (range 15 [worst] to 75 points [best]). Patients with a CDS score $\leq 68$ are considered as care dependent [25].

Physical mobility was assessed using the Timed 'Up and Go' (TUG) test which measures the time (in seconds) needed to stand up from a chair, walk a distance of three metres, turn and walk back to the chair and sit down again [26]. Patients were allowed to use their walking aid and/or oxygen.

Disease-specific health status was assessed using the SGRQ, which contains 76 items. Each item is weighted using empirically derived weights. The SGRQ provides three domain scores (symptoms, activity and impact) and a total score, ranging from 0 (optimal) to 100 points (worst) [27]. A change of 4 units in total score is considered as the minimum clinically important difference (MCID) [28].

\section{Statistics}

Categorical variables were described as frequencies. Continuous variables were tested for normality and were described as mean and standard deviation (SD). Only patients who had complete SGRQ data at baseline and 12 months were included for analyses. Paired Sample T-Tests were used to compare the SGRQ mean scores at baseline and 12 months. Baseline patient characteristics and the 12-months changes in these variables were compared between patients with a clinical significant deterioration in SGRQ total score $(\Delta \geq+4$ points), no clinical significant change in SGRQ total score ( $\Delta-3.99$ to +3.99 points), or a clinical significant improvement in SGRQ total score ( $\Delta \leq-4$ points). Continuous variables were compared using univariate analysis of variance followed by post hoc least significance difference (LSD) multiple comparisons or Kruskal-Wallis test followed by Mann-Whitney U test, as appropriate. Categorical variables were compared using Chi-Square tests. Stepwise multiple regression analysis was used to determine predictive variables for change in SGRQ total score. Change in SGRQ total score was entered as dependent variable. Baseline patient characteristics and changes in clinical characteristics (listed in Table 1 and 2) were entered as independent variables. For patients who were unable to perform the TUG test, the missing value was replaced by the worst value of patients who were able to perform the TUG test, as described before [15]. A pvalue $\leq 0.05$ was interpreted as statistically significant [29]. All statistical analyses were performed using IBM SPSS statistics, Version 19.0. 


\section{RESULTS}

\section{Baseline characteristics}

In total, 85 patients (81.0\% of the patients at baseline) completed one-year follow-up, had complete data for the primary outcome variable and were included for analyses. Nine patients (8.6\%) died during one-year follow-up and 10 patients $(9.5 \%)$ withdrew because of other reasons. One patient was excluded because of incomplete SGRQ data. $62.4 \%$ of the patients were male and used long-term oxygen therapy. On average, patients were slightly overweight and the majority had very severe COPD (Table 1 ).

TABLE 1. Patient characteristics after stratification for change in SGRQ total score

\begin{tabular}{|c|c|c|c|c|}
\hline & \multirow[b]{2}{*}{$\begin{array}{l}\text { Baseline } \\
(n=85)\end{array}$} & \multicolumn{3}{|c|}{ SGRQ total score } \\
\hline & & $\begin{array}{l}\text { Improvement } \\
(\triangle S G R Q \leq-4 \\
\text { points }) \\
(n=35)\end{array}$ & $\begin{array}{l}\text { No change } \\
(\Delta=-3.99-3.99) \\
(n=13)\end{array}$ & $\begin{array}{l}\text { Deterioration } \\
(\triangle S G R Q \geq 4 \\
\text { points }) \\
(n=37)\end{array}$ \\
\hline Baseline SGRQ total score, points & $54.9(16.4)$ & $62.8(14.2)^{\star}$ & $56.9(13.0)^{\star}$ & $46.7(15.8)$ \\
\hline Male, n (\%) & $53(62.4)$ & $16(45.7)^{\star}$ & $9(69.2)$ & $28(75.7)$ \\
\hline $\begin{array}{l}\text { Marital status (married/living } \\
\text { with partner), } \mathrm{n}(\%)\end{array}$ & $59(69.4)$ & $24(68.6)$ & $9(69.2)$ & $26(70.3)$ \\
\hline Age, years & $65.8(9.2)$ & $63.8(9.1)$ & $66.9(8.1)$ & $68.0(9.8)$ \\
\hline $\mathrm{BMI}, \mathrm{kg} / \mathrm{m}^{2 \dagger}$ & $26.6(6.9)$ & $28.4(8.5)$ & $26.0(4.4)$ & $25.0(5.7)$ \\
\hline Current smokers, n (\%) & $23(27.1)$ & $10(28.6)$ & $3(23.1)$ & $10(27.0)$ \\
\hline $\mathrm{FEV}_{1}, \%$ predicted ${ }^{\ddagger \dagger}$ & $34.3(13.6)$ & $32.3(15.5)$ & $36.4(8.9)$ & $35.3(13.3)$ \\
\hline $\begin{array}{l}\text { Charlson Comorbidity index, } \\
\text { points }\end{array}$ & $2.4(1.7)$ & $2.9(1.9)$ & $1.9(1.9)$ & $2.2(1.5)$ \\
\hline Long-term oxygen therapy, n (\%) & $53(62.4)$ & $23(65.7)$ & $5(38.5)$ & $25(67.6)$ \\
\hline NRS dyspnoea score, points & $4.8(2.0)$ & $5.4(2.0)^{\star}$ & $5.5(2.0)^{\star}$ & $4.1(1.8)$ \\
\hline NRS fatigue score, points & $4.4(2.4)$ & $5.0(2.4)^{\star}$ & $5.2(2.2)^{\star}$ & $3.6(2.3)$ \\
\hline HADS-A score, points & $5.5(4.2)$ & $6.4(4.0)$ & $5.3(4.6)$ & $4.8(4.2)$ \\
\hline HADS-D score, points & $6.1(4.0)$ & $6.3(3.6)$ & $7.0(3.5)$ & $5.6(4.5)$ \\
\hline TUG test, seconds $^{\dagger}$ & $11.3(5.1)$ & $10.9(4.2)$ & $10.2(2.9)$ & $12.1(6.3)$ \\
\hline CDS, points & $68.8(6.0)$ & $68.5(4.9)$ & $69.3(6.8)$ & $69.0(6.7)$ \\
\hline Exacerbations, $\mathrm{n}^{\S^{\dagger}}$ & $3.1(2.3)$ & $3.6(2.4)$ & $2.5(2.2)$ & $2.7(2.3)$ \\
\hline
\end{tabular}

Values expressed as mean (standard deviation) or number of patients (n), proportion (\%). Abbreviations. BMI, body mass index; $\mathrm{FEV}_{1}$, forced expiratory volume in the first second; NRS, numeric rating scale; HADS-A, Hospital Anxiety and Depression Scale, Anxiety subscale; HADS-D, Hospital Anxiety and Depression Scale, Depression subscale; TUG, Timed 'Up and Go' test; CDS, Care Dependency Scale; SGRQ, St. George Respiratory Questionnaire. ${ }^{\dagger}$ non-parametric statistic tests were used because of skewed data; ${ }^{\ddagger} n=82$ ('Baseline'), $n=32$ ('Improvement'); ${ }^{*} p \leq 0.05$ versus 'Deterioration'; \& $\mathrm{n}=83$ ('Baseline'), $\mathrm{n}=35$ ('Deterioration') 
Patients who withdrew from the study were more care dependent and needed more time to perform the TUG test than patients who completed the study (see supplementary material for details). At baseline, the mean SGRQ total score was 54.9 [16.4] points. The mean SGRQ symptom domain score was 59.2 [21.8] points, the mean SGRQ activity domain score was 73.1 [21.5] points and the SGRQ impact domain was 43.1 [18.2] points.

\section{Changes in SGRQ total score and domain scores}

The mean SGRQ total score did not change during one-year follow-up $(+1.3$ [14.9] points, $p=0.42)$, as well as the SGRQ symptom domain score $(-0.9$ [22.2] points, $p=0.72)$, SGRQ activity domain score $(+3.8[20.1]$ points, $p=0.08)$, and SGRQ impact domain score (+0.6 [17.7] points, $p=0.74)$. After one-year followup, 35 patients $(41.2 \%)$ reported an improved disease-specific health status, 37 patients (43.5\%) reported a decline in disease-specific health status and disease-specific health status of 13 patients (15.3\%) remained stable. Figure 1 demonstrates SGRQ total scores and domain scores at baseline, four, eight and 12 months after stratification for one-year change in SGRQ total score.
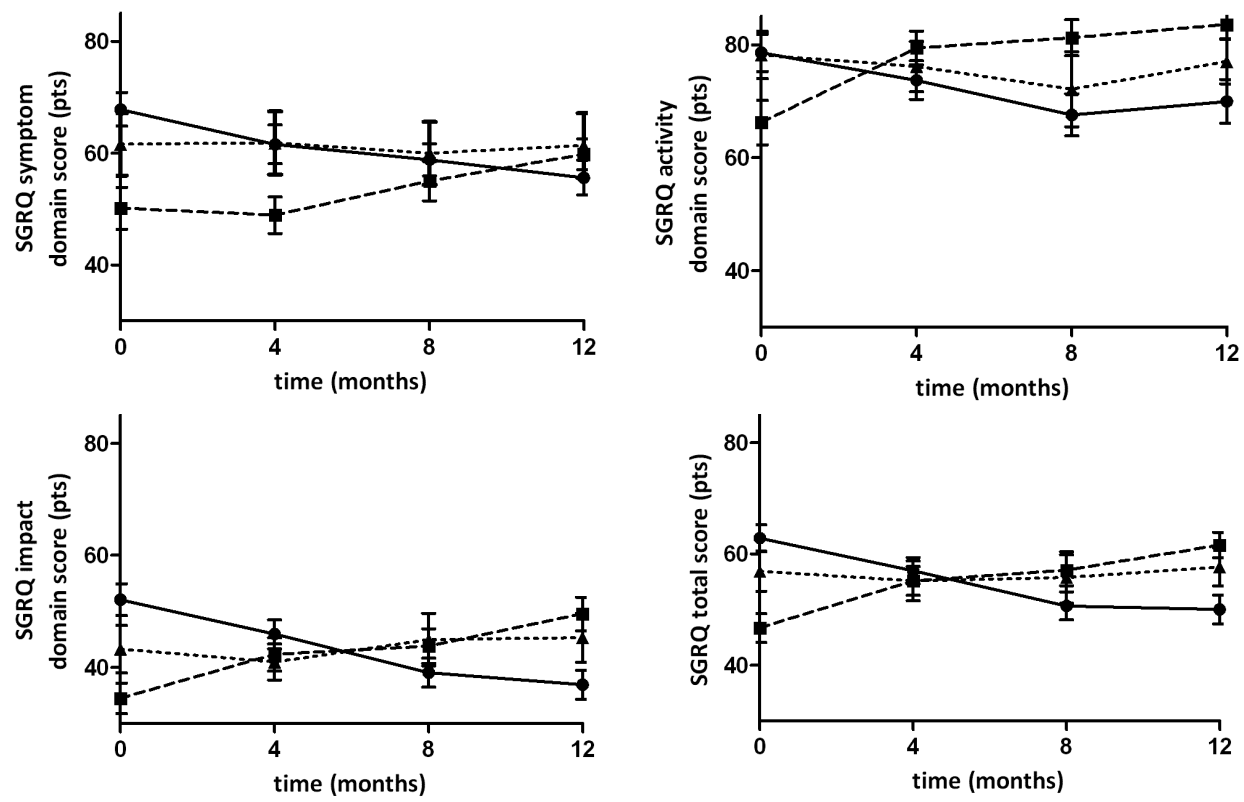

FIGURE 1. One year changes in SGRQ domain scores and total score after stratification for change in SGRQ total score. $\mathrm{n}=85$

$\rightarrow-$ Improvement, $\rightarrow$-Deterioration, $-\mathbf{t}$-No change 


\section{Relationship of patient characteristics and changes in SGRQ total score: univariate analyses}

Table 1 shows the patient characteristics after stratification for change in SGRQ total score. Univariate analyses have shown that patients whose diseasespecific health status improved or remained stable over time had higher SGRQ total scores and dyspnoea and fatigue NRS scores at baseline compared to those patients whose health status deteriorated (Table 1).

\section{Relationship of changes in patient characteristics and changes in SGRQ total score: univariate analyses}

Table 2 shows the one-year changes in patient characteristics after stratification for change in SGRQ total score. Patients whose health status deteriorated reported a greater increase in the level of care dependency than patients whose health status improved over time. Patients whose health status improved reported a decrease in severe dyspnoea and fatigue as assessed by NRS while patients whose health status deteriorated over time reported an increase in dyspnoea and fatigue. Furthermore, patients whose health status improved reported a decrease in depressive symptoms as assessed by HADS-D while patients whose health status remained stable reported an increase in depressive symptoms (Table 2).

TABLE 2. One-year changes in patient characteristic after stratification for change in SGRQ total score

\begin{tabular}{|c|c|c|c|}
\hline & \multicolumn{3}{|c|}{ SGRQ total score } \\
\hline & $\begin{array}{l}\text { Improvement } \\
(\triangle \mathrm{SGRQ} \leq-4 \\
\text { points }) \\
(\mathrm{n}=35)\end{array}$ & $\begin{array}{l}\text { No change } \\
(\Delta=-3.99-3.99) \\
(n=13)\end{array}$ & $\begin{array}{l}\text { Deterioration } \\
(\triangle S G R Q \geq 4 \\
\text { points }) \\
(n=37)\end{array}$ \\
\hline$\geq 1$ hospitalizations within 12 months, $\mathrm{n}$ (\%) & $13(37.1)$ & $3(23.1)$ & $14(37.8)$ \\
\hline Change in $\mathrm{BMI}, \mathrm{kg} / \mathrm{m}^{2+\ddagger}$ & $0.1(2.9)$ & $0.9(1.5)$ & $-0.2(1.4)$ \\
\hline $\begin{array}{l}\text { Change in Charlson Comorbidity Index, } \\
\text { points }{ }^{\ddagger}\end{array}$ & $0.1(0.7)$ & $-0.5(1.7)$ & $0.1(0.3)$ \\
\hline Change in NRS dyspnoea score, points & $-0.5(1.9) *$ & $-0.2(1.6) *$ & $1.0(1.7)$ \\
\hline Change in NRS fatigue score, points & $-0.8(2.2) *$ & $-0.2(1.8)$ & $1.2(2.9)$ \\
\hline Change in HADS-A score, points & $-0.9(3.8)$ & $0.5(3.0)$ & $-0.1(4.3)$ \\
\hline Change in HADS-D score, points ${ }^{\ddagger}$ & $-1.5(3.2) \star^{\#}$ & $1.5(5.6)$ & $0.0(3.5)$ \\
\hline Change in TUG test, seconds & $3.2(8.9)$ & $3.9(9.6)$ & $5.1(8.7)$ \\
\hline Change in CDS, points ${ }^{\ddagger}$ & $-1.0(6.1) *$ & $-1.2(3.5)$ & $-5.8(8.6)$ \\
\hline
\end{tabular}

Values expressed as mean (standard deviation) or number of patients (n), proportion (\%). Abbreviations: see legend table $1 .{ }^{\dagger} \mathrm{n}=34$ ('Improvement'), $\mathrm{n}=36$ ('Deterioration'); ${ }^{\ddagger}$ non-parametric statistic tests were used because of skewed data; ${ }^{*} p \leq 0.05$ versus 'Deterioration'; ${ }^{\#} p \leq 0.05$ versus 'No change'. 


\section{Determinants of one-year change in disease-specific health status}

The variables listed in Table 1 and 2 were entered in the stepwise multiple regression model. This model showed that baseline SGRQ total score, baseline TUG test, change in TUG test, change in NRS dyspnoea score and baseline HADS-D score explained $48.4 \%(p<0.001)$ of the variance in change in SGRQ total score over one year. Lower baseline SGRQ total scores, more time needed to complete the TUG test and more depressive symptoms at baseline were associated with a deterioration in disease-specific health status, as assessed by SGRQ. Furthermore, an increase of dyspnoea and deterioration in mobility after one year were associated with a deterioration in disease-specific health status (Table 3).

TABLE 3. Change in SGRQ total score: Stepwise Multiple Regression Analysis, final model

\begin{tabular}{lll}
\hline & \multicolumn{2}{l}{ Change in SGRQ total score } \\
\cline { 2 - 3 } & Beta & p-value \\
\hline Baseline SGRQ total score & -0.746 & $<0.001$ \\
Baseline CDS score & -0.190 & 0.072 \\
Baseline TUG & 0.223 & 0.018 \\
Change in TUG & 0.302 & 0.001 \\
Change in NRS dyspnoea score & 0.254 & 0.005 \\
Baseline HADS-D score & 0.251 & 0.016 \\
\hline
\end{tabular}

$\mathrm{n}=85$. Abbreviations. Please see legend table 1

Variables excluded from the final model: sex, marital status, age, BMl, smoking status, FEV ${ }_{1}$, Charlson index, LTOT, NRS dyspnoea and fatigue scores, HADS-A score, hospitalisations, change in BMI, change in Charlson Comorbidity Index, change in NRS fatigue score, change in HADS-A, change in HADS-D and change in CDS

\section{DISCUSSION}

The present study has shown that after one-year follow-up, $41.2 \%$ of the patients reported a clinically relevant improvement in disease-specific health status, $43.5 \%$ of the patients reported a clinically relevant deterioration in diseasespecific health status and disease-specific health status of $15.3 \%$ patients remained stable during 12 months. Furthermore, lower SGRQ total score at baseline (i.e., better disease-specific health status), higher HADS scores and more time needed to complete the TUG test at baseline, as well as an increase in time needed to complete the TUG and an increase in dyspnoea during one-year follow-up were predictors of deterioration in disease-specific health status. 


\section{One-year changes in disease specific health status}

According to the current study, mean SGRQ total score remained stable during one year. Previous pharmacological trials (i.e., Understanding Potential Longterm Impacts on Function with Tiotropium [UPLIFT] trial, TOwards a Revolution in COPD Health [TORCH] study) suggested a deterioration of disease-specific health status during three- and four-year follow-up [7, 30]. However, one-year changes in disease-specific health status in these studies were similar to the findings of the current study. Moreover, $41.2 \%$ of the patients reported an improved disease-specific health status. A previous study by Habraken et al. [5] found that disease-specific health status deteriorated slightly over time in the majority of patients with end-stage COPD. Several factors may contribute to this disparity. For example, Habraken et al. [5] included patients with GOLD stage IV, while in the present study also patients with GOLD stage III were included. Additionally, patient characteristics cannot be compared adequately due to a different stratification of the study population: Habraken et al. [5] distributed their population into three equal sized groups stratified by change in SGRQ total score, while we used the MCID as cutoff points to identify clinically relevant changes. Ferrari et al. [31] studied changes in health status in patients with mild to severe COPD and reported that disease-specific health status as assessed by SGRQ worsened ( $\geq 4 \%$ ) in $51 \%$ of the patients and improved in $28 \%$ of the patients.

Furthermore, patients whose health status deteriorated reported a better disease-specific health status at baseline than patients whose disease-specific health status improved (table 1; figure 1) which is in line with previous results [5]. These findings suggest that patients with a more favorable disease-specific health status at baseline have a higher chance to change for the worse. Professionals should keep this in mind and observe and assess disease-specific health status regularly, also in patients with a relatively less impairment in health status. Moreover, this phenomenon could also be explained by a statistical artefact like regression to the mean.

\section{Determinants of changes in disease-specific health status}

A previous cross-sectional analysis identified care dependency as an important correlate of disease-specific health status [15]. Inconsistent with our hypothesis, our multivariate model did not show an association between care dependency and change in disease-specific health status, despite the fact that our univariate analysis suggested a relationship. These results may indicate that there is no causal relationship between care dependency and disease-specific health status in patients with advanced COPD. 
The current study has shown that an increase in dyspnoea is associated with a deterioration in disease-specific health status. Our findings are supported by previous findings. Dourado et al. [32] suggested that the reduction of dyspnoea as assessed by Baseline Dyspnoea Index (BDI) after physical training is associated with improvement in disease-specific health status among patients with moderate COPD. Furthermore, Ferrari et al. [31] reported an association between the change in modified Medical Research Council (mMRC) scale and deterioration in disease-specific health status in patients with COPD.

Previously, physical mobility has been shown to be associated with generic and disease-specific health status in patients with COPD $[33,34]$. In the current study, a lower level of physical mobility or a decrease in physical mobility as assessed by the TUG test was associated with a deterioration in diseasespecific health status. Recently, a cross-sectional study by Jehn et al. [35] identified walking intensity as an independent predictor for SGRQ total score. The current study extends these cross-sectional results and indicates an important longitudinal association between physical mobility as assessed by TUG test and disease-specific health status.

\section{Implications for clinical practice}

As shown in the current study, impairment in disease-specific health status was associated with several determinants which underlines the systemic nature of COPD [36]. Therefore, as indicated before [37], a multidisciplinary approach is necessary to assess and manage COPD. The current study obtained further evidence that optimizing disease-specific health status of patients with advanced COPD should be directed at regular assessment and improvement of physical mobility and dyspnoea. Dyspnoea is strongly related to mortality and the most important symptom for patients with advanced COPD [18, 36, 38]. Treatment strategies should be developed to interrupt the dyspnoea-inactivitydyspnoea cycle in such patients to possibly decrease the risk for deterioration in disease-specific health status. Moreover, nurse-led interventions may have an important role in improvement of dyspnoea in patients with advanced COPD [39]. Due to the fact that the current study identified higher HADS scores as a predictor of deterioration in disease specific health status, it is important to be aware of the fact that physical activity has also been shown to reduce depressive symptoms in patients with chronic illnesses [40]. Furthermore, depressive symptoms were associated with more exacerbations [41]. Thus, next to the assessment of mobility and dyspnoea, professionals should consider depressive symptoms regularly. Accordingly, effective pharmacological treatment of dyspnoea can improve disease-specific health status [42]. Pulmonary rehabilita- 
tion has been shown to be able to improve dyspnoea, psychological status and health status [43].

Furthermore, SGRQ total score and SGRQ domain scores should be interpreted separately to gain complete inside into all aspects and the changes of all aspects of disease-specific health status. As suggested before, using the SGRQ total score as single outcome may increase the chance to obtain false-negative results [44].

\section{Methodological considerations}

The present study has several methodological considerations that should be considered in interpreting the results. First, the study population consists of a convenience sample of patients with GOLD stage III or IV. Thus, it remains unknown whether these data are applicable for patients with GOLD stage I or II. Second, about $20 \%$ of the baseline study sample withdrew from the study during one-year follow-up. These patients were more dependent in personal care and performed the TUG test worse than patients who completed the study. However, disease-specific health status between patients who withdrew from the study and patients who completed the study were comparable at baseline (see supplementary material detailed information). Third, the generalizability is restricted because of the limited sample size. Furthermore, change in $\mathrm{FEV}_{1}$ was not studied which may be a predictor of change in disease-specific health status [45]. However, disease-specific health status has been shown to improve, even in the absence of changes in $\mathrm{FEV}_{1}$ [7]. Another previous study suggested that there is no relationship between the change in pulmonary function and change in disease-specific health status [46]. The identified predictors were able to explain $48.4 \%$ of the variance. Other potential predictors that were not assessed in the current study are participating in a pulmonary rehabilitation program [47] and compliance to medication [10,48]. Indeed, pulmonary rehabilitation has been shown to be effective in improving disease-specific health status as assessed by SGRQ, even in patients with severe to very severe COPD [47]. Seasonality $[13,49]$ and living environment $[10]$ may also explain part of the variance in change in disease-specific health status. Finally, part of the shown variance may be due to a statistical artefact like regression to the mean [50].

\section{CONCLUSION}

The present study shows that patients who reported a better disease-specific health status, had more symptoms of depression, worse mobility at baseline, as 
well as deterioration in mobility or increase in dyspnoea during one year, are at risk for a deterioration in disease-specific health status. The current study reinforces the promotion of physical mobility and treatment of dyspnoea and depressive symptoms as important components for treatment programs to optimize or stabilize disease-specific health status in patients with advanced COPD. 


\section{REFERENCES}

1. Rabe KF, Hurd S, Anzueto A, Barnes PJ, Buist SA, Calverley P, Fukuchi Y, Jenkins C, RodriguezRoisin R, van Weel C, Zielinski J: Global strategy for the diagnosis, management, and prevention of chronic obstructive pulmonary disease: GOLD executive summary. Am J Respir Crit Care Med 2007, 176:532-555.

2. Jones PW, Brusselle G, Dal Negro RW, Ferrer M, Kardos P, Levy ML, Perez T, Soler-Cataluna JJ, van der Molen T, Adamek L, Banik N: Health-related quality of life in patients by COPD severity within primary care in Europe. Respir Med 2011, 105:57-66.

3. Janssen DJ, Spruit MA, Leue C, Gijsen C, Hameleers H, Schols JM, Wouters EF: Symptoms of anxiety and depression in COPD patients entering pulmonary rehabilitation. Chron Respir Dis 2010, 7:147-157.

4. Spruit MA, Pennings HJ, Janssen PP, Does JD, Scroyen S, Akkermans MA, Mostert R, Wouters EF: Extra-pulmonary features in COPD patients entering rehabilitation after stratification for MRC dyspnea grade. Respir Med 2007, 101:2454-2463.

5. Habraken JM, van der Wal WM, Ter Riet G, Weersink EJ, Toben F, Bindels PJ: Health-related quality of life and functional status in end-stage COPD: a longitudinal study. Eur Respir J2011, 37:280-288.

6. Antonelli-Incalzi R, Pedone C, Scarlata S, Battaglia S, Scichilone N, Forestiere F, Bellia V: Correlates of mortality in elderly COPD patients: focus on health-related quality of life. Respirology 2009, 14:98-104.

7. Jones PW, Anderson JA, Calverley PM, Celli BR, Ferguson GT, Jenkins C, Yates JC, Vestbo J, Spencer MD: Health status in the TORCH study of COPD: treatment efficacy and other determinants of change. Respir Res 2011, 12:71.

8. Oga T, Tsukino M, Hajiro T, Ikeda A, Koyama H, Mishima M, Chin K, Nishimura K: Multidimensional analyses of long-term clinical courses of asthma and chronic obstructive pulmonary disease. Allergol Int 2010, 59:257-265.

9. Spencer S, Calverley PM, Sherwood Burge P, Jones PW: Health status deterioration in patients with chronic obstructive pulmonary disease. Am J Respir Crit Care Med 2001, 163:122-128.

10. Hesselink AE, van der Windt DA, Penninx BW, Wijnhoven HA, Twisk JW, Bouter LM, van Eijk JT: What predicts change in pulmonary function and quality of life in asthma or COPD? J Asthma 2006, 43:513-519.

11. Balcells E, Gea J, Ferrer J, Serra I, Orozco-Levi M, de Batlle J, Rodriguez E, Benet M, DonaireGonzalez D, Anto JM, Garcia-Aymerich J: Factors affecting the relationship between psychological status and quality of life in COPD patients. Health Qual Life Outcomes 2010, 8:108.

12. Akinci AC, Yildirim E: Factors affecting health status in patients with chronic obstructive pulmonary disease. Int J Nurs Pract 2013, 19:31-38.

13. Miravitlles M, Ferrer M, Pont A, Zalacain R, Alvarez-Sala JL, Masa F, Verea H, Murio C, Ros F, Vidal R: Effect of exacerbations on quality of life in patients with chronic obstructive pulmonary disease: a 2 year follow up study. Thorax 2004, 59:387-395.

14. Oga $T$, Nishimura $K$, Tsukino $M$, Sato $S$, Hajiro $T$, Mishima $M$ : Longitudinal deteriorations in patient reported outcomes in patients with COPD. Respir Med 2007, 101:146-153.

15. Janssen DJ, Franssen FM, Wouters EF, Schols JM, Spruit MA: Impaired health status and care dependency in patients with advanced COPD or chronic heart failure. Qual Life Res 2011, 20:1679-1688.

16. Janssen DJ, Wouters EF, Schols JM, Spruit MA: Self-perceived symptoms and care needs of patients with severe to very severe chronic obstructive pulmonary disease, congestive heart failure or chronic renal failure and its consequences for their closest relatives: the research protocol. BMC Palliat Care 2008, 7:5.

17. Janssen DJ, Spruit MA, Schols JM, Wouters EF: A call for high-quality advance care planning in outpatients with severe COPD or chronic heart failure. Chest 2011, 139:1081-1088. 
18. Janssen DJ, Spruit MA, Uszko-Lencer NH, Schols JM, Wouters EF: Symptoms, comorbidities, and health care in advanced chronic obstructive pulmonary disease or chronic heart failure. $J$ Palliat Med 2011, 14:735-743.

19. Janssen DJ, Spruit MA, Schols JM, Cox B, Nawrot TS, Curtis JR, Wouters EF: Predicting changes in preferences for life-sustaining treatment among patients with advanced chronic organ failure. Chest 2012, 141:1251-1259.

20. Janssen DJ, Spruit MA, Wouters EF, Schols JM: Family caregiving in advanced chronic organ failure. J Am Med Dir Assoc 2012, 13:394-399.

21. Wilke S, Janssen DJ, Wouters EF, Schols JM, Franssen FM, Spruit MA: Correlations between disease-specific and generic health status questionnaires in patients with advanced COPD: a one-year observational study. Health Qual Life Outcomes 2012, 10:98.

22. Janssen DJ, Spruit MA, Schols JM, Wouters EF: Dynamic Preferences for Site of Death Among Patients With Advanced Chronic Obstructive Pulmonary Disease, Chronic Heart Failure, or Chronic Renal Failure. J Pain Symptom Manage 2013.

23. Charlson ME, Pompei P, Ales KL, MacKenzie CR: A new method of classifying prognostic comorbidity in longitudinal studies: development and validation. J Chronic Dis 1987, 40:373-383.

24. Zigmond AS, Snaith RP: The hospital anxiety and depression scale. Acta Psychiatr Scand 1983, 67:361-370.

25. Dijkstra A, Tiesinga LJ, Plantinga L, Veltman G, Dassen TW: Diagnostic accuracy of the care dependency scale. J Adv Nurs 2005, 50:410-416.

26. Podsiadlo D, Richardson S: The timed "Up \& Go": a test of basic functional mobility for frail elderly persons. J Am Geriatr Soc 1991, 39:142-148.

27. Jones PW, Quirk FH, Baveystock CM, Littlejohns P: A self-complete measure of health status for chronic airflow limitation. The St. George's Respiratory Questionnaire. Am Rev Respir Dis 1992, 145:1321-1327.

28. Jones PW: Interpreting thresholds for a clinically significant change in health status in asthma and COPD. Eur Respir J2002, 19:398-404.

29. Altman DG, Bland JM: Statistics notes: the normal distribution. BMJ1995, 310:298.

30. Hanania NA, Sharafkhaneh A, Celli B, Decramer M, Lystig T, Kesten S, Tashkin D: Acute bronchodilator responsiveness and health outcomes in COPD patients in the UPLIFT trial. Respir Res 2011, 12:6.

31. Ferrari R, Tanni SE, Caram LM, Naves CR, Godoy I: Predictors of health status do not change over three-year periods and exacerbation makes difference in chronic obstructive pulmonary disease. Health Qual Life Outcomes 2011, 9:112.

32. Dourado VZ, Antunes LC, Tanni SE, Godoy I: Factors associated with the minimal clinically important difference for health-related quality of life after physical conditioning in patients with COPD. J Bras Pneumo/2009, 35:846-853.

33. Moy ML, Matthess K, Stolzmann K, Reilly J, Garshick E: Free-living physical activity in COPD: assessment with accelerometer and activity checklist. J Rehabil Res Dev2009, 46:277-286.

34. Waschki B, Spruit MA, Watz H, Albert PS, Shrikrishna D, Groenen M, Smith C, Man WD, TalSinger R, Edwards LD, et al: Physical activity monitoring in COPD: compliance and associations with clinical characteristics in a multicenter study. Respir Med2012, 106:522-530.

35. Jehn M, Schindler C, Meyer A, Tamm M, Schmidt-Trucksass A, Stolz D: Daily walking intensity as a predictor of quality of life in patients with chronic obstructive pulmonary disease. Med Sci Sports Exerc 2012, 44:1212-1218.

36. Celli BR, Cote CG, Marin JM, Casanova C, Montes de Oca M, Mendez RA, Pinto Plata V, Cabral $\mathrm{HJ}$ : The body-mass index, airflow obstruction, dyspnea, and exercise capacity index in chronic obstructive pulmonary disease. N Eng/ J Med 2004, 350:1005-1012.

37. McDonald VM, Simpson JL, Higgins I, Gibson PG: Multidimensional assessment of older people with asthma and COPD: clinical management and health status. Age Ageing 2011, 40:42-49.

38. Nishimura K, Izumi T, Tsukino M, Oga T: Dyspnea is a better predictor of 5-year survival than airway obstruction in patients with COPD. Chest 2002, 121:1434-1440. 
39. Nurmatov U, Buckingham S, Kendall M, Murray SA, White P, Sheikh A, Pinnock H: Effectiveness of holistic interventions for people with severe chronic obstructive pulmonary disease: systematic review of controlled clinical trials. PLoS One 2012, 7:e46433.

40. Herring MP, Puetz TW, O'Connor PJ, Dishman RK: Effect of exercise training on depressive symptoms among patients with a chronic illness: a systematic review and meta-analysis of randomized controlled trials. Arch Intern Med 2012, 172:101-111.

41. Jennings $\mathrm{JH}$, Digiovine $B$, Obeid D, Frank C: The association between depressive symptoms and acute exacerbations of COPD. Lung 2009, 187:128-135.

42. Jones PW, Mahler DA, Gale R, Owen R, Kramer B: Profiling the effects of indacaterol on dyspnoea and health status in patients with COPD. Respir Med 2011, 105:892-899.

43. Ergun $P$, Kaymaz D, Gunay E, Erdogan Y, Turay UY, Demir N, Canak E, Sengul F, Egesel N, Kose SK: Comprehensive out-patient pulmonary rehabilitation: Treatment outcomes in early and late stages of chronic obstructive pulmonary disease. Ann Thorac Med 2011, 6:70-76.

44. Moullec G, Favreau H, Lavoie KL, Labrecque M: Does a self-management education program have the same impact on emotional and functional dimensions of HRQoL? COPD 2012, 9:3645.

45. Westwood M, Bourbeau J, Jones PW, Cerulli A, Capkun-Niggli G, Worthy G: Relationship between FEV1 change and patient-reported outcomes in randomised trials of inhaled bronchodilators for stable COPD: a systematic review. Respir Res 2011, 12:40.

46. Oga T, Nishimura K, Tsukino M, Hajiro T, Sato S, Ikeda A, Hamadas C, Mishima M: Longitudinal changes in health status using the chronic respiratory disease questionnaire and pulmonary function in patients with stable chronic obstructive pulmonary disease. Qual Life Res 2004, 13:1109-1116.

47. van Ranst $\mathrm{D}$, Otten $\mathrm{H}$, Meijer JW, van 't Hul AJ: Outcome of pulmonary rehabilitation in COPD patients with severely impaired health status. Int J Chron Obstruct Pulmon Dis 2011, 6:647657.

48. Calverley PM, Spencer S, Willits L, Burge PS, Jones PW, Group IS: Withdrawal from treatment as an outcome in the ISOLDE study of COPD. Chest 2003, 124:1350-1356.

49. Jenkins CR, Celli B, Anderson JA, Ferguson GT, Jones PW, Vestbo J, Yates JC, Calverley PM: Seasonality and determinants of moderate and severe COPD exacerbations in the TORCH study. Eur Respir J2012, 39:38-45.

50. Barnett AG, van der Pols JC, Dobson AJ: Regression to the mean: what it is and how to deal with it. Int J Epidemio/2005, 34:215-220. 


\section{SUPPLEMENTAL MATERIAL}

\section{METHODS}

\section{Statistics}

To compare baseline differences between patients who completed the study and those who withdrew from the study, an independent sample t-test or MannWhitney $\mathrm{U}$ test was used, as appropriate.

SUPPLEMENTARY TABLE S1. Baseline patient characteristics

\begin{tabular}{|c|c|c|c|}
\hline & $\begin{array}{l}\text { Study completed } \\
(\mathrm{n}=85)\end{array}$ & $\begin{array}{l}\text { Dropout } \\
(\mathrm{n}=19)\end{array}$ & p-value \\
\hline Baseline SGRQ total score, points & $54.9(16.4)$ & $61.5(19.7)$ & 0.13 \\
\hline Male, n (\%) & $53(62.4)$ & $11(57.9)$ & 0.72 \\
\hline Marital status (married/living with partner), n (\%) & $59(69.4)$ & $18(94.7)$ & 0.001 \\
\hline Age, years & $65.8(9.2)$ & $68.8(8.2)$ & 0.19 \\
\hline $\mathrm{BMI}, \mathrm{kg} / \mathrm{m}^{2+}$ & $26.6(6.9)$ & $25.5(5.4)$ & 0.93 \\
\hline Current smokers, n (\%) & $23(27.1)$ & $3(15.8)$ & 0.26 \\
\hline $\mathrm{FEV}_{1}, \%$ predicted $^{\dagger}$ & $34.3(13.6)^{\ddagger}$ & $32.7(13.1)$ & 0.59 \\
\hline Charlson index, points & $2.4(1.7)$ & $2.7(1.7)$ & 0.51 \\
\hline Long-term oxygen therapy, n (\%) & $53(62.4)$ & $9(47.4)$ & 0.23 \\
\hline NRS dyspnoea score, points & $4.8(2.0)$ & $4.9(2.1)$ & 0.83 \\
\hline NRS fatigue score, points & $4.4(2.4)$ & $5.3(2.8)$ & 0.15 \\
\hline HADS-A score, points & $5.5(4.2)$ & $7.5(5.6)$ & 0.08 \\
\hline HADS-D score, points & $6.1(4.0)$ & $7.7(3.4)$ & 0.12 \\
\hline TUG test, seconds $^{\dagger}$ & $11.3(5.1)$ & $16.2(8.7)$ & 0.03 \\
\hline Care Dependency Scale, points & $68.8(6.0)$ & $59.3(12.6)$ & 0.004 \\
\hline
\end{tabular}

Values expressed as mean (standard deviation [SD]) or number of patients (n), proportion (\%). Abbreviations. BMI, body mass index; $\mathrm{FEV}_{1}$, forced expiratory volume in the first second; NRS, numeric rating scale; HADS-A, Hospital Anxiety and Depression Scale, Anxiety subscale; HADS-D, Hospital Anxiety and Depression Scale, Depression subscale; TUG, Timed 'Up and Go' test; SGRQ, St. George Respiratory Questionnaire; ${ }^{\dagger}$ non-parametric statistic tests were used because of skewed data; ${ }^{\ddagger} \mathrm{n}=82$ 


\section{CHAPTER 4}

One-year change in health status and subsequent outcomes in chronic obstructive pulmonary disease

Sarah Wilke, Paul W. Jones, Hana Müllerova, Jørgen Vestbo, Ruth Tal-Singer, Frits M.E. Franssen, Alvar Agusti, Per Bakke, Peter M. Calverley, Harvey O. Coxson, Courtney Crim, Lisa D. Edwards, David A. Lomas, William MacNee, Stephen I. Rennard, Julie C. Yates, Emiel F.M. Wouters, and Martijn A. Spruit

Thorax 2015; 70: 420-425 



\section{ABSTRACT}

\section{BACKGROUND}

Poor health status has been associated with morbidity and mortality in patients with COPD. To date, the impact of changes in health status on these outcomes remains unknown.

\section{AIMS}

To explore the relationship of clinically relevant changes in health status with exacerbation, hospitalization or death in patients with COPD.

\section{METHODS}

Characteristics and health status (St. George's Respiratory Questionnaire, SGRQ) were assessed over a period of 3 years in 2,138 patients with COPD enrolled in the ECLIPSE study: a longitudinal, prospective, observational study. Associations between change in health status ( $=4$ units in SGRQ score) during year 1 and time to first exacerbation, hospitalizations and death during 2-year follow-up were assessed using Kaplan-Meier plots and log-rank test.

\section{RESULTS}

$1,832\left(85.7 \%\right.$ ) patients (age $63.4 \pm 7.0$ years, $65.4 \%$ male, $\mathrm{FEV}_{1} 48.7 \pm 15.6 \%$ predicted) underwent assessment at baseline and 1 year. Compared with those who deteriorated, patients with improved or stable health status in year 1 have a lower likelihood of exacerbation (0.78 (0.67-0.89), $p<0.001$ and 0.84 (0.73-0.97), $p=0.016$, respectively), hospitalization $(0.72(0.58-0.90), p=0.004$ and $0.77(0.62-$ $0.96), p=0.023$, respectively) or dying (0.61 (0.39-0.95), $p=0.027$ and 0.58 (0.37$0.92), p=0.019$, respectively) during 2 -year follow-up $(p<0.05)$. This effect persisted after stratification for age and the number of exacerbations and hospitalizations during the first year of the study.

\section{CONCLUSIONS}

Patients with stable or improved health status during year 1 of ECLIPSE had a lower likelihood of exacerbation, hospitalization or dying during 2-year followup. Interventions that stabilize and improve health status may also improve outcomes in COPD patients. 


\section{INTRODUCTION}

Patients with chronic obstructive pulmonary disease (COPD) have impaired disease-specific health status [1, 2] that may deteriorate over time [3]. The St. George's Respiratory Questionnaire (SGRQ) is a disease-specific health status questionnaire reflecting a broad variety of health impacts in patients with chronic respiratory diseases [4]. High baseline SGRQ total scores (i.e., poor health status) have been associated with an increased number of exacerbations and hospitalizations in patients with COPD [5]. Moreover, higher baseline SGRQ scores were associated with worse survival [6].

An increase of four points or more in SGRQ total score can be considered as a meaningful worsening of patient's health status [7]. To date, it remains unknown whether and to what extent clinically relevant changes in disease-specific health status may affect morbidity and mortality in patients with COPD. Nevertheless, it seems reasonable to hypothesize that a worsening of the disease-specific health status will be associated with worsening of other important health outcomes.

We sought to explore the impact of clinically relevant one-year changes in SGRQ total scores on the likelihood of having an exacerbation, hospitalization or dying in patients with COPD, using data from the Evaluation of COPD Longitudinally to Identify Predictive Surrogate Endpoints (ECLIPSE) study [8].

\section{METHODS}

The ECLIPSE study is a multicenter, longitudinal, prospective three-year observational study to identify novel endpoints in COPD [8]. Participants were eligible if they were 40 to 75 years of age, had a smoking history of 10 or more pack-years and a diagnosis of COPD confirmed with postbronchodilator $\mathrm{FEV}_{1} / \mathrm{FVC}<0.7$. Demographic and clinical characteristics were assessed as described before [9].

\section{Health status}

Disease-specific health status was assessed using the COPD-specific version of the SGRQ (SGRQ-C) to provide SGRQ scores. The SGRQ-C has three domain scores (Symptoms, Activity and Impact) and a Total score, ranging from 0 (optimal) to 100 points (worst) [4]. Health status was assessed at baseline, one, two and three years. A change of four units in Total score is considered as the minimum clinically important difference (MCID) [10]. Only the SGRQ Total scores were analyzed here. 


\section{Study outcomes}

Following the initial period of SGRQ Total score change determination, during year 1 , the following outcomes were determined: survival (=all-cause mortality), time to first moderate-to-severe exacerbation and time to first COPD hospitalization. Exacerbations were defined as events diagnosed by a clinicians that led to the prescription of antibiotics and/or corticosteroids and/or to hospitalization, as described elsewhere [11]. Hospitalizations were limited to severe exacerbations requiring hospital admissions. In ECLIPSE, adverse outcomes were assessed at each visit plus monthly phone calls [8].

\section{Statistics}

Categorical variables were described as frequencies. Continuous variables were tested for normality and were described as mean and standard deviation (SD). Only patients who had complete SGRQ data at baseline and at one-year followup were included in the current analyses. To compare baseline characteristics between patients who completed the first year and those who dropped out during that time, an independent sample t-test or Mann-Whitney $U$ test was used. Further, baseline characteristics were compared between patients with a clinically significant one-year deterioration in SGRQ score ( $\Delta \geq+4$ points), nonclinically significant one-year change in SGRQ score ( $\Delta-3.99$ to +3.99 points), or a clinically significant one-year improvement in SGRQ score ( $\Delta \leq-4$ points). Continuous variables were compared using a univariate analysis of variance followed by post hoc least significance difference (LSD) multiple comparisons or Kruskal-Wallis test followed by Mann-Whitney $U$ test, as appropriate. Categorical variables were compared using Chi-Square tests.

For the study outcomes, events were flagged and time to event observed over a period of two years starting after the one-year assessment. End of observation time was set at day 1,060. Kaplan-Meier plots illustrate a relationship between one-year change in SGRQ score and study outcomes. Interactions between variables were tested and Kaplan-Meier curves were constructed for the whole group and further stratified by median baseline age ( $>64$ versus $\leq 64$ years) and number of exacerbations ( $<2$ versus $\geq 2$ exacerbations) and hospitalizations ( $<1$ versus $\geq 1$ hospitalizations) during the first year of the study. Hazard ratios (HR), accompanied with $95 \%$ confidence intervals $(95 \% \mathrm{Cl})$, represent the ratio of the hazard rates derived from un-adjusted survival analysis. The log-rank test was used for pairwise comparisons between groups.

Kaplan Meier-curves were constructed using GraphPad Prism 5. Statistical analyses were performed using IBM SPSS statistics, Version 19.0. 


\section{RESULTS}

\section{Baseline characteristics}

A total of 2,138 patients with COPD participated in the ECLIPSE study, of whom $1,832(85.7 \%)$ underwent the one-year assessment. They were mostly men, slightly overweight, had a moderate to severe airflow limitation, an impaired exercise capacity, and an impaired health status (table 1). Symptoms of dyspnea, depression or fatigue occurred in $52.0 \%, 25.3 \%$, and $73.7 \%$ of patients, respectively.

Patients who completed the one-year assessment had a significantly better baseline lung function, 6MWD, health status and less symptoms compared with those who dropped out during the first year $(n=306$, Table 1$)$.

TABLE 1. Baseline patient characteristics: $1^{\text {st }}$ year completers vs. $1^{\text {st }}$ year dropout

\begin{tabular}{|c|c|c|}
\hline & $\begin{array}{l}1^{\text {st }} \text { year completers } \\
\mathrm{N}=1832\end{array}$ & $\begin{array}{l}1^{\text {st }} \text { year dropout } \\
N=306\end{array}$ \\
\hline Age, years & $63.4(7.0)$ & $63.9(7.8)$ \\
\hline Male, n (\%) & $1199(65.4)$ & 195 (63.7) \\
\hline Current smokers, n (\%) & $659(36.0)$ & $114(37.3)$ \\
\hline $\mathrm{BMI}, \mathrm{kg} / \mathrm{m}^{2+}$ & $26.0(22.7-29.6)$ & $25.6(22.4-29.5)$ \\
\hline $\mathrm{FEV}_{1}, \%$ predicted $^{\mathrm{a}}$ & $48.7(15.6)^{\star}$ & $45.8(16.1)$ \\
\hline $\mathrm{FEV}_{1}$, liters $^{\mathrm{a}}$ & $1.4(0.5)^{\star}$ & $1.3(0.5)$ \\
\hline $\mathrm{FVC}_{\text {, liters }}{ }^{\mathrm{a}}$ & $3.1(0.9)^{\star}$ & $2.9(1.0)$ \\
\hline $\mathrm{FEV}_{1} / \mathrm{FVC}(\%)^{\mathrm{a}}$ & $44.9(11.5)$ & $43.8(11.6)$ \\
\hline Exacerbations previous 12 months, $\mathrm{n}^{+}$ & $0.9(1.2)$ & $0.9(1.2)$ \\
\hline $6 \mathrm{MWD}$, meters ${ }^{\mathrm{b}, \mathrm{c}}$ & $378(119)^{\star \star}$ & $324(126)$ \\
\hline mMRC dyspnea score (\%) ${ }^{d, e}$ & $1.6(1.1)^{\star \star}$ & $1.9(1.1)$ \\
\hline BODE index, points f,g & $3.1(2.1)^{\star \star}$ & $3.8(2.3)$ \\
\hline CES-D score, points h,i & $11.2(9.3)^{\star \star}$ & $13.2(9.3)$ \\
\hline FACIT score, points $\mathrm{j}, \mathrm{k}$ & $35.4(10.6)^{\star \star}$ & $33.1(10.7)$ \\
\hline SGRQ symptom score, points ${ }^{\prime}$ & $60.1(21.5)^{\star \star}$ & $64.8(21.1)$ \\
\hline SGRQ activity score, points ${ }^{\mathrm{m}}$ & $61.8(21.9) * \star$ & $68.3(20.9)$ \\
\hline SGRQ impact score, points ${ }^{n}$ & $35.5(19.3)^{\star \star}$ & $39.8(20.0)$ \\
\hline SGRQ total score, points ${ }^{\circ}$ & $47.6(18.3)^{\star \star}$ & $52.7(18.2)$ \\
\hline
\end{tabular}

Values expressed as mean (standard deviation (SD), median [25\% - 75\% percentile] or number of patients (n), proportion (\%). Abbreviations. BMI, body mass index; $\mathrm{FEV}_{1}$, forced expiratory volume in the first second; FVC, forced vital capacity; 6MWD, 6-minute walk distance; mMRC, modified Medical Research Council dyspnea scale; BODE, body-mass index, airway obstruction, dyspnea, and exercise tolerance; CES-D, Center for Epidemiologic Studies Depression Scale; FACIT, Functional Assessment of Chronic Illness Therapy fatigue scale; SGRQ, Saint George's Respiratory Questionnaire; ${ }^{\dagger}$ non-parametric tests were used for skewed data; ${ }^{*} p \leq 0.05 ;{ }^{* \star} p \leq 0.001$ 
${ }^{a} \mathrm{n}=1828\left({ }^{\text {' }} 1^{\text {st }}\right.$ year completers'), ${ }^{\mathrm{b}} \mathrm{n}=1791$ (' $1^{\text {st }}$ year completers'), ${ }^{\mathrm{c}} \mathrm{n}=298\left({ }^{\text {(' }} 1^{\text {st }}\right.$ year dropout'), ${ }^{\mathrm{d}} \mathrm{n}=$

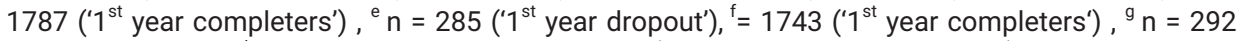
(' $1^{\text {st }}$ year dropout'); ${ }^{h} n=1801$ (' $1^{\text {st }}$ year completers'), ${ }^{i} n=297\left({ }^{\text {(' }} 1^{\text {st }}\right.$ year dropout') ${ }^{j} n=1794$ (' $1^{\text {st }}$ year completers'), ${ }^{\mathrm{k}} \mathrm{n}=293$ ('1 ${ }^{\text {st }}$ year dropout'), ${ }^{\mathrm{C}} \mathrm{n}=281$ (' $1^{\text {st }}$ year dropout'), ${ }^{\mathrm{m}} \mathrm{n}=251$ (' $1^{\text {st }}$ year dropout'), ${ }^{\mathrm{n}}$ $n=249\left({ }^{\prime} 1^{\text {st }}\right.$ year dropout') ${ }^{\circ} \mathrm{n}=229\left({ }^{\prime} 1^{\text {st }}\right.$ year dropout')

\section{One-year change in health status}

Patients with a one-year improvement in health status ( $n=675,36.8 \%)$ had a worse baseline health status compared with those who remained stable or deteriorated ( $n=630$ and $n=527$, respectively; Table 2). Age, baseline lung function, $6 \mathrm{MWD}, \mathrm{mMRC}$ dyspnea grades, depression scores and fatigue scores were comparable between groups.

TABLE 2. Baseline Patient Characteristics

\begin{tabular}{|c|c|c|c|c|}
\hline & \multirow[b]{2}{*}{$\begin{array}{l}\text { Whole group } \\
(n=1832)\end{array}$} & \multicolumn{3}{|l|}{ SGRQ total score } \\
\hline & & $\begin{array}{l}\text { Improvement } \\
(\Delta \leq-4 \text { points }) \\
(n=675)\end{array}$ & $\begin{array}{l}\text { No change } \\
(\Delta=-3.99-3.99) \\
(n=630)\end{array}$ & $\begin{array}{l}\text { Deterioration } \\
(\Delta \geq 4 \text { points }) \\
(n=527)\end{array}$ \\
\hline Age, years & $63.4(7.0)$ & $63.0(7.0)$ & $63.6(7.1)$ & $63.6(6.9)$ \\
\hline Male, n (\%) & $1199(65.4)$ & $438(64.9)$ & $411(65.2)$ & $350(66.4)$ \\
\hline Current smokers, n (\%) & $659(36.0)$ & $258(38.2)^{*}$ & $202(32.1)^{\#}$ & $199(37.8)$ \\
\hline $\mathrm{BMI}, \mathrm{kg} / \mathrm{m}^{21}$ & $26.0(22.7-29.6)$ & $25.9(22.9-29.3)$ & $26.5(23.2-29.9)^{\#}$ & \# $25.6(22.1-29.6)$ \\
\hline $\mathrm{FEV}_{1}, \%$ predicted $^{\mathrm{a}, \mathrm{b}}$ & $48.7(15.6)$ & $48.8(15.2)$ & $49.3(15.9)$ & $47.7(15.7)$ \\
\hline $\mathrm{FEV}_{1}$, liters ${ }^{\mathrm{a}, \mathrm{b}}$ & $1.4(0.5)$ & $1.4(0.5)$ & $1.4(0.6)$ & $1.3(0.5)$ \\
\hline FVC, liters ${ }^{a, b}$ & $3.1(0.9)$ & $3.1(0.9)$ & $3.1(0.9)$ & $3.0(0.9)$ \\
\hline $\mathrm{FEV}_{1} / \mathrm{FVC}(\%)^{\mathrm{a}, \mathrm{b}}$ & $44.9(11.5)$ & $44.9(11.4)$ & $45.6(11.8)$ & $44.1(11.4)$ \\
\hline $\begin{array}{l}\text { Exacerbations previous } 12 \\
\text { months, } \mathrm{n}^{1}\end{array}$ & $0.9(1.2)$ & $0.8(1.2)$ & $0.9(1.3)$ & $0.9(1.2)$ \\
\hline 6MWD, meters ${ }^{c, d, e}$ & 378 (119) & $382(112)$ & 378 (127) & $371(118)$ \\
\hline mMRC dyspnea score (\%) $)^{\mathrm{t}, \mathrm{g}, \mathrm{h}, \mathrm{i}}$ & $1.6(1.1)$ & $1.7(1.0)$ & $1.7(1.1)$ & $1.6(1.1)$ \\
\hline BODE index, points ${ }^{j, k, l, m}$ & $3.1(2.1)$ & $3.0(1.9)$ & $3.1(2.2)$ & $3.2(2.1)$ \\
\hline CES-D score, points ${ }^{n, o, p, q}$ & $11.2(9.3)$ & $11.7(9.3)$ & $10.9(9.2)$ & $10.7(9.3)$ \\
\hline FACIT score, points ${ }^{\mathrm{i}, \mathrm{r}, \mathrm{r}}$ & $35.4(10.6)$ & $34.8(10.5)$ & $35.6(11.0)$ & $36.0(10.3)$ \\
\hline SGRQ symptom score, points & $60.1(21.5)$ & $64.1(20.4)^{\# \star}$ & $58.5(21.9)$ & $56.7(21.5)$ \\
\hline SGRQ activity score, points & $61.8(21.9)$ & $65.5(19.6)^{\# \star}$ & $60.3(23.7)$ & $58.8(21.8)$ \\
\hline SGRQ impact score, points & $35.5(19.3)$ & $40.0(18.8)^{\# \star}$ & $34.7(20.3)^{\#}$ & $30.9(17.4)$ \\
\hline SGRQ total score, points & $47.6(18.3)$ & $51.8(16.9)^{\# \star}$ & $46.4(19.7)^{\#}$ & $43.6(17.1)$ \\
\hline $\begin{array}{l}\text { One-year change SGRQ total } \\
\text { score, points }\end{array}$ & $-1.3(10.7)$ & $-11.8(7.5)^{\#_{\star}}$ & $0.3(2.3)^{\#}$ & $10.7(5.9)$ \\
\hline
\end{tabular}

Values expressed as mean (standard deviation (SD), median [25\% - 75\% percentile] or number of patients (n), proportion (\%). Abbreviations. BMI, body mass index; $\mathrm{FEV}_{1}$, forced expiratory volume in the first second; FVC, forced vital capacity; 6MWD, 6-minute walk distance; MRC, Medical Research 
Council dyspnea scale; BODE, body-mass index, airway obstruction, dyspnea, and exercise tolerance; CES-D, Center for Epidemiologic Studies Depression Scale; SGRQ, Saint George's Respiratory Questionnaire; * $p \leq 0.05$ versus 'Deterioration'; * $p \leq 0.05$ versus 'No change';

${ }^{a} n=1828$ ('whole group'), ${ }^{b}=671$ ('improvement'), ${ }^{c} n=1791$ ('whole group'), ${ }^{d} n=617$ ('no change'), ${ }^{e} \mathrm{n}=512$ ('deterioration'), ${ }^{\mathrm{f}} \mathrm{n}=1787$ (whole group'), ${ }^{9} \mathrm{n}=658$ ('improvement'), ${ }^{\mathrm{h}} \mathrm{n}=611$ ('no change'), ${ }^{\mathrm{i}}$ $n=518$ ('deterioration'), ${ }^{j} n=1743$ ('whole group'), ${ }^{k} n=641$ ('improvement'),,$n=667$ ('no change'), ${ }^{m}$ $\mathrm{n}=504$ ('deterioration'), ${ }^{\mathrm{n}} \mathrm{n}=1801$ ('whole group'), ${ }^{\circ} \mathrm{n}=598$ ('improvement'), ${ }^{\mathrm{p}} \mathrm{n}=614$ ('no change'), ${ }^{a} n=520$ ('deterioration'), $n=665$ ('improvement'); ${ }^{1}$ non-parametric tests were used for skewed data

\section{Exacerbations, hospitalizations and mortality}

During the two-year follow-up period (years 2 and 3 of the ECLIPSE study), 1,234 $(67.7 \%)$ patients reported an exacerbation; of these hospitalization occurred in $486(26.7 \%)$ patients. There were $113(6.2 \%)$ deaths during two-year follow-up, with an average time to death of 754 (183) days from baseline assessment.

Patients with a one-year improvement had better survival than those who deteriorated $(\mathrm{HR}=0.61,95 \%-\mathrm{Cl} 0.39-0.95, P=0.027)$, similarly those who remained stable had better survival $(\mathrm{HR}=0.58,95 \%-\mathrm{Cl} 0.37-0.92, \mathrm{Pp}=0.019$ versus deterioration; Figure $1 \mathrm{a}$, Table 3 ). Patients who improved or remained stable also had a lower likelihood of having a hospitalization ( $\mathrm{HR}=0.72,95 \%-\mathrm{Cl} 0.58-0.90, \mathrm{p}=0.004$ improvement versus deterioration; $\mathrm{HR}=0.77,95 \%-\mathrm{Cl} 0.62-0.96, p=0.023$ no change versus deterioration; Figure $1 \mathrm{~b}$, Table 3 ). A similar observation was noted with risk of exacerbation ( $\mathrm{HR}=0.78,95 \%-\mathrm{Cl} 0.67-0.89, P<0.001$ improvement versus deterioration; $\mathrm{HR}=0.84,95 \%-\mathrm{Cl} 0.73-0.97, \mathrm{p}=0.016$ no change versus deterioration; Figure 1c, Table 3). The association between one-year change in health status and exacerbation, hospitalization and dying was affected by age and number of exacerbations and hospitalizations during year 1. Nevertheless, patients with a one-year deterioration in health status had worst outcomes in most scenarios (Figure 1, online supplementary Figures E1-E3, Table E1). The results retrieved from the SGRQ total score are comparable with the results retrieved from the SGRQ impact domain scores (online supplementary Figure E4, Table E2). 


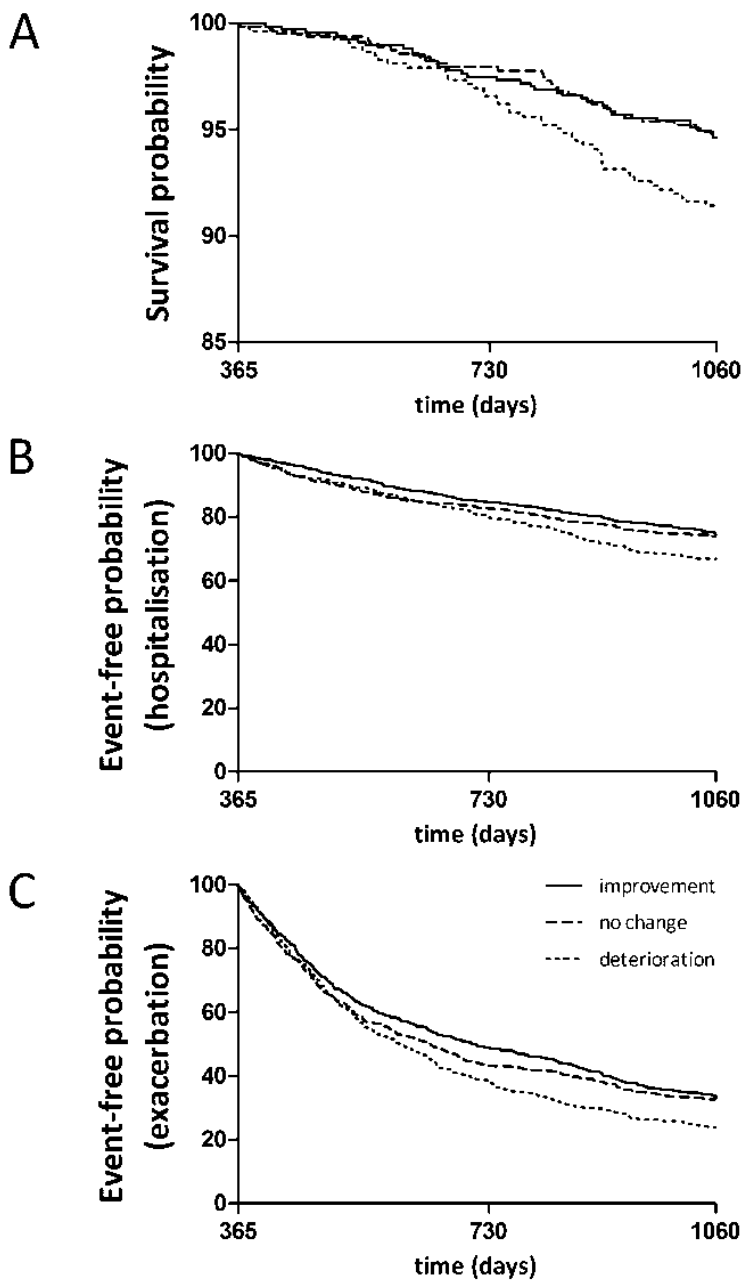

FIGURE 1. Impact of one-year change in disease-specific health status on (A) mortality $(n=1832),(B)$ hospitalization $(n=1823)(C)$ exacerbation $(n=1823)$.

TABLE 3. Hazard ratios (HR), accompanied with $95 \%$ confidence intervals $(95 \% \mathrm{Cl})$ for the whole group

\begin{tabular}{llll}
\hline & \multicolumn{3}{l}{ Hazard Ratio $(95 \% \mathrm{Cl})$} \\
\cline { 2 - 4 } $\begin{array}{l}\text { Improvement vs. No } \\
\text { change }\end{array}$ & $\begin{array}{l}\text { No change vs. } \\
\text { Deterioration }\end{array}$ & $\begin{array}{l}\text { Improvement vs. } \\
\text { Deterioration }\end{array}$ \\
\hline Survival & SGRQ total score, whole group & \\
Hospitalization & $1.05(0.65-1.69)$ & $0.58(0.37-0.92)$ & $0.61(0.39-0.95)$ \\
Exacerbation & $0.94(0.76-1.17)$ & $0.77(0.62-0.97)$ & $0.72(0.58-0.90)$ \\
\hline
\end{tabular}

Bold printed numbers represent significant $(p \leq 0.05)$ results. 


\section{DISCUSSION}

This is the first study exploring the association between changes in health status and the likelihood of having an exacerbation, hospitalization and dying in a large cohort of patients with COPD. Patients with a one-year improvement or stable health status had a lower likelihood of having an exacerbation, hospitalization or dying compared with patients who worsened.

Recent studies have identified numerous determinants of change in health status [12-14], but knowledge however about the importance of such changes is scarce. In the current study, patients with a deterioration in health status during one year had a higher chance of an exacerbation, hospitalization or dying during two-years follow-up. These findings support the recommendation by the GOLD committee to include the improvement of health status as an objective in COPD management [15]. As stated before, "health status measurement is a means of quantifying, in a standardized and objective manner, the impact of disease on patients' daily life, health, and wellbeing. It is a process that is essentially similar to a highly structured clinical history, although the end product is not a clinical impression but an objective measurement that can be used for scientific purposes. It is no more "soft" [...] than any well taken clinical history" [16]. The current study suggests a prognostic role for health status measurement that may help professionals to identify patients at increased risk of adverse health events.

The current study showed that the results retrieved from the SGRQ total score are comparable with those retrieved from the SGRQ impact domain score. This is not surprising since the SGRQ impact domain score behaves similar to the total score whereas the SGRQ symptom domain score has been identified as the weakest correlate with overall health. The SGRQ impact domain covers aspects concerning social functioning and psychological disturbances related to the disease. It is the broadest domain with the most items that correlates best with outcomes in COPD [17]. Thus, health status is rather a measure of the impact of the disease and the illness perception of the patient than a measure of general well-being. For instance, a previous study showed that patients with a poor health status were more likely to be referred to the respiratory specialist [18]. Furthermore, patients whose health status improved had a decreased consultation and hospitalization rate [19]. Consequently, health status may be closely related to self-management and coping strategies. Indeed, patients with COPD specified coping as a relevant component of health status [20]. Previously, psychological distress and difficulty in coping with their disease has been shown to impact mortality in patients with severe COPD [21]. Therefore, self- 
regulation could significantly assist participants to control their individual symptoms and avoid acute exacerbations [22]. Consequently, a worsening in health status may be associated with important health outcomes, such as hospitalization and death. The current study demonstrates that patients' perceptions and changes of patients' perceptions about their health as assessed by SGRQ can play a meaningful role in COPD prognosis.

These data suggest that monitoring for trends in health status over time are important, but they are confined to health status measured using the SGRQ, which is too complex for use in routine practice. However there is already evidence that the shorter instruments such as the COPD Assessment Test (CAT), which were designed for routine use, can also predict exacerbations in patients already known to be at high risk [23].

Even in younger patients (age $\leq 64$ years) whose health status deteriorated during the first year, there was a greater risk of dying or an exacerbation compared with patients whose health status remained stable or improved. Bentsen and colleagues [24] recently showed that younger patients and those with higher anxiety scores reported worse health status. The authors explained this phenomenon by the fact that younger patients are still learning how to cope with their disease and that elderly patients experience functional impairment more often as a part of getting older [24]. In the current study, younger patients reported significantly higher CES-D scores (i.e. more symptoms of depression) and worse health status at baseline compared with older patients (online supplementary Table E3). The current study underlines the importance to pay special attention to the health status of younger patients with COPD and their perceptions of the impact of the disease.

COPD as a leading cause of death is increasing [25] and the economic burden of the disease is substantial [26-28]. Indeed, COPD exacerbations requiring hospitalization are a "major cost driver" [28] that continue to increase [27]. Consequently, prognostic measurements for the progression of the disease are important. Moreover, prevention and early treatment of exacerbations are needed. The current study indicates a need for assessing health status as a possible part of exacerbation-prevention strategies. Furthermore, the current study supports the interest in stabilizing or enhancing health status in patients with COPD. A previous study showed that frequent exacerbations are related to poor health status [29]. Since the current study identified a decline in health status as a contributing risk factor for getting an exacerbation, even after stratification for the exacerbation and hospitalization frequency during year 1 , it is important to interrupt this vicious circle and intervene on time. Stabilizing and/or improving health status can be achieved by providing optimal pharmacological [30], medi- 
cal/surgical [31] and non-pharmacological treatment, including pulmonary rehabilitation [32]. Finally, the enhancement of patient's compliance with treatment is important since patients who withdrew from treatment showed a more rapid decline in health status [33]. However, since health status share causative factors with other outcomes reflecting different processes, it is important to recognize that treatments resulting in improved health status will also have similar effects on other mechanisms.

Although the ECLIPSE study is a multicenter, longitudinal, prospective threeyear study that included a large number of patients worldwide, thus allowing an in-depth characterization of the COPD population, there are relevant limitations that should be taken into account. First, the study consisted of a convenience sample of secondary care patients. Patients were eligible if they had moderate to very severe COPD, excluding patients with mild airflow limitation (GOLD stage I). Furthermore, patients who reported a better health status at baseline had a greater chance to worsen during one-year follow-up and vice versa. Consequently, part of the effect of change in health status could be explained by a statistical artifact such as regression to the mean [34]; however that would not explain the association between change in health status and the other outcomes. Moreover, there was no interaction between change in SGRQ score and baseline SGRQ score. Finally, the current findings need to be interpreted in the light of the number of comparisons that were made in the present study [35] [35]. Nonetheless, multiple findings in the same direction, rather than a single statistically significant result, suggest that these are not due to chance alone.

\section{CONCLUSION}

ECLIPSE COPD subjects with a one-year improvement or stable health status had a lower likelihood of having an exacerbation, hospitalization or dying during two-year follow-up compared with those whose health status deteriorated. The current study supports the concept of routine monitoring health status of COPD patients with the aim of improving or at least stabilizing health status in patients with COPD. 


\section{REFERENCES}

1. Spruit MA, Pennings HJ, Janssen PP, Does JD, Scroyen S, Akkermans MA, Mostert R, Wouters EF: Extra-pulmonary features in COPD patients entering rehabilitation after stratification for MRC dyspnea grade. Respir Med 2007, 101:2454-2463.

2. Wilke S, Janssen DJ, Wouters EF, Schols JM, Franssen FM, Spruit MA: Correlations between disease-specific and generic health status questionnaires in patients with advanced COPD: a one-year observational study. Health Qual Life Outcomes 2012, 10:98.

3. Habraken JM, van der Wal WM, Ter Riet G, Weersink EJ, Toben F, Bindels PJ: Health-related quality of life and functional status in end-stage COPD: a longitudinal study. Eur Respir J2011, 37:280-288.

4. Jones PW, Quirk FH, Baveystock CM, Littlejohns P: A self-complete measure of health status for chronic airflow limitation. The St. George's Respiratory Questionnaire. Am Rev Respir Dis 1992, 145:1321-1327.

5. Yorgancioglu A, Havlucu Y, Celik P, Dinc G, Saka A: Relation between quality of life and morbidity and mortality in COPD patients: Two-year follow-up study. COPD 2010, 7:248-253.

6. Domingo-Salvany A, Lamarca R, Ferrer M, Garcia-Aymerich J, Alonso J, Felez M, Khalaf A, Marrades RM, Monso E, Serra-Batlles J, Anto JM: Health-related quality of life and mortality in male patients with chronic obstructive pulmonary disease. Am J Respir Crit Care Med 2002, 166:680-685.

7. Jones PW: St. George's Respiratory Questionnaire: MCID. COPD 2005, 2:75-79.

8. Vestbo J, Anderson W, Coxson HO, Crim C, Dawber F, Edwards L, Hagan G, Knobil K, Lomas DA, MacNee W, et al: Evaluation of COPD Longitudinally to Identify Predictive Surrogate End-points (ECLIPSE). Eur Respir J 2008, 31:869-873.

9. Spruit MA, Watkins ML, Edwards LD, Vestbo J, Calverley PM, Pinto-Plata V, Celli BR, Tal-Singer R, Wouters EF: Determinants of poor 6-min walking distance in patients with COPD: the ECLIPSE cohort. Respir Med 2010, 104:849-857.

10. Jones PW: Interpreting thresholds for a clinically significant change in health status in asthma and COPD. Eur Respir J 2002, 19:398-404.

11. Hurst JR, Vestbo J, Anzueto A, Locantore N, Mullerova H, Tal-Singer R, Miller B, Lomas DA, Agusti $A$, Macnee $W$, et al: Susceptibility to exacerbation in chronic obstructive pulmonary disease. N Engl J Med 2010, 363:1128-1138.

12. Monteagudo $M$, Rodriguez-Blanco $T$, Llagostera $M$, Valero $C$, Bayona $X$, Ferrer $M$, Miravitlles $M$ : Factors associated with changes in quality of life of COPD patients: a prospective study in primary care. Respir Med 2013, 107:1589-1597.

13. Rolink M, van Dijk W, van den Haak-Rongen S, Pieters W, Schermer T, van den Bemt L: Using the DOSE index to predict changes in health status of patients with COPD: a prospective cohort study. Prim Care Respir J2013, 22:169-174.

14. Wilke S, Spruit MA, Wouters EF, Schols JM, Franssen FM, Janssen DJ: Determinants of 1-year changes in disease-specific health status in patients with advanced chronic obstructive pulmonary disease: A 1-year observational study. Int J Nurs Pract 2015, 21:239-248.

15. Vestbo J, Hurd SS, Agusti AG, Jones PW, Vogelmeier C, Anzueto A, Barnes PJ, Fabbri LM, Martinez FJ, Nishimura M, et al: Global strategy for the diagnosis, management, and prevention of chronic obstructive pulmonary disease: GOLD executive summary. Am J Respir Crit Care Med 2013, 187:347-365.

16. Jones PW: Health status measurement in chronic obstructive pulmonary disease. Thorax 2001, 56:880-887.

17. Jones PW, Quirk FH, Baveystock CM: The St George's Respiratory Questionnaire. Respir Med 1991, 85 Suppl B:25-31; discussion 33-27.

18. Osman IM, Godden DJ, Friend JA, Legge JS, Douglas JG: Quality of life and hospital readmission in patients with chronic obstructive pulmonary disease. Thorax 1997, 52:67-71. 
19. Cox NJ, Hendricks JC, Binkhorst RA, van Herwaarden CL: A pulmonary rehabilitation program for patients with asthma and mild chronic obstructive pulmonary diseases (COPD). Lung 1993, 171:235-244.

20. Paap M, Bode C, Lenferink L, Groen LC, Terwee CB, Ahmed S, Eilayyan O, van der Palen J: Identifying key domains of health-related quality of life for patients with Chronic Obstructive Pulmonary Disease: the patient perspective. Health Qual Life Outcomes 2014, 12:106.

21. Ashutosh K, Haldipur C, Boucher ML: Clinical and personality profiles and survival in patients with COPD. Chest 1997, 111:95-98.

22. Kuo CC, Lin CC, Lin SY, Yang YH, Chang CS, Chen CH: Effects of self-regulation protocol on physiological and psychological measures in patients with chronic obstructive pulmonary disease. J Clin Nurs 2013, 22:2800-2811.

23. Lee SD, Huang MS, Kang J, Lin CH, Park MJ, Oh YM, Kwon N, Jones PW, Sajkov D: The COPD assessment test (CAT) assists prediction of COPD exacerbations in high-risk patients. Respir Med 2014, 108:600-608.

24. Bentsen SB, Miaskowski C, Rustoen T: Demographic and clinical characteristics associated with quality of life in patients with chronic obstructive pulmonary disease. Qual Life Res 2014, 23:991-998.

25. Hurd S: The impact of COPD on lung health worldwide: epidemiology and incidence. Chest 2000, 117:1S-4S.

26. Perera PN, Armstrong EP, Sherrill DL, Skrepnek GH: Acute exacerbations of COPD in the United States: inpatient burden and predictors of costs and mortality. COPD 2012, 9:131-141.

27. Blanchette $C M$, Dalal AA, Mapel D: Changes in COPD demographics and costs over 20 years. $J$ Med Econ 2012, 15:1176-1182.

28. Teo WS, Tan WS, Chong WF, Abisheganaden J, Lew YJ, Lim TK, Heng BH: Economic burden of chronic obstructive pulmonary disease. Respirology 2012, 17:120-126.

29. Mackay AJ, Donaldson GC, Patel AR, Jones PW, Hurst JR, Wedzicha JA: Usefulness of the Chronic Obstructive Pulmonary Disease Assessment Test to evaluate severity of COPD exacerbations. Am J Respir Crit Care Med 2012, 185:1218-1224.

30. Spencer S, Calverley PM, Burge PS, Jones PW: Impact of preventing exacerbations on deterioration of health status in COPD. Eur Respir J2004, 23:698-702.

31. Benzo R, Farrell MH, Chang CC, Martinez FJ, Kaplan R, Reilly J, Criner G, Wise R, Make B, Luketich J, et al: Integrating health status and survival data: the palliative effect of lung volume reduction surgery. Am J Respir Crit Care Med 2009, 180:239-246.

32. Spruit MA, Singh SJ, Garvey C, Zuwallack R, Nici L, Rochester C, Hill K, Holland AE, Lareau SC, Man WD, et al: An official american thoracic society/european respiratory society statement: key concepts and advances in pulmonary rehabilitation. Am J Respir Crit Care Med 2013, 188:e13-64.

33. Calverley PM, Spencer S, Willits L, Burge PS, Jones PW: Withdrawal from treatment as an outcome in the ISOLDE study of COPD. Chest 2003, 124:1350-1356.

34. Barnett AG, van der Pols JC, Dobson AJ: Regression to the mean: what it is and how to deal with it. Int J Epidemio/2005, 34:215-220.

35. Perneger TV: What's wrong with Bonferroni adjustments. BMJ1998, 316:1236-1238.

Reproduced from One-year change in health status and subsequent outcomes in COPD; Wilke $S$, Jones PW, Müllerova H, Vestbo J, Tal-Singer R, Franssen FM, Agusti A, Bakke P, Calverley PM, Coxson HO, Crim C, Edwards LD, Lomas DA, MacNee W, Rennard SI, Yates JC, Wouters EF, Spruit $M A ; 7,420-425,2015$ with permission from BMJ Publishing Group Ltd. 


\section{SUPPLEMENTAL MATERIAL}

TABLE E1. Hazard ratios (HR), accompanied with $95 \%$ confidence intervals (95\% Cl) stratified for baseline age, number of exacerbations and hospitalizations during year 1

\begin{tabular}{|c|c|c|c|}
\hline & \multicolumn{3}{|c|}{ Hazard Ratio $(95 \% \mathrm{Cl})$} \\
\hline & $\begin{array}{l}\text { Improvement vs. } \\
\text { No change }\end{array}$ & $\begin{array}{l}\text { No change vs. } \\
\text { Deterioration }\end{array}$ & $\begin{array}{l}\text { Improvement vs. } \\
\text { Deterioration }\end{array}$ \\
\hline & Age $\leq 64$ years & & \\
\hline Survival & $1.70(0.67-4.30)$ & $0.29(0.13-0.65)$ & $0.46(0.22-0.94)$ \\
\hline Hospitalization & $0.92(0.67-1.25)$ & $0.82(0.59-1.13)$ & $0.74(0.54-1.03)$ \\
\hline \multirow[t]{2}{*}{ Exacerbation } & $1.04(0.86-1.25)$ & $0.75(0.62-0.92)$ & $0.77(0.63-0.93)$ \\
\hline & Age $>64$ years & & \\
\hline Survival & $0.93(0.53-1.62)$ & $0.82(0.48-1.41)$ & $0.76(0.44-1.33)$ \\
\hline Hospitalization & $0.76(0.44-1.32)$ & $0.75(0.56-1.02)$ & $0.72(0.53-0.97)$ \\
\hline \multirow[t]{2}{*}{ Exacerbation } & $0.82(0.68-1.01)$ & $0.94(0.77-1.15)$ & $0.77(0.63-0.94)$ \\
\hline & 0-1 exacerbations & & \\
\hline Survival & $1.13(0.63-2.02)$ & $0.55(0.32-0.97)$ & $0.62(0.36-1.06)$ \\
\hline Hospitalization & $1.02(0.75-1.40)$ & $0.71(0.51-0.97)$ & $0.72(0.53-0.98)$ \\
\hline \multirow[t]{2}{*}{ Exacerbation } & $0.98(0.82-1.17)$ & $0.79(0.66-0.95)$ & $0.76(0.64-0.92)$ \\
\hline & $\geq 2$ exacerbations & & \\
\hline Survival & $0.92(0.40-2.12)$ & $0.65(0.31-1.37)$ & $0.60(0.28-1.30)$ \\
\hline Hospitalization & $0.93(0.68-1.26)$ & $0.88(0.65-1.19)$ & $0.82(0.60-1.11)$ \\
\hline \multirow[t]{2}{*}{ Exacerbation } & $1.02(0.82-1.26)$ & $1.02(0.82-1.26)$ & $1.03(0.83-1.28)$ \\
\hline & 0 hospitalizations & & \\
\hline Survival & $1.02(0.59-1.77)$ & $0.62(0.36-1.05)$ & $0.62(0.37-1.05)$ \\
\hline Hospitalization & $0.94(0.72-1.23)$ & $0.78(0.59-1.02)$ & $0.73(0.56-0.95)$ \\
\hline \multirow[t]{2}{*}{ Exacerbation } & $0.94(0.76-1.17)$ & $0.83(0.71-0.97)$ & $0.77(0.66-0.90)$ \\
\hline & $\geq 1$ hospitalizations & & \\
\hline Survival & $1.25(0.48-3.24)$ & $0.57(0.25-1.31)$ & $0.71(0.31-1.61)$ \\
\hline Hospitalization & $0.97(0.66-1.44)$ & $0.91(0.63-1.33)$ & $0.88(0.61-1.29)$ \\
\hline Exacerbation & $0.99(0.71-1.37)$ & $1.06(0.78-1.46)$ & $1.02(0.74-1.14)$ \\
\hline
\end{tabular}

Bold printed numbers represent significant $(p \leq 0.05)$ results. 
TABLE E2. Hazard ratios (HR), accompanied with 95\% confidence intervals (95\% CI) for SGRQ domain scores

\begin{tabular}{|c|c|c|c|}
\hline & \multicolumn{3}{|c|}{ Hazard Ratio $(95 \% \mathrm{Cl})$} \\
\hline & $\begin{array}{l}\text { Improvement vs. } \\
\text { No change }\end{array}$ & $\begin{array}{l}\text { No change vs. } \\
\text { Deterioration }\end{array}$ & $\begin{array}{l}\text { Improvement vs. } \\
\text { Deterioration }\end{array}$ \\
\hline & \multicolumn{3}{|c|}{ SGRQ symptom domain } \\
\hline Survival & $0.63(0.37-1.07)$ & $0.89(0.55-1.42)$ & $0.57(0.37-0.88)$ \\
\hline Hospitalization & $0.79(0.62-1.00)$ & $1.07(0.84-1.36)$ & $0.85(0.69-1.05)$ \\
\hline \multirow[t]{2}{*}{ Exacerbation } & $0.77(0.66-0.90)$ & $1.10(0.94-1.28)$ & $0.85(0.75-0.97)$ \\
\hline & \multicolumn{3}{|c|}{ SGRQ activity domain } \\
\hline Survival & $0.86(0.53-1.39)$ & $0.80(0.52-1.24)$ & $0.69(0.44-1.07)$ \\
\hline Hospitalization & $0.85(0.68-1.07)$ & $0.94(0.75-1.16)$ & $0.80(0.64-0.99)$ \\
\hline \multirow[t]{2}{*}{ Exacerbation } & $0.85(0.74-0.98)$ & $1.03(0.90-1.19)$ & $0.88(0.77-1.01)$ \\
\hline & \multicolumn{3}{|c|}{ SGRQ impact domain } \\
\hline Survival & $0.99(0.62-1.59)$ & $0.75(0.48-1.19)$ & $0.74(0.48-1.14)$ \\
\hline Hospitalization & $1.11(0.88-1.39)$ & $0.71(0.57-0.89)$ & $0.78(0.63-0.96)$ \\
\hline Exacerbation & $1.16(1.01-1.33)$ & $0.75(0.65-0.87)$ & $0.87(0.76-0.99)$ \\
\hline
\end{tabular}

Bold printed numbers represent significant $(p \leq 0.05)$ results. 
TABLE E3. Baseline patient characteristics: $\leq 64$ years vs. $>64$ years

\begin{tabular}{|c|c|c|}
\hline & $\begin{array}{l}\text { Age } \leq 64 \text { years } \\
N=969\end{array}$ & $\begin{array}{l}\text { Age }>64 \text { years } \\
N=863\end{array}$ \\
\hline Age, years & $58.0(4.9)$ & $69.4(3.0) * \star$ \\
\hline Male, n (\%) & $584(60.3)$ & $615(71.3) * *$ \\
\hline Current smokers, n (\%) & $426(44.0)$ & $233(27.0) \star \star$ \\
\hline $\mathrm{BMI}, \mathrm{kg} / \mathrm{m}^{2}$ & $26.5(6.1)$ & $26.6(5.2)$ \\
\hline $\mathrm{FEV}_{1}, \%$ predicted & $48.4(16.0)$ & $49.0(15.3)$ \\
\hline $\mathrm{FEV}_{1}$, liters & $1.4(0.5)$ & $1.3(0.5) * *$ \\
\hline FVC, liters & $3.1(0.9)$ & $2.9(0.8) \star \star$ \\
\hline $\mathrm{FEV}_{1} / \mathrm{FVC}(\%)$ & $45.5(11.8)$ & $44.3(11.2)$ * \\
\hline Exacerbations, $\mathrm{n}$ & $0.9(1.2)$ & $0.8(1.3)$ \\
\hline 6MWD, meters & $392(120)$ & $361(116) * \star$ \\
\hline mMRC dyspnea score (\%) & $1.6(1.0)$ & $1.7(1.1)$ * \\
\hline BODE index, points & $3.0(2.1)$ & $3.1(2.1)$ \\
\hline CES-D score, points & $12.0(10.1)$ & $10.2(8.1) * \star$ \\
\hline FACIT score, points & $34.6(10.6)$ & $36.3(10.6)$ * \\
\hline SGRQ symptom score, points & $62.2(21.8)$ & 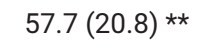 \\
\hline SGRQ activity score, points & $61.7(22.4)$ & $61.8(21.3)$ \\
\hline SGRQ impact score, points & $36.6(19.3)$ & $34.3(19.3)$ * \\
\hline SGRQ total score, points & $48.5(18.5)$ & $46.5(18.0)$ * \\
\hline
\end{tabular}

Values expressed as mean (standard deviation (SD) or number of patients (n), proportion (\%). Abbreviations: BMI, body mass index; FEV1, forced expiratory volume in the first second; FVC, forced vital capacity; 6MWD, 6-minute walk distance; MMRC, modified Medical Research Council dyspnea scale; BODE, body-mass index, airway obstruction, dyspnea, and exercise tolerance; CES-D, Center for Epidemiologic Studies Depression Scale; FACIT, Functional Assessment of Chronic Illness Therapy fatigue scale; SGRQ, Saint George's Respiratory Questionnaire; $p \leq 0.05 ; * * p \leq 0.001$ 

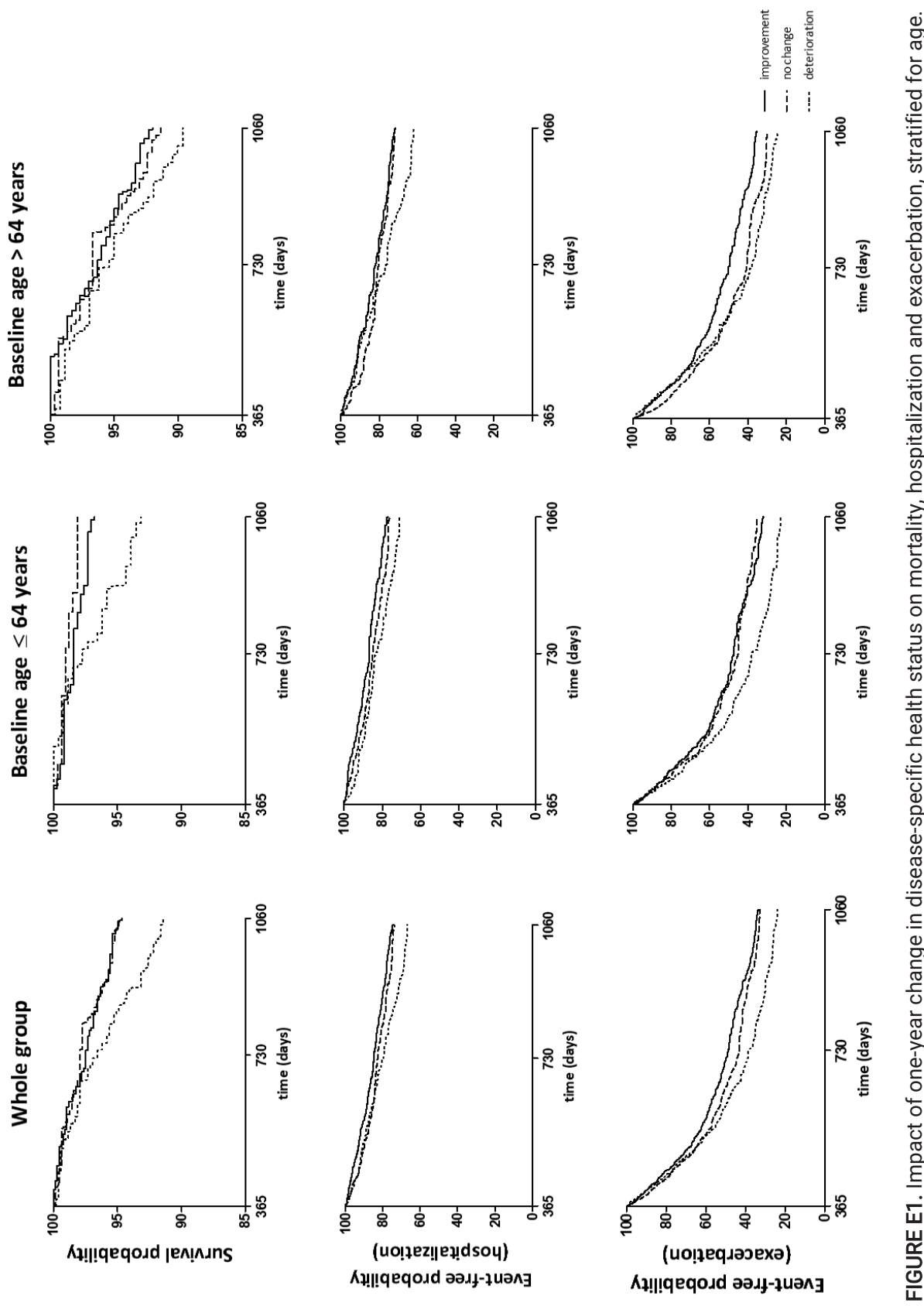

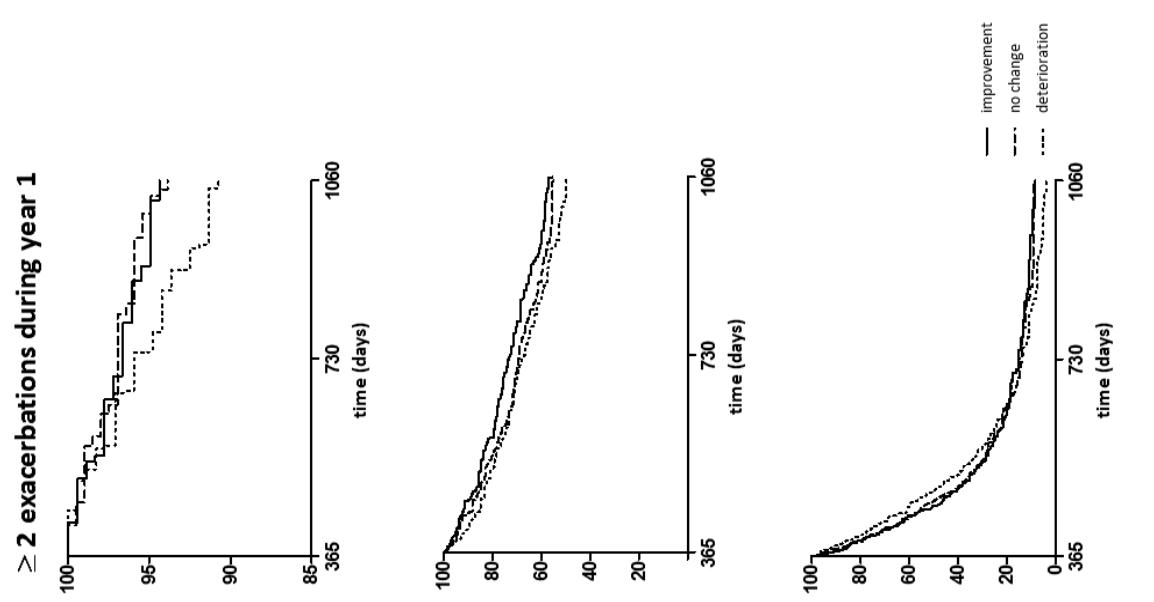

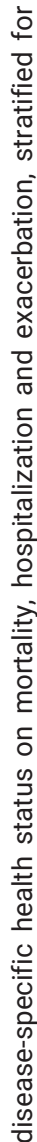
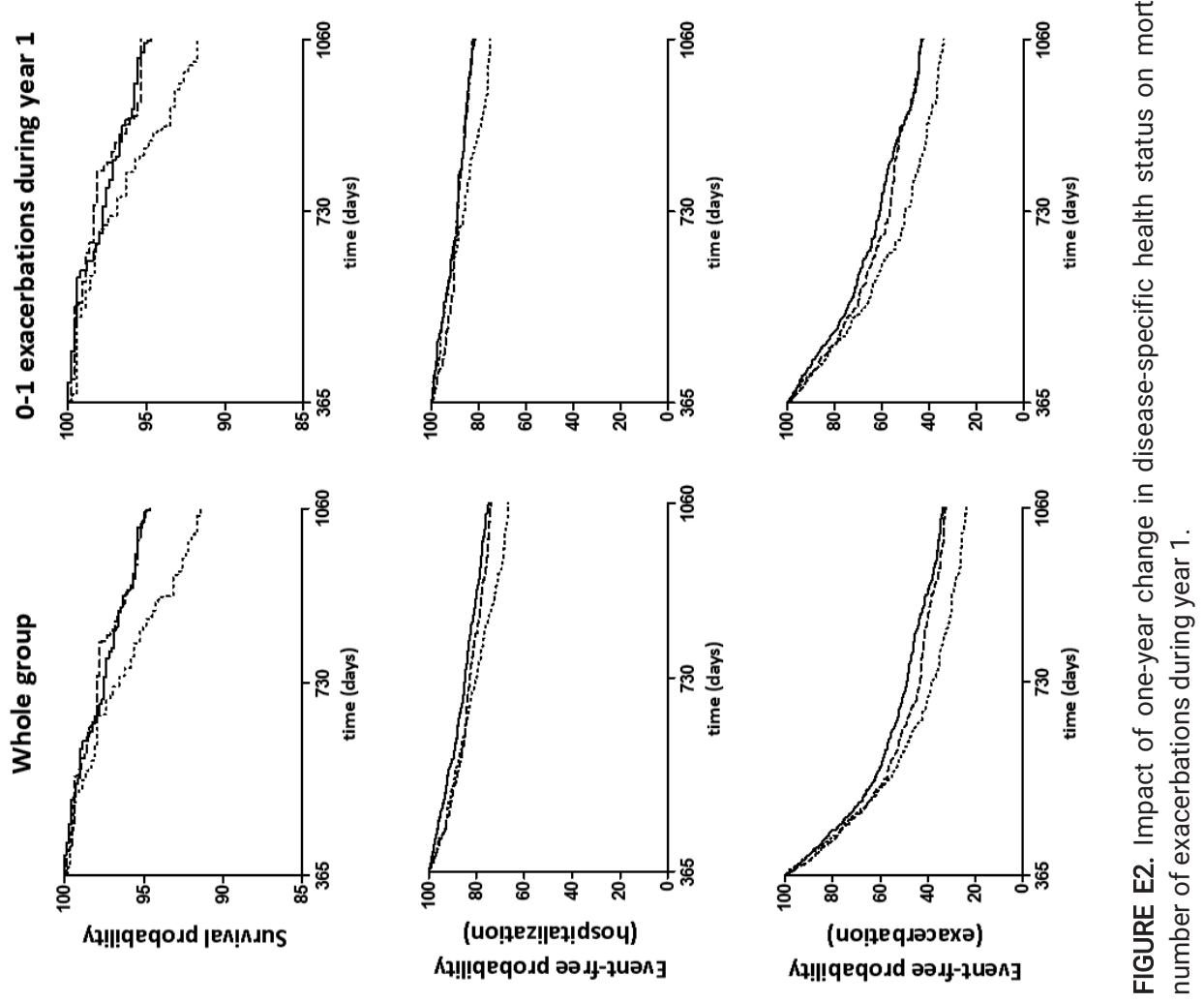

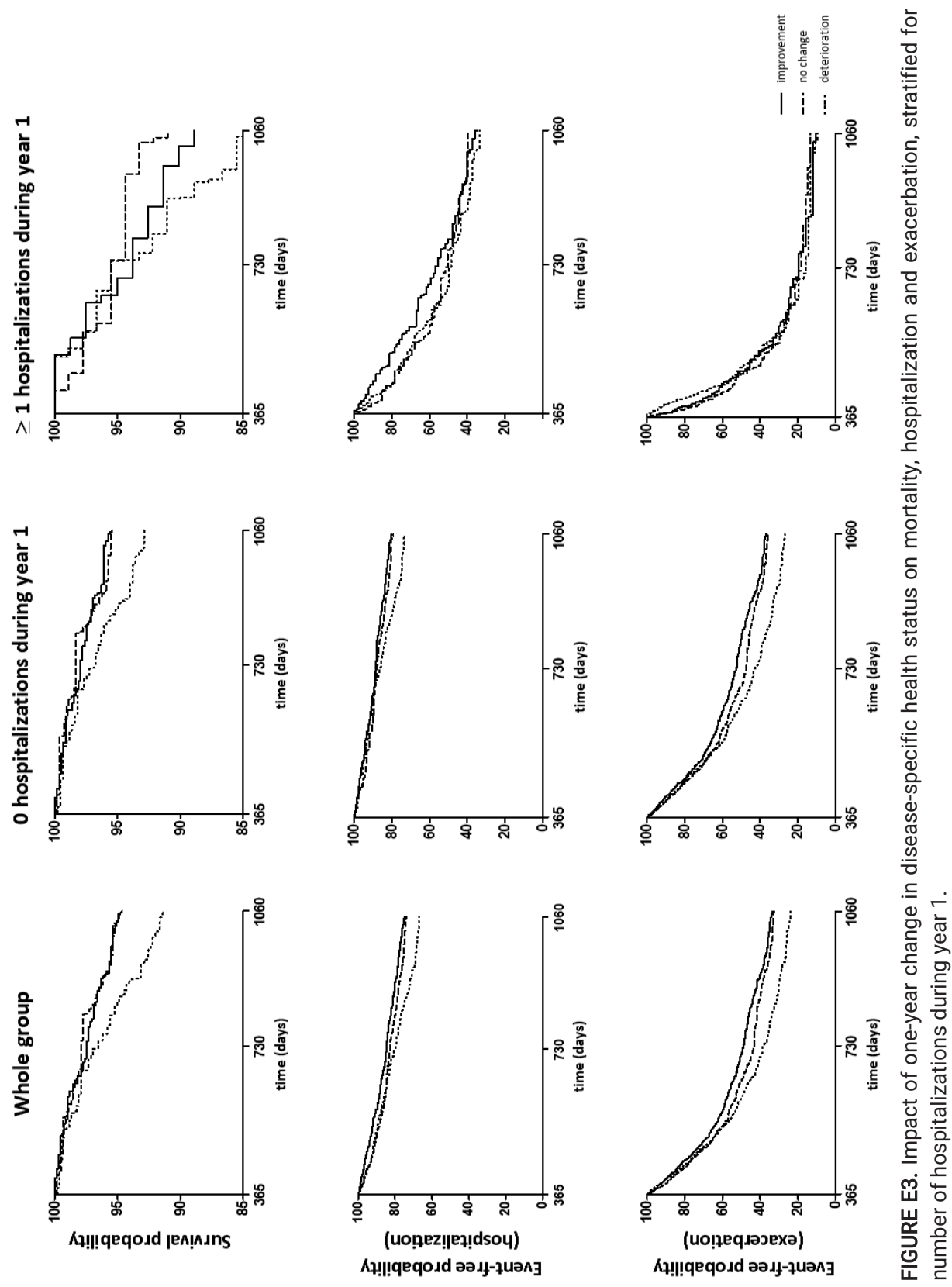


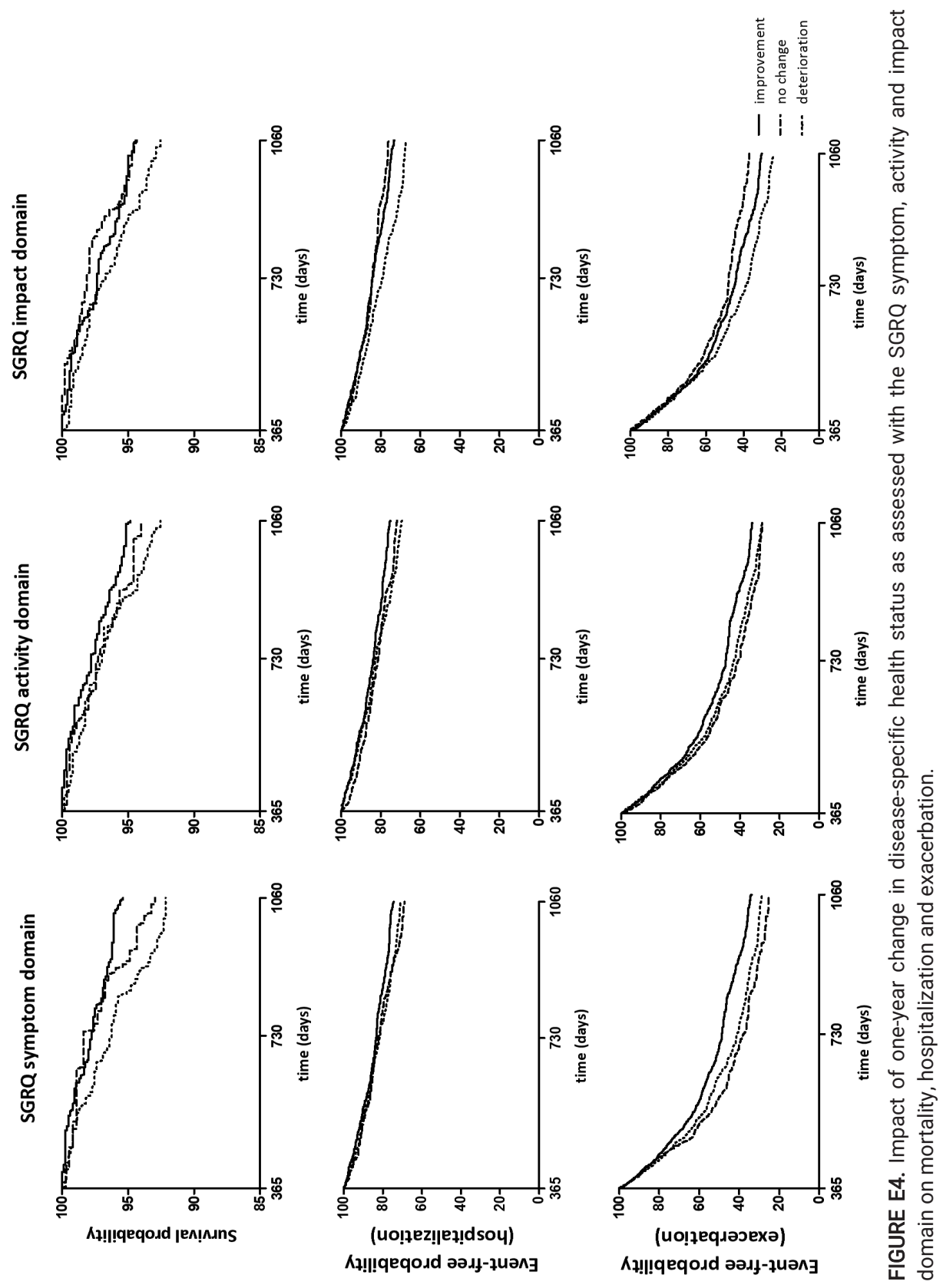





\section{CHAPTER 5 \\ The 2014 updated GOLD strategy: a comparison of the various scenarios}

Sarah Wilke*, Dionne E. Smid*, Martijn A. Spruit, Daisy J.A. Janssen, Jean W.M. Muris, Thys van der Molen, Marjan van den Akker, Paul W. Jones, Emiel F.M. Wouters, and Frits M.E. Franssen

* contributed equally to this manuscript and are joint first authors

Chronic Obstructive Pulmonary Diseases: Journal of the COPD Foundation 2014; 1: 212-220. 



\section{ABSTRACT}

\section{BACKGROUND}

The 2014 updated GOLD strategy added the St. Georges Respiratory Questionnaire (SGRQ) as the fourth possible symptoms measure. The impact of the suggested tools for symptoms of COPD and the different definitions of future risk on the frequency distribution and clinical characteristics of the GOLD groups remain unknown.

\section{METHODS}

Demographic and clinical characteristics were assessed in 542 patients with COPD (57.7\% male, age 64.6 (9.0) years, $\mathrm{FEV}_{1} 54.7$ (22.3)\% predicted). Health status was assessed by the COPD-specific SGRQ and symptoms of anxiety and depression by the Hospital Anxiety and Depression Scale, anxiety (HADS-A) and depression (HADS-D) subscale. Cohen's Kappa was used to assess agreement between groups.

\section{RESULTS}

Level of agreement in frequency distribution using the modified Medical Research Council dyspnea (mMRC) scale $\geq 2$, COPD Assessment Test (CAT) $\geq 10$, Clinical COPD Questionnaire (CCQ) $\geq 1$ and SGRQ $\geq 25$ was moderate to very good. Best agreement was reached between CCQ and SGRQ $(K=0.838$ or $0.851, p<0.001)$. Patients classified in mMRC GOLD A reported higher SGRQ scores, higher HADS-A and HADS-D scores compared to patients classified in CAT GOLD A or SGRQ GOLD A. Outcomes were comparable between the risk assessment groups.

\section{CONCLUSIONS}

Choice of symptom measure impacts GOLD groups more than choice of exacerbation risk assessment. Healthcare professionals should be aware that patients are heterogeneous in terms of health status and symptoms of anxiety and depression based on the symptom measure used. 


\section{INTRODUCTION}

The 2007 Global initiative for chronic Obstructive Lung Disease (GOLD) statement classified COPD patients into four groups (GOLD I to IV), based on the degree of airflow limitation [1]. This parameter, however, is only poorly-tomoderately associated with disease activity and progression, extra-pulmonary features and comorbidities, and prognosis in COPD patients [2-4]. Therefore, the 2011 GOLD strategy started classifying patients in four new groups (GOLD A to D) based on the combination of the degree of airflow limitation and the number of exacerbations in the past twelve months (A/B versus $C / D)$; and the severity of symptoms (A/C versus $B / D)$ (Table 1$)$. To assess the severity of symptoms, the GOLD strategy recommends new, simple and reliable assessment tools, designed for use in routine daily clinical practice [5].

TABLE 1. Overview GOLD strategies

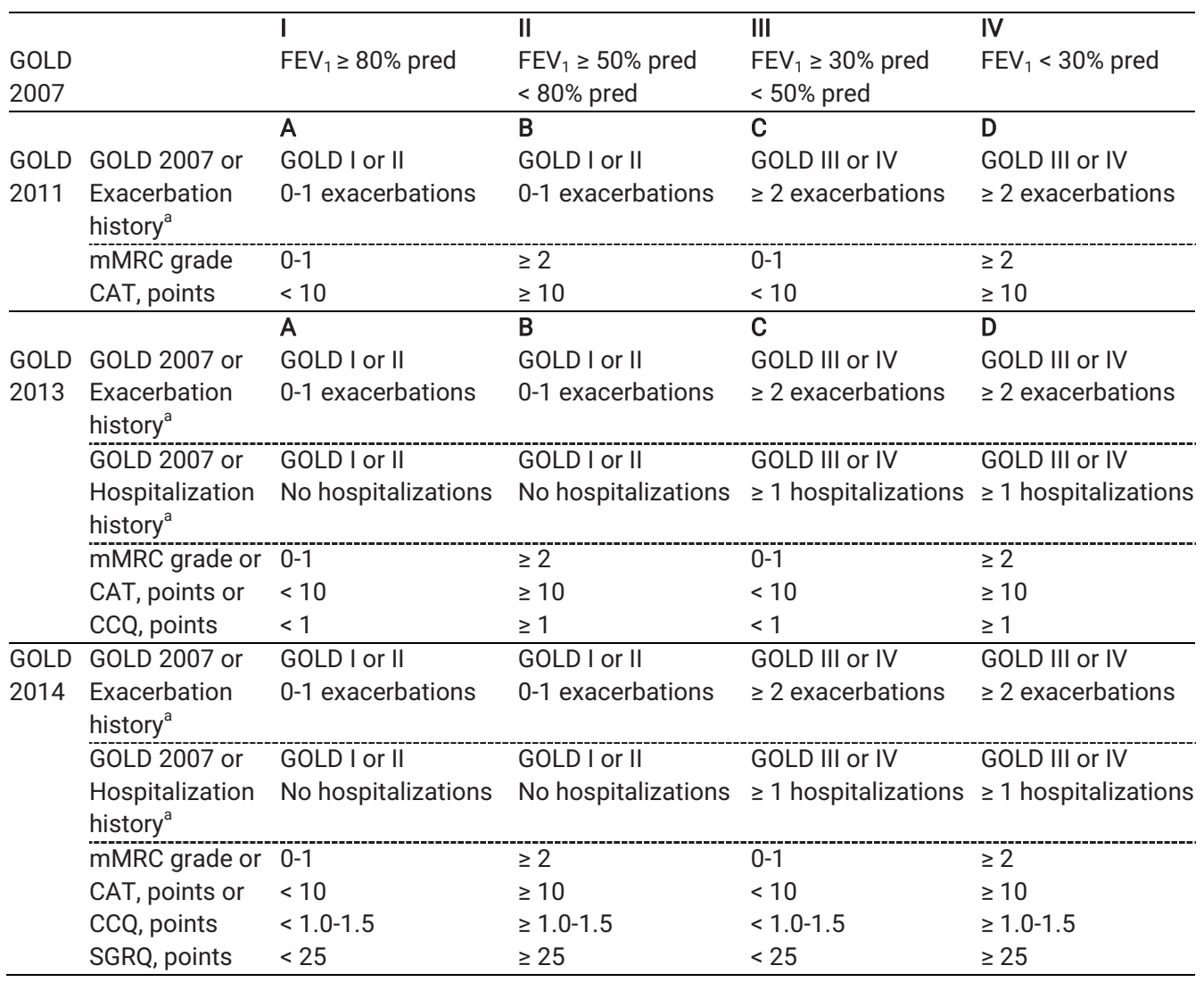

${ }^{a}$ If there is a discrepancy between the risk group as classified by airflow limitation or exacerbation history, the GOLD strategy suggests to use the parameter with worst future risk. 
Jones and colleagues [6] were the first to study the impact of the choice of symptom measure (modified Medical Research Council dyspnea scale (mMRC) or COPD Assessment Test (CAT)) on the frequency distribution and clinical characteristics of the GOLD groups. The current mMRC cut-point of grade $\geq 2$ did not match with the current CAT cut-point of $\geq 10$ points [6]. Thus, the choice of symptom measure clearly influences the new GOLD classification [6, 7], and, in turn the necessity for refinement of the current mMRC and/or CAT cut-points was suggested.

The 2013 GOLD strategy added the Clinical COPD Questionnaire (CCQ) as the third possibility to classify patients to the low $(A / C)$ or high $(B / D)$ symptom group. Moreover, the number of COPD hospitalizations in the past twelve months (cut-point: $\geq 1$ hospitalizations) was added as the third criterion to classify patients as GOLD low (A/B) or high (C/D) risk [8]. Casanova and colleagues [9] showed that the symptom measure (i.e. mMRC, CAT or CCQ) used "can substantially alter group assignment". Since the St. George's Respiratory Questionnaire (SGRQ) is the most documented measure and commonly used in COPD studies, the 2014 updated GOLD strategy added the SGRQ (cut-point: $\geq 25$ points) as a fourth possibility to grade symptoms [10]. To date, the impact of all these introduced assessment tools on the frequency distribution and clinical characteristics of the GOLD groups remain unknown. Therefore, the aims of the present study were: 1) to investigate the impact of the four different assessment tools for symptoms (mMRC, CAT, CCQ or SGRQ) and different definitions of future risk (degree of airflow limitation/ $\geq 2$ COPD exacerbations, and degree of airflow limitation $/ \geq 1$ hospitalizations for COPD exacerbation) on the frequency distribution of GOLD A to D; and 2) to study differences in health status, functional mobility, symptoms of anxiety and depression, and self-reported comorbidities between the GOLD groups using these different scenarios. We hypothesized a priori that the symptom measures impact the GOLD distribution as well as the clinical characteristics of the GOLD groups.

\section{METHODS}

\section{Design}

The current cross-sectional analyses are part of an ongoing prospective observational study about determinants of health status assessed with CAT in a broad sample of COPD patients. The Medical Ethical Committee of the Maastricht University Medical Centre+ (MUMC+), Maastricht, the Netherlands (METC 11-3-070) approved this study, which was registered at the Dutch Trial Register (NTR 3416). 


\section{Study population}

Patients were eligible to participate if they had a primary diagnosis of COPD and if they were clinically stable for at least four weeks preceding enrolment. Patients were excluded if they had a history of other lung diseases, had undergone lung surgery or had a malignancy within the last five years. All patients gave written informed consent.

Patients were recruited in primary, secondary and tertiary care settings between April 2012 and April 2014. Primary care patients were only received treatment by their general practitioner and never contacted a chest physician or were treated in tertiary care before. Secondary care patients were only treated by a chest physician but were not treated in tertiary care before. Primary and secondary care patients were recruited through general practitioner practices selected from the 'RNH' Registration Network of Family Practices [11]. Tertiary care patients were recruited at $\mathrm{CIRO}+$, a center for pulmonary rehabilitation in Horn, the Netherlands, during their pre-rehabilitation assessment.

\section{Measurements}

Primary and secondary care patients were assessed during home visits, while tertiary care patients were measured during an inpatient pre-rehabilitation assessment [12]. Demographics, body mass index (BMI), smoking status, number of exacerbations and hospitalizations during the last twelve months, use of long-term oxygen therapy, current medication, post-bronchodilator spirometry (forced expiratory volume in the first second, $\mathrm{FEV}_{1}$, and forced vital capacity, FVC), mMRC dyspnea grade [13], functional mobility (Timed Up-and-Go (TUG) test) [14] and self-reported comorbidities (Charlson Comorbidity Index) [15] were assessed. Symptoms of anxiety and depression were assessed by using the Hospital Anxiety and Depression Scale, consisting of an anxiety subscale (HADS-A) and depression subscale (HADS-D) [16, 17]. In addition, diseasespecific health status was assessed using the CAT [18], the CCQ [19] and the COPD-specific version of the SGRQ (SGRQ-C) [20]. SGRQ scores were used to assess differences in health status between the various scenarios.

\section{Statistics}

Allocation to GOLD groups was made using $\mathrm{mMRC} \geq 2$ versus, CAT $\geq 10$ or CCQ $\geq 1$ or SGRQ $\geq 25$ and degree of airflow limitation/ $\geq 2$ exacerbations versus degree of airflow limitation/ $\geq 1$ hospitalizations in the previous twelve months. Bivariate correlations (Pearson's product-moment correlation) between mMRC, CAT, CCQ and SGRQ scores were assessed. Cohen's Kappa was used to assess 
agreement between the frequencies of patients classified into GOLD groups A to $D$ using the different cut-points. Kappa values were categorized as poor $(<0.0)$, slight $(0.00-0.20)$, fair $(0.21-0.40)$, moderate $(0.41-0.60)$, substantial (0.61-0.80), and very good (0.81-1.00) agreement [21]. Patient characteristics were compared between GOLD groups $A$ to $D$ using univariate analysis of variance for continuous variables, followed by post hoc least significance difference (LSD) multiple comparisons, or Kruskal-Wallis test followed by MannWhitney $\mathrm{U}$ test, as appropriate. Categorical variables were compared using ChiSquare tests. The same statistics were used to compare patient characteristics and health status, symptoms of anxiety and depression, the TUG test, and selfreported comorbidities between GOLD groups. For other tests, independent sample t-test or Mann-Whitney $\mathrm{U}$ test were used, as appropriate. All statistical analyses were performed using SPSS for Windows, Version 19.0. A p-value $\leq 0.01$ was interpreted as statistically significant.

\section{RESULTS}

\section{Patient characteristics}

In total, 542 patients with moderate to very severe COPD were included. Characteristics of the study population are presented in Table 2. 


\section{CHAPTER 5}

TABLE 2. Patient characteristics

\begin{tabular}{lc}
\hline Men, $\mathrm{n}(\%)$ & $313(57.7)$ \\
Age, years & $64.6(9.0)$ \\
Current smoker, $\mathrm{n}(\%)$ & $132(24.4)$ \\
Packyears, $\mathrm{n}$ & $42.6(28.0)$ \\
$\mathrm{FEV}_{1} \%$ predicted & $54.7(22.3)$ \\
$\mathrm{FEV}_{1} / \mathrm{FVC} \%$ & $42.2(13.7)$ \\
BMI, kg/m ${ }^{2}$ & $26.1(5.3)$ \\
Exacerbations previous 12 months $\geq 2, \mathrm{n}(\%)$ & $256(47.2)$ \\
Hospitalizations previous 12 months $\geq 1, \mathrm{n}(\%)$ & $187(34.5)$ \\
Charlson Comorbidity Index, points & $1.8(1.2)$ \\
mMRC, grade & $2.1(1.2)$ \\
CAT, points & $19.9(7.3)$ \\
CCQ, points & $2.3(1.1)$ \\
SGRQ total, points & $53.1(21.6)$ \\
HADS-A, points & $6.8(4.4)$ \\
HADS-D, points & $6.5(4.3)$ \\
TUG test, seconds & \\
Primary care patients, $\mathrm{n}(\%)$ & $10.3(3.6)$ \\
Secondary care patients, $\mathrm{n}(\%)$ & $63(11.6)$ \\
Tertiary care patients, $\mathrm{n}(\%)$ & $97(17.9)$ \\
\hline
\end{tabular}

$\mathrm{n}=542$. Values expressed as mean (standard deviation) or number of patients (n), proportion (\%). Abbreviations: $\mathrm{FEV}_{1}$, forced expiratory volume in the first second; BMl, body mass index; mMRC, modified Medical Research Council scale; CAT, COPD Assessment Test; CCQ, Clinical COPD Questionnaire; SGRQ, St. George Respiratory Questionnaire score; TUG, Timed 'Up and Go' test; HADS-A, Hospital Anxiety and Depression Scale, Anxiety subscale; HADS-D, Hospital Anxiety and Depression Scale, Depression subscale; ${ }^{a} n=534$.

\section{The impact of symptom measure on frequency distribution}

The mMRC, CAT, CCQ and SGRQ scores were moderately to strongly correlated, with the best relationship between CCQ and SGRQ $(r=0.853, p<0.001)$ (eFigure 1). Using the cut-points selected, the majority of the patients were classified as GOLD D, irrespective of the symptom measure used (Figure 1). 
Exacerbation

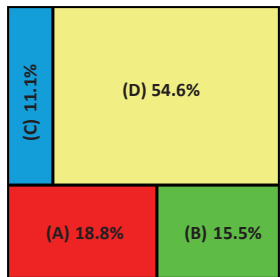

Figure 1 a. $m M R C ~ \geq 2$

Hospitalization

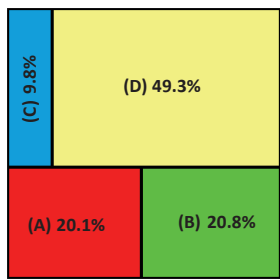

Figure 1 e. $m M R C \geq 2$

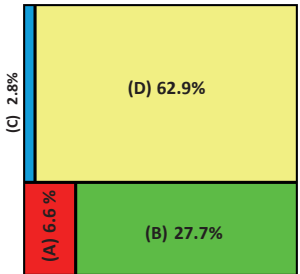

Figure $1 \mathrm{~b}$. CAT $\geq 10$

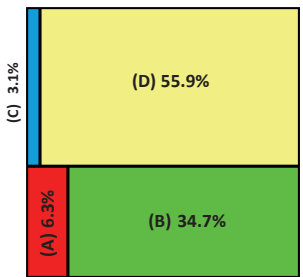

Figure 1f. CAT $\geq 10$

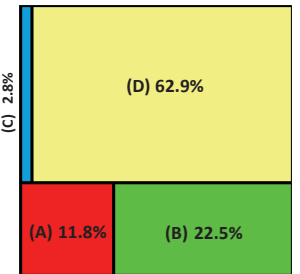

Figure 1c. CCQ $\geq 1$

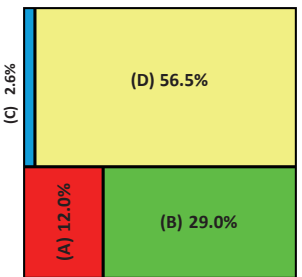

Figure 1g. CCQ $\geq 1$

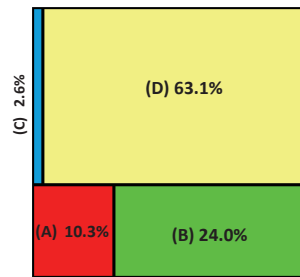

Figure 1 d. SGRQ $\geq 25$

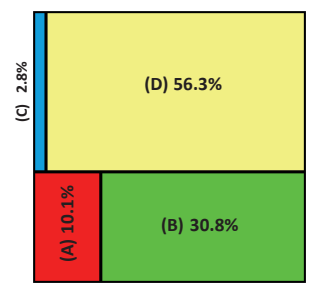

Figure 1 h. SGRQ $\geq 25$

FIGURE 1. Frequency distribution stratified by symptom measure and exacerbation risk assessment.

The agreement of classification (Kappa values) into low (A/C) of high (B/D) symptom GOLD groups using the mMRC, CAT, CCQ or SGRQ scores is summarized in Table 3. There was a moderate to substantial agreement $(K=0.602$ or $0.626, p<0.001)$ between mMRC and CAT and very good agreement $(K=0.838$ or $0.851, p<0.001$ ) between CCQ and SGRQ scores.

TABLE 3. Cohen's Kappa between symptom measures and same risk assessments

\begin{tabular}{|c|c|c|c|}
\hline \multicolumn{4}{|c|}{ Exacerbation history/degree of airflow limitation as risk assessment } \\
\hline & CAT & CCQ & SGRQ \\
\hline $\mathrm{mMRC}$ & 0.602 & 0.694 & 0.678 \\
\hline CAT & - & 0.806 & 0.787 \\
\hline CCQ & - & - & 0.838 \\
\hline \multicolumn{4}{|c|}{ Hospitalization history/degree of airflow limitation as risk assessment } \\
\hline & CAT & CCQ & SGRQ \\
\hline mMRC & 0.626 & 0.712 & 0.698 \\
\hline CAT & - & 0.820 & 0.803 \\
\hline CCQ & - & - & 0.851 \\
\hline
\end{tabular}

All results: $p<0.001$ 
The impact of symptom measure on clinical characteristics

On average, GOLD B/D patients had worse disease-specific health status scores compared to GOLD A/C patients, with worst (=highest) health status scores in GOLD D groups (Figure 2, e-Table 1a/b).
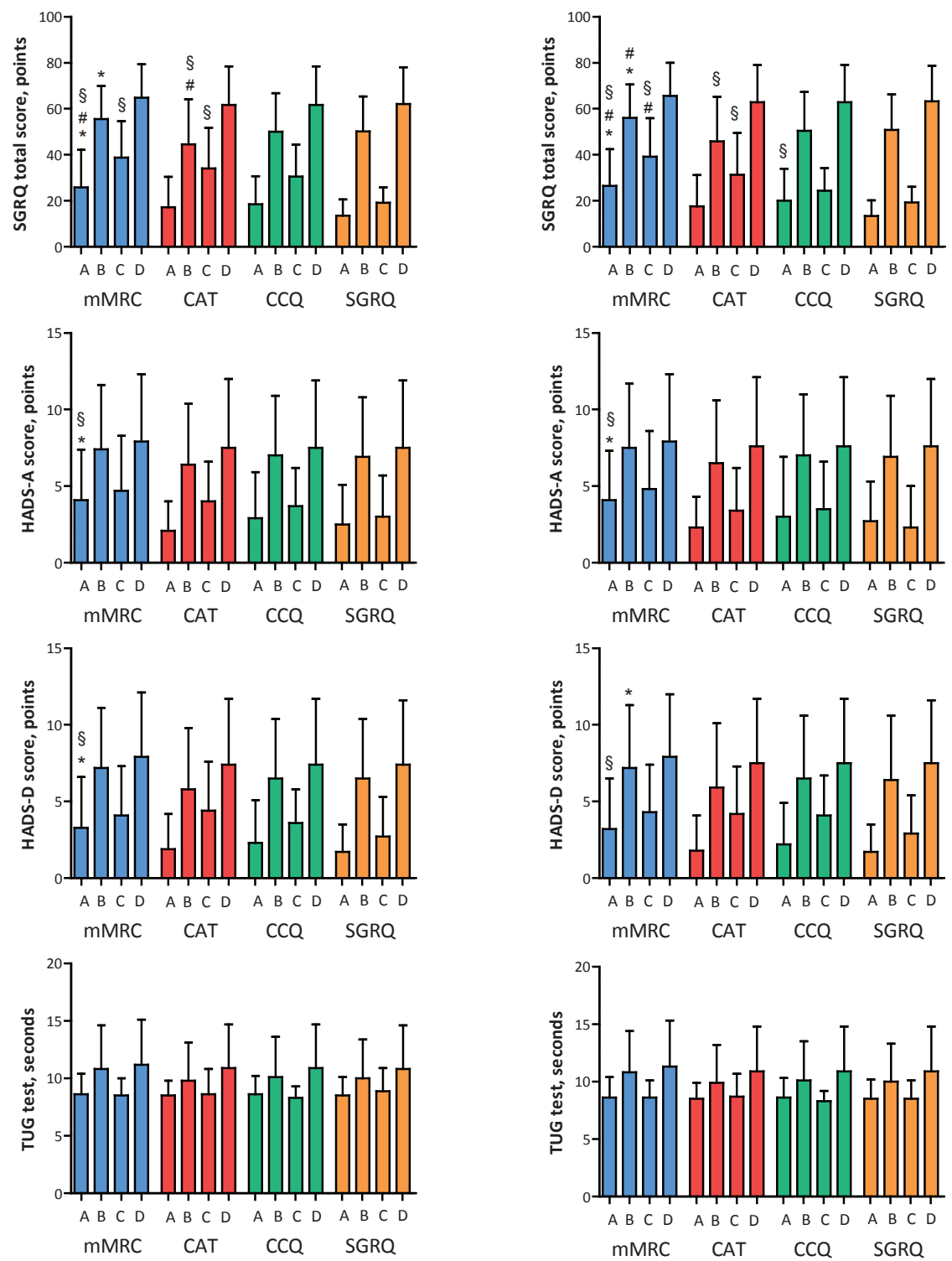

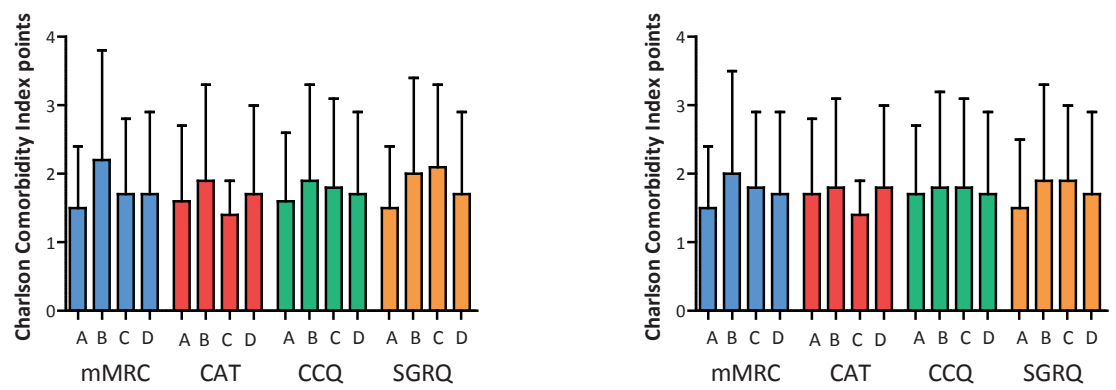

FIGURE 2. Health status as assessed by a) SGRQ, b) symptoms of anxiety (HADS-A) and c) depression (HADS-D), d) functional mobility (TUG test) and e) self-reported comorbidities (Charlson Comorbidity Index) stratified by symptom measure and exacerbation risk assessment (left column: degree of airflow limitation/exacerbation history; right column: degree of airflow limitation/hospitalization history). Significances are only described for comparison between similar GOLD groups using different symptom measures (e.g. mMRC GOLD A versus CAT GOLD A versus CCQ GOLD A versus SGRQ GOLD A. For significances within each symptom measure please see online supplementary table E1a and E1b). ${ }^{*} p \leq 0.01$ versus $C A T ;{ }^{*} p \leq 0.01$ versus $C C Q ;{ }^{\circledR} p \leq 0.01$ versus SGRQ

mMRC GOLD A patients had a significantly worse health status compared to CAT GOLD A, CCQ GOLD A and SGRQ GOLD A patients. mMRC GOLD B, CCQ GOLD B and SGRQ GOLD B patients reported significantly worse health status compared to CAT GOLD B patients. In GOLD C and D however, mean SGRQ scores were comparable between the symptom measures mMRC, CAT and CCQ. mMRC GOLD C and CAT GOLD C patients reported worse health status compared to SGRQ GOLD C patients (Figure 2). On average, GOLD B/D patients needed more time to complete the TUG test compared to GOLD A/C patients, with worst impairment in GOLD D patients. mMRC GOLD B patients and SGRQ GOLD B patients reported more comorbidities compared to mMRC GOLD A, C and $D$ patients and SGRQ A and D patients, respectively (e-Table $1 \mathrm{a} / \mathrm{b}$ ). There were no differences in the number of self-reported comorbidities and time needed to complete the TUG test between GOLD groups using mMRC, CAT, CCQ or SGRQ (Figure 2). On average, GOLD B/D patients reported significantly higher HADS-A and HADS-D scores compared to GOLD A/C patients (e-Table $1 \mathrm{a} / 1 \mathrm{~b}$ ). mMRC GOLD A patients had higher (=worse) HADS-A and HADS-D scores compared to CAT GOLD A and SGRQ GOLD A patients.

\section{The impact of exacerbation risk assessment on frequency distribution}

Table 4 shows that there is a substantial agreement between the classifications using the exacerbation history and hospitalization history as risk assessment. 
TABLE 4. Cohen's Kappa between different risk assessments and same symptom measures

\begin{tabular}{llllll}
\hline & & \multicolumn{4}{l}{ Degree of airflow limitation/hospitalization } \\
\cline { 3 - 6 } & & mMRC & CAT & CCQ & SGRQ \\
\hline Degree of airflow & mMRC & 0.801 & - & - & - \\
limitation/ & CAT & - & 0.764 & - & - \\
exacerbation & CCQ & - & - & 0.771 & - \\
& SGRQ & - & - & - & 0.769 \\
\hline
\end{tabular}

All results: $p<0.001$

\section{The impact of exacerbation risk assessment on clinical characteristics}

In general, the impact of choice of symptom cut-point measure on demographic and clinical characteristics was similar for both exacerbation risk assessment groups (Figure 2, e-Table 1a/1b). Health status, physical mobility, symptoms of anxiety and depression and self-reported comorbidities were comparable between both exacerbation risk assessment groups (Figure 2).

\section{DISCUSSION}

This is the first study investigating the impact of the four GOLD-recommended symptom measures (mMRC, CAT, CCQ and SGRQ) and the two measures for exacerbation risk (exacerbations and hospitalisation) on the frequency distribution of GOLD A to D, and their clinical characteristics in COPD patients. It shows that the choice of symptom measure influences the frequency distribution of the new GOLD groups more than measures for exacerbation risk. Moreover, health status and psychological symptoms differ between different outcome measures used to identify high and low symptom patients, in particular in GOLD $A$ and $B$. Thus, our hypothesis that the symptom measures impact the GOLD distribution as well as the clinical characteristics of the GOLD groups is partly confirmed.

\section{The impact of symptom measure on frequency distribution}

The distribution of patients between GOLD A/C or B/D was dependent on the choice of symptom measure. As suggested before [6], this is not surprising since CAT, CCQ and SGRQ cover a broad variety of symptoms and have been developed differently compared to mMRC $[18,19]$. The current study extends previous reports $[6,22]$ and shows that the mMRC cut-point of $\geq 2$ gives an over representation of patients classified in groups $A$ and $C$ compared with cutpoints of the CAT, CCQ and SGRQ. In addition, previous studies only included 
primary and secondary care patients $[22,23]$, while the majority of patients in the current analyses was recruited in tertiary care. As suggested before [23], the distribution of patients across GOLD groups seems to differ by sample population. The results also show that the impact of the choice of symptom measure is most pronounced in the low risk groups GOLD A/B. Probably, the impact of severe airflow limitation or exacerbations/hospitalizations on health status is more pronounced in the high-risk groups GOLD C/D, compared to the low-risk groups GOLD A/B, which may overwhelm the impact of choice of symptom measure in the high-risk groups. The current study found a similar degree of agreement between mMRC and CAT compared to previous studies $[6,9,22]$ and showed even a better agreement between MMRC-CCQ and CAT-CCQ with best agreement between CCQ-SGRQ. However, the current study extends previous findings [24] showing a similarly strong relationship between CAT and CCQ $(r=$ $0.771, p<0.001)$ and the best relationship between CCQ and SGRQ $(r=0.853, p$ $<0.001$ ) (e-Figure 1).

Patients with a CAT-score $\geq 10$ points experience a negative impact of their disease in their daily lives [25]. Jones and colleagues [6] showed that the classification of low symptom patients were approximately equivalent using the cutpoints of mMRC grade $\geq 1$ and CAT score $\geq 10$. Other studies suggest a CAT cutpoint of 22 points [23] or 13 points [26] to determine low symptom groups which correspond with a mMRC cut-point of 2 or more. However, the choice of an adequate cut-point remains debatable: the updated GOLD 2014 document suggested a cut-point for the CCQ between 1.0-1.5 points [9] while the current study suggests a CCQ cut-point of $\geq 0.6$ points and a mMRC grade of $\geq 1$ matching with a CAT cut-point of $\geq 10$ points to reach the best agreement (e-Figure 2 and 3). The classification is important since treatment is recommended according to the classification of the disease described in the GOLD document. Although, the CAT and CCQ are both useful tools to assess patients' experience of COPD [24], it has been suggested to be challenging using both tools in clinical practice [27]. Kim and colleagues [22] suggested to use the worse score on CAT or mMRC to allocate patients to GOLD A/C or B/D, like the procedure for exacerbation risk assessment. However, if this procedure is applied in the current study, only $4.8 \%$ of all patients are classified in GOLD A/C of which most of them in low risk group $A$. Therefore, this procedure probably gives an underestimation of low symptom patients (GOLD A/C).

\section{The impact of symptom measure on clinical characteristics}

Furthermore, the current study showed that patients classified as $A / C$ using mMRC reported worse health status compared to CAT or CCQ. This supports and extends previous findings [6]. Interestingly, in mMRC GOLD B, CCQ GOLD B 
and SGRQ GOLD B patients reported worse health status compared with CAT GOLD B patients. Furthermore, mMRC GOLD A patients reported higher HADS-A and HADS-D scores compared to CAT GOLD A and SGRQ GOLD A patients. Previously, dyspnea and CAT scores have been associated with symptoms of anxiety and depression [28-30]. Since mMRC GOLD A patients reported worse health status scores (Figure 2, e-Table $1 \mathrm{a} / \mathrm{b}$ ), it is reasonable that those patients also report higher HADS scores.

The current study identified significantly more self-reported comorbidities in mMRC GOLD B and SGRQ GOLD B/C compared to mMRC GOLD A, C and D and SGRQ A or D patients, respectively, while there were no differences in selfreported comorbidities between the GOLD groups when using the alternative GOLD-recommended symptom measures. Although previous studies also showed the highest prevalence of comorbidities in GOLD B [31, 32], the present results once again emphasize the importance of the choice of symptom measure. In addition, these studies only used the mMRC to categorize symptoms [31, 32] while the current study considered all various scenarios.

Finally, the choice of risk assessment did not impact the frequency distribution or the clinical characteristics which is in line with a recent published report [23] suggesting a $4.2 \%$ shift from low risk patients to high risk patients, independent of the symptom measure used. While the authors concluded that the meaning was clinically uncertain [23], the present study indicates that both measures for risk assessment are comparable.

\section{Limitations}

There are a number of aspects that need to be taken into consideration regarding the current study. The proportion of patients from primary (11.6\%), secondary $(17.9 \%)$ and tertiary $(70.5 \%)$ care is not equally distributed, which may limit the external validity of the current findings. Furthermore, the current findings need to be interpreted in the light of the number of comparisons that were made in the present study [33]. Nonetheless, multiple findings in the same direction, rather than a single statistically significant result, suggest that these are not due to chance alone. Future studies are necessary to further assess the impact of the use of mMRC, CAT, CCQ and SGRQ on prognosis in all groups and to provide recommendations for disease management. 


\section{CONCLUSION}

In contrast to the possibilities to assess future risk, the four possible symptom measures impact upon the distribution of patients between the new GOLD groups. This is especially seen in the low-risk GOLD groups A and B, in terms of impact health status and psychological symptoms. Healthcare professionals should be aware that patients differ in terms of health status and symptoms of anxiety and depression based on the symptom measure used. 


\section{REFERENCES}

1. Rabe KF, Hurd S, Anzueto A, Barnes PJ, Buist SA, Calverley P, Fukuchi Y, Jenkins C, RodriguezRoisin R, van Weel C, Zielinski J: Global strategy for the diagnosis, management, and prevention of chronic obstructive pulmonary disease: GOLD executive summary. Am J Respir Crit Care Med 2007, 176:532-555.

2. Vanfleteren LE, Spruit MA, Groenen M, Gaffron S, van Empel VP, Bruijnzeel PL, Rutten EP, Op 't Roodt J, Wouters EF, Franssen FM: Clusters of comorbidities based on validated objective measurements and systemic inflammation in patients with chronic obstructive pulmonary disease. Am J Respir Crit Care Med 2013, 187:728-735.

3. Spruit MA, Polkey MI, Celli B, Edwards LD, Watkins ML, Pinto-Plata V, Vestbo J, Calverley PM, Tal-Singer R, Agusti A, et al: Predicting outcomes from 6-minute walk distance in chronic obstructive pulmonary disease. J Am Med Dir Assoc 2012, 13:291-297.

4. Graat-Verboom L, van den Borne BE, Smeenk FW, Spruit MA, Wouters EF: Osteoporosis in COPD outpatients based on bone mineral density and vertebral fractures. $J$ Bone Miner Res 2011, 26:561-568.

5. Vestbo J, Hurd SS, Agusti AG, Jones PW, Vogelmeier C, Anzueto A, Barnes PJ, Fabbri LM, Martinez FJ, Nishimura M, et al: Global strategy for the diagnosis, management, and prevention of chronic obstructive pulmonary disease: GOLD executive summary. Am J Respir Crit Care Med 2013, 187:347-365.

6. Jones PW, Adamek L, Nadeau G, Banik N: Comparisons of health status scores with MRC grades in COPD: implications for the GOLD 2011 classification. Eur Respir J2013, 42:647-654.

7. Han MLK, Muellerova H, Curran-Everett D, Dransfield MT, Washko GR, Regan EA, Bowler RP, Beaty TH, Hokanson JE, Lynch DA, et al: GOLD 2011 disease severity classification in COPDGene: a prospective cohort study. The Lancet Respiratory Medicine 2012, 1:43-50.

8. Agusti A, Hurd S, Jones P, Fabbri LM, Martinez F, Vogelmeier C, Vestbo J, Rodriguez-Roisin R: FAQs about the GOLD 2011 assessment proposal of COPD: a comparative analysis of four different cohorts. Eur Respir J2013, 42:1391-1401.

9. Casanova C, Marin JM, Martinez-Gonzalez C, de Lucas-Ramos P, Mir-Viladrich I, Cosio B, Peces-Barba G, Calle-Rubio M, Solanes-Garcia I, Agüero R, et al: New GOLD classification: Iongitudinal data on group assignment. Respir Res 2014, 15:3

10. Global Initiative for Chronic Obstructive Lung Disease (GOLD). Global strategy for the diagnosis, management and prevention of COPD. http://www.goldcopd.org/ . Published 2011. Updated: Jan 2014. Date accessed: March 2014

11. Metsemakers JF, Hoppener P, Knottnerus JA, Kocken RJ, Limonard CB: Computerized health information in The Netherlands: a registration network of family practices. Br J Gen Pract 1992, 42:102-106.

12. Spruit MA, Pennings HJ, Janssen PP, Does JD, Scroyen S, Akkermans MA, Mostert R, Wouters EF: Extra-pulmonary features in COPD patients entering rehabilitation after stratification for MRC dyspnea grade. Respir Med 2007, 101:2454-2463.

13. Mahler DA, Wells CK: Evaluation of clinical methods for rating dyspnea. Chest 1988, 93:580586.

14. Mesquita R, Janssen DJ, Wouters EF, Schols JM, Pitta F, Spruit MA: Within-day test-retest reliability of the Timed Up \& Go test in patients with advanced chronic organ failure. Arch Phys Med Rehabil2013, 94:2131-2138.

15. Charlson ME, Pompei $P$, Ales KL, MacKenzie CR: A new method of classifying prognostic comorbidity in longitudinal studies: development and validation. J Chronic Dis 1987, 40:373383.

16. Zigmond AS, Snaith RP: The hospital anxiety and depression scale. Acta Psychiatr Scand 1983, 67:361-370. 
17. Puhan MA, Frey M, Buchi S, Schunemann HJ: The minimal important difference of the hospital anxiety and depression scale in patients with chronic obstructive pulmonary disease. Health Qual Life Outcomes 2008, 6:46.

18. Jones PW, Harding G, Berry P, Wiklund I, Chen WH, Kline Leidy N: Development and first validation of the COPD Assessment Test. Eur Respir J 2009, 34:648-654.

19. van der Molen T, Willemse BW, Schokker S, ten Hacken NH, Postma DS, Juniper EF: Development, validity and responsiveness of the Clinical COPD Questionnaire. Health Qual Life Outcomes 2003, 1:13.

20. Jones PW, Quirk FH, Baveystock CM: The St George's Respiratory Questionnaire. Respir Med 1991, 85 Suppl B:25-31; discussion 33-27.

21. Landis JR, Koch GG: The measurement of observer agreement for categorical data. Biometrics 1997, 33:159-174.

22. Kim S, Oh J, Kim Yl, Ban HJ, Kwon YS, Oh IJ, Kim KS, Kim YC, Lim SC: Differences in classification of COPD group using COPD assessment test (CAT) or modified Medical Research Council (mMRC) dyspnea scores: a cross-sectional analyses. BMC Pulm Med 2013, 13:35.

23. Jones PW, Nadeau G, Small M, Adamek L: Characteristics of a COPD population categorised using the GOLD framework by health status and exacerbations. Respir Med 2014, 108:129-135.

24. Tsiligianni IG, van der Molen T, Moraitaki D, Lopez I, Kocks JW, Karagiannis K, Siafakas N, Tzanakis N: Assessing health status in COPD. A head-to-head comparison between the COPD assessment test (CAT) and the clinical COPD questionnaire (CCQ). BMC Pulm Med 2012, 12:20.

25. Jones PW, Tabberer M, Chen WH: Creating scenarios of the impact of COPD and their relationship to COPD Assessment Test (CAT) scores. BMC Pulm Med 2011, 11:42.

26. Pillai AP, Turner AM, Stockley RA: Global Initiative for Chronic Obstructive Lung Disease 2011 symptom/risk assessment in alpha1-antitrypsin deficiency. Chest 2013, 144:1152-1162.

27. Langhammer A, Jones R: Usefulness of the COPD assessment test (CAT) in primary care. Prim Care Respir J 2013, 22:8-9.

28. Janssen DJ, Spruit MA, Leue C, Gijsen C, Hameleers H, Schols JM, Wouters EF: Symptoms of anxiety and depression in COPD patients entering pulmonary rehabilitation. Chron Respir Dis 2010, 7:147-157.

29. Nagata K, Tomii K, Otsuka K, Tachikawa R, Takeshita J, Tanaka K, Matsumoto T, Monden K: Evaluation of the chronic obstructive pulmonary disease assessment test for measurement of health-related quality of life in patients with interstitial lung disease. Respirology 2012, 17:506512.

30. Hilmarsen CW, Wilke S, Engan H, Spruit MA, Rodenburg J, Janssen DJ, Steinshamn S, Jones PW, Wouters EF, Oldervoll L, Franssen FM: Impact of symptoms of anxiety and depression on COPD Assessment Test (CAT) scores. Eur Respir J2013.

31. Lange P, Marott JL, Vestbo J, Olsen KR, Ingebrigtsen TS, Dahl M, Nordestgaard BG: Prediction of the clinical course of chronic obstructive pulmonary disease, using the new GOLD classification: a study of the general population. Am J Respir Crit Care Med 2012, 186:975-981.

32. Agusti A, Edwards LD, Celli B, Macnee W, Calverley PM, Mullerova H, Lomas DA, Wouters E, Bakke P, Rennard S, et al: Characteristics, stability and outcomes of the 2011 GOLD COPD groups in the ECLIPSE cohort. Eur Respir J 2013, 42:636-646.

33. Perneger TV: What's wrong with Bonferroni adjustments. BMJ1998, 316:1236-1238.

Reprinted with permission from Chronic Obstructive Pulmonary Diseases: Journal of the COPD Foundation (2014; 1[2]:212-220. doi: http//dx.doi.org/10.15326/jcopdf.1.2.2014.0135). Copyright 2014 COPD Foundation 


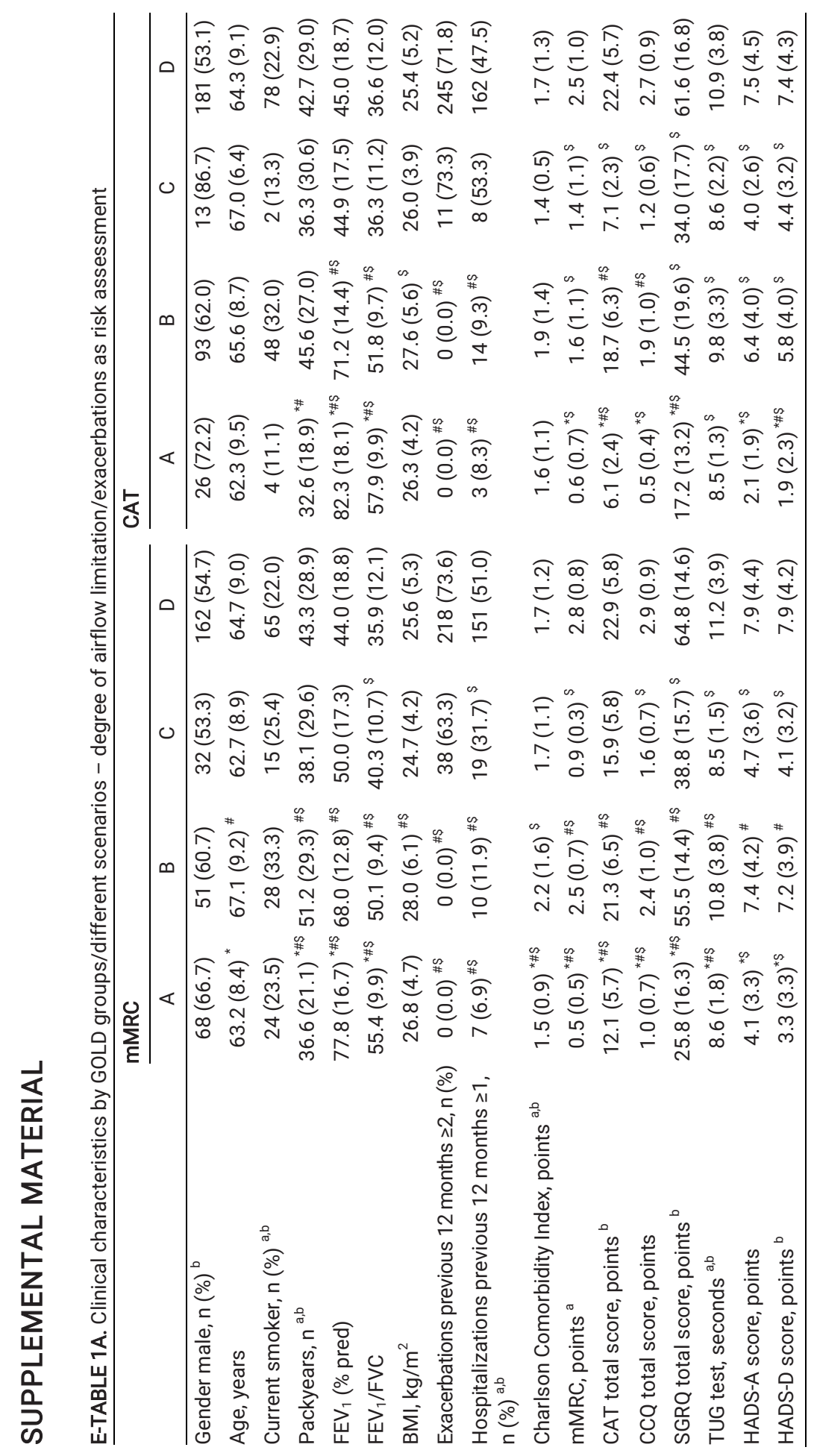




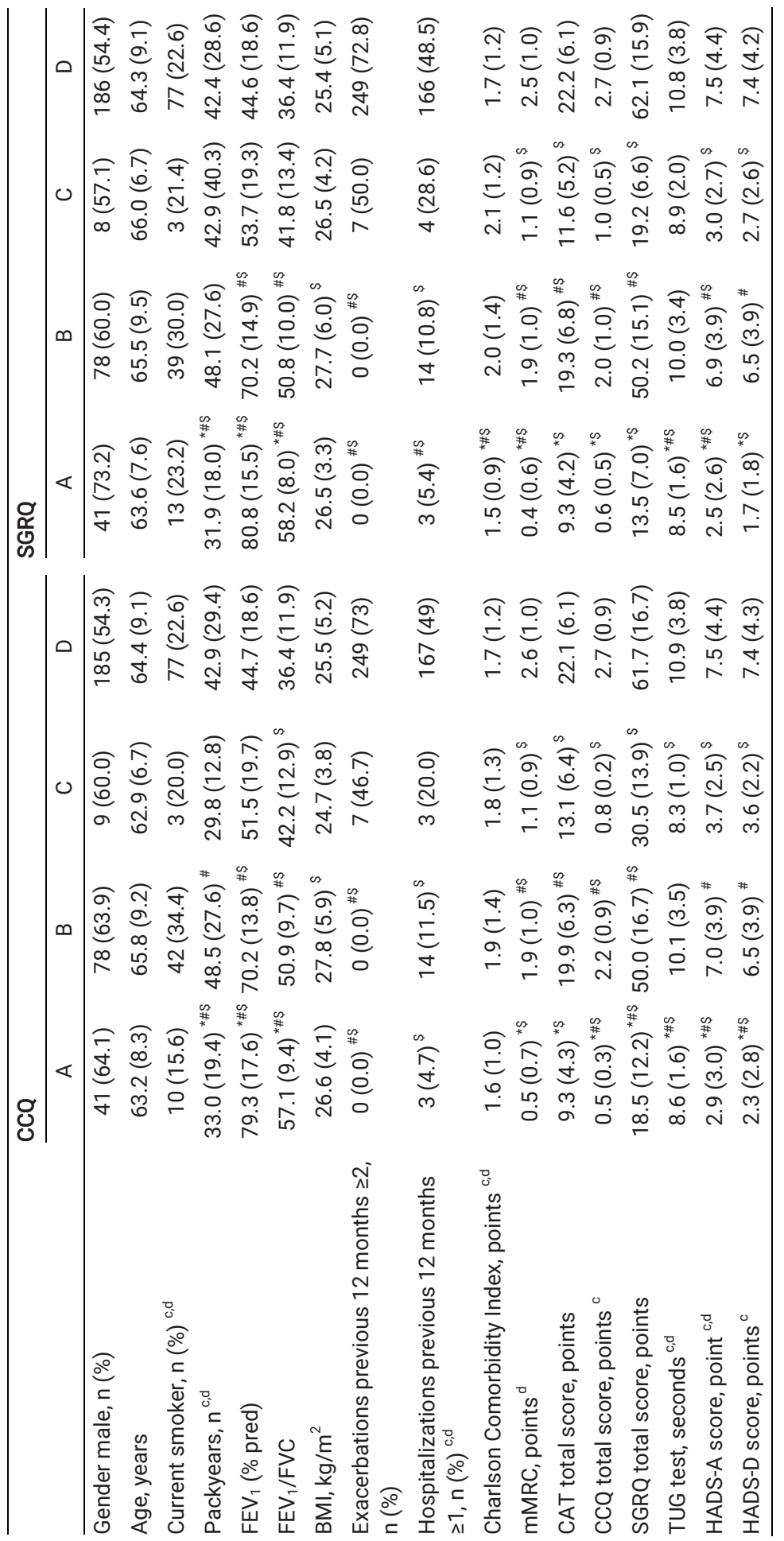




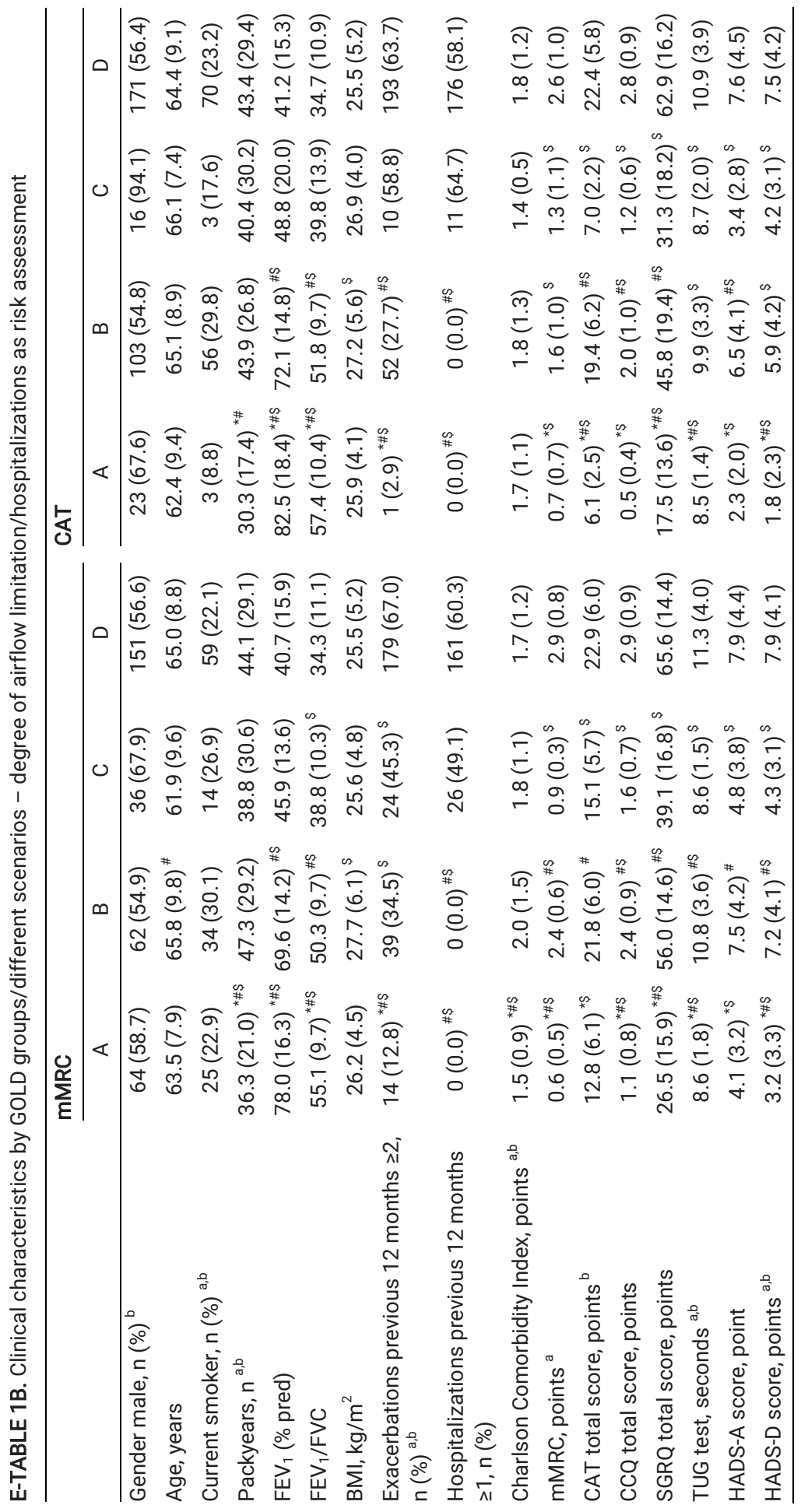




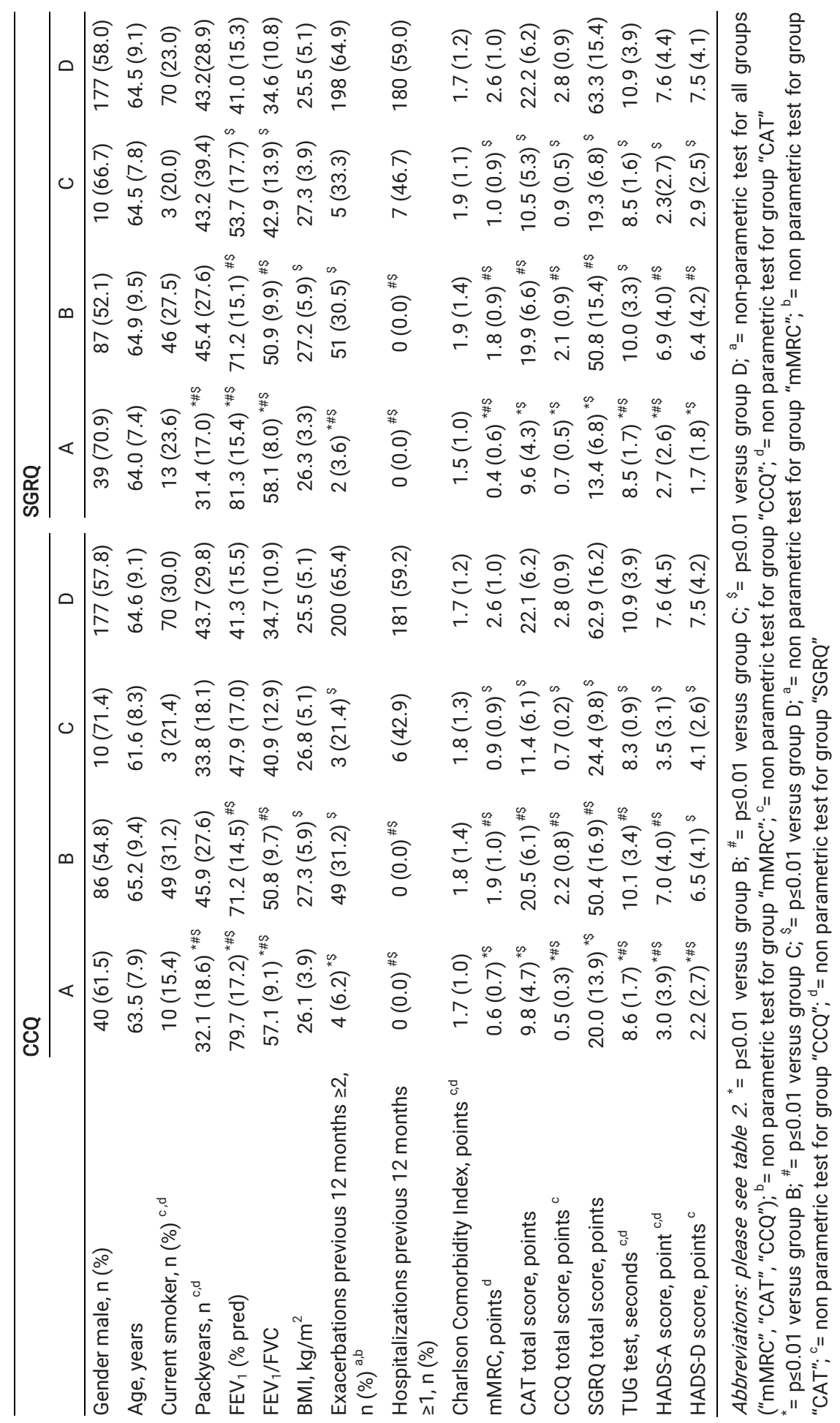



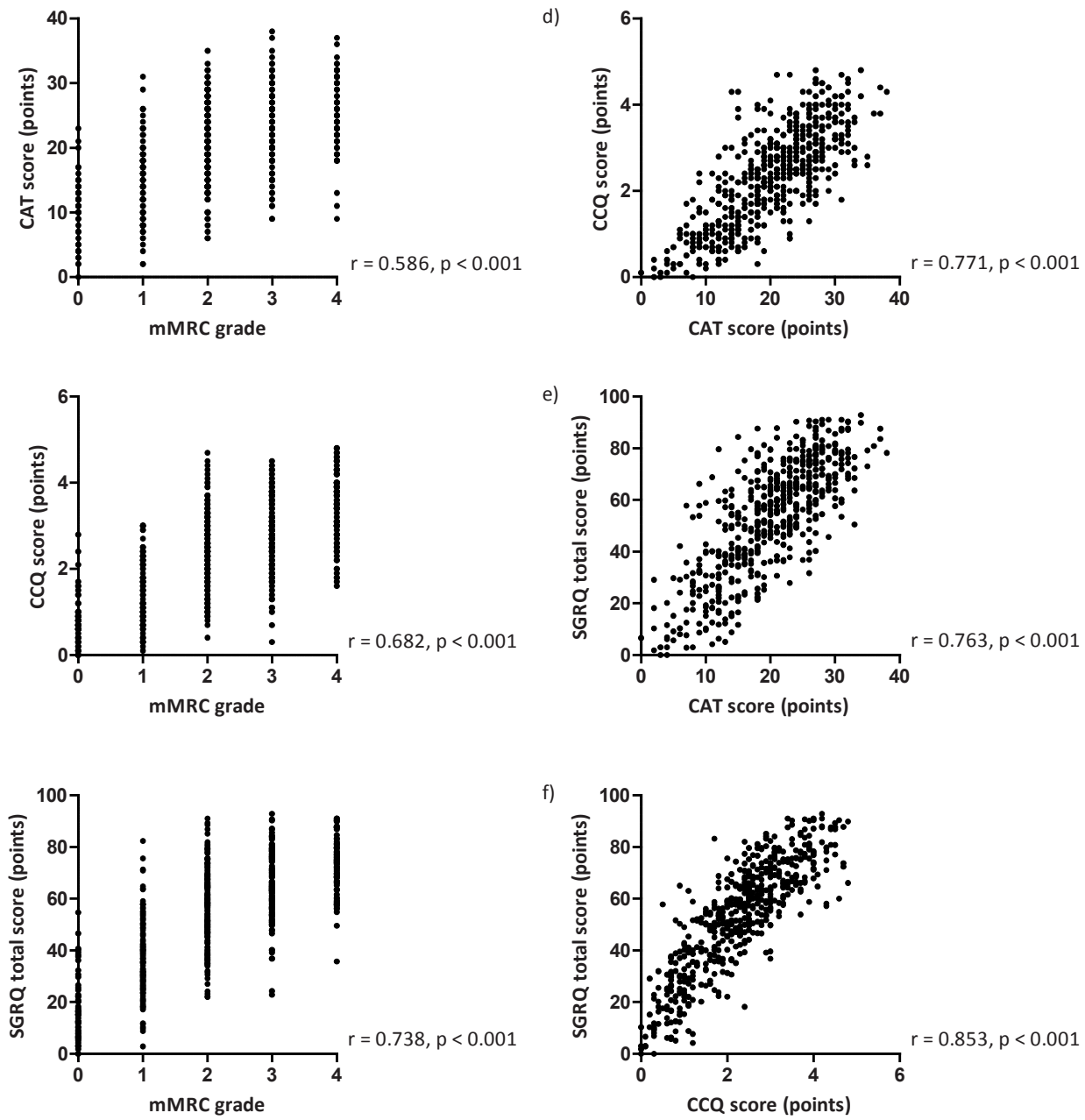

E-FIGURE 1. Pearson Correlation between a) mMRC and CAT; b) mMRC and CCQ; c) mMRC and SGRQ; d) CAT and CCQ; e) CAT and SGRQ; f) CCQ and SGRQ 


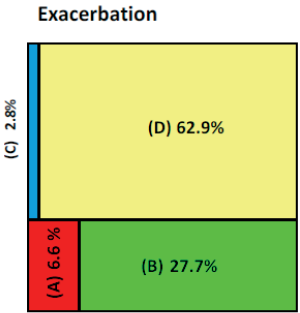

e-Figure $2 a$. CAT $\geq 10$

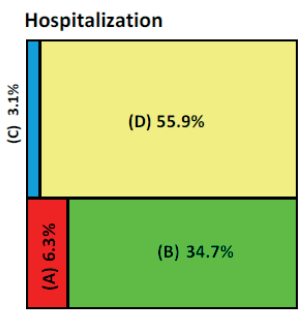

e-Figure 2e. CAT $\geq 10$

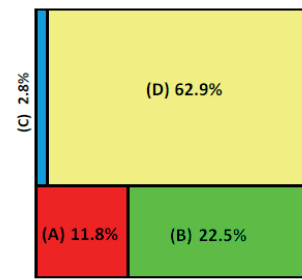

e-Figure $2 b . C C Q \geq 1, K=0.806$

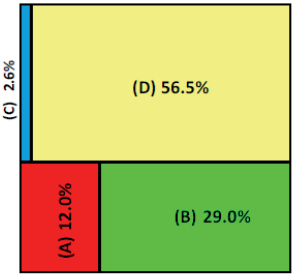

e-Figure 2f. $C C Q \geq 1, K=0.820$

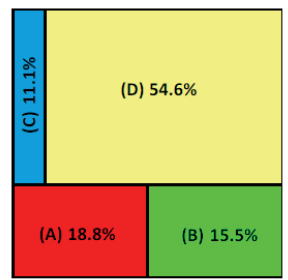

e-Figure $2 c . \quad C C Q \geq 1.5, K=0.689$

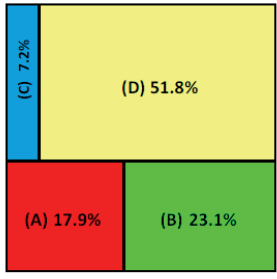

e-Figure 2g. $C C Q \geq 1.5, K=0.710$

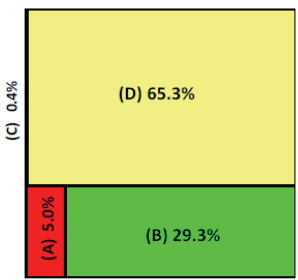

e-Figure 2 d. $C C Q \geq 0.6, K=0.868$

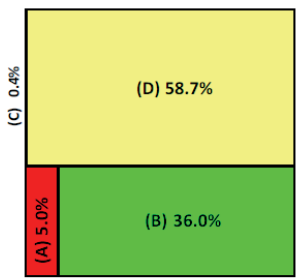

e-Figure $2 h$. $C C Q \geq 0.6, K=0.878$

E-FIGURE 2. Frequency distribution stratified by symptom measure and exacerbation risk assessment using alternative cut-points for CCQ.

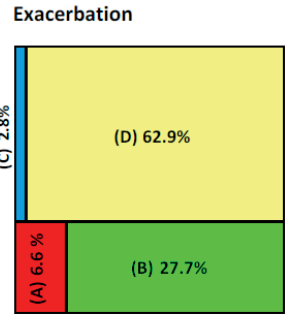

e-Figure 3a. CAT $\geq 10$

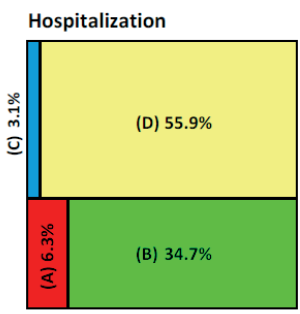

e-Figure 3e. CAT $\geq 10$

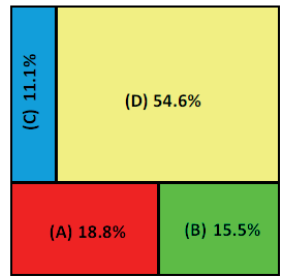

e-Figure $3 b$. $m M R C \geq 2, K=0.602$

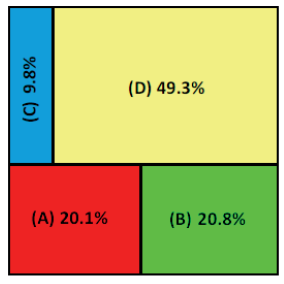

e-Figure 3f. $m M R C \geq 2, k=0.626$

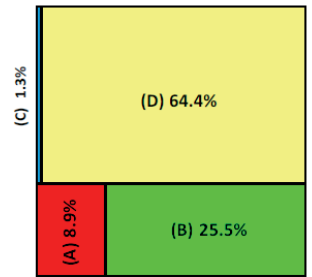

e-Figure $3 c$. $m M R C \geq 1, K=0.765$

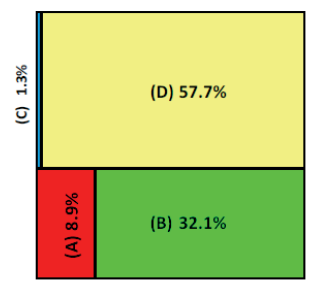

e-Figure 3g. $m M R C \geq 1, K=0.782$

E-FIGURE 3. Frequency distribution stratified by symptom measure and exacerbation risk assessment using alternative cut-points for mMRC. 

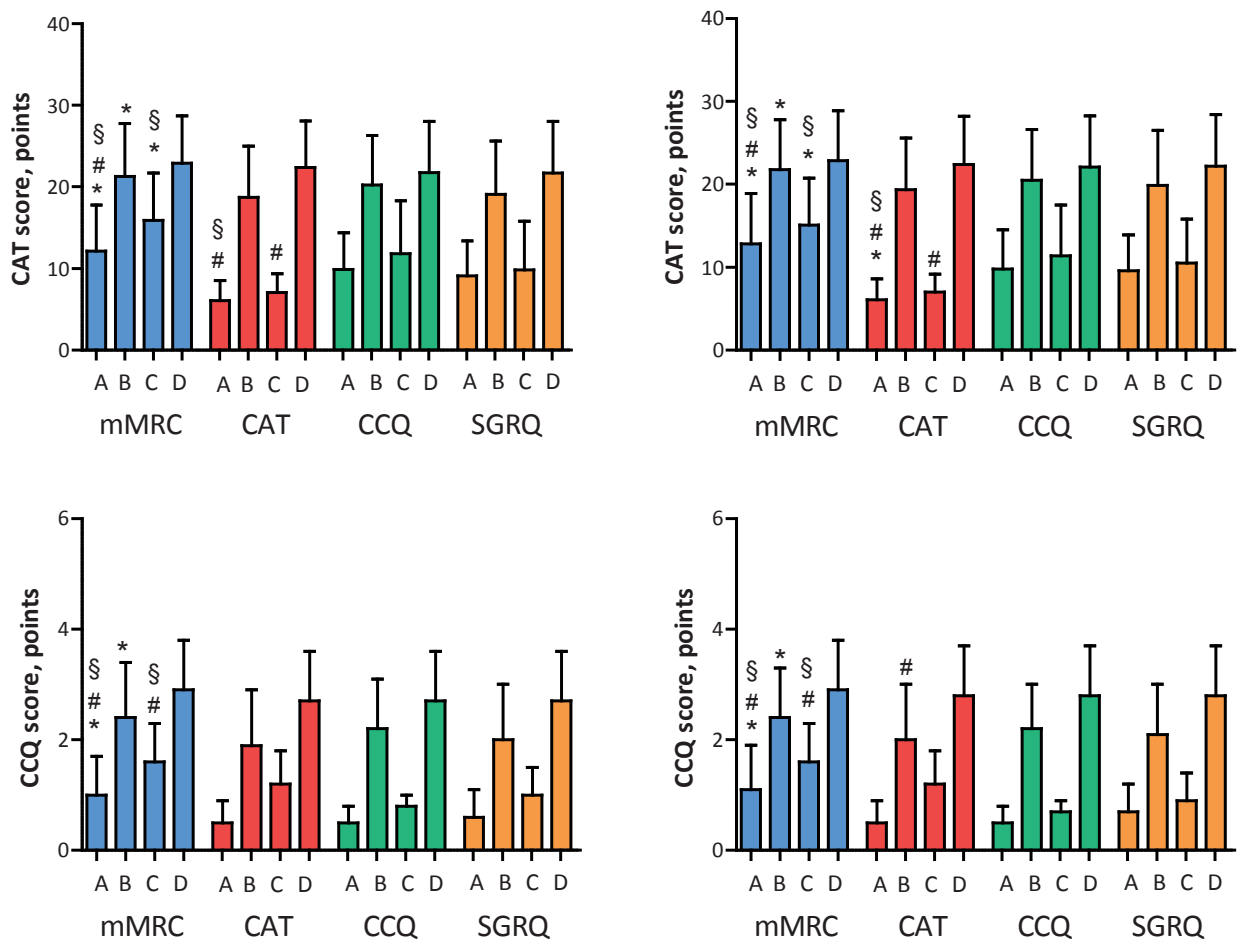

E-FIGURE 4. Health status as assessed by a) CAT and b) CCQ (left column: degree of airflow limitation/exacerbation history; right column: degree of airflow limitation/hospitalization history). Significances are only described for comparison between similar GOLD groups using different symptom measures (e.g. mMRC GOLD A versus CAT GOLD A versus CCQ GOLD A versus SGRQ GOLD A. For significances within each symptom measure please see online supplementary table E1a and E1b). ${ }^{*} p \leq 0.01$ versus $C A T ;{ }^{\#} p \leq 0.01$ versus $C C Q ;{ }^{\S} p \leq 0.01$ versus SGRQ 


\section{CHAPTER 6 \\ Impact of symptoms of anxiety and depression on COPD Assessment Test (CAT) scores}

Christina W. Hilmarsen*, Sarah Wilke*, Harald Engan, Martijn A. Spruit, Johan Rodenburg, Daisy J.A. Janssen, Sigurd Steinshamn, Paul W. Jones, Emiel F.M. Wouters, Line Oldervoll, and Frits M.E. Franssen

* contributed equally to this manuscript and are joint first authors

European Respiratory Journal 2014; 43: 898-900 

Anxiety and depression are common comorbidities in patients with chronic obstructive pulmonary disease (COPD) and affect patients' health status [1, 2]. Health status in COPD patients is frequently assessed by the St. George's Respiratory Questionnaire (SGRQ), which is a validated disease-specific questionnaire widely used in clinical trials [3], but complex and time consuming to complete and score. Consequently, the COPD Assessment Test (CAT) has been developed [4]: a disease-specific health status questionnaire containing eight items with good sensitivity, reliability and responsiveness [4]. CAT scores are strongly positively correlated with SGRQ scores in patients with COPD [4]. Therefore, it is reasonable to hypothesize those COPD patients with symptoms of anxiety and/or depression will report higher CAT scores (=worse health status) compared to those without symptoms.

The latest version of the Global Initiative for Chronic Obstructive Lung Disease (GOLD) document [5] recommends the CAT as a tool to assess the impact of COPD on the individual patient beyond airflow limitation. Although it was known that clinically relevant symptoms of anxiety and depression are more common in patients in GOLD stage IV compared to patients in GOLD stages I and II [1], the frequency distribution of patients with symptoms of anxiety and depression across the updated GOLD classification remains unknown. Recently, Sillen and colleagues reported a prevalence of symptoms of anxiety and depression of $38 \%$ and $32 \%$ in COPD patients with GOLD D, respectively [6].

We aimed to assess the impact of symptoms of anxiety and depression on disease-specific health status as assessed by CAT in patients with COPD entering pulmonary rehabilitation. Secondary, we aimed to investigate the relationship between the updated GOLD classification and symptoms of anxiety and depression.

Demographic and clinical characteristics (number of exacerbations in the last 12 months, current medication, post-bronchodilator spirometry, and functional exercise capacity as assessed by six-minute walk distance (6MWD)) were assessed in stable patients with COPD, entering pulmonary rehabilitation at Center of Expertise on Organ Failure (CIRO+), Netherlands, and LHL Health Röros, Norway. Patients were eligible if they had a primary diagnosis of COPD [5] and were clinically stable. Patients were excluded if they had a history of other lung diseases, had undergone lung surgery or had malignancy within the last five years. The Regional Committee for Medical and Health Research Ethics in Central Norway (REK Midt 2012/1495) and the Medical Ethical Commission of the Maastricht University Medical Centre+ (MUMC+), Maastricht, the Netherlands (METC 11-3-070) approved this study. 
Symptoms of anxiety and depression were assessed using the Hospital Anxiety and Depression Scale (HADS) [7]. The scores for each subscale range from 0 (optimal) to 21 (worst) points. A score equal to or higher than 10 points on the anxiety (HADS-A) or depression (HADS-D) subscale may indicate the presence of clinically relevant symptoms [7]. Disease-specific health status was assessed using the CAT (4). The score ranges from 0 (no impact) to 40 points (severe impact) (4).

Three hundred and seven patients ( $51 \%$ male, age $63.9 \pm 8.6$ years, $\mathrm{FEV}_{1} 50 \pm 21$ $\%$ predicted), were included. In general, the sample was slightly overweight $\left(26.5 \pm 6.1 \mathrm{~kg} / \mathrm{m}^{2}\right)$ and functional exercise capacity $(434 \pm 132$ metres) as well as disease-specific health status (CAT: $21.1 \pm 6.5$ points) were impaired. Thirtyeight (12.4\%) patients reported clinically relevant symptoms of anxiety, 28 (9.1 $\%)$ patients reported clinically relevant symptoms of depression, and 50 (16.3 $\%)$ patients reported a combination of both symptoms. There were no differences in HADS-D scores between patients treated with antidepressants $(n=57)$ compared to patients not treated with antidepressants $(n=250 ; 7.0 \pm 4.4$ points versus $6.1 \pm 4.3$ points, $p=0.13$ ). Patients treated with anxiolytics $(n=47)$ reported higher HADS-A scores compared to patients not treated with anxiolytics $(n=260$; $10.0 \pm 5.1$ points versus $6.6 \pm 4.1$ points, $p \leq 0.001$ ).

Patients without symptoms of anxiety and/or depression had lower CAT scores (19.6 \pm 6.0 points) than patients with symptoms of anxiety $(22.8 \pm 6.2$ points, $\mathrm{p}=0.020)$, symptoms of depression $(24.8 \pm 6.3$ points, $\mathrm{p}<0.001)$ or both symptoms (23.2 \pm 8.8 points, $\mathrm{p}=0.002$ ) (Figure 1 ). 


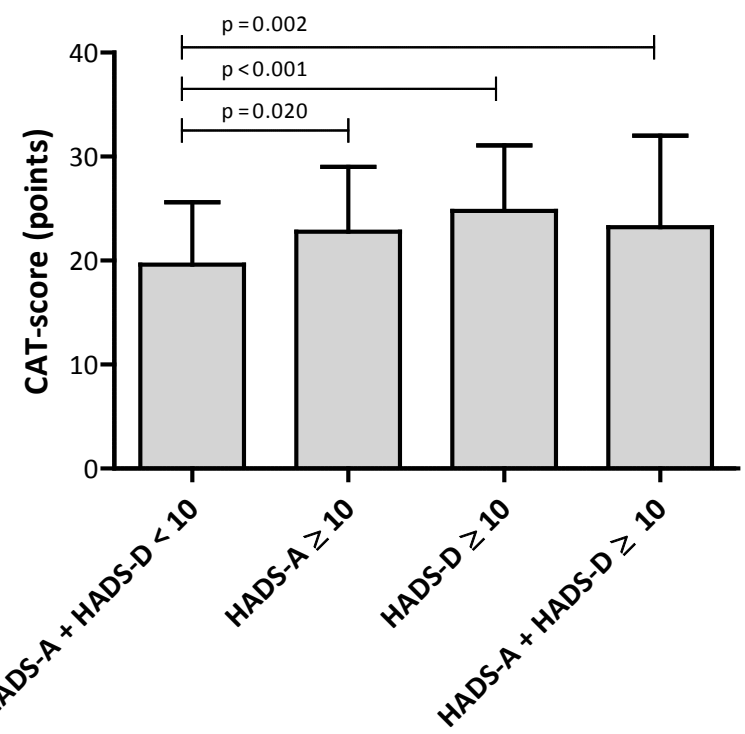

FIGURE 1. CAT scores stratified by HADS scores

CAT scores were modestly correlated with HADS-A scores $(r=0.30, p<0.001)$ and HADS-D scores $(r=0.35, p<0.001)$. There were no differences in proportion of patients with clinically relevant symptoms of anxiety and/or depression between GOLD groups A to D (Table 1).

TABLE 1. Proportion of patients reporting clinically relevant symptoms of anxiety (HADS-A $\geq 10$ points) and depression (HADS-D $\geq 10$ HADS) stratified by updated GOLD groups.

\begin{tabular}{llll}
\hline GOLD group & Patients $(\mathrm{n})$ & HADS-D $\geq 10$ points & HADS-A $\geq 10$ points \\
\hline A & 6 & 16.7 & 16.7 \\
B & 70 & 18.6 & 30.0 \\
C & 8 & 12.5 & 0.0 \\
D & 213 & 28.2 & 29.6 \\
\hline
\end{tabular}

The current study has two novel findings: 1) COPD patients with symptoms of anxiety and/or depression referred for pulmonary rehabilitation reported a worse disease-specific health status as assessed by CAT than patients without these symptoms; 2 ) the prevalence of symptoms of anxiety and depression was equally distributed across the updated GOLD groups.

Lou et al. [2] reported that SGRQ scores were comparable between patients with symptoms of anxiety and patients with symptoms of depression. Our study shows comparable findings for symptoms of anxiety or depression and CAT scores. Patients hospitalized for a COPD exacerbation with depressive symp- 
toms (using Beck's Depression Inventory (BDI)) reported higher CAT scores (= worse health status) than patients without depressive symptoms [8]. The current study extends to these findings that symptoms of depression and/or depression affect patients' health status in stable patients.

In the present study, $37.8 \%$ of the patients had clinically relevant symptoms of anxiety and/or depression. This frequency is comparable to previous findings $[1,2]$. Antidepressants were more widely used than anxiolytics in our data. This might be explained by the fact that antidepressants have mixed effects, and that symptoms of anxiety and depression often coincide [9]. HADS-D scores were similar between patients treated with antidepressants and untreated patients, while patients treated with anxiolytics had higher HADS-A scores compared to those untreated. Psychological screening for anxiety and depression could have enlightened these findings as a HADS score of $\geq 10$ points indicates the presence of symptoms of anxiety and depression but does not necessarily indicate a disorder [7].

Janssen et al. [1] identified a higher proportion of patients with clinically relevant symptoms of anxiety and depression in GOLD stage IV compared to patients in GOLD I and II. Recently, Lee et al. [10] reported a significantly higher proportion of patients with depression in GOLD groups B and D compared to GOLD groups $A$ and $C$ and concluded that "the frequency of depression differed by current symptoms, but not by the severity of the airway limitation." However, these results are not directly comparable with our findings since depression was assessed by the patient health questionnaire-9 (PHQ-9) [10]. In the present study, symptoms of anxiety and depression were equally distributed across the updated GOLD stages, indicating that the new classification does not capture clinically relevant symptoms of anxiety and depression. Accordingly, psychological symptoms should be assessed in individual COPD patients entering pulmonary rehabilitation, irrespective of GOLD group.

To conclude, patients with COPD with symptoms of anxiety and/or depression report worse disease-specific health status as assessed by CAT than patients without these symptoms. Symptoms of anxiety and depression are equally distributed across the updated GOLD groups in COPD patients referred for pulmonary rehabilitation. 


\section{REFERENCES}

1. Janssen DJ, Spruit MA, Leue C, Gijsen C, Hameleers H, Schols JM, Wouters EF: Symptoms of anxiety and depression in COPD patients entering pulmonary rehabilitation. Chron Respir Dis 2010, 7:147-157.

2. Lou P, Zhu Y, Chen P, Zhang P, Yu J, Zhang N, Chen N, Zhang L, Wu H, Zhao J: Prevalence and correlations with depression, anxiety, and other features in outpatients with chronic obstructive pulmonary disease in China: a cross-sectional case control study. BMC Pulm Med2012, 12:53.

3. Jones PW, Quirk FH, Baveystock CM, Littlejohns P: A self-complete measure of health status for chronic airflow limitation. The St. George's Respiratory Questionnaire. Am Rev Respir Dis 1992, 145:1321-1327.

4. Jones PW, Harding G, Berry P, Wiklund I, Chen WH, Kline Leidy N: Development and first validation of the COPD Assessment Test. Eur Respir J2009, 34:648-654.

5. Vestbo J, Hurd SS, Agusti AG, Jones PW, Vogelmeier C, Anzueto A, Barnes PJ, Fabbri LM, Martinez FJ, Nishimura M, et al: Global Strategy for the Diagnosis, Management and Prevention of Chronic Obstructive Pulmonary Disease, GOLD Executive Summary. Am J Respir Crit Care Med 2012.

6. Sillen MJ, Franssen FM, Delbressine JM, Uszko-Lencer NH, Vanfleteren LE, Rutten EP, Wouters EF, Spruit MA: Heterogeneity in clinical characteristics and co-morbidities in dyspneic individuals with COPD GOLD D: Findings of the DICES trial. Respir Med2013, 107:1186-1194.

7. Zigmond AS, Snaith RP: The hospital anxiety and depression scale. Acta Psychiatr Scand1983, 67:361-370.

8. Papaioannou Al, Bartziokas K, Tsikrika S, Karakontaki F, Kastanakis E, Banya W, Haniotou A, Papiris S, Loukides S, Polychronopoulos V, Kostikas K: The impact of depressive symptoms on recovery and outcome of hospitalised COPD exacerbations. Eur Respir J2013, 41:815-23.

9. Kunik ME, Roundy K, Veazey C, Souchek J, Richardson P, Wray NP, Stanley MA: Surprisingly high prevalence of anxiety and depression in chronic breathing disorders. Chest 2005, 127:1205-1211.

10. Lee YS, Park S, Oh YM, Lee SD, Park SW, Kim YS, In KH, Jung BH, Lee KH, Ra SW, et al: Chronic obstructive pulmonary disease assessment test can predict depression: a prospective multicenter study. J Korean Med Sci2013, 28:1048-1054.

Reproduced with permission of the European Respiratory Society @ E Eur Respir J March 2014 43:898-900; published ahead of print October 10, 2013, doi:10.1183/09031936.0016391 



\section{CHAPTER 7}

Prevalence of peripheral artery disease and its impact in patients with COPD in the COSYCONET study

Sarah Wilke, Rudolf A. Jörres, Robert Bals, Frits M.E. Franssen,

Sven Gläser, Rolf Holle, Annika Karch, Helgo Magnussen, Armin Koch, Holger Schulz, Martijn A. Spruit, Margarethe M. Wacker, Tobias Welte, Emiel F.M. Wouters, Claus Vogelmeier, and Henrik Watz 



\section{ABSTRACT}

\section{RATIONALE}

Knowledge about the prevalence of objectively assessed peripheral artery disease (PAD) and its impact in patients with COPD is scarce.

\section{OBJECTIVES}

We aimed to assess (1) the prevalence of PAD and (2) the association between PAD and functional capacity as well as health status in a large cohort of patients with COPD.

\section{METHODS}

The ankle-brachial index $(A B I)$ was used to diagnose PAD $(A B I \leq 0.9)$. 6-MinuteWalk-Distance (6MWD), Timed-Up-and-Go (TUG) test, health status (COPDspecific version of the St. George's Respiratory Questionnaire [SGRQ]), COPD Assessment Test [CAT] and EuroQol-5-Dimensions [EQ-5D], and further clinical characteristics were assessed in patients enrolled in the German COPD and Systemic Consequences-Comorbidities Network (COSYCONET) cohort study.

\section{MEASUREMENTS AND MAIN RESULTS}

2,088 patients with COPD (61.1\% male, mean [SD] age 65.3 [8.2] years, GOLD stage I, II, III, IV: $9.4 \%, 42.5 \%, 37.5 \%, 10.5 \%$, respectively) were included. Patients with PAD ( $n=184,8.8 \%$, GOLD stage I, II, III, IV: $5.1 \%, 7.4 \%, 11.1 \%, 9.5 \%)$ had a significantly different 6MWD (356 [108] vs 422 [103] m, $p<0.001)$, TUG test (median [interquartile-range]: $7.5[6.0-9.0]$ vs $6.5[5.4-8.0] \mathrm{s}, \mathrm{p}<0.001)$, SGRQ total score (49.7 [20.1] vs 42.7 [20.0] points, $p<0.001)$, CAT score (19.6 [7.4] vs 17.9 [7.4] points, $p=0.004)$, EQ-5D utility score $(0.79$ [0.2] vs 0.82 [0.2] points, $\mathrm{p}=0.020)$ and EQ-5D VAS (51.2 [19.0] vs 57.2 [19.6] points, $\mathrm{p} \leq 0.001)$. Differences remained significant after correction for several confounders.

\section{CONCLUSIONS}

In a large cohort of patients with COPD, 8.8\% were objectively diagnosed with PAD. PAD had a clinically relevant impact on functional capacity and health status. 


\section{INTRODUCTION}

Chronic obstructive pulmonary disease (COPD) is a highly prevalent chronic disease which is primarily characterized by progressive airflow limitation [1]. Beyond respiratory impairment, patients with COPD often suffer from coexisting diseases, the majority (up to $98 \%$ ) showing one or more comorbidities [2, 3]. Therefore, the interest in understanding COPD as a complex multisystem disease is increasing [4].

Because of their direct impact on survival [5-7], cardiovascular diseases are probably the most important coexisting diseases in COPD [1]. Peripheral artery disease (PAD) is an atherosclerotic process that refers to the occlusion of the arteries in the lower limbs [8]. PAD is a risk factor for further cardiovascular diseases and often described as a "silent killer" as a high number of persons with PAD are asymptomatic and unaware of the disorder [9]. Currently, there is no established indicator to simply and accurately assess cardiovascular risk in patients with COPD in routine clinical practice.

The ankle-brachial index (ABI) is the ratio of the systolic blood pressure measured at the ankle to that measured at the brachial artery [10]. The ABI is not only a common diagnostic measure for PAD but also an indicator of atherosclerosis at other vascular sites. This renders the $\mathrm{ABI}$ a good prognostic marker for cardiovascular events [10], even beyond traditional risk calculations like the Framingham risk score [11]. While an $A B I \leq 0.90$ should be considered the threshold for confirming $P A D$, subjects with an $A B I<1.0$ are considered borderline in terms of cardiovascular risk [10]. Accordingly, an $A B I<1.0$ has been demonstrated to be related to increased cardiovascular and all-cause mortality in the general population [12] and also in a small cohort of patients with COPD [13].

However, knowledge about the prevalence and impact of objectively assessed PAD in a large cohort of patients with COPD is scarce. Therefore, we aimed (1) to determine the prevalence of PAD in a large cohort of patients with COPD and patients with symptoms of chronic bronchitis with a similar risk profile in terms of smoking but without fixed airflow limitation and (2) to assess the impact of PAD on functional capacity as well as disease-specific and generic health status in a large cohort of patients with COPD. 


\section{METHODS}

The cohort comprises 2,741 patients who were enrolled in the German COPD and Systemic Consequences-Comorbidities Network (COSYCONET) cohort study which is a multicentre, longitudinal, prospective, observational study focussing on the interaction of lung disorder and comorbidities over time. Patients were recruited from September 2010 to December 2013 in 31 study centres throughout Germany and were eligible if they were $\geq 40$ years of age, had a diagnoses of COPD or symptoms of chronic bronchitis [14]. Patients with missing lung function data, unclassified patients, patients with alpha- 1 antitrypsin deficiency and patients with missing $A B I$ measurement were excluded from the current analyses resulting in 2425 patients. $13.9 \%$ of these patients $(n=337)$ had a post-bronchodilator ratio of $\mathrm{FEV}_{1} / \mathrm{FVC}>70 \%$ but (a) had a doctor diagnosis of chronic bronchitis and/or (b) reported $\geq 3$ points on the COPD Assessment Test (CAT) item regarding symptoms of cough and/or (c) reported $\geq 3$ points on the CAT item regarding symptoms of phlegm. These patients were classified as patients "at risk" for COPD or GOLD stage 0 according to former guidelines [15]. In some analyses, patients at GOLD stage 0 were excluded leading to an analysis population of 2088 patients.

Demographics and clinical characteristics were assessed at the participating study centre. Post-bronchodilator spirometry (45 min after administration of $400 \mu \mathrm{g}$ salbutamol and $80 \mu \mathrm{g}$ ipratropium bromide) was performed according to ATS/ERS recommendations using established reference values [16]. Transfer Factor of the Lung for Carbon Monoxide (TLCO) has been assessed twice by whole body plethysmography while the mean value of both measurements was used for analyses. Predicted values were calculated using previously published reference values [17]. Patients were classified according to the spirometric criteria of GOLD [18] and the GOLD group A to D criteria [1]. The CAT was used to classify patients into low symptom groups $A / C$ or high symptom groups $B / D$. Doctor-diagnosed comorbidities (e.g., hypertension, diabetes, disturbed peripheral blood flow; assessment by a structured interview), as well as the levels of high-sensitive C-reactive protein (hsCRP), cholesterol and triglycerides were assessed and included as possible risk factors for PAD in the current study.

\section{Peripheral artery disease}

PAD was objectively diagnosed using the $A B I$, which represents the ratio of ankle systolic pressure to brachial systolic pressure. Systolic pressures were measured by a sphygmomanometer (VASCassist, iSYMED GmbH, Butzbach, Germany) on the left and right side. The lowest $A B I$ value was selected for anal- 
yses. A cut-point of $A B I \leq 0.90$ was used to define $P A D$, values between 0.91 and 1.00 were considered as borderline PAD [10]. Furthermore, a cut-point of $\geq$ 1.40 , which has been defined as abnormally high and may indicate calcified arteries and arterial stiffness [10], was used. The current analysis focusses on the prevalence and impact of established $P A D$, defined as $A B I \leq 0.90$.

\section{Outcomes}

Functional capacity was assessed by the 6-Minute Walk Distance (6MWD) and Timed-Up-and-Go (TUG) test. The 6MWD was conducted according to previous guidelines [19]. The minimum important difference (MID) of the 6MWD is $30 \mathrm{~m}$ [20]. Predicted values were calculated using previously published reference values [21]. The TUG test, an established test in gerontology, has previously been described as a reliable measure also in COPD [22]. It uses the time (in seconds) needed to rise from a chair, walk three metres, turn, walk back and sit down again. Patients were instructed to walk on a quick but safe speed. The MID of the TUG test has not been established as a consensus yet but has been suggested to be about $2 \mathrm{~s}$ [22].

Disease-specific health status was assessed using the St. George's Respiratory Questionnaire (SGRQ) [23] and the CAT [24]. The SGRQ provides a symptom, activity and impact domain score and a total score, all ranging from 0 to 100 points. The MID of SGRQ is 4 points for each scale and the total score [25]. The CAT consists of eight items and provides a total score ranging from 0 to 40 . The MID of the CAT is 2 points [26]. Higher scores represent worse diseasespecific health status in both questionnaires.

Generic health status was assessed using the EuroQol-5-Dimensions (EQ-5D) instrument. It consists of five items (mobility, self-care, usual activity, pain/discomfort, and anxiety/depression) with three levels (no problems, some problems and extreme problems) and a visual analogue scale (VAS) for valuing health on a rating scale from 0 (worst imaginable health state) to 100 (best imaginable health state). Utility scores can be obtained from the five items by weighting the answers according to a weighting scheme. The German Time Trade Off (TTO) tariff was used to calculate utility scores ranging from 0 to 1 with higher values indicating better health [27]. The MCID of 8 points for the EQ5D VAS has been proposed for patients with moderate-to-severe COPD [28]. A MCID for the EQ-5D utility score is not yet established but may range between 0.08 and 0.10 according to studies in non-COPD patients [29-31]. 


\section{Statistics}

The current analysis is a cross-sectional analysis of the COSYCONET cohort study (visit 1). Data are presented as mean and standard deviation [SD] or median value and quartiles, depending on the distribution of the data. Characteristics were compared between patients with and without PAD using an Independent Sample T-Test or Mann-Whitney U-Test, as appropriate. Categorical variables were compared using single-proportion $\mathrm{x}^{2}$-tests. Logistic regression analyses were performed to detect the association between PAD $(A B I \leq 0.9)$ and age, gender, smoking status, TLCO \% predicted, GOLD stage, self-reported hypertension, self-reported diabetes, hsCRP and triglycerides. A further logistic model including patients with GOLD stage 0 has been performed. Possible confounders were identified by univariate analyses; i.e. outcomes which significantly differ between patients with and without PAD have been included in the multivariate model. General linear models were used to compare functional capacity (i.e., 6MWD and TUG test) between patients with and without PAD, correcting for possible confounders (age, gender, height, weight, TLCO \% predicted, GOLD stage, smoking status) and health status between patients with and without PAD, correcting for possible confounders (age, gender, TLCO \% predicted, GOLD stage and smoking status). Statistics were performed using SPSS 20.0 (SPSS Inc, Chicago, IL) and SAS 9.3 (SAS Institute Inc., Cary, NC). Figures were constructed using GraphPad Prism. Statistical significance was set at $p \leq 0.05$.

\section{RESULTS}

On average, COPD patients were 65 years old and had moderate to severe airflow limitation (Table 1). $8.3 \%, 29.8 \%, 4.7 \%$ and $57.2 \%$ of the patients were classified in GOLD group A, B, C, D, respectively. 
TABLE 1. Baseline Characteristics of COPD patients stratified by peripheral artery disease (PAD)

\begin{tabular}{|c|c|c|c|}
\hline & $\begin{array}{l}\text { Whole group } \\
(n=2088)\end{array}$ & $\begin{array}{l}\text { Patients with PAD } \\
\qquad(A B I \leq 0.9) \\
(n=184)\end{array}$ & $\begin{array}{c}\text { Patients without } \\
\text { PAD }(A B \mid>0.9) \\
(n=1904)\end{array}$ \\
\hline Age, years & $65.3(8.2)$ & $68.5(7.0)^{\star}$ & $65.0(8.2)$ \\
\hline Male, n (\%) & $1276(61.1)$ & $131(71.2)^{\star}$ & $1145(60.1)$ \\
\hline \multicolumn{4}{|l|}{ Smoking status ${ }^{a}$} \\
\hline Never smoker, n (\%) & $114(5.5)$ & $4(2.2)^{\star}$ & $110(5.8)$ \\
\hline Current smoker, n (\%) & $550(26.3)$ & $64(34.8)^{\star}$ & $486(25.5)$ \\
\hline Former smoker, $\mathrm{n}(\%)$ & $1424(68.2)$ & $116(63.0)$ & $1308(68.7)$ \\
\hline \multicolumn{4}{|l|}{$\mathrm{BMI}, \mathrm{kg} / \mathrm{m}^{2 \mathrm{~b}}$} \\
\hline$<18.5$ & $74(3.5)$ & $8(4.3)$ & $66(3.5)$ \\
\hline $18.5-25.0$ & $758(36.3)$ & $68(37.0)$ & $690(36.3)$ \\
\hline $25.0-30.0$ & $772(37.0)$ & $69(37.5)$ & 703 (36.9) \\
\hline$>30.0$ & $483(23.1)$ & $39(21.2)$ & $444(23.3)$ \\
\hline $\mathrm{FEV}_{1}$, liter ${ }^{\ddagger}$ & $1.4(1.1-1.9)$ & $1.3(1.0-1.7)^{\star}$ & $1.5(1.1-2.0)$ \\
\hline $\mathrm{FEV}_{1}, \%$ predicted & $52.9(18.7)$ & $48.4(17.5)^{\star}$ & $53.4(18.8)$ \\
\hline $\mathrm{FEV}_{1} / \mathrm{FVC}, \%^{\ddagger}$ & $52.2(43.4-60.9)$ & $49.6(41.9-60.4)$ & $52.3(43.4-60.9)$ \\
\hline $\operatorname{TLCO}^{\mathrm{c}}$ & $4.5(1.9)$ & $4.0(1.9)^{\star}$ & $4.6(1.9)$ \\
\hline TLCO, \% predicted ${ }^{c}$ & $52.9(20.8)$ & $47.5(20.2)^{\star}$ & $53.5(20.8)$ \\
\hline \multicolumn{4}{|l|}{ GOLD stage } \\
\hline 1 & $197(9.4)$ & $10(5.4)$ & $187(9.8)$ \\
\hline II & $887(42.5)$ & $66(35.9)$ & $821(43.1)$ \\
\hline III & $784(37.5)$ & $87(47.3)^{\star}$ & $697(36.6)$ \\
\hline IV & $220(10.5)$ & $21(11.7)$ & $199(10.5)$ \\
\hline \multicolumn{4}{|l|}{ mMRC dyspnea score (\%) ${ }^{d}$} \\
\hline 0 & $168(8.1)$ & $11(6.0)$ & $157(8.3)$ \\
\hline 1 & $911(44.1)$ & $62(33.9)^{*}$ & $849(45.0)$ \\
\hline 2 & $589(28.5)$ & $50(27.3)$ & $539(28.6)$ \\
\hline 3 & $377(18.1)$ & $53(29.0)^{\star}$ & $324(17.2)$ \\
\hline 4 & $23(1.1)$ & $7(3.8)^{\star}$ & $16(0.8)$ \\
\hline $\mathrm{ABI}^{\ddagger}$ & $1.2(1.1-1.2)$ & $0.8(0.7-0.9)^{\star}$ & $1.2(1.1-1.2)$ \\
\hline hsCRP mg/L Le $^{\ddagger}$ & $4.5(2.0-7.3)$ & $5.0(2.2-9.1)^{\star}$ & $4.3(2.0-7.1)$ \\
\hline Triglyceride, $\mathrm{mg} / \mathrm{dL}^{\ddagger f}$ & $115.0(84.0-168.9)$ & $125.0(93.6-183.8)^{\star}$ & $114.0(83.0-167.6)$ \\
\hline Cholesterol, mg/dL ${ }^{g}$ & $216.2(44.0)$ & $211.2(44.7)$ & $216.6(43.9)$ \\
\hline Self-reported hypertension, n (\%) & $1171(56.1)$ & $131(71.2)^{\star}$ & $1040(54.6)$ \\
\hline Self-reported diabetes ${ }^{b}$ & $276(13.2)$ & $38(20.7)$ & $238(12.5)$ \\
\hline
\end{tabular}

${ }^{\ddagger}=$ non-parametric tests were used due to skewed data; values expressed as median (IQR).

* $\mathrm{p} \leq 0.05$ compared to patients without PAD.

Abbreviations: $\mathrm{BMI}$, body mass index; $\mathrm{FEV}_{1}$, forced expiratory volume in the first second; $\mathrm{FVC}$, forced vital capacity; TLCO, Transfer Factor of the Lung for Carbon Monoxide; mMRC, modified Medical Research Council scale; $\mathrm{ABI}$, ankle-brachial index; hsCRP, high-sensitive C-reactive protein. 


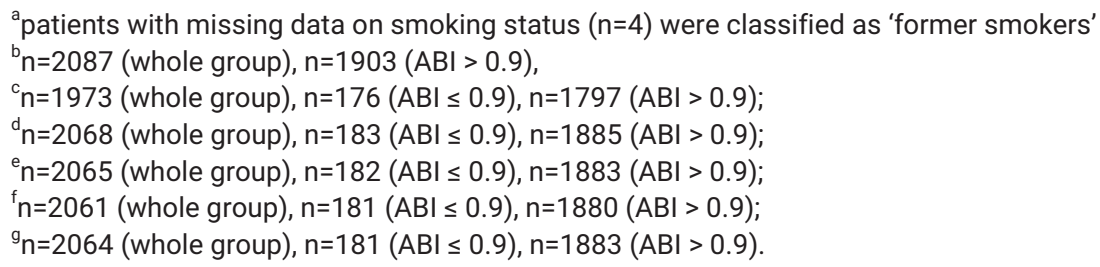

\section{Prevalence of PAD}

PAD $(A B I \leq 0.9)$ was detected in $8.8 \%$ of the patients with COPD $(n=184)$. Of these, $65.8 \%$ did not report PAD in their medical history. 184 patients with COPD (8.8\%) were diagnosed with borderline PAD, of which $76.6 \%$ had no PAD in their self-reported medical history. 46 patients with COPD (2.2\%) had an abnormally high $A B I$ of which $91.3 \%$ did not report PAD in their medical history.

PAD was detected in $5.9 \%$ of the patients with GOLD stage $0(n=20)$. Of these, $55.0 \%$ did not report PAD in their medical history. 21 patients with GOLD stage 0 (6.2\%) were diagnosed with borderline PAD, of which $61.9 \%$ had no PAD in their self-reported medical history. 11 patients (3.3\%) had an abnormally high $A B I$ of which $90.9 \%$ did not report PAD in their medical history.

The frequency distribution of $A B I$ values stratified by GOLD 0, GOLD stages and GOLD groups is shown in Figure E1 in the online data supplement. Figure 1 shows the prevalence of PAD, borderline PAD and abnormally high PAD stratified by GOLD 0 and GOLD stages I-IV and GOLD groups A-D. The proportion of patients with PAD differs between GOLD stages (GOLD 0/I/II/III/IV: $5.9 \% / 5.1 \% / 7.4 \% / 11.1 \% / 9.6 \%, p=0.006$ ) and GOLD groups (GOLD 0/A/B/C/D: $5.9 \% / 5.2 \% / 7.1 \% / 7.1 \% / 10.3 \%, p=0.015)$. There were significant differences in proportion of patients with borderline PAD between the GOLD stages (GOLD 0/I/II/III/IV: $6.2 \% / 7.6 \% / 7.0 \% / 11.0 \% / 9.6 \%, p=0.021)$ and GOLD groups (GOLD 0/A/B/C/D: $5.9 \% / 8.7 \% / 6.8 \% / 14.3 \% / 9.1 \%, p=0.040$ ). The proportion of patients with an abnormally high ABI did not significantly depend on GOLD stages (GOLD 0/I/II/III/IV: $3.3 \% / 4.1 \% / 2.3 \% / 1.5 \% / 2.7 \%, p=0.184$ ) and GOLD groups (GOLD O/A/B/C/D: $3.3 \% / 3.5 \% / 2.6 \% / 2.0 \% / 1.9 \%, p=0.457)$. 

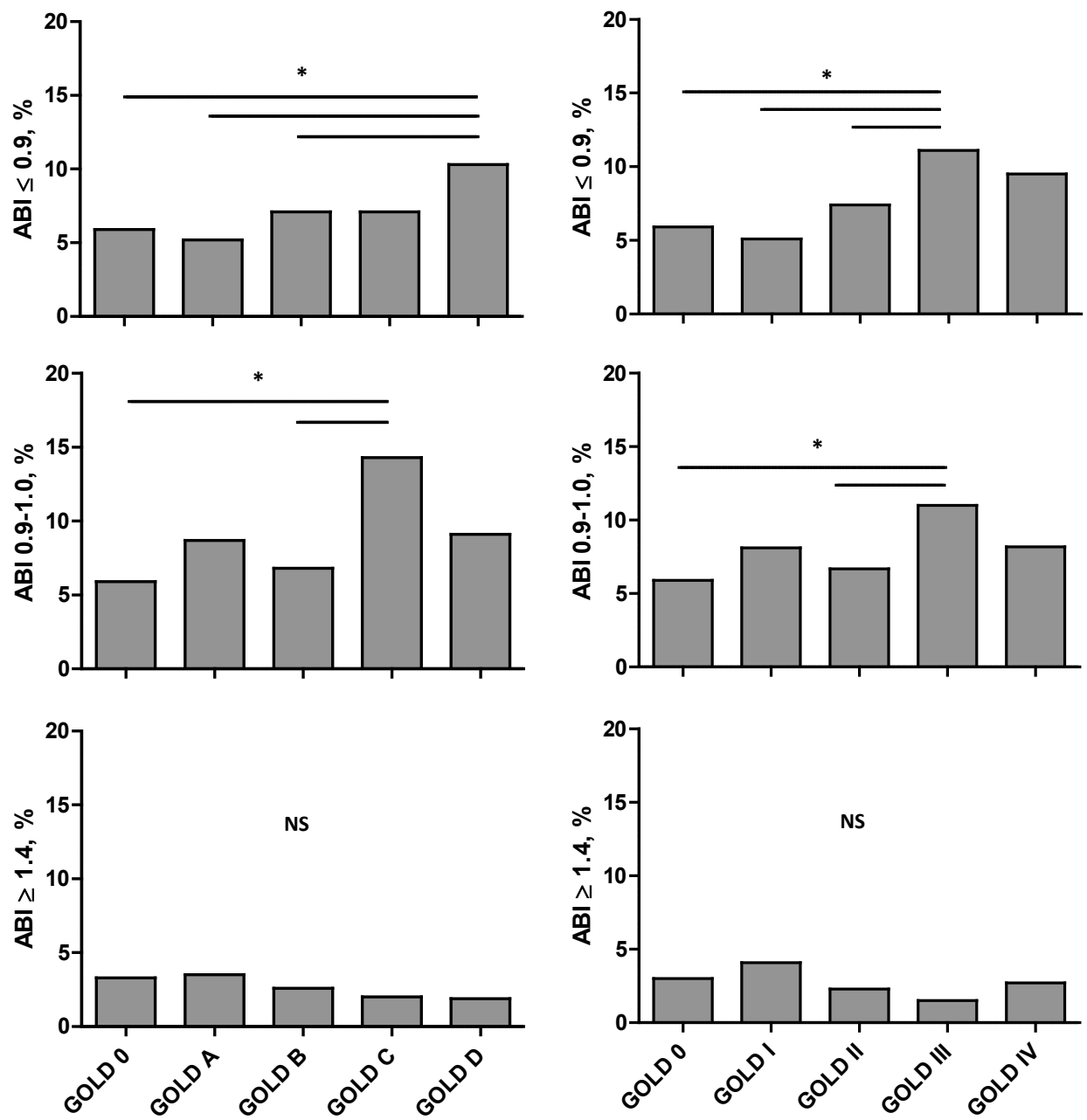

FIGURE 1. Prevalence of peripheral artery disease (PAD), borderline PAD and an abnormally high ankle-brachial index (ABI) stratified by GOLD stages and GOLD groups

In patients with COPD, PAD was independently associated with older age, current smoking status, worse diffusion capacity, self-reported hypertension and self-reported diabetes (Table 2). Independent predictors remained comparable when patients with GOLD stage 0 were included (see Table E1 in the online data supplement). 
TABLE 2. Independent predictors of peripheral artery disease in patients with COPD GOLD stage I-IV

\begin{tabular}{lllll}
\hline Covariates & Exp (B) & \multicolumn{2}{c}{$95 \% \mathrm{Cl}$ for HR } & p-value \\
& & Lower & Upper & \\
\hline Age & 1.070 & 1.046 & 1.095 & $<0.001$ \\
Gender (male) & 1.385 & 0.957 & 2.004 & 0.084 \\
Smoking status & & & & \\
Smoking status (current smoker) & 6.200 & 1.843 & 20.859 & 0.003 \\
Smoking status (former smoker) & 2.859 & 0.872 & 9.369 & 0.083 \\
GOLD & & & & \\
II & 1.151 & 0.566 & 2.339 & 0.698 \\
III & 1.664 & 0.801 & 3.459 & 0.172 \\
IV & 1.593 & 0.639 & 3.972 & 0.318 \\
TLCO predicted & 0.987 & 0.977 & 0.997 & 0.009 \\
hsCRP & 1.001 & 0.996 & 1.006 & 0.650 \\
Triglycerides & 1.001 & 1.000 & 1.002 & 0.127 \\
Self-reported hypertension & 1.661 & 1.163 & 2.372 & 0.005 \\
Self-reported diabetes & 1.599 & 1.059 & 2.416 & 0.026 \\
\hline
\end{tabular}

Logistic regression - dependent variable $A B I \leq 0.90(n=184$ with $A B I \leq 0.90)$.

Abbreviations: see table 1.

\section{Relation to outcome measures}

Patients with COPD and comorbid PAD were older and had worse lung function compared to those without PAD. Furthermore, a higher proportion of patients with PAD was male, current smokers and classified as GOLD III patients (Table 1). Descriptive characteristics for patients with GOLD stage 0 stratified by PAD are shown in Table E2 in the online data supplement.

Patients with PAD had a worse functional capacity as assessed with 6MWD (356 [108] vs 422 [103] $\mathrm{m}, \mathrm{p}<0.001$ ), and needed more time to complete the TUG test (median [interquartile-range]: 7.5 [6.0-9.0] vs 6.5 [5.4-8.0] s, $p<0.001) \mathrm{com}$ pared to those without PAD (Figure 2a, Table 3). Accordingly, 6MWD in terms percent-of-predicted was lower in patients with PAD compared to those without PAD (56.8 (17.0) \% predicted vs. 66.3 (16.1) \% predicted; $p<0.001)$. The differences in functional capacity measures remained significant after correction for possible confounders (Table 3 ). 


\section{CHAPTER 7}

TABLE 3. Difference in functional capacity between COPD patients with peripheral artery disease and without peripheral artery (PAD)

\begin{tabular}{lcccccc}
\hline $\begin{array}{l}\text { Dependent } \\
\text { variable }\end{array}$ & Total group & $\begin{array}{c}\mathrm{ABI} \leq 0.9 \\
\mathrm{n}=184\end{array}$ & $\begin{array}{c}\mathrm{ABI}>0.9 \\
\mathrm{~N}=1904\end{array}$ & $\begin{array}{c}\text { Unadjusted } \\
\text { p-value }\end{array}$ & $\begin{array}{c}\text { Adjusted mean } \\
\text { difference } \\
(95 \% \mathrm{Cl})\end{array}$ & $\begin{array}{c}\text { Adjusted } \\
\text { p-value }\end{array}$ \\
\hline 6MWD, meters $^{\mathrm{a}}$ & $417(106)$ & $356(108)$ & $422(103)$ & $<0.001$ & $-43.9(-57.4$ to -30.5$)$ & $<0.001$ \\
TUG, seconds $^{\mathrm{b}}$ & $6.6(5.5-8.0)$ & $7.5(6.0-9.0)$ & $6.5(5.4-8.0)$ & $<0.001$ & $0.7(0.3$ to 1.0$)$ & $<0.001$ \\
\hline
\end{tabular}

Values expressed as mean (SD) or median (IQR). 6MWD, 6-minute-walk-distance; TUG, Timed-Upand-Go Test.

Unadjusted $\mathrm{p}$-value based on independent sample t-test or Mann-Whitney $\mathrm{U}$ test, as appropriate; adjusted $p$-value based on linear regression after correction for age, gender, height, weight, TLCO \% predicted, GOLD stage and smoking status

(Method: Enter)

${ }^{a} n=2028$ (whole group), $n=178(A B I \leq 0.9), n=1850(A B \mid>0.9)$,

${ }^{b} n=2041$ (whole group), $n=180(A B I \leq 0.9), n=1861(A B I>0.9)$.

Furthermore, patients with PAD showed a worse disease-specific health status as assessed with SGRQ domain scores and total score, with most pronounced differences in SGRQ activity (67.4 [22.9] vs 56.9 [25.9] points, $p<0.001)$ and total score (49.7 [20.1] vs 42.7 [20.0] points, $p<0.001$ ) (Figure $2 b$, Table 4).

a

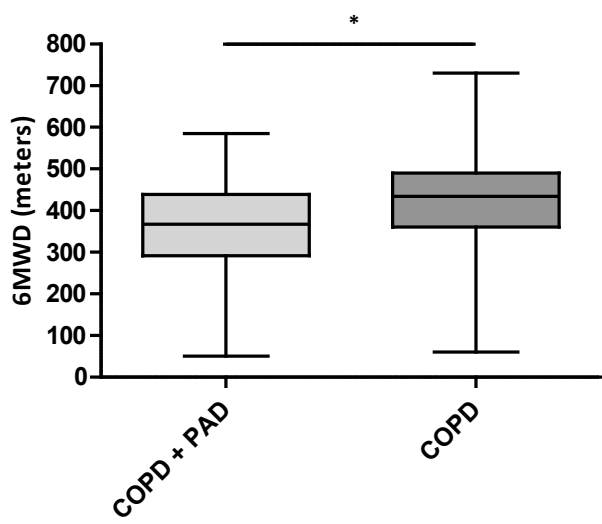

b

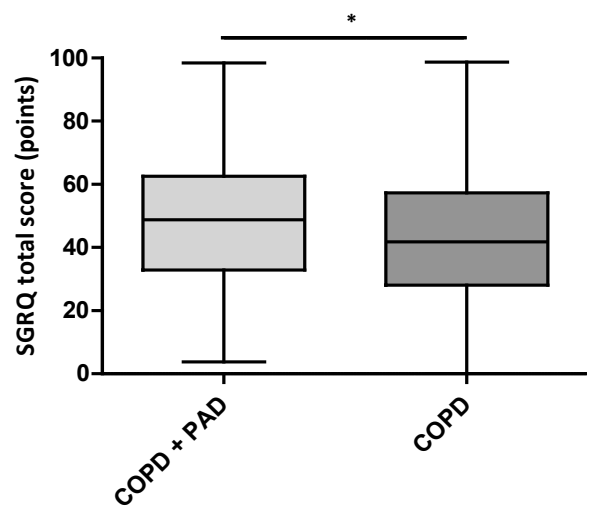

FIGURE 2. (a) 6-Minute-Walk-Distance (6MWD) and (b) St. George's Respiratory Questionnaire (SGRQ) stratified by patients with and without peripheral artery disease (PAD) * $p<0.05)$

Similarly, the CAT score was significantly higher in patients with PAD (19.6 [7.4] vs 17.9 [7.4] points, $p=0.004$ ). In addition, generic health status was more impaired in patients with PAD (e.g., EQ-5D VAS (51.2 [19.0] vs 57.1 [19.6] points, $\mathrm{p} \leq 0.001)$. Specifically, a higher proportion of patients with PAD reported more 'some problems' or 'severe problems' of mobility ( $55.4 \%$ vs $38.7 \%, p<0.001)$, self-care $(22.3 \%$ vs $14.4 \% \mathrm{p}=0.004)$ and usual activity $(58.7 \%$ vs $50.3 \%, \mathrm{p}=0.03)$ 
compared to those without PAD. The differences in disease-specific and generic health status scores remained significant after correction for possible confounders, except for SGRQ symptom score (Table 4).

TABLE 4. Difference in health status between COPD patients with peripheral artery disease and without peripheral artery (PAD)

\begin{tabular}{|c|c|c|c|c|c|c|}
\hline Dependent variable & Total group & $\begin{array}{c}\mathrm{ABI} \leq 0.9 \\
\mathrm{n}=184\end{array}$ & $\begin{array}{l}\mathrm{ABI}>0.9 \\
\mathrm{~N}=1904\end{array}$ & $\begin{array}{c}\text { Unadjuste } \\
\text { p-value }\end{array}$ & $\begin{array}{l}\text { Unstandardized } \\
\text { Coefficient B } \\
(95 \% \mathrm{Cl})\end{array}$ & $\begin{array}{l}\text { Adjusted } \\
\text { p-value }\end{array}$ \\
\hline SGRQ total score, points ${ }^{a}$ & $43.3(20.1)$ & $49.7(20.1)$ & $42.7(20.0)$ & $<0.001$ & $\begin{array}{c}5.39 \\
(2.54 \text { to } 8.25)\end{array}$ & $<0.001$ \\
\hline $\begin{array}{l}\text { SGRQ symptom score, } \\
\text { points }\end{array}$ & $55.7(21.3)$ & $59.1(20.4)$ & $55.4(21.3)$ & 0.025 & $\begin{array}{c}2.57 \\
(-0.67 \text { to } 5.81)\end{array}$ & 0.133 \\
\hline $\begin{array}{l}\text { SGRQ activity score, } \\
\text { points }{ }^{a}\end{array}$ & $57.9(25.8)$ & $67.4(22.8)$ & $57.0(25.9)$ & $<0.001$ & $\begin{array}{c}7.68 \\
\text { (4.19 to } 11.16)\end{array}$ & $<0.001$ \\
\hline $\begin{array}{l}\text { SGRQ impact score, } \\
\text { points a }\end{array}$ & $30.5(21.0)$ & $36.1(22.6)$ & $29.9(20.8)$ & $<0.001$ & $\begin{array}{c}4.99 \\
(1.91 \text { to } 8.07)\end{array}$ & 0.001 \\
\hline CAT total score, points ${ }^{b}$ & $18.1(7.4)$ & $19.6(7.4)$ & $17.9(7.4)$ & 0.004 & $\begin{array}{c}1.54 \\
(0.43 \text { to } 2.65)\end{array}$ & 0.007 \\
\hline $\begin{array}{l}\text { EQ-5D utility score, points } \\
c\end{array}$ & $0.82(0.2)$ & $0.79(0.2)$ & $0.82(0.2)$ & 0.020 & $\begin{array}{c}-0.04 \\
(-0.07 \text { to }-0.01)\end{array}$ & 0.015 \\
\hline EQ-5D VAS, points ${ }^{d}$ & $56.6(19.6)$ & $51.2(19.0)$ & $57.2(19.6)$ & $<0.001$ & $\begin{array}{c}-4.45 \\
(-7.35 \text { to }-1.55)\end{array}$ & 0.003 \\
\hline
\end{tabular}

Values expressed as mean (SD). CAT, COPD Assessment Test; SGRQ, St. George's Respiratory Questionnaire.

Unadjusted $\mathrm{p}$-value based on independent sample t-test; adjusted $\mathrm{p}$-value based on general linear model after correction for age, gender, TLCO \% predicted, GOLD stage and smoking status

${ }^{a} n=2070$ (whole group), $n=183(A B I \leq 0.9), n=1887(A B I>0.9)$,

${ }^{b} \mathrm{n}=2075$ (whole group), $\mathrm{n}=182(\mathrm{ABI} \leq 0.9), \mathrm{n}=1893(\mathrm{ABI}>0.9)$;

${ }^{c} n=2075$ (whole group), $n=184(A B \mid<0.9), n=1891(A B I>0.9)$

${ }^{d} n=2065$ (whole group), $n=184(A B \mid<0.9), n=1881(A B I>0.9)$

\section{DISCUSSION}

In a large cohort of patients with COPD of all degrees of severity, $8.8 \%$ were objectively diagnosed with PAD and $8.8 \%$ with borderline PAD resulting in a total prevalence of $17.6 \%$ of patients being at risk for cardiovascular morbidity and impaired prognosis. Of note, more than two third of these patients did not report PAD in their medical history which required a doctors diagnosis prior to inclusion. Patients affected by comorbid PAD showed a worse functional capacity and worse health status compared to those without PAD. 


\section{Prevalence}

The currently available studies regarding the prevalence of PAD in patients with COPD are rather limited and do not allow using robust models to properly correct for potential confounders and consequently draw firm conclusions. In a Taiwanese cohort of 427 patients with COPD, 8\% of the patients have been identified with asymptomatic PAD [32]. While the severity stages of COPD in this Taiwanese cohort were comparable to those in our cohort, the generalizability of these data is difficult as almost exclusively male patients (98\%) were enrolled in this single-centre study. Other reported frequencies of an $A B I<0.9$ in COPD have been derived from smaller single-centre studies and range up to $37 \%$ [33-35]. The highest prevalence of $37 \%$ was found in patients hospitalized for an acute exacerbation of COPD [35]. Interestingly, the prevalence of PAD in our study was comparable between subjects with non-fixed airflow obstruction (GOLD stage 0) and patients with established mild to moderate COPD which may suggest a predominant role of respiratory symptoms or a shared risk profile in terms of smoking in the development of PAD. Indeed, Bloemenkamp and colleagues identified chronic bronchitis as an independent risk factor for PAD in a cohort of 212 middle-aged women with PAD [36].

Owing to its size, the current study provided enough power to study multiple relationships. PAD was associated with older age, current smoking status, worse diffusion capacity, self-reported hypertension and self-reported diabetes. Our results are in line with a previous report that identified older age, hypertension and packyears as risk factors for asymptomatic PAD in COPD [32]. Furthermore, diabetes has been identified as major risk factor for cardiovascular events, including PAD [37]. Previous findings indicated a higher prevalence of PAD in more severe patients $[33,38]$ which is supported by our univariate analyses. In a multivariate regression model however, diffusion capacity remained an independent predictor of PAD while GOLD stages III and IV had odds ratios of 1.7 and 1.6, respectively, without statistical significance. This study is the first showing a relationship with peripheral artery disease and diffusion capacity as a measure for emphysema severity in patients with COPD. Previously, coronary artery calcification severity has been shown to be associated with emphysema severity [39] demonstrating an association between a atherosclerotic process and diffusion capacity. In the current study, smoking status was the strongest independent predictor of PAD. This is in line with the finding that smoking is an important shared risk factor for both COPD and cardiovascular morbidity, e.g. atherosclerosis [4]. Current smokers showed the strongest association with PAD indicating a dose-response relationship, in accordance with a systematic review on the effect of smoking regarding PAD in non-COPD popula- 
tions [40]. However, there is evidence that patients with COPD may develop subclinical atherosclerosis, independent of cigarette smoking $[41,42]$.

\section{Functional capacity}

The 6MWD is assumed to evaluate the integrated responses of all systems involved during exercise, including peripheral circulation [19]. Our study clearly demonstrates an association between objectively assessed PAD and functional capacity as quantified with 6MWD in COPD. Previously, the 6MWD has been found to be positively correlated with the $A B I(r=0.78 ; p=0.05)$ in 151 COPD patients with GOLD stages II and III [38]. Recently, Sun et al. studied the impact of PAD in 200 patients with COPD but did not demonstrate a statistical significant difference in 6MWD between patients without PAD and those with PAD (439 [86] $\mathrm{m}$ vs 408 [74] $m, P=0.159$ ) [43]. However, the magnitude of the impact of PAD on $6 \mathrm{MWD}$ in a large cohort of patients has not been studied before. In our cohort, a reduction in 6MWD in patients with PAD compared to those without PAD, adjusted for confounders, exceeds the minimal clinically important difference compared to those without PAD. The differences in TUG test were less pronounced than those in 6MWD which might be explained by the shorter duration and lower intensity of the test. Our observation might be of relevance for interventional studies using 6MWD as an outcome to demonstrate changes after the intervention. It might be reasonable to speculate that the magnitude of response to a pulmonary intervention (e.g. pulmonary rehabilitation) might be clearly affected by the presence of PAD. However, as exercise-based rehabilitative interventions have positive effects on exercise performance and exercise-induced pain in patients with claudication intermittens [44], pulmonary rehabilitation in COPD patients with PAD may still be beneficial. Indeed, exercise training can improve both arterial stiffness in patients with COPD [45] and health status and perceived walking distance in patients with PAD [46].

\section{Health status}

Recently, the COMorbidities in Chronic Obstructive Lung Disease (COMCOLD) index has been developed which include PAD as one of the five most important comorbidities affecting patients' health status as measured by the VAS [47]. The current study confirms these findings as it demonstrates an impact of PAD on disease-specific health status which is of clinically relevant magnitude.

Previous COPD studies primarily assessed the role of self-reported comorbidities or comorbidities retrieved from medical records. For instance, Putcha and colleagues recently studied the impact of several comorbidities taken from the medical records of almost 3700 patients with COPD GOLD II-IV on clinical outcomes. They did neither detect a statistically significant nor a clinically relevant 
difference between patients with and without PAD, regarding the diseasespecific health status as assessed with SGRQ [48]. The current study is the first evaluating the relationship between objectively assessed PAD and diseasespecific as well as generic health status in patients with COPD. Since worse health status has been shown to be associated with diminished physical functioning $[49,50]$, it is not unexpected that the impairment in health status corresponded to the functional impairment in our cohort. Indeed, impairments in health status were most pronounced in the SGRQ activity domain. However, the difference in all other domains also clearly exceeds the minimum clinically relevant difference of 4 points. It seems to be a general finding that subjects with PAD report an impaired generic health status; this has been demonstrated using the Medical Outcomes Study 36-Item Short-Form Health Survey [51]. Although differences in generic health status as measured by EQ-5D were statistically significant in the current study, their clinical relevance might be disputable. Their lower sensitivity in the population studies is in line with reports that diseasespecific questionnaires might be more sensitive in patients with COPD [52].

\section{Limitations}

Although the COSYCONET cohort study is a multicenter, longitudinal, prospective study that included a large number of patients throughout Germany, there are limitations that must be taken into account. First, the study did not employ the Doppler method to detect PAD which might have led to an underestimation of PAD. Second, although study centers have gained extensive experience in all procedures and developed internal structures that are needed for follow-up visits and continuous engagement in the study, there might be some differences between centers. However, all centers used the same device and assessed all measurements according to standard operation procedures.

\section{CONCLUSIONS}

In a large cohort of patients with COPD, 8.8\% were diagnosed with PAD and $8.8 \%$ with borderline PAD. Patients with PAD showed a worse functional capacity and disease-specific health status compared to those without PAD, and these differences were of clinically relevant magnitude. Our study demonstrates that the presence of PAD has a clear-cut, clinically relevant impact on clinical outcome measures that are established for monitoring patients with COPD. Early identification (e.g., $A B I$ measurement) and treatment of comorbid PAD in patients with COPD may mitigate this burden. Further studies are needed to evaluate the impact of concomitant PAD on the response to interventions and also prognosis. 


\section{REFERENCES}

1. Vestbo J, Hurd SS, Agusti AG, Jones PW, Vogelmeier C, Anzueto A, Barnes PJ, Fabbri LM, Martinez FJ, Nishimura M, et al: Global strategy for the diagnosis, management, and prevention of chronic obstructive pulmonary disease: GOLD executive summary. Am J Respir Crit Care Med 2013, 187:347-365.

2. Vanfleteren LE, Spruit MA, Groenen M, Gaffron S, van Empel VP, Bruijnzeel PL, Rutten EP, Op 't Roodt J, Wouters EF, Franssen FM: Clusters of comorbidities based on validated objective measurements and systemic inflammation in patients with chronic obstructive pulmonary disease. Am J Respir Crit Care Med 2013, 187:728-735.

3. Schnell K, Weiss CO, Lee T, Krishnan JA, Leff B, Wolff JL, Boyd C: The prevalence of clinicallyrelevant comorbid conditions in patients with physician-diagnosed COPD: a cross-sectional study using data from NHANES 1999-2008. BMC Pulm Med 2012, 12:26.

4. Barnes PJ, Celli BR: Systemic manifestations and comorbidities of COPD. Eur Respir J 2009, 33:1165-1185.

5. Mullerova H, Agusti A, Erqou S, Mapel DW: Cardiovascular comorbidity in COPD: systematic literature review. Chest 2013, 144:1163-1178.

6. Macchia A, Rodriguez Moncalvo JJ, Kleinert M, Comignani PD, Gimeno G, Arakaki D, Laffaye N, Fuselli JJ, Massolin HP, Gambarte J, et al: Unrecognised ventricular dysfunction in COPD. Eur Respir J 2012, 39:51-58.

7. Sibila O, Mortensen EM, Anzueto A, Laserna E, Restrepo MI: Prior cardiovascular disease increases long-term mortality in COPD patients with pneumonia. Eur Respir J 2014, 43:36-42.

8. Gillum RF: Peripheral arterial occlusive disease of the extremities in the United States: hospitalization and mortality. Am Heart J 1990, 120:1414-1418.

9. Dhaliwal G, Mukherjee D: Peripheral arterial disease: Epidemiology, natural history, diagnosis and treatment. Int J Angio/2007, 16:36-44.

10. Aboyans V, Criqui MH, Abraham P, Allison MA, Creager MA, Diehm C, Fowkes FG, Hiatt WR, Jonsson B, Lacroix $\mathrm{P}$, et al: Measurement and interpretation of the ankle-brachial index: a scientific statement from the American Heart Association. Circulation 2012, 126:2890-2909.

11. Fowkes FG, Murray GD, Butcher I, Heald CL, Lee RJ, Chambless LE, Folsom AR, Hirsch AT, Dramaix $\mathrm{M}$, deBacker $\mathrm{G}$, et al: Ankle brachial index combined with Framingham Risk Score to predict cardiovascular events and mortality: a meta-analysis. JAMA 2008, 300:197-208.

12. O'Hare AM, Katz R, Shlipak MG, Cushman M, Newman AB: Mortality and cardiovascular risk across the ankle-arm index spectrum: results from the Cardiovascular Health Study. Circulation 2006, 113:388-393.

13. Waschki B, Kirsten A, Holz O, Muller KC, Meyer T, Watz H, Magnussen $\mathrm{H}$ : Physical activity is the strongest predictor of all-cause mortality in patients with COPD: a prospective cohort study. Chest 2011, 140:331-342.

14. Jorres RA, Welte T, Bals R, Koch A, Schnoor M, Vogelmeier C: [Systemic manifestations and comorbidities in patients with chronic obstructive pulmonary disease (COPD) and their effect on clinical state and course of the disease--an overview of the cohort study COSYCONET]. Dtsch Med Wochenschr 2010, 135:446-449.

15. Thirapatarapong W, Armstrong HF, Bartels MN: Comparison of cardiopulmonary exercise testing variables in COPD patients with and without coronary artery disease. Heart Lung 2014, 43:146-151.

16. Quanjer PH, Stanojevic S, Cole TJ, Baur X, Hall GL, Culver BH, Enright PL, Hankinson JL, Ip MS, Zheng J, Stocks J: Multi-ethnic reference values for spirometry for the 3-95-yr age range: the global lung function 2012 equations. Eur Respir J 2012, 40:1324-1343.

17. Cotes JE, Chinn DJ, Quanjer PH, Roca J, Yernault JC: Standardization of the measurement of transfer factor (diffusing capacity). Eur Respir J1993, 6 Suppl 16:41-52. 
18. Rabe KF, Hurd S, Anzueto A, Barnes PJ, Buist SA, Calverley P, Fukuchi Y, Jenkins C, RodriguezRoisin R, van Weel C, Zielinski J: Global strategy for the diagnosis, management, and prevention of chronic obstructive pulmonary disease: GOLD executive summary. Am J Respir Crit Care Med 2007, 176:532-555.

19. ATS statement: guidelines for the six-minute walk test. Am J Respir Crit Care Med 2002, 166:111-117.

20. Black-Shinn JL, Kinney GL, Wise AL, Regan EA, Make B, Krantz MJ, Barr RG, Murphy JR, Lynch D, Silverman EK, et al: Cardiovascular Disease is Associated with COPD Severity and Reduced Functional Status and Quality of Life. COPD 2014, 11:546-51.

21. Troosters $T$, Gosselink R, Decramer M: Six minute walking distance in healthy elderly subjects. Eur Respir J1999, 14:270-274.

22. Mesquita R, Janssen DJ, Wouters EF, Schols JM, Pitta F, Spruit MA: Within-day test-retest reliability of the Timed Up \& Go test in patients with advanced chronic organ failure. Arch Phys Med Rehabil 2013, 94:2131-2138.

23. Jones PW, Quirk FH, Baveystock CM, Littlejohns P: A self-complete measure of health status for chronic airflow limitation. The St. George's Respiratory Questionnaire. Am Rev Respir Dis 1992, 145:1321-1327.

24. Jones PW, Harding G, Berry P, Wiklund I, Chen WH, Kline Leidy N: Development and first validation of the COPD Assessment Test. Eur Respir J 2009, 34:648-654.

25. Jones PW: St. George's Respiratory Questionnaire: MCID. COPD 2005, 2:75-79.

26. Kon SS, Canavan JL, Jones SE, Nolan CM, Clark AL, Dickson MJ, Haselden BM, Polkey MI, Man WD: Minimum clinically important difference for the COPD Assessment Test: a prospective analysis. Lancet Respir Med 2014, 2:195-203.

27. Greiner W, Claes C, Busschbach JJ, von der Schulenburg JM: Validating the EQ-5D with time trade off for the German population. Eur J Health Econ 2005, 6:124-130.

28. Zanini A, Aiello M, Adamo D, Casale S, Cherubino F, Della Patrona S, Raimondi E, Zampogna E, Chetta A, Spanevello A: Estimation of minimal clinically important difference in EQ-5D visual analog scale score after pulmonary rehabilitation in subjects with COPD. Respir Care 2015, 60:88-95.

29. Kim SK, Kim SH, Jo MW, Lee SI: Estimation of minimally important differences in the EQ-5D and SF-6D indices and their utility in stroke. Health Qual Life Outcomes 2015, 13:227.

30. Kwakkenbos L, Fransen J, Vonk MC, Becker ES, Jeurissen M, van den Hoogen FH, van den Ende $\mathrm{CH}$ : A comparison of the measurement properties and estimation of minimal important differences of the EQ-5D and SF-6D utility measures in patients with systemic sclerosis. Clin Exp Rheumato/2013, 31:50-56.

31. Pickard AS, Neary MP, Cella D: Estimation of minimally important differences in EQ-5D utility and VAS scores in cancer. Health Qual Life Outcomes 2007, 5:70.

32. Lin MS, Hsu KY, Chen YJ, Chen CR, Chen CM, Chen W: Prevalence and risk factors of asymptomatic peripheral arterial disease in patients with COPD in Taiwan. PLoS One 2013, 8:e64714.

33. Watz $\mathrm{H}$, Waschki B, Boehme C, Claussen M, Meyer T, Magnussen H: Extrapulmonary effects of chronic obstructive pulmonary disease on physical activity: a cross-sectional study. $A m \mathrm{~J}$ Respir Crit Care Med 2008, 177:743-751.

34. Blum A, Simsolo C, Sirchan R, Haiek S: "Obesity paradox" in chronic obstructive pulmonary disease. Isr Med Assoc J2011, 13:672-675.

35. Pecci R, De La Fuente Aguado J, Sanjurjo Rivo AB, Sanchez Conde P, Corbacho Abelaira M: Peripheral arterial disease in patients with chronic obstructive pulmonary disease. Int Angiol 2012, 31:444-453.

36. Bloemenkamp DG, van den Bosch MA, Mali WP, Tanis BC, Rosendaal FR, Kemmeren JM, Algra A, Visseren FL, van der Graaf Y: Novel risk factors for peripheral arterial disease in young women. Am J Med 2002, 113:462-467.

37. Diabetes mellitus: a major risk factor for cardiovascular disease. A joint editorial statement by the American Diabetes Association; The National Heart, Lung, and Blood Institute; The Juvenile 
Diabetes Foundation International; The National Institute of Diabetes and Digestive and Kidney Diseases; and The American Heart Association. Circulation 1999, 100:1132-1133.

38. Castagna O, Boussuges A, Nussbaum E, Marqueste L, Brisswalter J: Peripheral arterial disease: an underestimated aetiology of exercise intolerance in chronic obstructive pulmonary disease patients. Eur J Cardiovasc Prev Rehabil 2008, 15:270-277.

39. O'Hare PE, Ayres JF, O'Rourke RL, Slaughter RE, Marshall HM, Bowman RV, Fong KM, Yang IA: Coronary artery calcification on computed tomography correlates with mortality in chronic obstructive pulmonary disease. J Comput Assist Tomogr 2014, 38:753-759.

40. Willigendael EM, Teijink JA, Bartelink ML, Kuiken BW, Boiten J, Moll FL, Buller HR, Prins MH: Influence of smoking on incidence and prevalence of peripheral arterial disease. $J$ Vasc Surg 2004, 40:1158-1165.

41. Iwamoto $\mathrm{H}$, Yokoyama A, Kitahara $\mathrm{Y}$, Ishikawa $\mathrm{N}$, Haruta $\mathrm{Y}$, Yamane $\mathrm{K}$, Hattori $\mathrm{N}$, Hara $\mathrm{H}$, Kohno $\mathrm{N}$ : Airflow limitation in smokers is associated with subclinical atherosclerosis. Am J Respir Crit Care Med 2009, 179:35-40.

42. Maclay JD, MacNee W: Cardiovascular disease in COPD: mechanisms. Chest 2013, 143:798807.

43. Sun KS, Lin MS, Chen YJ, Chen YY, Chen SC, Chen W: Is asymptomatic peripheral arterial disease associated with walking endurance in patients with COPD? Int $J$ Chron Obstruct Pulmon Dis 2015, 10:1487-1492.

44. Hamburg NM, Balady GJ: Exercise rehabilitation in peripheral artery disease: functional impact and mechanisms of benefits. Circulation 2011, 123:87-97.

45. Vivodtzev I, Tamisier R, Baguet JP, Borel JC, Levy P, Pepin JL: Arterial stiffness in COPD. Chest 2014, 145:861-875.

46. Parmenter BJ, Dieberg G, Phipps G, Smart NA: Exercise training for health-related quality of life in peripheral artery disease: A systematic review and meta-analysis. Vasc Med 2015, 20:30-40.

47. Frei A, Muggensturm P, Putcha N, Siebeling L, Zoller M, Boyd CM, ter Riet G, Puhan MA: Five comorbidities reflected the health status in patients with chronic obstructive pulmonary disease: the newly developed COMCOLD index. J Clin Epidemio/2014, 67:904-911.

48. Putcha N, Han MK, Martinez CH, Foreman MG, Anzueto AR, Casaburi R, Cho MH, Hanania NA, Hersh CP, Kinney GL, et al: Comorbidities of COPD have a major impact on clinical outcomes, particularly in African Americans. Chronic Obstr Pulm Dis (Miami) 2014, 1:105-114.

49. Wilke S, Spruit MA, Wouters EF, Schols JM, Franssen FM, Janssen DJ: Determinants of 1-year changes in disease-specific health status in patients with advanced chronic obstructive pulmonary disease: A 1-year observational study. Int J Nurs Pract 2015, 21:239-248.

50. Durr S, Zogg S, Miedinger D, Steveling EH, Maier S, Leuppi JD: Daily physical activity, functional capacity and quality of life in patients with COPD. COPD 2014, 11:689-696.

51. Maksimovic M, Vlajinac $\mathrm{H}$, Marinkovic J, Kocev N, Voskresenski T, Radak D: Health-Related Quality of Life Among Patients With Peripheral Arterial Disease. Angiology 2013, 65:501-506.

52. Maly $\mathrm{M}$, Vondra V: Generic versus disease-specific instruments in quality-of-life assessment of chronic obstructive pulmonary disease. Methods Inf Med 2006, 45:211-215. 


\section{SUPPLEMENTAL MATERIAL}

TABLE E1. Independent predictors of peripheral artery disease (PAD) in patients with COPD and GOLD stage 0

\begin{tabular}{lllll}
\hline Covariates & Exp $(\mathrm{B})$ & \multicolumn{3}{l}{$95 \% \mathrm{Cl}$ for $\mathrm{HR}$} \\
\cline { 3 - 5 } & & Lower & Upper & $\mathrm{p}$-value \\
\hline Age & 1.070 & 1.047 & 1.094 & $<0.001$ \\
Gender (male) & 1.290 & 0.913 & 1.823 & 0.149 \\
Smoking status & & & & \\
Smoking status (current smoker) & 6.547 & 2.264 & 18.932 & 0.001 \\
Smoking status (former smoker) & 2.819 & 1.001 & 7.939 & 0.050 \\
GOLD & & & & \\
I & 0.887 & 0.392 & 2.003 & 0.772 \\
II & 1.017 & 0.577 & 1.792 & 0.955 \\
III & 1.481 & 0.826 & 2.657 & 0.188 \\
IV & 1.430 & 0.648 & 3.157 & 0.376 \\
TLCO \% predicted & 0.987 & 0.978 & 0.996 & 0.005 \\
hsCRP & 1.001 & 0.997 & 1.006 & 0.582 \\
Triglycerides & 1.001 & 1.000 & 1.002 & 0.055 \\
Self-reported hypertension & 1.735 & 1.231 & 2.445 & 0.002 \\
Self-reported diabetes & 1.633 & 1.112 & 2.397 & 0.012 \\
\hline
\end{tabular}

Logistic regression - dependent variable $A B I \leq 0.90(A B I \leq 0.90=1 ; n=204)$. Abbreviations. TLCO, Transfer Factor of the Lung for Carbon Monoxide; hsCRP, high-sensitive C-reactive protein; 
TABLE E2. Baseline Characteristics of patients with GOLD stage 0 stratified by peripheral artery disease (PAD)

\begin{tabular}{|c|c|c|c|}
\hline & $\begin{array}{l}\text { Whole group } \\
\quad(n=337)\end{array}$ & $\begin{array}{l}\text { Patients with PAD } \\
\qquad(A B I \leq 0.9) \\
(n=20)\end{array}$ & $\begin{array}{c}\text { Patients without } \\
\text { PAD }(A B I>0.9) \\
(n=317)\end{array}$ \\
\hline Age, years & $64.8(9.6)$ & $67.2(6.9)$ & $64.6(9.8)$ \\
\hline Male, n (\%) & $172(51.0)$ & $10(50.0)$ & $162(51.1)$ \\
\hline \multicolumn{4}{|l|}{ Smoking status } \\
\hline Never smoker, n (\%) & $47(13.9)$ & $1(5.0)$ & $46(24.0)$ \\
\hline Current smoker, n (\%) & $85(25.2)$ & $9(45.0)$ & $76(24.0)$ \\
\hline Former smoker, n (\%) & $205(60.8)$ & $10(50.0)$ & $195(61.5)$ \\
\hline \multicolumn{4}{|l|}{$\mathrm{BMI}, \mathrm{kg} / \mathrm{m}^{2}$} \\
\hline$<18.5$ & $7(2.1)$ & $1(5.0)$ & $6(1.9)$ \\
\hline $18.5-24.9$ & $79(23.4)$ & $2(10.0)$ & $77(24.3)$ \\
\hline $25.0-30.0$ & $115(34.1)$ & $7(35.0)$ & $108(34.1)$ \\
\hline$>30.0$ & $136(40.4)$ & $10(50.0)$ & $126(39.7)$ \\
\hline $\mathrm{FEV}_{1}$, liter & $2.3(0.8)$ & $1.9(0.6)$ & $2.3(0.8)$ \\
\hline $\mathrm{FEV}_{1}, \%$ predicted & $80.1(18.6)$ & $73.2(13.5)$ & $80.5(18.8)$ \\
\hline $\mathrm{FEV}_{1} / \mathrm{FVC}, \%$ & $76.4(72.3-80.4)$ & $75.7(72.8-82.1)$ & $76.4(72.3-80.4)$ \\
\hline TLCO $^{a}$ & $6.1(2.0)$ & $5.2(1.8)$ & $6.1(2.0)$ \\
\hline TLCO predicted $^{\mathrm{a}}$ & $72.4(20.0)$ & $66.5(20.1)$ & $72.8(20.0)$ \\
\hline \multicolumn{4}{|l|}{ mMRC dyspnea score (\%) ${ }^{\mathrm{b}}$} \\
\hline 0 & $47(13.9)$ & - & $47(14.8)$ \\
\hline 1 & $172(51.0)$ & $9(45.0)$ & $163(51.4)$ \\
\hline 2 & $80(23.7)$ & $5(25.0)$ & $75(23.7)$ \\
\hline 3 & $34(10.1)$ & $5(25.0)$ & $29(9.1)$ \\
\hline 4 & $2(0.6)$ & $1(5.0)$ & $1(0.3)$ \\
\hline $\mathrm{ABI}$ & $1.2(1.1-1.3)$ & $0.8(0.7-0.8)$ & $1.2(1.1-1.3)$ \\
\hline hsCRP mg/ L $^{c}$ & $5.0(2.0-9.0)$ & $10.5(3.8-14.0)$ & $5.0(2.0-8.2)$ \\
\hline Triglyceride, $\mathrm{mg} / \mathrm{dL}^{\mathrm{d}}$ & $134.0(101.9-191.3)$ & $153.0(98.0-256.0)$ & $134(102.0-188.0)$ \\
\hline Cholesterol, mg/dL ${ }^{e}$ & $214.7(43.0)$ & $204.4(48.7)$ & $215.3(42.6)$ \\
\hline Self-reported hypertension, $\mathrm{n}(\%)$ & $209(62.0)$ & $17(85.8)$ & $192(60.6)$ \\
\hline Self-reported diabetes, n (\%) & $70(20.8)$ & $8(40.0)$ & $62(19.6)$ \\
\hline
\end{tabular}

Abbreviations: BMI, body mass index; FEV1, forced expiratory volume in the first second; FVC, forced vital capacity, mMRC, modified Medical Research Council scale; ABI, ankle-brachial index; hsCRP, high-sensitive $\mathrm{C}$-reactive protein.

${ }^{a} n=317$ (whole group), $n=19(A B I \leq 0.9), n=298(A B I>0.9)$

${ }^{\mathrm{b}} \mathrm{n}=355$ (whole group), $\mathrm{n}=315(\mathrm{ABI}>0.9)$

${ }^{c} n=327$ (whole group), $n=19(A B I \leq 0.9), n=310(A B I>0.9)$

${ }^{d} n=330$ (whole group), $n=19(A B I \leq 0.9), n=311(A B I>0.9)$

${ }^{e} n=329$ (whole group), $n=19(A B I \leq 0.9), n=310(A B \mid>0.9)$ 

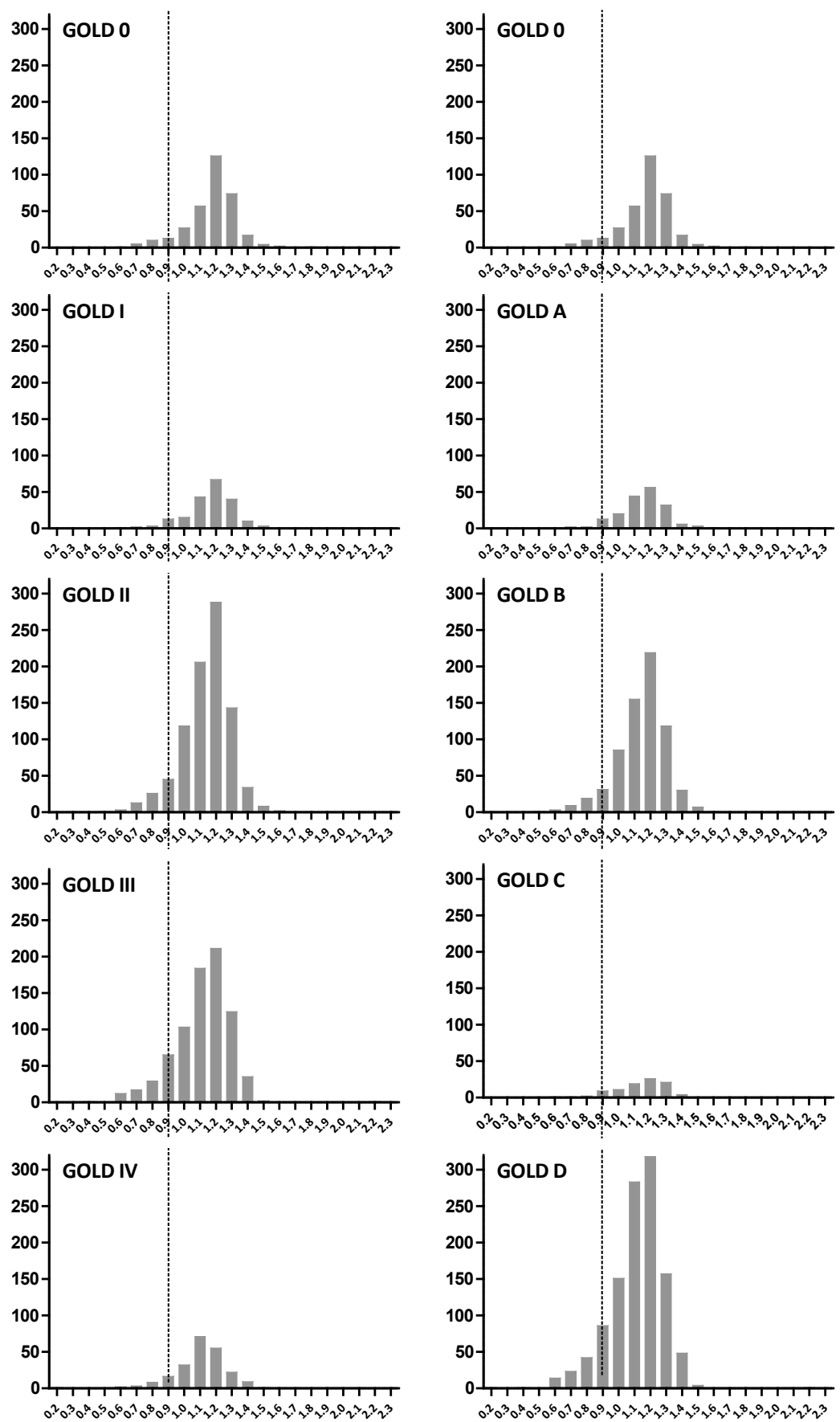

FIGURE E1. Frequency distribution of ankle-brachial index (ABI) values stratified by GOLD stages and GOLD groups 


\section{CHAPTER 8}

Echocardiographic abnormalities and their impact on health status in patients with COPD

Sarah Wilke, Martijn A. Spruit, Nicole H.M.K. Uszko-Lencer,

Gosia Otkinska, Lowie E.G.W. Vanfleteren, Henrik Watz, Paul W. Jones, Emiel F.M. Wouters, and Frits M.E. Franssen 



\section{ABSTRACT}

\section{BACKGROUND}

Both patients with cardiac diseases as well as those with chronic obstructive pulmonary disease (COPD) report an impaired health status. The frequencies of objectively assessed comorbid cardiac diseases and their impact on health status in patients with COPD is unknown. We aimed to investigate echocardiographic abnormalities and their impact on health status in a large cohort of patients with COPD referred for pulmonary rehabilitation (PR).

\section{METHODS}

Demographic and clinical characteristics were assessed during an inpatient prePR assessment. All patients underwent a Doppler echocardiographic evaluation. Disease-specific health status was assessed using the COPD Assessment Test (CAT), the Clinical COPD Questionnaire (CCQ) and the St. George's Respiratory Questionnaire (SGRQ).

\section{RESULTS}

514 patients (55.3\% male, age 64.1 [9.1] years, $\mathrm{FEV}_{1} 48.6$ [20.0]\% predicted) were included for analyses. 276 patients (53.7\%) were diagnosed with one or more echocardiographic abnormalities. Most prevalent were left ventricular hypertrophy (LVH, 31.0\%), increased right ventricular systolic pressure (RVSP, $20.4 \%$ ) and impaired left ventricular ejection fraction (LVEF, 16.5\%). 178 (63.8\%) of the patients with echocardiographic abnormalities did not have any of these in their medical history. Patients with echocardiographic abnormalities reported a worse health status as assessed with the SGRQ total score (62.5 [17.1] vs. 59.3 [17.6] points, $p=0.044$ ). CCQ and CAT did not differ between groups.

\section{CONCLUSIONS}

More than half of the patients referred to PR had echocardiographic abnormalities of which two third did not have such abnormalities recorded in their medical history. We detected a limited impact of echocardiographic abnormalities on health status. 


\section{INTRODUCTION}

While chronic obstructive pulmonary disease (COPD) is defined by the presence of chronic airflow limitation, it is well-recognized that COPD is just one component of a multimorbid condition [1]. Cardiac disease is one of the most prevalent and impactful coexisting disease in patients with COPD [2]. Consequently, the Global initiative for chronic Obstructive Pulmonary Disease (GOLD) document recommends to diagnose and treat cardiac diseases in patients with COPD appropriately [3]. However, patients with COPD are at high risk for underdiagnosis and under-treatment of cardiac risk factors and diseases as these conditions can be masked by similar symptoms $[4,5]$.

Since pulmonary rehabilitation (PR) offers a unique platform to assess and treat the heterogeneous factors that impact on the patients [6], it is important to increase our knowledge about the prevalence and impact of cardiac diseases. Whilst it was reported that $20 \%$ of patients with COPD entering PR have ischemic ECG changes [7], the frequency of cardiac diseases as objectively assessed by echocardiography in patients referred for comprehensive PR is currently unknown. Furthermore, patients with cardiac diseases [8] as well as patients with COPD [9] report an impaired health status. A previous report suggested that patients with COPD and self-reported comorbid cardiac diseases reported a worse health status compared to those without these comorbid conditions [10]. However, these data have not been confirmed by others using objectively echocardiography.

Therefore, we aimed 1) to investigate the frequencies of echocardiographic abnormalities in a large cohort of patients with COPD referred for PR; 2) to study the rates of under-diagnosis and under-treatment of these abnormalities and; 3 ) to examine the impact of objectively identified echocardiographic abnormalities on health status.

\section{METHODS}

\section{Design}

The current cross-sectional analyses are part of an observational, prospective, single-centre study about COPD, health status and cardiovascular comorbidities (the Chance study) in a broad sample of patients with COPD [11]. The Medical Ethical Committee of the Maastricht University Medical Centre+ (METC 11-3070) approved this registered study (NTR 3416). 


\section{Study population}

Eligible patients had a primary diagnosis of COPD [3] and were clinically stable for at least four weeks preceding enrolment. Patients were excluded if they had a history of other lung diseases, had undergone lung surgery or had a malignancy within the last five years. Patients were recruited at CIRO (Horn, the Netherlands), during their inpatient pre-PR assessment between April 2012 and September 2014. All patients gave written informed consent.

\section{Measurements}

Demographics and clinical characteristics were measured as described before [12]. In brief, post-bronchodilator spirometry and 6-minute walk distance (6MWD) were assessed according to international guidelines and standard operating procedures $[12,13]$. Disease-specific health status was assessed using the COPD Assessment Test (CAT) [14], the Clinical COPD Questionnaire (CCQ) [15] and the COPD-specific version of the St. George's Respiratory Questionnaire (SGRQ) $[16,17]$. The CAT consists of 8 items and provides a total score ranging from 0 to 40 points. The CCQ consists of 10 items with an overall score ranging from 0 to 6 points. The SGRQ provides three domain scores (symptom, activity and impact) and a total score, all ranging from 0 to 100 points. Higher scores represent a worse health status in all three health status questionnaires.

\section{Cardiac evaluation}

Patients underwent a Doppler echocardiographic evaluation (My Lab, Esaote) at rest. Standard views were used to obtain subcostal, parasternal and apical views. The following abnormalities were assessed: left ventricular hypertrophy ( $L V H$, defined as interventricular septum $\geq 10 \mathrm{~mm}$ ), impaired left ventricular ejection fraction (LVEF, defined as LVEF $\leq 50 \%$ ), increased right ventricular systolic pressures (RVSP, defined as RVSP $\geq 40 \mathrm{mmHg}$ ), presence of relevant wall motion abnormalities, valvular abnormalities, aortic stenosis, and other abnormalities (e-Table 1, online supplementary material). Due to diagnostic challenges (i.e., suboptimal echocardiographic images), parameters of diastolic dysfunction have not been included in the current analyses. All examinations were done by one examiner (G.O.). Additionally, all patients underwent a resting electrocardiogram (ECG). All echocardiographic reports and ECG's were evaluated by one cardiologist (N.H.M.K.U.L.) who was blinded for patients' clinical characteristics for the evaluation of all ECG's. Cardiac Infarction Injury Score (CIIS) was used to score the ECG's. The CIIS is based on specific electrocardiographic characteristics that are weighted and combined into a single score. Myocardial infarction is defined as a CIIS score $\geq 20$ points [18]. 


\section{Statistics}

Categorical variables were reported as frequencies. Continuous variables were described as mean and standard deviation (SD) or median and interquartile range [IQR], as appropriate. Only patients with complete and reliable echocardiographic results were included in the current analyses $(n=514)$. Echocardiographic abnormalities are presented in valid percentages; number of observations are demonstrated in e-Table 1 in the online data supplement. To compare characteristics between patients with and without echocardiographic abnormalities, an independent sample t-test or Mann-Whitney $\mathrm{U}$ test was used, as appropriate. Categorical variables were compared using Chi-Square tests. Echocardiographic abnormalities were further stratified in several groups (LVH versus normal LV thickness; increased RVSP versus normal RVSP; and impaired LVEF versus normal LVEF) to compare health status using Mann-Whitney $U$ test. Bar diagrams were constructed using GraphPad Prism 5. Statistical analyses were performed using IBM SPSS statistics, Version 20.0. A p-value $\leq 0.05$ was interpreted as statistically significant.

\section{RESULTS}

A total of 518 patients with COPD participated. For the current analyses, four patients had to be excluded because of unreliable echocardiographic data resulting in a sample of 514 patients (99.2\%). In general, participants were mostly men, slightly overweight, had moderate to very severe airflow limitation and a clear exercise intolerance (Table 1). 
TABLE 1. Baseline Patient Characteristics

\begin{tabular}{|c|c|c|c|}
\hline & $\begin{array}{l}\text { Whole group } \\
\quad(n=514)\end{array}$ & $\begin{array}{l}\text { Patients with } \\
\text { abnormalities } \\
(n=276)\end{array}$ & $\begin{array}{l}\text { Patients without } \\
\text { abnormalities } \\
(\mathrm{n}=238)\end{array}$ \\
\hline Age, years & $64.1(9.1)$ & $66.5(8.9)^{\star}$ & $61.3(8.6)$ \\
\hline Male, n (\%) & $284(55.3)$ & $191(69.2)^{\star}$ & $93(39.1)$ \\
\hline Current smokers, n (\%) & $111(21.6)$ & $48(17.4)^{\star}$ & $63(26.5)$ \\
\hline $\mathrm{BMI}, \mathrm{kg} / \mathrm{m}^{2 \mathrm{~b}}$ & $25.7(21.7-29.3)$ & $26.9(22.4-31.1)^{\star}$ & $24.2(20.9-27.8)$ \\
\hline $\mathrm{FEV}_{1}, \%$ predicted & $48.6(20.0)$ & $48.7(20.4)$ & $48.5(19.6)$ \\
\hline $\mathrm{FEV}_{1} / \mathrm{FVC}, \%$ & $37.5(12.2)$ & $38.3(12.9)$ & $36.7(11.4)$ \\
\hline 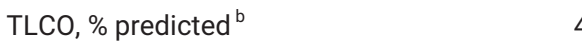 & $46.6(37.0-60.0)$ & $46.0(34.3-61.5)$ & $46.8(39.1-58.0)$ \\
\hline$\geq 2$ exacerbations previous 12 months, $n$ (\%) & $290(56.4)$ & $161(58.3)$ & $129(54.2)$ \\
\hline$\geq 1$ hospitalisations previous 12 months, $n$ (\%) & $232(45.1)$ & $151(54.7)^{\star}$ & $81(34.0)$ \\
\hline LTOT & $124(24.1)$ & $78(28.3)^{\star}$ & $46(19.3)$ \\
\hline \multicolumn{4}{|l|}{ mMRC dyspnea grade, $\mathrm{n}(\%)$} \\
\hline 0 & $10(2.0)$ & $5(1.8)$ & $5(2.1)$ \\
\hline 1 & $85(16.7)$ & $30(10.9)^{\star}$ & $5(23.6)$ \\
\hline 2 & $193(38.0)$ & $101(36.7)$ & $92(39.5)$ \\
\hline 3 & $127(25.0)$ & $72(26.1)$ & $55(23.6)$ \\
\hline 4 & $93(18.3)$ & $67(24.3)^{\star}$ & $26(11.2)$ \\
\hline Charlson Comorbidity Index, points ${ }^{\mathrm{b}}$ & $1.0(1.0-2.0)$ & $2.0(1.0-2.0)^{\star}$ & $1.0(1.0-1.0)$ \\
\hline 6MWD, meters & $426(124)$ & $395(124)^{\star}$ & $460(113)$ \\
\hline $6 \mathrm{MWD}, \%$ predicted & $67.3(17.8)$ & $63.4(18.9)^{*}$ & $71.9(15.2)$ \\
\hline HADS anxiety score, points & $7.8(4.5)$ & $8.0(4.5)$ & $7.6(4.5)$ \\
\hline HADS depression score, points & $7.5(4.3)$ & $7.8(4.2)$ & $7.3(4.5)$ \\
\hline
\end{tabular}

Values expressed as mean (standard deviation), median ( $25 \%-75 \%$ percentile) or number of patients (n), proportion (\%). ${ }^{\mathrm{b}}$ non-parametric tests were used because of skewed data

Abbreviations. $\mathrm{BMI}$, body mass index; $\mathrm{FEV}_{1}$, forced expiratory volume in the first second; $\mathrm{FVC}$, forced vital capacity; TLCO, transfer coefficient for carbon monoxide; LTOT, long-term oxygen therapy; mMRC, modified Medical Research Council dyspnea scale; 6MWD, 6-minute; HADS, Hospital Anxiety and Depression Scale. * $p \leq 0.05$ versus patients without abnormalities

Most patients used long-acting antimuscarinic agent (LAMA) and/or inhaled corticosteroid/long-acting beta agonist (ICS-LABA) (71\% and 68\%, respectively). Moreover, about one quarter of patients used beta-blockers and angiotensin converting enzyme inhibitors (ACE)/angiotensin receptor blockers (ARB) (25\% and $28 \%$ respectively) (see Table $\mathrm{E} 2$ in the online data supplement).

\section{Echocardiographic abnormalities}

Echocardiographic results of the whole study population are shown in e-Table 1 of the online supplementary material. 276 patients $(53.7 \%)$ had one or more 
echocardiographic abnormalities while 121 (23.5\%) patients had two or more. Most prevalent abnormalities were LVH (31.0\%), increased RVSP $(20.4 \%)$, and impaired LVEF (16.5\%). Of the 276 patients with abnormal echocardiography, $176(63.8 \%)$ did not have such abnormalities in their medical history (Figure 1).

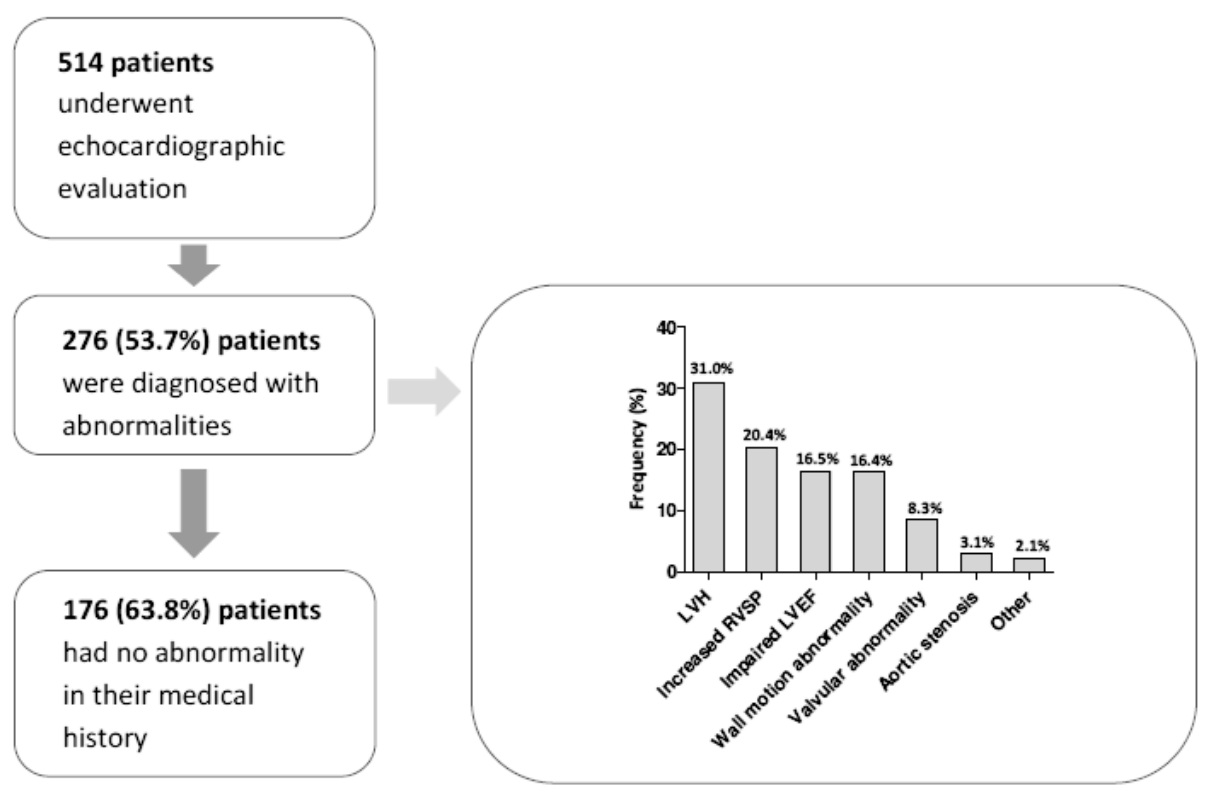

FIGURE 1. Frequency of echocardiographic abnormalities

46 (9.0\%) patients had a CIIS $\geq 20$ points indicating myocardial infarction. 15 ECG's could not be scored due to left bundle-branch block $(n=9)$, right bundlebranch block $(n=2)$, or implanted pacemaker $(n=5) .27 .3 \%$ of the patients with wall motion abnormalities as an indication for a previous myocardial infarction had a CIIS $\geq 20$.

\section{Echocardiographic abnormalities and clinical characteristics}

A higher proportion of patients with echocardiographic abnormalities was male, they were older, had a higher BMI, more self-reported comorbidities and a worse functional capacity compared to those without echocardiographic abnormalities (Table 1). Furthermore, a higher proportion of patients with echocardiographic abnormalities were highly symptomatic and admitted to the hospital 12 months before inclusion compared to patients without abnormalities. Lung function, depression and anxiety scores were comparable between groups ( $\mathrm{Ta}$ ble 1). Additionally, they used more cardiovascular medications (e.g., ACE inhib- 
itors/ARB, beta-blockers), antidiabetics and antibiotics compared to those without abnormalities (see Table E2 in the online data supplement).

\section{Echocardiographic abnormalities and health status}

Patients with echocardiographic abnormalities reported a worse health status as assessed with the SGRQ total score compared to those without abnormalities (Table 2). CCQ and CAT did not differ between groups.

TABLE 2. Health status stratified by echocardiographic abnormality

\begin{tabular}{lcccc}
\hline & $\begin{array}{c}\text { Whole group } \\
(\mathrm{n}=514)\end{array}$ & $\begin{array}{c}\text { Patients with } \\
\text { abnormalities } \\
(\mathrm{n}=276)\end{array}$ & $\begin{array}{c}\text { Patients without } \\
\text { abnormalities } \\
(\mathrm{n}=238)\end{array}$ & p-value \\
\hline CAT total score, points & $21.5(6.6)$ & $21.2(6.7)$ & $21.8(6.6)$ & 0.323 \\
SGRQ symptom score, points & $61.5(19.0)$ & $62.5(18.7)$ & $60.4(19.3)$ & 0.243 \\
SGRQ activity score, points & $79.9(18.8)$ & $81.4(18.8)$ & $78.3(18.7)$ & 0.067 \\
SGRQ impact score, points & $49.5(21.2)$ & $51.2(20.9)$ & $47.7(21.4)$ & 0.065 \\
SGRQ total score, points & $61.0(17.4)$ & $62.5(17.1)$ & $59.3(17.6)$ & 0.044 \\
CCQ total score, points & $2.6(1.0)$ & $2.7(1.1)$ & $2.6(1.0)$ & 0.197 \\
\hline
\end{tabular}

Abbreviations: CAT, COPD Assessment Test; SGRQ, St. George's Respiratory Questionnaire; CCQ, Clinical COPD Questionnaire

After stratification for specific abnormalities, only patients with an increased RVSP reported worse health status as assessed with SGRQ and CCQ compared to those with a normal RVSP (Table 3). There were no differences in health status after stratification for LVH and impaired LVEF. No differences in CAT-score were detected for all scenarios.

TABLE 3. Health status stratified by RVSP

\begin{tabular}{|c|c|c|c|c|}
\hline & $\begin{array}{l}\text { Whole group } \\
\qquad(\mathrm{n}=514)\end{array}$ & $\begin{array}{l}\text { Patients with } \\
\text { RVSP } \geq 40 \\
(n=81)\end{array}$ & $\begin{array}{c}\text { Patients with } \\
\text { RVSP < } 40 \\
(n=317)\end{array}$ & p-value \\
\hline CAT total score, points & $21.5(6.6)$ & $22.7(6.0)$ & $21.2(6.6)$ & 0.071 \\
\hline SGRQ symptom score, points & $61.5(19.0)$ & $64.9(19.1)$ & $60.4(18.6)$ & 0.057 \\
\hline SGRQ activity score, points & $79.9(18.8)$ & $88.6(13.5)$ & $77.8(19.7)$ & $<0.001$ \\
\hline SGRQ impact score, points & $49.5(21.2)$ & $58.7(18.8)$ & $47.6(21.2)$ & $<0.001$ \\
\hline SGRQ total score, points & $61.0(17.4)$ & $69.0(14.4)$ & $59.2(17.7)$ & $<0.001$ \\
\hline CCQ total score, points & $2.6(1.0)$ & $3.0(0.9)$ & $2.5(1.0)$ & $<0.001$ \\
\hline
\end{tabular}

Abbreviations: see Table 2. 


\section{DISCUSSION}

The current study is the first that we know of investigating echocardiographic abnormalities and their impact on health status in patients with COPD referred for PR. Echocardiographic abnormalities occurred in almost $54 \%$ of the patients, of which $64 \%$ did not have echocardiographic abnormalities recorded in their medical history. Echocardiographic abnormalities had a limited impact on health status.

\section{Prevalence of echocardiographic abnormalities}

Echocardiographic abnormalities were observed in more than half of the patients referred for PR. Recently, a prevalence of $64 \%$ of echocardiographic abnormalities have been reported in patients with COPD at their first hospital admission, of which about one third did not have any previously diagnosed heart disease [19]. Matamis and colleagues reported signs of heart failure in 3 out of 4 patients admitted to the ICU receiving mechanical ventilation of which $41 \%$ had no heart failure in their medical history [20]. Thus, patients with COPD are at risk of (undetected) cardiac diseases, irrespective of care setting.

In our study, LVH (31.0\%), increased RVSP (20.4\%) and impaired LVEF (16.5\%) were the most prevalent abnormalities. A comparable prevalence of LVH has previously been reported (30.1\%) although the LV mass index was used as indication for LVH [21]. Andersen and colleagues studied pulmonary hypertension in patients referred to the out-patient clinic after a hospital admission and reported a prevalence of $14 \%$ which supports our findings [22]. Others used several right ventricular parameters and a lower cut-point for RVSP $(\geq 35 \mathrm{mmHg})$ and reported an increased RVSP in $38.7 \%$ of patients referred for PR [23]. In line with our results, Freixa and colleagues detected left ventricular dysfunction (defined as a LVEF $<50 \%$ ) in $13.3 \%$ of patients with COPD at their first hospital admission [19]. Another study detected a decreased LVEF in $5.6 \%$ of hospitalized patients with an acute exacerbation [24], but more than half of these patients were GOLD I and II patients. Macchia and colleagues previously reported a prevalence of $14 \%$ of LVEF [25]. However, they only included patients aged 60 years or older and used a lower cut-point to define LVEF (LVEF $<40 \%$ ). In the current study, only 36 patients $(7 \%)$ had a LVEF $\leq 40 \%$. Although previous studies often used different parameters or cut-points to diagnose the abnormality at hand, our findings give an appropriate picture of echocardiographic abnormalities in patients with COPD referred for PR. 


\section{Impact on clinical characteristics}

Patients with echocardiographic abnormalities were older, had a higher $\mathrm{BMI}$ and a higher proportion were men, all known risk factors for cardiac diseases [26, 27]. Interestingly, a lower percentage of patients with echocardiographic abnormalities was currently smoking which might be explained by the fact that these patients were older and had been confronted with the need of smoking cessation. They reported more comorbidities which is also reflected in their medication used. However, since a high proportion of echocardiographic abnormalities were previously unknown, our results underline the importance to detect and adapt medical therapy appropriately. Additionally, a higher proportion of patients with echocardiographic abnormalities reported higher grades of dyspnea. The co-occurrence of both diseases may worsen the clinical presentation, i.e. dyspnea [4], which again underlines the importance of detecting concomitant cardiac diseases to understand and treat the patients' symptoms appropriately. Awareness of cardiac diseases in COPD not only provides a therapeutic window for the individual patient, it may modify the course of the disease $[20,28]$.

\section{Impact on disease-specific health status}

Previously, patients with COPD and self-reported cardiac diseases reported a worse health status compared to those without cardiovascular comorbidities [10]. Freixa and colleagues were the first who studied the impact of echocardiographic abnormalities on health status as assessed with SGRQ in patients with COPD at their first hospital admission but did not detect differences in health status between groups. However, they compared the proportion of patients with abnormalities stratified by a specific SGRQ cut-point ( $\leq 33$ points) [19]. The impact of these abnormalities on health status has not been studied before. The present study showed that objectively identified echocardiographic abnormalities had a significant impact on SGRQ total score, but no impact on CAT and CCQ scores. However, the effect on health status is limited since the differences in SGRQ score was only 3.2 points and did not reach the minimal clinically important difference of 4 points [29] and the $p$-value was of borderline significance $(p=0.044)$. Differences were more prominent in specific subgroups: patients with an increased RVSP had a clinically relevant worse health status compared to those with a normal RVSP as measured with SGRQ and CCQ. Indeed, patients with pulmonary hypertension previously reported impaired health status [30] and defined breathlessness as the most common physiologic symptom causing them to make adjustments to their lives [31]. 
In the current study, only the SGRQ detected differences in health status between patients with and without echocardiographic abnormalities while the CCQ only differed significantly after stratification for RVSP. In line with a previous study using medical records to define cardiac diseases [32], we could not detect any difference in CAT score between patients with echocardiographic abnormalities compared to those without echocardiographic abnormalities in general or any specific abnormalities. The SGRQ covers a wide range of disturbances of functional and psycho-social health [16] which might consequently be more sensitive to detect differences in clinical status than the CAT. The CCQ also covers several aspects of health status but is less comprehensive compared to the SGRQ [15] which might explain the limited sensitivity.

Our results suggest that the actual impact of cardiac diseases on health status is more limited than previously reported. Alternatively, since a higher percentage of these echocardiographic abnormalities were previously unknown, this discrepancy might be explained by a lack of awareness of these patients. However, we could not detect significant differences in health status between patients with previously known abnormalities versus patients with known abnormalities in our population.

\section{Clinical implications}

Although we only detected a limited impact of echocardiographic abnormalities on health status, early identification and treatment of cardiovascular comorbidities are still important to ensure patients' safety and to improve their prognosis. Indeed, a higher percentage of patients with echocardiographic abnormalities were admitted at least once to the hospital in the previous year. Also, patients with such abnormalities more often reported severe dyspnea. The use of betablockers has been shown to decrease overall mortality and reduce the risk of exacerbations in COPD [28]. Recently, statin use has been shown to be associated with a reduced risk of exacerbations in patients with COPD and coexisting cardiac diseases [33]. Furthermore, the current study demonstrates an additional value of echocardiography beyond ECG in patients with COPD. While CIIS is primarily a marker of previous myocardial infarction [18], subsequent wall motion abnormalities are only one of the described echocardiographic abnormalities. However, only 21 out of 77 patients $(27.3 \%)$ with wall motion abnormalities had a CIIS $\geq 20$. Second, ECG alone is not an appropriate diagnostic for other important cardiac conditions (e.g., increased right ventricular systolic pressure or valvular disease).

It is important to detect, treat and monitor comorbid diseases to consequently understand their clinical effects. However, Carreiro and colleagues reported that 
patients in all comorbid subgroups showed improvements following PR and suggest that "the presence of comorbidities in COPD patients, if clinically controlled, should not preclude access to PR" [34]. These findings have further been confirmed by a recent study [35]. In addition, physical activity may improve systolic function [36] but may also lead to LVH in patients with COPD [37] suggesting that it is important to assess cardiac function before and preferably after a PR programme. Finally, "pulmonary rehabilitation staff must be trained to recognise the symptoms and signs of the common comorbidities, since some comorbidities may not have been recognised prior to the patient's enrolment in pulmonary rehabilitation" [38].

\section{Limitations}

There are some limitations which should be taken into account. First, the study population consisted of a convenience sample of patients with moderate to very severe COPD referred for PR limiting the external validity of our results. Second, we did not examine echocardiographic abnormalities in a matched sample of healthy controls. However, a recent study established unrecognized heart failure in $34 \%$ of 570 elderly individuals (76 [6] years of age, $45 \%$ male) [39]. Patients with COPD are at increased risk for developing cardiac diseases, which underlines the importance of detecting echocardiographic abnormalities in this group. Unfortunately, due to diagnostic challenges, we could not adequately assess left ventricular diastolic dysfunction which might affect patients' impairment [40].

\section{CONCLUSION}

More than half of the patients referred to PR had echocardiographic abnormalities of which two third were previously unknown. Although we only detected a limited impact on disease-specific health status, early identification and treatment are important to understand the effects of concurrent cardiac diseases and may consequently affect the course of the disease. Further research is required to study the impact of echocardiographic abnormalities on outcomes of PR. 


\section{REFERENCES}

1. Vanfleteren LE, Spruit MA, Groenen M, Gaffron S, van Empel VP, Bruijnzeel PL, Rutten EP, Op 't Roodt J, Wouters EF, Franssen FM: Clusters of comorbidities based on validated objective measurements and systemic inflammation in patients with chronic obstructive pulmonary disease. Am J Respir Crit Care Med 2013, 187:728-735.

2. Mullerova H, Agusti A, Erqou S, Mapel DW: Cardiovascular comorbidity in COPD: systematic literature review. Chest 2013, 144:1163-1178.

3. Vestbo J, Hurd SS, Agusti AG, Jones PW, Vogelmeier C, Anzueto A, Barnes PJ, Fabbri LM, Martinez FJ, Nishimura M, et al: Global Strategy for the Diagnosis, Management, and Prevention of Chronic Obstructive Pulmonary Disease: GOLD Executive Summary. Am J Respir Crit Care Med 2013, 187:347-365.

4. Hawkins NM, Virani S, Ceconi C: Heart failure and chronic obstructive pulmonary disease: the challenges facing physicians and health services. Eur Heart J 2013, 34:2795-2803.

5. Rutten FH, Cramer MJ, Grobbee DE, Sachs AP, Kirkels JH, Lammers JW, Hoes AW: Unrecognized heart failure in elderly patients with stable chronic obstructive pulmonary disease. Eur Heart J 2005, 26:1887-1894.

6. Spruit MA, Singh SJ, Garvey C, Zuwallack R, Nici L, Rochester C, Hill K, Holland AE, Lareau SC, Man WD, et al: An official american thoracic society/european respiratory society statement: key concepts and advances in pulmonary rehabilitation. Am J Respir Crit Care Med 2013, 188:e13-64.

7. Vanfleteren LE, Franssen FM, Uszko-Lencer NH, Spruit MA, Celis M, Gorgels AP, Wouters EF: Frequency and relevance of ischemic electrocardiographic findings in patients with chronic obstructive pulmonary disease. Am J Cardio/2011, 108:1669-1674.

8. Wu JR, Lennie TA, Frazier SK, Moser DK: Health-Related Quality of Life, Functional Status, and Cardiac Event-Free Survival in Patients With Heart Failure. J Cardiovasc Nurs 2015.

9. Wilke S, Jones PW, Mullerova H, Vestbo J, Tal-Singer R, Franssen FM, Agusti A, Bakke P, Calverley $\mathrm{PM}$, Coxson $\mathrm{HO}$, et al: One-year change in health status and subsequent outcomes in COPD. Thorax 2015, 70:420-425.

10. Black-Shinn JL, Kinney GL, Wise AL, Regan EA, Make B, Krantz MJ, Barr RG, Murphy JR, Lynch D, Silverman EK, et al: Cardiovascular Disease is Associated with COPD Severity and Reduced Functional Status and Quality of Life. COPD 2014.

11. Smid DE, Wilke S, Jones PW, Muris JW, Wouters EF, Franssen FM, Spruit MA: Impact of cardiovascular comorbidities on COPD Assessment Test (CAT) and its responsiveness to pulmonary rehabilitation in patients with moderate to very severe COPD: protocol of the Chance study. BMJ Open 2015, 5:e007536.

12. Spruit MA, Pennings HJ, Janssen PP, Does JD, Scroyen S, Akkermans MA, Mostert R, Wouters EF: Extra-pulmonary features in COPD patients entering rehabilitation after stratification for MRC dyspnea grade. Respir Med 2007, 101:2454-2463.

13. Holland AE, Spruit MA, Troosters T, Puhan MA, Pepin V, Saey D, McCormack MC, Carlin BW, Sciurba FC, Pitta F, et al: An official European Respiratory Society/American Thoracic Society technical standard: field walking tests in chronic respiratory disease. Eur Respir J 2014, 44:1428-1446.

14. Jones PW, Harding G, Berry P, Wiklund I, Chen WH, Kline Leidy N: Development and first validation of the COPD Assessment Test. Eur Respir J2009, 34:648-654.

15. van der Molen T, Willemse BW, Schokker S, ten Hacken NH, Postma DS, Juniper EF: Development, validity and responsiveness of the Clinical COPD Questionnaire. Health Qual Life Outcomes $2003,1: 13$.

16. Jones PW, Quirk FH, Baveystock CM, Littlejohns P: A self-complete measure of health status for chronic airflow limitation. The St. George's Respiratory Questionnaire. Am Rev Respir Dis $1992,145: 1321-1327$. 
17. Meguro M, Barley EA, Spencer S, Jones PW: Development and Validation of an Improved, COPD-Specific Version of the St. George Respiratory Questionnaire. Chest 2007, 132:456-463.

18. Rautaharju PM, Warren JW, Jain U, Wolf HK, Nielsen CL: Cardiac infarction injury score: an electrocardiographic coding scheme for ischemic heart disease. Circulation 1981, 64:249-256.

19. Freixa X, Portillo K, Pare C, Garcia-Aymerich J, Gomez FP, Benet M, Roca J, Farrero E, Ferrer J, Fernandez-Palomeque $\mathrm{C}$, et al: Echocardiographic abnormalities in patients with COPD at their first hospital admission. Eur Respir J 2013, 41:784-791.

20. Matamis D, Tsagourias M, Papathanasiou A, Sineffaki H, Lepida D, Galiatsou E, Nakos G: Targeting occult heart failure in intensive care unit patients with acute chronic obstructive pulmonary disease exacerbation: effect on outcome and quality of life. J Crit Care 2014, 29:315 e317314.

21. Anderson WJ, Lipworth BJ, Rekhraj S, Struthers AD, George J: Left ventricular hypertrophy in COPD without hypoxemia: the elephant in the room? Chest 2013, 143:91-97.

22. Andersen CU, Mellemkjaer S, Nielsen-Kudsk JE, Sonderskov LD, Laursen BE, Simonsen U, Hilberg O: Echocardiographic screening for pulmonary hypertension in stable COPD outpatients and NT-proBNP as a rule-out test. COPD 2012, 9:505-512.

23. Gologanu D, Stanescu C, Ursica T, Balea MI, lonita D, Bogdan MA: Prevalence and Characteristics of Pulmonary Hypertension Associated with COPD - A Pilot Study in Patients Referred to a Pulmonary Rehabilitation Program Clinic. Maedica (Buchar) 2013, 8:243-248.

24. Nishimura K, Nishimura T, Onishi K, Oga T, Hasegawa Y, Jones PW: Changes in plasma levels of B-type natriuretic peptide with acute exacerbations of chronic obstructive pulmonary disease. Int J Chron Obstruct Pulmon Dis 2014, 9:155-162.

25. Macchia A, Rodriguez Moncalvo JJ, Kleinert M, Comignani PD, Gimeno G, Arakaki D, Laffaye N, Fuselli JJ, Massolin HP, Gambarte J, et al: Unrecognised ventricular dysfunction in COPD. Eur Respir J2012, 39:51-58.

26. Garcia-Rio F, Soriano JB, Miravitlles M, Munoz L, Duran-Tauleria E, Sanchez G, Sobradillo V, Ancochea J: Impact of obesity on the clinical profile of a population-based sample with chronic obstructive pulmonary disease. PLoS One 2014, 9:e105220.

27. Wilkins JT, Ning H, Berry J, Zhao L, Dyer AR, Lloyd-Jones DM: Lifetime risk and years lived free of total cardiovascular disease. JAMA 2012, 308:1795-1801.

28. Du Q, Sun Y, Ding N, Lu L, Chen Y: Beta-blockers reduced the risk of mortality and exacerbation in patients with COPD: a meta-analysis of observational studies. PLOS One 2014, 9:e113048.

29. Jones PW: St. George's Respiratory Questionnaire: MCID. COPD 2005, 2:75-79.

30. Matura LA, McDonough A, Carroll DL: Health-related quality of life and psychological states in patients with pulmonary arterial hypertension. J Cardiovasc Nurs 2014, 29:178-184.

31. McDonough A, Matura LA, Carroll DL: Symptom experience of pulmonary arterial hypertension patients. Clin Nurs Res 2011, 20:120-134.

32. Jones PW, Brusselle G, Dal Negro RW, Ferrer M, Kardos P, Levy ML, Perez T, Soler Cataluna JJ, van der Molen T, Adamek L, Banik N: Properties of the COPD assessment test in a crosssectional European study. Eur Respir J 2011, 38:29-35.

33. Ingebrigtsen TS, Marott JL, Nordestgaard BG, Lange P, Hallas J, Vestbo J: Statin use and exacerbations in individuals with chronic obstructive pulmonary disease. Thorax 2015, 70:33-40.

34. Carreiro A, Santos J, Rodrigues F: Impact of comorbidities in pulmonary rehabilitation outcomes in patients with chronic obstructive pulmonary disease. Rev Port Pneumol 2013, 19:106-113

35. Mesquita R, Vanfleteren LEGW, Franssen FME, Sarv J, Taib Z, Groenen M, Gaffron S, Bruijnzeel PL, Pitta F, Wouters E, Spruit MA: Objectively identified comorbidities in chronic obstructive pulmonary disease: impact on pulmonary rehabilitation outcomes. Eur Respir J2015.

36. Bronstad E, Tjonna AE, Rognmo O, Dalen H, Heggli AM, Wisloff U, Ingul CB, Steinshamn S: Aerobic exercise training improves right- and left ventricular systolic function in patients with COPD. COPD 2013, 10:300-306. 


\section{CHAPTER 8}

37. Alter P, Luetteken L, Nell C, Haid D, Kehr K, Greulich T, Apelt S, Langenhan K, Hohmann C, Vogelmeier CF, Koczulla AR: Exercise training leads to physiological left ventricular hypertrophy in COPD. Int J Cardio/2014, 174:156-157.

38. Franssen FM, Rochester CL: Comorbidities in patients with COPD and pulmonary rehabilitation: do they matter? Eur Respir Rev 2014, 23:131-141.

39. van Mourik Y, Bertens LC, Cramer MJ, Lammers JW, Reitsma JB, Moons KG, Hoes AW, Rutten FH: Unrecognized heart failure and chronic obstructive pulmonary disease (COPD) in frail elderly detected through a near-home targeted screening strategy. J Am Board Fam Med 2014, 27:811-821.

40. Lopez-Sanchez M, Munoz-Esquerre M, Huertas D, Gonzalez-Costello J, Ribas J, Manresa F, Dorca J, Santos S: High Prevalence of Left Ventricle Diastolic Dysfunction in Severe COPD Associated with A Low Exercise Capacity: A Cross-Sectional Study. PLoS One 2013, 8:e68034. 


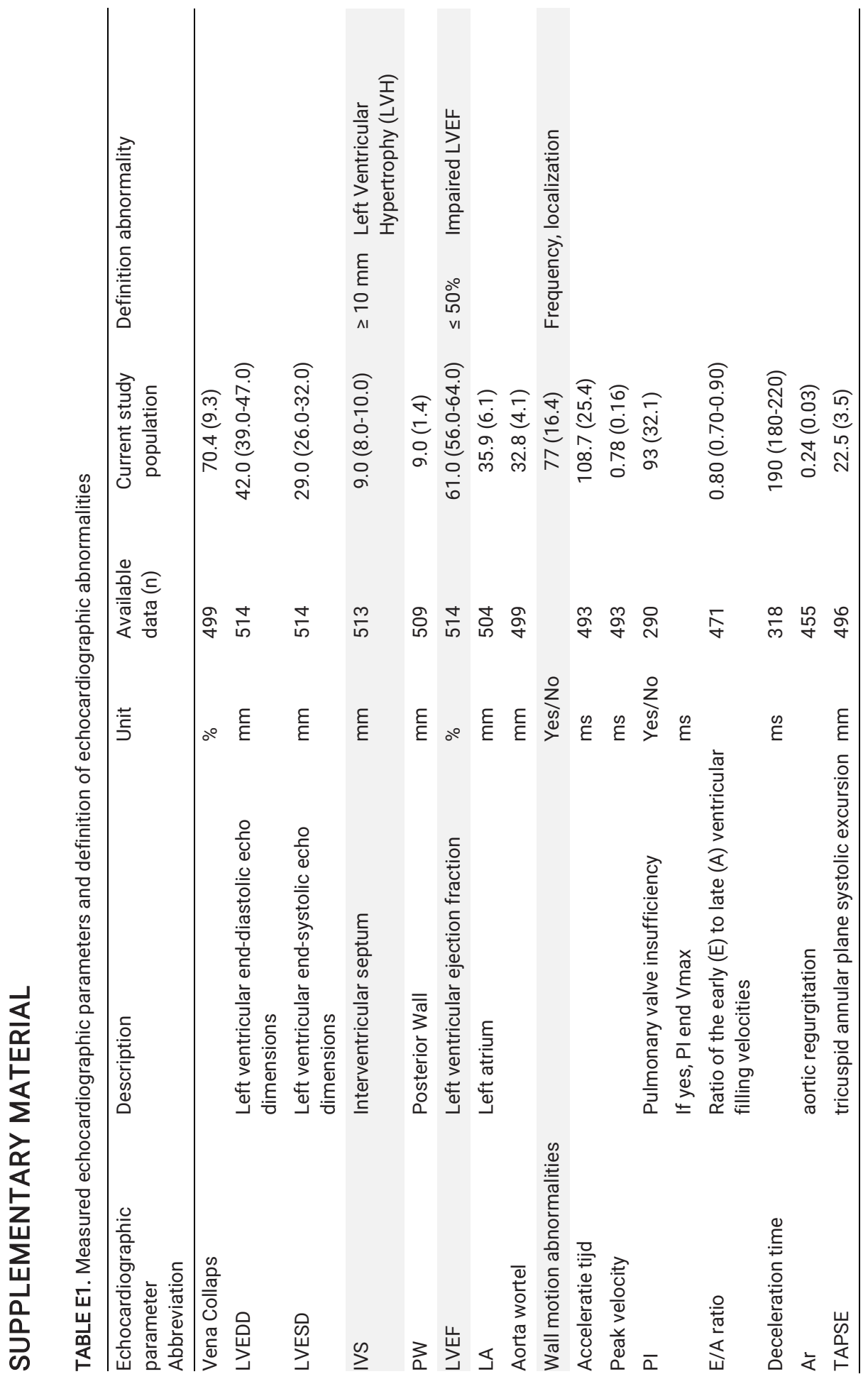


CHAPTER 8

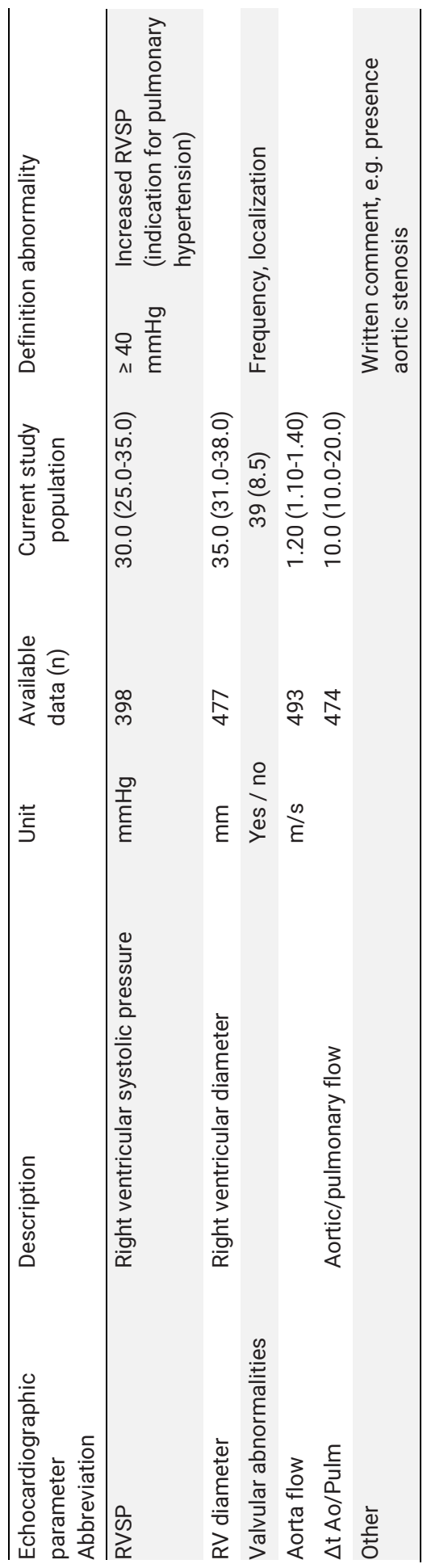


TABLE E2. Medication

\begin{tabular}{|c|c|c|c|}
\hline & Whole group & Patients with abnormalities & Patients without abnormalities \\
\hline SABA & $227(44.2)$ & $126(45.7)$ & $101(42.4)$ \\
\hline SAMA & $82(16.0)$ & $46(16.7)$ & $36(15.1)$ \\
\hline SABA-SAMA & $108(21.0)$ & $59(21.4)$ & $49(20.6)$ \\
\hline LABA & $130(25.3)$ & $58(21.0)$ & $72(30.3)$ \\
\hline LAMA & $365(71.0)$ & $201(72.8)$ & $164(68.9)$ \\
\hline ICS & $103(20.0)$ & $51(18.5)$ & $52(21.8)$ \\
\hline ICS-LABA & $350(68.1)$ & $197(71.4)$ & $153(64.3)$ \\
\hline Theophylline & $40(7.8)$ & $26(9.4)$ & $14(5.9)$ \\
\hline Prednisone & $93(18.1)$ & $48(17.4)$ & $45(18.9)$ \\
\hline Anti-Leukotrienes & $12(2.3)$ & $7(2.5)$ & $5(2.1)$ \\
\hline Antihistaminicum & $25(4.9)$ & $14(5.1)$ & $11(4.6)$ \\
\hline Nasal corticosteroids & $14(2.7)$ & $7(2.5)$ & $7(2.9)$ \\
\hline ACE/ARB & $142(27.6)$ & $97(35.1)$ & $45(18.9)$ \\
\hline Beta-blockers & $127(24.7)$ & $84(30.4)$ & $43(18.1)$ \\
\hline Calcium-blockers & $78(15.2)$ & $51(18.5)$ & $27(11.3)$ \\
\hline Anti-arrythmica & $20(3.9)$ & $13(4.7)$ & $7(2.9)$ \\
\hline Nitrates & $55(10.7)$ & $44(15.9)$ & $11(4.6)$ \\
\hline Diuretics & $124(24.1)$ & $80(29.0)$ & 44 (18.5) \\
\hline Antilipemics & $184(35.8)$ & $123(44.6)$ & $61(25.6)$ \\
\hline Anti-aggregates & $141(27.4)$ & $94(34.1)$ & 47 (19.7) \\
\hline Coumarines & $62(12.1)$ & 44 (15.9) & $18(7.6)$ \\
\hline Oral antidiabetics & 51 (9.9) & $37(13.4)$ & $14(5.9)$ \\
\hline Calcium & $100(19.5)$ & $63(22.8)$ & $37(15.5)$ \\
\hline Bisfosfonates & $63(12.3)$ & $38(13.8)$ & $25(10.5)$ \\
\hline Antidepressant & 68 (13.2) & 34 (12.3) & 34 (14.3) \\
\hline Anxiolytics & 109 (21.2) & $62(22.5)$ & 47 (19.7) \\
\hline Paracetamol & $37(7.2)$ & $18(6.5)$ & $19(8.0)$ \\
\hline NSAIDS & $19(3.7)$ & $9(3.3)$ & $10(4.2)$ \\
\hline Morfine & $27(5.3)$ & $17(6.2)$ & $10(4.2)$ \\
\hline Codeine & $20(3.9)$ & $12(4.3)$ & $8(3.4)$ \\
\hline PPI & $231(44.9)$ & $129(46.7)$ & $102(42.9)$ \\
\hline Antibiotics & $52(10.1)$ & 35 (12.7) & $17(7.1)$ \\
\hline Acetylcystein & $46(8.9)$ & $31(11.2)$ & $15(6.3)$ \\
\hline Other & $194(37.7)$ & $110(39.9)$ & $84(35.3)$ \\
\hline
\end{tabular}

Bold printed numbers show significant results $(\mathrm{p} \leq 0.05)$.

Abbreviations: SABA, short-acting beta-agonist; SAMA, short-acting muscarinic antagonist; SABASAMA, Combination short-acting beta-2 agonist \& short-acting muscarinic antagonist; LABA, LongActing Beta-Agonists; LAMA, long-acting muscarinic antagonists; ICS, inhaled corticosteroids; ICSLABA, combination inhaled corticosteroid/long-acting beta agonist; ACE/ARB, angiotensin converting enzyme inhibitors/angiotensin receptor blockers; NSAIDS, nonsteroidal anti-inflammatory drugs; PPI, Proton Pump Inhibitors 



\section{CHAPTER 9}

General Discussion 



\section{HEALTH STATUS: A KEY CONCEPT IN COPD}

COPD is a highly prevalent disease [1] with a substantial economic as well as humanistic burden [2]. Beyond progressive airflow limitation, patients with COPD report an impaired health status [3], decreased physical activity levels [4] and more problems in activities of daily life [5]. However, current assessment of COPD severity primarily focusses on the degree of airflow limitation although this parameter does not reflect the full impact of the disease appropriately [6-8]. Also, it is not well correlated with the patient's perception of symptoms and health status (Figure 1). Consequently, clinicians might be blinded to the impact of the disease for the individual patient and for relevant benefits patients gain from treatment [9].

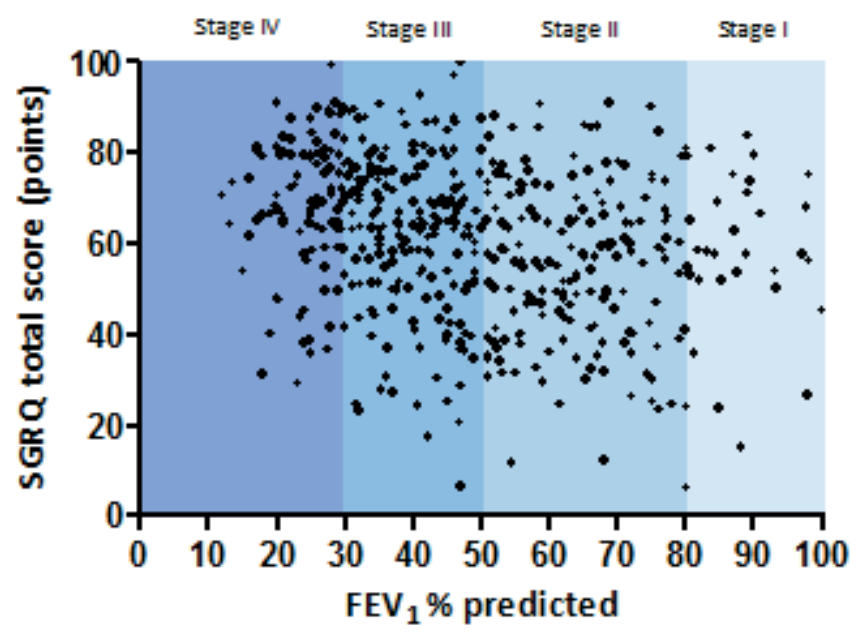

FIGURE 1. Relationship between $\mathrm{FEV}_{1}$ and health status as assessed by the St. George's Respiratory Questionnaire (SGRQ). Data retrieved from the Chance Study [10].

This thesis underlines the importance and complexity of health status measurement in COPD management. As stated before, "health status measurement is a means of quantifying, in a standardised and objective manner, the impact of disease on patients' daily life, health, and wellbeing. It is a process that is essentially similar to a highly structured clinical history, although the end product is not a clinical impression but an objective measurement that can be used for scientific purposes. It is no more "soft" or "touchy-feely" than any well taken clinical history' [11]. 


\section{HEALTH STATUS MEASUREMENT - THE USE OF QUESTIONNAIRES}

In the last decades, there has been growing interest to include health status measures as important outcomes in both clinical management as well as research. Health status can be assessed by disease-specific (i.e., intended to measure the impact of a specific disease) and generic (i.e., intended for general use, irrespective of the underlying disease) instruments [9].

The first aim of this thesis was to assess whether and to what extent one disease-specific questionnaire correlates with generic health status questionnaires at four different time points in patients with advanced COPD; and to determine the correlation between changes in these health status questionnaires during one-year follow-up. Chapter 2 showed that disease-specific and generic health status questionnaires were moderately to strongly correlated at four, eight and 12 months after baseline. However, the correlation between changes over time in these questionnaires was weak to moderate which might be explained by the slight agreement of the direction of changes. This chapter also showed that SGRQ domain scores might be sensitive to changes while the total score was not suggesting that domain scores as well as total scores should be examined to achieve a correct and overall understanding of patients' health status. Furthermore, chapter 2 demonstrated a trend - although not significantly different - that the SGRQ activity domain might generally deteriorate over time while the symptom domain rather improves which has exactly been observed in a recent report [12], again underlying the importance of paying attention to all health status domains. However, another recent report analysing the psychometric properties of the SGRQ concluded that domain scores should be used with care since these do not capture the multidimensionality of this instrument very well [13].

To the best of our knowledge, chapter 2 was one of the first reports studying generic health status as assessed with the Assessment of Quality of Life instrument (AQOL) in patients with COPD. In the meantime, Paddison and colleagues published their report studying the generic properties of the AQoL in a smaller sample of patients with COPD referred for pulmonary rehabilitation and showed a comparable correlation between the AQoL and SGRQ [14]. The authors conclude that the AQoL might be applied as generic health status instrument in patients with COPD.

Since COPD as a multi-system disease requires a comprehensive assessment, it is important to not only assess the disease-specific impact but also the over- 
all burden of the disease on daily functioning and wellbeing [15]. Thus, diseasespecific and generic instruments can complement each other and should preferably be used together to get an overall understanding of the impact of the disease on a patient's life [16]. Weldam and colleagues systematically reviewed the properties of several health status instruments but could not recommend the best health status instrument. However, the authors generally suggested to use disease-specific questionnaires to evaluate health status in patients with COPD [17]. However, the authors aimed to identify the most suitable instrument to assess health status related to the disease. Indeed, disease-specific questionnaires might be more applicable to detect changes or differences in clinical status of the underlying disease [9] but since COPD affects patients' life beyond respiratory symptoms, generic health status questionnaires might give an additional understanding of the overall effects of the disease.

Pakhale and colleagues constructed a new questionnaire (McGill-COPD Quality of Life Questionnaire) by combining items of a disease-specific questionnaire with qualities of a generic questionnaire to measure health status in COPD patients [18] which shows high internal consistency, test-retest reliability, validity and moderate responsiveness in patients with COPD [19]. Recently, another health status questionnaire has been developed by combining several existing questionnaires which correlated well with generic as well as disease-specific questionnaires [20]. However, since a variety of health status questionnaires already exists - which is rather confusing than providing a practical guide for health status assessment in clinical practice and research - the development of new instruments should be discouraged. Instead, studies evaluating the psychometric properties of existing instruments are encouraged contributing to a progression in the field of health status assessment [17].

As suggested before, 'an instrument by itself is not inherently valid, but rather it is valid for the specific uses for which it has been evaluated' [9]. In general, health status questionnaires should be evaluative (i.e., the ability to detect changes with disease progression or treatment) as well as discriminative (i.e., the ability to distinguish between different levels of impaired health between patients) for the purpose at hand [11]. Choosing the right instrument depends on the study objectives, study population and the changes which are planned to be measured and are relevant to patients and physicians [21]. Both, diseasespecific as well as generic health status questionnaires might be suitable measures for the study objective at hand. 


\section{UNDERSTANDING DETERMINANTS AND OUTCOMES OF CHANGES IN HEALTH STATUS}

Chapter 3 aimed to study cross-sectional and longitudinal determinants of change in disease-specific health status and showed that patients who reported a better disease-specific health status, had more symptoms of depression, had worse mobility at baseline, or experienced a deterioration in mobility or an increase in dyspnoea during one year were at risk for a deterioration in diseasespecific health status (chapter 3 ). Our findings have further been supported and extended by recent work in this field [22-24]. Liang and colleagues aimed to study determinants of deterioration in disease-specific health status as assessed with SGRQ in 491 patients with COPD from 10 hospitals. The authors showed that dyspnea grade 4 or 5 and 3 or more exacerbations were independently associated with deterioration in health status [22]. Siebeling and colleagues aimed to study predictors of disease-specific health status as assessed by the Chronic Respiratory Questionnaire (CRQ) at 6 and 12 months follow-up in 490 primary care patients and concluded that the CRQ score at baseline was the best predictor for health status [23]. In addition, the authors suggested that assessing patient-related outcomes, e.g. dyspnea, fatigue, depression and how patients cope with COPD, may provide additional important information about future health status [23]. Monteagudo and colleagues extended our findings and showed in 791 patients with COPD from primary care that deterioration in disease-specific health status was associated with worsening in respiratory symptoms and increased hospitalizations while improvement in health status was associated with starting polymedication, pulmonology visits, balanced diet, quitting smoking, not being a frequent exacerbator and ending respiratory rehabilitation [24]. Interestingly, none of these studies identified the degree of airflow obstruction ( $\left.\mathrm{FEV}_{1}\right)$ as important predictor for (deterioration in) health status which again underlines the importance of multidimensional COPD assessment. Furthermore, a recent study suggested that changes in health status (i.e., changes in SGRQ scores) depend on the component studied and their determinants are markedly different dependent on these components [12].

Chapter 3 reinforces the promotion of physical mobility and the treatment of dyspnoea and depressive symptoms as important components for treatment programs to optimize or stabilize disease-specific health status in patients with advanced COPD. Understanding health status is important to adequately manage the disease. Previously, health status has been shown to be associated with treatment adherence (e.g. completing pulmonary rehabilitation [25] or adherence to medication [26]) and withdrawal from clinical studies [27, 28]. Pulmonary rehabilitation as a multidimensional, interdisciplinary approach has 
been shown to be able to improve dyspnoea, psychological status and health status [29].

Furthermore, chapter 3 showed that there was no relevant change in health status in general but a substantial proportion (43.5\%) of patients with a clinically relevant worsening in disease-specific health status during one year. A previous study in primary care patients with COPD detected a clinically relevant deterioration in health status in nearly one third $(29.2 \%)$ of patients [24]. While a previous report among patients with even more advanced COPD concluded that health status gradually deteriorated over time [30], the current results suggest, in line with a previous report [24], that the overall change was minimal but there was great variability on the individual groups level (e.g. clinically relevant deterioration, improvement or no change).

However, knowledge about the importance of such changes is scarce. Therefore, chapter 4 further investigated the impact of clinically relevant changes in disease-specific health status on outcomes and showed an association between changes in health status and the likelihood of having an exacerbation, hospitalisation and dying. Patients with an improved or stable health status during year one had a lower likelihood of having an exacerbation, hospitalisation or dying during two year follow-up compared with patients who worsened. This again underlines the importance of understanding and interrupting the decline in health status (chapter 3). Also, these findings suggest a prognostic role of health status measurement that may help professionals to identify patients at risk. Furthermore, these findings support the concept of routine monitoring health status of patients with COPD with the aim of improving or at least stabilising their health status. This has further been emphasized by an Editorial underlining the importance of the current findings: 'There is no doubt (...) that we should be actively seeking out those high-risk patients with declining health status. To do this in any clinically meaningful way, health status needs to be measured accurately and regularly, and this needs to be embedded in the routine follow-up of patients with COPD [31].

A previous report showed that patients are able to identify exacerbations based on visible symptoms (e.g. cough) and invisible symptoms (e.g. chest sensations) and used additional self-management strategies during an exacerbation. Thus, health-care professionals and clinicians should keep this 'expert patient' knowledge in mind and use this knowledge to facilitate early awareness and treatment of exacerbations [32]. Further, novel concepts, like illness perception, locus of control and emotional intelligence, may play an important role in treatment strategies to enhance illness understanding and self-management skills $[33,34]$. 
Nonetheless, it is important to note that health status reflects an overall impairment but does not directly cause it: 'It is very likely that not only does impaired health status reflect underlying patho-physiological processes, but also that impaired well-being contributes to those processes' [35]. Consequently, besides the individual evaluation of changes in health status, the assessment of a careful clinical history is required [11]. However, health status remains an important part of the downward spiral between airflow limitation, dyspnea and outcomes in patients with COPD (Figure 2).

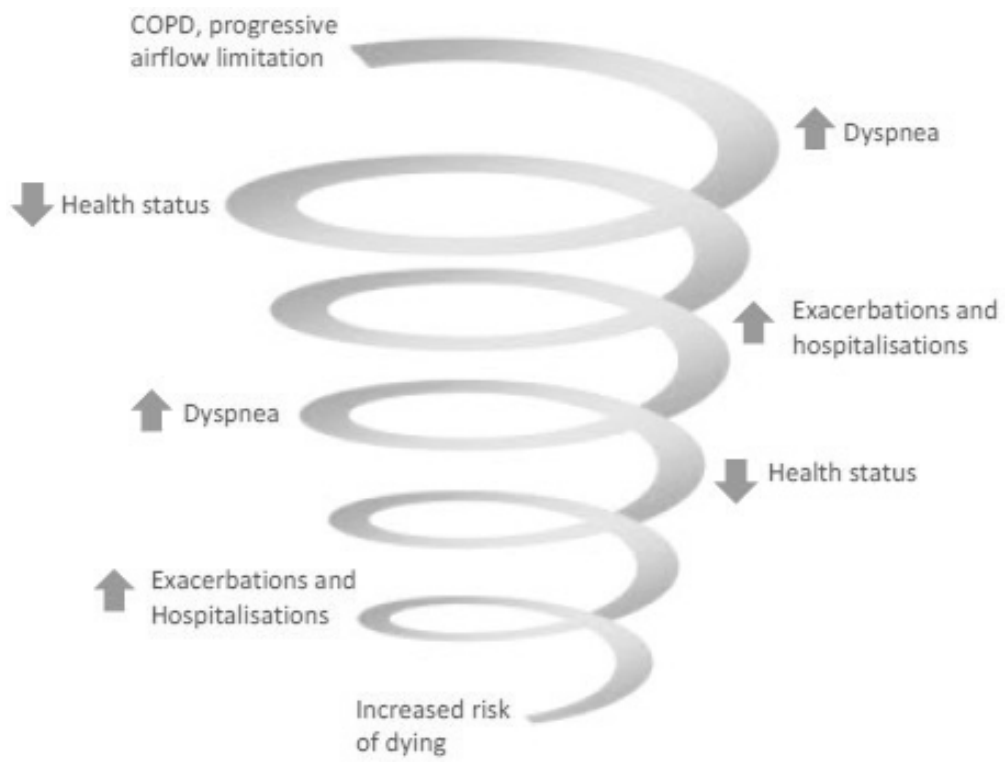

FIGURE 2. Downward spiral regarding progressive airflow limitation [36], increase of dyspnea [37], decline in health status [38], increase of exacerbations and hospitalizations [39] and finally increased risk of dying $[39,40]$.

\section{HEALTH STATUS - ESSENTIAL IN COPD DIAGNOSIS?}

As suggested before, 'there is a need for a measure that can aggregate into a single score the summed effect of the multiple pathophysiological processes that involve different organs and systems' [11]. Health status instruments play an indispensable role in COPD studies but are not widely used in clinical practice yet. These instruments however can be of great advantage because information can systematically be collected [41]. Furthermore, it has previously been stated that health status measurement is an established method for assessing the overall efficacy of treatment for patients with chronic lung disease [42]. 
Given this importance of health status in COPD, the GOLD document recommends to include the assessment of health status as an objective in disease diagnosis and management [36]. To assess the severity of symptoms, the GOLD strategy recommends several tools which might impact patient assignment [43]. Chapter 5 aimed to study the impact of the four GOLD-recommended symptom measures (modified Medical Research Council dyspnea scale, mMRC; COPD Assessment Test, CAT; Clinical COPD Questionnaire, CCQ; and SGRQ) and the two measures for exacerbation risk (exacerbation and hospitalization history) on the frequency distribution of GOLD groups $A$ to $D$, and their clinical characteristics in patients with COPD. This chapter showed that the choice of symptom measure influences the frequency distribution of the new GOLD groups more than the measures for exacerbation risk. Moreover, health status and psychological symptoms differed between different outcome measures used to identify high and low symptom patients, in particular in GOLD groups A and $B$. Health care professionals should be aware that patients differ in terms of health status and symptoms of anxiety and depression based on the symptom measure used. Furthermore, the updated GOLD classification might have a better ability to predict exacerbations [44].

Beyond the multidimensional evaluation of the severity of COPD, the combined COPD assessment has some more advantages. A recent report evaluated predictive factors for inadequate diagnoses among patients with COPD and showed that patients whose physician routinely use health status questionnaires were less likely to be inadequately diagnosed [45]. During the development of the CAT, patients indicated that they would appreciate a method that would enable the assessment of their disease severity and communicate this information to their physicians [46]. Previously, a survey in primary care patients revealed that patients are more satisfied when health status measures are used in routine clinical practice which consequently encourages their compliance to treatment [47]. Furthermore, health status instruments may improve the communication between physicians and patients. Without this tool, physicians are less likely to bring up this subject. Also, it further prevents misunderstandings about the treatment and its usefulness in relation to perceived health status [48]. In addition, physicians might underestimate the impact on patients' health [49]. Finally, patients often experience difficulties in expressing the burden of their disease and physicians do not have sufficient time to collect this information. Thus, using these measures can help patients as well as health care professionals to improve their knowledge about the impact of COPD on patient health [21]. 


\section{HEALTH STATUS AND COMORBIDITIES}

Beyond respiratory impairment, patients with COPD often suffer from coexisting diseases: the majority of patients (up to $98 \%$ ) have one or more comorbidities (Figure 3) $[6,50]$.

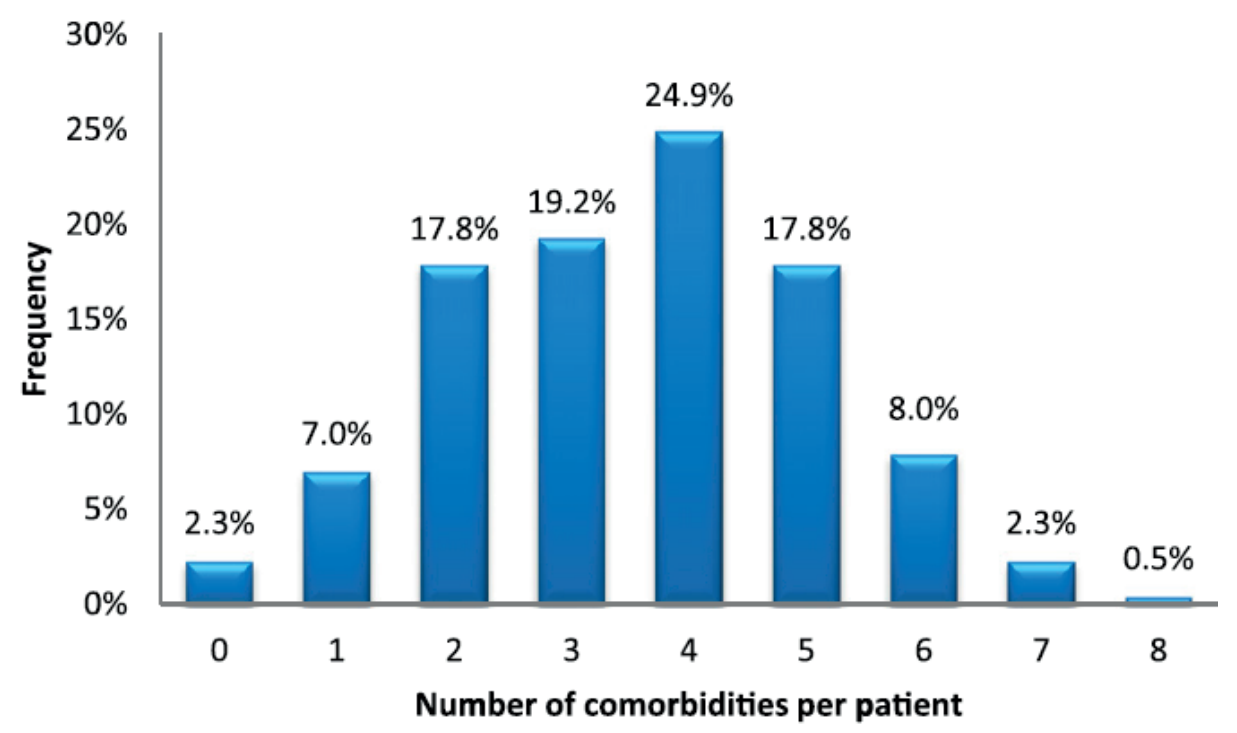

FIGURE 3. Number of objectified comorbidities in 213 patients with COPD [6].

In addition, comorbidities in patients with COPD have a relevant clinical impact [51]; the number of comorbidities has been shown to be correlated with exacerbations [52], hospitalizations [53] and mortality [54]. Therefore, the interest in understanding COPD as a complex multisystem disease is increasing [55].

\section{HEALTH STATUS AND SYMPTOMS OF ANXIETY AND DEPRESSION}

Chapter 6 aimed to assess the impact of symptoms of anxiety and depression on disease-specific health status as assessed by CAT and to investigate the relationship between the updated GOLD classification and symptoms of anxiety and depression in patients with COPD entering pulmonary rehabilitation. The study found that patients with COPD and symptoms of anxiety and/or depression reported worse disease-specific health status as assessed by CAT than patients without these symptoms. In contrast to chapter 5 , symptoms of anxiety and depression were equally distributed across the updated GOLD groups in COPD patients referred for pulmonary rehabilitation. However, chapter 5 aimed to study continuous scores while chapter 6 compared proportions of patients 
with clinically relevant psychological symptoms. Furthermore, only 6 patients (2.0\%) were included in GOLD group A versus 76 (25.4\%), 119 (39.8\%) and 98 (32.8\%) patients in GOLD group B, C and D, respectively. In addition, only patients referred for pulmonary rehabilitation have been studied in chapter 5 demonstrating a convenience sample while a broader population has been included in chapter 6 .

The current results have been supported by previous findings showing that health status in patients with COPD might be worsened by psychological comorbidities $[6,16,56]$. Indeed, a systematic review concluded that anxiety and depression predict health status in patients with COPD [57]. Chapter 6 showed as one of the first the impact of clinically relevant symptoms of anxiety and depression on health status as assessed by CAT. Recently, Silva Junior and colleagues demonstrated that an increased CAT score ( $>20$ points) was associated with major depression diagnosed according to the Diagnostic and Statistical Manual of Mental Disorders criteria [58].

Consequently, psychological comorbidities, i.e. symptoms of anxiety and depression, should be assessed during COPD assessment and clinical management of COPD [59]. Indeed, chapter 3 showed that symptoms of depression are associated with a decline in disease-specific health status. Furthermore, the presence of anxiety and depression was associated with an increased referral to pulmonary rehabilitation [60] which can consequently improve psychological status $[29,61]$. Lower depressed mood has also been suggested as important predictor of completion of pulmonary rehabilitation [62] underlying the need of psychological assessment before pulmonary rehabilitation to preferably reduce dropout [63]. Smith and Wrobel identified ten major comorbidities including anxiety and depression underlying the importance of identification and management of this comorbid condition [51].

\section{HEALTH STATUS AND PERIPHERAL ARTERY DISEASE}

Beyond psychological comorbidities, patients with COPD often suffer from cardiovascular comorbid diseases which are probably the most important coexisting diseases due to their direct impact on survival [64].

Peripheral artery disease (PAD) is a risk factor for further cardiovascular diseases and often described as a "silent killer" as a high prevalence of persons with PAD are asymptomatic and unaware of the disease [65]. Chapter 7 studied PAD in a large cohort of patients with COPD and showed a prevalence of objectively assessed PAD of $8.8 \%$. More than two third of these patients had no PAD in their medical history. PAD was independently associated with older age, cur- 
rent and former smoking behaviour, more severe airflow limitation, higher levels of triglycerides and self-reported hypertension but not with systemic inflammation. Vanfleteren and colleagues studied arterial stiffness as assessed by aortic pulse-wave velocity in patients with COPD and showed that arterial stiffness is increased in patients but also not related to systemic inflammation as assessed with several inflammatory biomarkers [66]. These and our current results suggest a superior impact of other factors on PAD. Chapter 7 identified current smoking behaviour as the strongest predictor for PAD underlying the need of smoking cessation and illustrating a dose-response relationship as suggested earlier [67]. Indeed, changing smoking behaviour has previously been defined as "cornerstone" of improved cardiovascular health since it doubles the risk of all types of cardiovascular diseases [68]. Besides the benefits for cardiovascular health, smoking cessation has been shown to reduce this risk of hospitalisations for chronic conditions in elderly [69]. Furthermore, smoking has been identified as important risk factor for lung cancer in patients with COPD [70], again underlying the importance of smoking cessation in this population.

Patients affected by comorbid PAD had a clinically relevant worse functional capacity as assessed by 6-Minute-Walk-Distance and a clinically relevant worse disease-specific health status as assessed by SGRQ compared to those without PAD. Differences in Timed-Up-and-Go (TUG) test and CAT as well as generic health status were significantly different but not clinically relevant. Diseasespecific health status measures might be more responsive to change or differences in clinical status related to the disease [9]. Indeed, a higher proportion of patients with PAD reported more severe grades of dyspnoea compared to those without PAD. Furthermore, the impairment in disease-specific health status was primarily reflected by the SGRQ activity domain which covers a broader variety of aspects regarding physical activity and mobility than CAT. Thus, diagnosis of comorbid PAD in patients with COPD enhances the understanding of patients' impairment.

Furthermore, patients with comorbid PAD might benefit differently from treatment, e.g. pulmonary rehabilitation. However, Mesquita and colleagues recently showed that objectively identified comorbidities, i.e. atherosclerosis, do not preclude patients from obtaining significant and relevant improvements following pulmonary rehabilitation [71]. Although exercise training has been shown to improve arterial stiffness in patients with COPD [72], a recent report showed that pulmonary rehabilitation is unlikely to reduce peripheral blood pressure [73]. To date, studies concerning the impact of PAD in patients with COPD on (long-term) outcomes are scarce, underlying the importance of future research in this field. 


\section{HEALTH STATUS AND CARDIAC DISEASES}

An observational study among 13,471 subjects included in the Rotterdam study showed that COPD was associated with an increased risk of sudden cardiac death [74]. Recently, cardiac comorbidities have been shown to be associated with an increased risk of mortality in patients with COPD admitted to the intensive care unit [75]. However, under-diagnoses and under-treatment of cardiac risk factors and diseases are common in patients with COPD, probably due to shared risk factors (e.g., smoking) and clinical presentation (e.g., dyspnea) [76, 77]. Rutten and colleagues were one of the first who detected previously unknown heart failure in $20.5 \%$ of primary care patients with COPD [77]. Recently, a prevalence of $64 \%$ of echocardiographic abnormalities have been reported in patients with COPD at their first hospital admission, of which about one third did not have any previously diagnosed heart disease [78]. Thus, patients with COPD are at risk of (undetected) cardiac diseases but the prevalence may differ dependent on the population studied.

Chapter 8 demonstrated the frequency of cardiac abnormalities as objectively assessed by echocardiography and their impact on disease-specific health status in patients with COPD referred for pulmonary rehabilitation. Echocardiographic abnormalities occurred in almost $54 \%$ of the patients, of which $64 \%$ did not have echocardiographic abnormalities in their medical history. Patients diagnosed with echocardiographic abnormalities reported a worse diseasespecific health status compared to those without echocardiographic abnormalities. Differences in health status were more pronounced in patients with increased right ventricular pressure as indication for pulmonary hypertension. Indeed, common symptoms of pulmonary hypertension are dyspnea and fatigue [79] which have previously been shown to be associated with health status in patients with COPD $[3,80]$.

Although the current study only detected a limited impact of echocardiographic abnormalities on health status, early identification and treatment of cardiovascular comorbidities are important to ensure patients' safety and to preferably improve their prognosis. Previous reports underlined the importance of a combined and integrated approach for this 'cardiopulmonary continuum' to objectively identify both diseases at an early stage and to optimize and control respiratory and cardiovascular conditions [76, 81, 82]. Multimorbidity is further a challenge for an effective doctor-patient communication emphasizing the importance of an coordinated and integrated approach including patients, carers and staff members [83]. Furthermore, Geersing and colleagues underlined the need for new research approaches to deal with cardiopulmonary disease and multimorbidity in patients with COPD: comorbidites should be regarded as a 
"friend" and not as a "foe". To date, patients with potentially relevant comorbidities are currently excluded from clinical trials although they should preferably play a key role in clinical research [84].

\section{PULMONARY REHABILITATION - INTERRUPTING THE DOWNWARD SPIRAL}

Once understanding the impact of COPD, e.g. the impact on health status as well as the burden of comorbidities, a multidisciplinary approach plays a central role in the diagnoses and management of this complex, multisystem disease. Pulmonary rehabilitation represents an unique approach in clinical COPD management and has been defined as a "comprehensive intervention based on a thorough patient assessment followed by patient tailored therapies that include, but are not limited to, exercise training, education, and behaviour change, designed to improve the physical and psychological condition of people with chronic respiratory disease and to promote the long-term adherence to healthenhancing behaviours" [29]. Accordingly, patients undergoing pulmonary rehabilitation experience a complex health behaviour change process [85]. Pulmonary rehabilitation has further been described as core component of integrated care of patients with chronic respiratory diseases [86]. Indeed, health transitions, advance care planning and balance have recently been described as novel outcomes to evaluate the efficacy of pulmonary rehabilitation [87] which further underlines the comprehensiveness of pulmonary rehabilitation programs.

Health status has been identified as one of the most important outcomes of pulmonary rehabilitation [88]. Indeed, pulmonary rehabilitation has been shown to vastly improve patients' health status [89-91]. Furthermore, it is important to realize that patients with an impaired health status, younger age and current smoking behavior are at risk for drop-out from pulmonary rehabilitation (but not for non-response) while pulmonary function was not associated with these outcomes [25]. This study underlines the need to assess patient related outcomes, i.e. health status, in a pulmonary rehabilitation setting.

Furthermore, comorbidities should not preclude patients from pulmonary rehabilitation [92], but 'pulmonary rehabilitation staff must be trained to recognise the symptoms and signs of the common comorbidities, since some comorbidities may not have been recognised prior to the patient's enrolment in pulmonary rehabilitation' [93]. In line with a previous report studying the impact of several comorbidities retrieved from medical records on outcomes of pulmonary rehabilitation [92], a recent study showed that objectively identified comorbidities do 
not preclude patients from obtaining significant and relevant improvements following pulmonary rehabilitation [71].

\section{GENERAL CONCLUSION}

In conclusion, this thesis demonstrated that patients with COPD suffer from an impaired health status. Comprehensive health status measurement is challenging, but important and necessary to understand the overall effects and the impact of the disease. Ideally, both, generic as well as disease-specific health status questionnaires, should be used to get an overall understanding of the patients' health status. In addition, health status measurement might play an important role in COPD prognosis. Furthermore, since the assessment of health status has recently been included in the updated GOLD strategy to diagnose and manage COPD, the use and understanding of the instrument at hand is essential. Finally, this theses showed that comorbidities, e.g. symptoms of anxiety and depression, PAD as well as cardiac diseases, even worsen patients' health status. Pulmonary rehabilitation is an adequate, comprehensive approach to interrupt the vicious circle of airflow limitation, dyspnea, impaired health status and worse outcomes in patients with COPD. 


\section{REFERENCES}

1. Mannino DM, Buist AS: Global burden of COPD: risk factors, prevalence, and future trends. Lancet 2007, 370:765-773.

2. Srivastava K, Thakur D, Sharma S, Punekar YS: Systematic review of humanistic and economic burden of symptomatic chronic obstructive pulmonary disease. Pharmacoeconomics 2015, 33:467-488.

3. Janssen DJ, Franssen FM, Wouters EF, Schols JM, Spruit MA: Impaired health status and care dependency in patients with advanced COPD or chronic heart failure. Qual Life Res 2011, 20:1679-1688.

4. Donaire-Gonzalez D, Gimeno-Santos E, Balcells E, Rodriguez DA, Farrero E, de Batlle J, Benet M, Ferrer A, Barbera JA, Gea J, et al: Physical activity in COPD patients: patterns and bouts. Eur Respir J 2013, 42:993-1002.

5. Vaes AW, Wouters EF, Franssen FM, Uszko-Lencer NH, Stakenborg KH, Westra M, Meijer K, Schols AM, Janssen PP, Spruit MA: Task-related oxygen uptake during domestic activities of daily life in patients with COPD and healthy elderly subjects. Chest 2011, 140:970-979.

6. Vanfleteren LE, Spruit MA, Groenen M, Gaffron S, van Empel VP, Bruijnzeel PL, Rutten EP, Op 't Roodt J, Wouters EF, Franssen FM: Clusters of comorbidities based on validated objective measurements and systemic inflammation in patients with chronic obstructive pulmonary disease. Am J Respir Crit Care Med 2013, 187:728-735.

7. Spruit MA, Polkey MI, Celli B, Edwards LD, Watkins ML, Pinto-Plata V, Vestbo J, Calverley PM, Tal-Singer R, Agusti A, et al: Predicting outcomes from 6-minute walk distance in chronic obstructive pulmonary disease. J Am Med Dir Assoc 2012, 13:291-297.

8. Graat-Verboom L, van den Borne BE, Smeenk FW, Spruit MA, Wouters EF: Osteoporosis in COPD outpatients based on bone mineral density and vertebral fractures. $J$ Bone Miner Res 2011, 26:561-568.

9. Curtis JR, Patrick DL: The assessment of health status among patients with COPD. Eur Respir $J$ Supp/2003, 41:36s-45s.

10. Smid DE, Wilke S, Franssen FME, Jones PW, Muris JWM, Wouters EFM, Spruit MAS: The impact of cardiovascular comorbidities on COPD Assessment Test (CAT) and its responsiveness to pulmonary rehabilitation in patients with moderate to very severe COPD: the protocol of the Chance study. BMJ Open 2015, 21:e007536.

11. Jones PW: Health status measurement in chronic obstructive pulmonary disease. Thorax 2001, 56:880-887.

12. Nagai K, Makita H, Suzuki M, Shimizu K, Konno S, Ito YM, Nishimura M: Differential changes in quality of life components over 5 years in chronic obstructive pulmonary disease patients. Int $J$ Chron Obstruct Pulmon Dis 2015, 10:745-757.

13. Paap M, Bode C, Lenferink L, Groen LC, Terwee CB, Ahmed S, Eilayyan O, van der Palen J: Identifying key domains of health-related quality of life for patients with Chronic Obstructive Pulmonary Disease: the patient perspective. Health Qual Life Outcomes 2014, 12:106.

14. Paddison JS, Cafarella P, Frith P: Use of an Australian quality of life tool in patients with COPD. COPD 2012, 9:585-595.

15. Engstrom CP, Persson LO, Larsson S, Sullivan M: Health-related quality of life in COPD: why both disease-specific and generic measures should be used. Eur Respir J2001, 18:69-76.

16. Sundh J, Johansson G, Larsson K, Linden A, Lofdahl CG, Janson C, Sandstrom T: Comorbidity and health-related quality of life in patients with severe chronic obstructive pulmonary disease attending Swedish secondary care units. Int J Chron Obstruct Pulmon Dis 2015, 10:173-183.

17. Weldam SW, Schuurmans MJ, Liu R, Lammers JW: Evaluation of Quality of Life instruments for use in COPD care and research: A systematic review. Int J Nurs Stud 2013, 50:688-707. 
18. Pakhale S, Wood-Dauphinee S, Spahija J, Collet JP, Maltais F, Bernard S, Baltzan M, Rouleau M, Bourbeau J: Combining both generic and disease-specific properties: development of the McGill COPD quality of life questionnaire. COPD 2011, 8:255-263.

19. Pakhale S, Wood-Dauphinee S, Spahija A, Collet JP, Maltais F, Bernard S, Baltzan M, Rouleau M, Bourbeau J: Validation of a new questionnaire with generic and disease-specific qualities: the McGill COPD Quality of Life Questionnaire. Can Respir J2012, 19:367-372.

20. Ninot G, Soyez F, Prefaut C: A short questionnaire for the assessment of quality of life in patients with chronic obstructive pulmonary disease: psychometric properties of VQ11. Health Qual Life Outcomes 2013, 11:179.

21. Jones PW, Price $D$, van der Molen $T$ : Role of clinical questionnaires in optimizing everyday care of chronic obstructive pulmonary disease. Int J Chron Obstruct Pulmon Dis 2011, 6:289-296.

22. Liang L, Lin Y, Yang T, Zhang H, Li J, Wang C: Determinants of health-related quality of life worsening in patients with chronic obstructive pulmonary disease at one year. Chin Med J (Engl) 2014, 127:4-10.

23. Siebeling L, Musoro JZ, Geskus RB, Zoller M, Muggensturm P, Frei A, Puhan MA, ter Riet G: Prediction of COPD-specific health-related quality of life in primary care COPD patients: a prospective cohort study. NPJ Prim Care Respir Med 2014, 24:14060.

24. Monteagudo $M$, Rodriguez-Blanco $T$, Llagostera $M$, Valero $C$, Bayona $X$, Ferrer $M$, Miravitlles $M$ : Factors associated with changes in quality of life of COPD patients: a prospective study in primary care. Respir Med 2013, 107:1589-1597.

25. Selzler AM, Simmonds L, Rodgers WM, Wong EY, Stickland MK: Pulmonary rehabilitation in chronic obstructive pulmonary disease: predictors of program completion and success. COPD 2012, 9:538-545.

26. Agh T, Domotor P, Bartfai Z, Inotai A, Fujsz E, Meszaros A: Relationship Between Medication Adherence and Health-Related Quality of Life in Subjects With COPD: A Systematic Review. Respir Care 2015, 60:297-303.

27. Calverley $\mathrm{PM}$, Spencer $\mathrm{S}$, Willits L, Burge PS, Jones PW: Withdrawal from treatment as an outcome in the ISOLDE study of COPD. Chest 2003, 124:1350-1356.

28. Decramer M, Molenberghs G, Liu D, Celli B, Kesten S, Lystig T, Tashkin DP: Premature discontinuation during the UPLIFT study. Respir Med 2011, 105:1523-1530.

29. Spruit MA, Singh SJ, Garvey C, Zuwallack R, Nici L, Rochester C, Hill K, Holland AE, Lareau SC, Man WD, et al: An official american thoracic society/european respiratory society statement: key concepts and advances in pulmonary rehabilitation. Am J Respir Crit Care Med 2013, 188:e13-64.

30. Habraken JM, van der Wal WM, Ter Riet G, Weersink EJ, Toben F, Bindels PJ: Health-related quality of life and functional status in end-stage COPD: a longitudinal study. Eur Respir J 2011, 37:280-288.

31. McGarvey L: Keeping up appearances: the importance of maintaining health status in COPD. Thorax 2015, 70:813-814.

32. Williams $V$, Hardinge $M$, Ryan S, Farmer A: Patients' experience of identifying and managing exacerbations in COPD: a qualitative study. NPJ Prim Care Respir Med 2014, 24:14062.

33. Mewes R, Rief W, Kenn K, Ried J, Stenzel N: Psychological predictors for health-related quality of life and disability in persons with chronic obstructive pulmonary disease (COPD). Psychol Health 2015:1-31.

34. Benzo RP, Kirsch JL, Dulohery MM, Abascal-Bolado B: Emotional Intelligence: A Novel Outcome Associated with Wellbeing and Self-Management in Chronic Obstructive Pulmonary Disease. Ann Am Thorac Soc 2015.

35. Jones PW: Health status and the spiral of decline. COPD 2009, 6:59-63..

36. Vestbo J, Hurd SS, Agusti AG, Jones PW, Vogelmeier C, Anzueto A, Barnes PJ, Fabbri LM, Martinez FJ, Nishimura M, et al: Global strategy for the diagnosis, management, and prevention of chronic obstructive pulmonary disease: GOLD executive summary. Am J Respir Crit Care Med 2013, 187:347-365. 
of chronic obstructive pulmonary disease: GOLD executive summary. Am J Respir Crit Care Med 2013, 187:347-365.

37. Donaldson GC, Seemungal TA, Patel IS, Lloyd-Owen SJ, Wilkinson TM, Wedzicha JA: Longitudinal changes in the nature, severity and frequency of COPD exacerbations. Eur Respir J 2003, 22:931-936.

38. Wilke S, Spruit MA, Wouters EF, Schols JM, Franssen FM, Janssen DJ: Determinants of 1-year changes in disease-specific health status in patients with advanced chronic obstructive pulmonary disease: A 1-year observational study. Int J Nurs Pract 2015, 21:239-248.

39. Wilke S, Jones PW, Mullerova H, Vestbo J, Tal-Singer R, Franssen FM, Agusti A, Bakke P, Calverley PM, Coxson $\mathrm{HO}$, et al: One-year change in health status and subsequent outcomes in COPD. Thorax 2015, 70:420-425.

40. Garcia-Aymerich J, Serra Pons I, Mannino DM, Maas AK, Miller DP, Davis KJ: Lung function impairment, COPD hospitalisations and subsequent mortality. Thorax 2011, 66:585-590.

41. van der Molen T, Kocks JW: Do health-status measures play a role in improving treatment in chronic obstructive pulmonary disease? Expert Opin Pharmacother 2006, 7:57-61.

42. Jones PW: Interpreting thresholds for a clinically significant change in health status in asthma and COPD. Eur Respir J2002, 19:398-404.

43. Jones PW, Adamek L, Nadeau G, Banik N: Comparisons of health status scores with MRC grades in COPD: implications for the GOLD 2011 classification. Eur Respir J2013, 42:647-654.

44. Chen CZ, Ou CY, Hsu CH, Hsiue TR: Validation of the GOLD 2013 classification in predicting exacerbations and mortality in Taiwanese patients with chronic obstructive pulmonary disease. J Formos Med Assoc 2015.

45. Fernandez-Villar A, Lopez-Campos JL, Represas Represas C, Marin Barrera L, Leiro Fernandez V, Lopez Ramirez C, Casamor R: Factors associated with inadequate diagnosis of COPD: OnSint cohort analysis. Int J Chron Obstruct Pulmon Dis 2015, 10:961-967.

46. Jones PW, Harding G, Berry P, Wiklund I, Chen WH, Kline Leidy N: Development and first validation of the COPD Assessment Test. Eur Respir J 2009, 34:648-654.

47. Haddad S, Potvin L, Roberge D, Pineault R, Remondin M: Patient perception of quality following a visit to a doctor in a primary care unit. Fam Pract 2000, 17:21-29.

48. Janse AJ, Gemke RJ, Uiterwaal CS, van der Tweel I, Kimpen JL, Sinnema G: Quality of life: patients and doctors don't always agree: a meta-analysis. J Clin Epidemio/2004, 57:653-661.

49. Kessler R, Stahl E, Vogelmeier C, Haughney J, Trudeau E, Lofdahl CG, Partridge MR: Patient understanding, detection, and experience of COPD exacerbations: an observational, interviewbased study. Chest 2006, 130:133-142.

50. Schnell K, Weiss CO, Lee T, Krishnan JA, Leff B, Wolff JL, Boyd C: The prevalence of clinicallyrelevant comorbid conditions in patients with physician-diagnosed COPD: a cross-sectional study using data from NHANES 1999-2008. BMC Pulm Med 2012, 12:26.

51. Smith MC, Wrobel JP: Epidemiology and clinical impact of major comorbidities in patients with COPD. Int J Chron Obstruct Pulmon Dis 2014, 9:871-888.

52. Mullerova H, Shukla A, Hawkins A, Quint J: Risk factors for acute exacerbations of COPD in a primary care population: a retrospective observational cohort study. BMJ Open 2014, 4:e006171.

53. Mannino DM, Thorn D, Swensen A, Holguin F: Prevalence and outcomes of diabetes, hypertension and cardiovascular disease in COPD. Eur Respir J 2008, 32:962-969.

54. Ho TW, Tsai YJ, Ruan SY, Huang CT, Lai F, Yu CJ: In-hospital and one-year mortality and their predictors in patients hospitalized for first-ever chronic obstructive pulmonary disease exacerbations: a nationwide population-based study. PLoS One 2014, 9:e114866.

55. Barnes PJ, Celli BR: Systemic manifestations and comorbidities of COPD. Eur Respir J 2009, 33:1165-1185.

56. Miravitlles M, Molina J, Quintano JA, Campuzano A, Perez J, Roncero C: Factors associated with depression and severe depression in patients with COPD. Respir Med 2014, 108:16151625 . 
57. Blakemore A, Dickens C, Guthrie E, Bower P, Kontopantelis E, Afzal C, Coventry PA: Depression and anxiety predict health-related quality of life in chronic obstructive pulmonary disease: systematic review and meta-analysis. Int J Chron Obstruct Pulmon Dis 2014, 9:501-512.

58. Silva Junior JL, Conde MB, de Sousa Correa K, da Silva C, da Silva Prestes L, Rabahi MF: COPD Assessment Test (CAT) score as a predictor of major depression among subjects with chronic obstructive pulmonary disease and mild hypoxemia: a case-control study. BMC Pulm Med 2014, 14:186.

59. Pumar MI, Gray CR, Walsh JR, Yang IA, Rolls TA, Ward DL: Anxiety and depression-Important psychological comorbidities of COPD. J Thorac Dis 2014, 6:1615-1631.

60. Li LS, Caughey G, Johnston K: Comorbidity associated with referral to pulmonary rehabilitation in people hospitalized with chronic obstructive pulmonary disease. J Cardiopulm Rehabil Prev 2014, 34:430-436.

61. da Costa CC, de Azeredo Lermen C, Colombo C, Canterle DB, Machado ML, Kessler A, Teixeira PJ: Effect of a Pulmonary Rehabilitation Program on the levels of anxiety and depression and on the quality of life of patients with chronic obstructive pulmonary disease. Rev Port Pneumol 2014, 20:299-304.

62. Busch AM, Scott-Sheldon LA, Pierce J, Chattillion EA, Cunningham K, Buckley ML, Mazer JM, Blaney CL, Carey MP: Depressed mood predicts pulmonary rehabilitation completion among women, but not men. Respir Med 2014, 108:1007-1013.

63. Tselebis A, Kosmas E, Bratis D, Pachi A, llias I, Harikiopoulou M, Theodorakopoulou E, Velentzas K, Dumitru S, Moussas G, et al: Contribution of psychological factors in dropping out from chronic obstructive pulmonary disease rehabilitation programs. Biomed Res Int 2014, 2014:401326.

64. Mullerova H, Agusti A, Erqou S, Mapel DW: Cardiovascular comorbidity in COPD: systematic literature review. Chest 2013, 144:1163-1178.

65. Dhaliwal G, Mukherjee D: Peripheral arterial disease: Epidemiology, natural history, diagnosis and treatment. Int J Angio/2007, 16:36-44.

66. Vanfleteren LE, Spruit MA, Groenen MT, Bruijnzeel PL, Taib Z, Rutten EP, Op 't Roodt J, Akkermans MA, Wouters EF, Franssen FM: Arterial stiffness in patients with COPD: the role of systemic inflammation and the effects of pulmonary rehabilitation. Eur Respir $J$ 2014, 43:13061315.

67. Willigendael EM, Teijink JA, Bartelink ML, Kuiken BW, Boiten J, Moll FL, Buller HR, Prins MH: Influence of smoking on incidence and prevalence of peripheral arterial disease. $J$ Vasc Surg 2004, 40:1158-1165.

68. Godtfredsen NS, Prescott E: Benefits of smoking cessation with focus on cardiovascular and respiratory comorbidities. Clin Respir J2011, 5:187-194.

69. Tran B, Falster MO, Douglas K, Blyth F, Jorm LR: Smoking and potentially preventable hospitalisation: The benefit of smoking cessation in older ages. Drug Alcohol Depend 2015, 150:85-91.

70. Powell HA, Iyen-Omofoman B, Baldwin DR, Hubbard RB, Tata LJ: Chronic obstructive pulmonary disease and risk of lung cancer: the importance of smoking and timing of diagnosis. $J$ Thorac Onco/2013, 8:6-11.

71. Mesquita R, Vanfleteren LEGW, Franssen FME, Sarv J, Taib Z, Groenen M, Gaffron S, Bruijnzeel $\mathrm{PL}$, Pitta F, Wouters E, Spruit MA: Objectively identified comorbidities in chronic obstructive pulmonary disease: impact on pulmonary rehabilitation outcomes. Eur Respir J2015.

72. Vivodtzev I, Tamisier R, Baguet JP, Borel JC, Levy P, Pepin JL: Arterial stiffness in COPD. Chest 2014, 145:861-875.

73. Canavan JL, Kaliaraju D, Nolan CM, Clark AL, Jones SE, Kon SS, Polkey MI, Man WD: Does pulmonary rehabilitation reduce peripheral blood pressure in patients with chronic obstructive pulmonary disease? Chron Respir Dis 2015.

74. Lahousse L, Niemeijer MN, van den Berg ME, Rijnbeek PR, Joos GF, Hofman A, Franco OH, Deckers JW, Eijgelsheim M, Stricker BH, Brusselle GG: Chronic obstructive pulmonary disease and sudden cardiac death: the Rotterdam study. Eur Heart J 2015. 
75. Ongel EA, Karakurt Z, Salturk C, Takir HB, Burunsuzoglu B, Kargin F, Ekinci GH, Mocin O, Gungor G, Adiguzel N, Yilmaz A: How do COPD comorbidities affect ICU outcomes? Int J Chron Obstruct Pulmon Dis 2014, 9:1187-1196.

76. Hawkins NM, Virani S, Ceconi C: Heart failure and chronic obstructive pulmonary disease: the challenges facing physicians and health services. Eur Heart J 2013, 34:2795-2803.

77. Rutten FH, Cramer MJ, Grobbee DE, Sachs AP, Kirkels JH, Lammers JW, Hoes AW: Unrecognized heart failure in elderly patients with stable chronic obstructive pulmonary disease. Eur Heart J2005, 26:1887-1894.

78. Freixa X, Portillo K, Pare C, Garcia-Aymerich J, Gomez FP, Benet M, Roca J, Farrero E, Ferrer J, Fernandez-Palomeque $\mathrm{C}$, et al: Echocardiographic abnormalities in patients with COPD at their first hospital admission. Eur Respir J2013, 41:784-791.

79. Benisty Jl: Cardiology patient page. Pulmonary hypertension. Circulation 2002, 106:e192-194.

80. Baltzan MA, Scott AS, Wolkove N, Bailes S, Bernard S, Bourbeau J, Maltais F: Fatigue in COPD: prevalence and effect on outcomes in pulmonary rehabilitation. Chron Respir Dis 2011, 8:119128.

81. de Miguel Diez J, Chancafe Morgan J, Jimenez Garcia R: The association between COPD and heart failure risk: a review. Int J Chron Obstruct Pulmon Dis 2013, 8:305-312.

82. Ukena C, Mahfoud F, Kindermann M, Kindermann I, Bals R, Voors AA, van Veldhuisen DJ, Bohm $\mathrm{M}$ : The cardiopulmonary continuum systemic inflammation as 'common soil' of heart and lung disease. Int J Cardio/2010, 145:172-176.

83. Doos L, Bradley E, Rushton CA, Satchithananda D, Davies SJ, Kadam UT: Heart failure and chronic obstructive pulmonary disease multimorbidity at hospital discharge transition: a study of patient and carer experience. Health Expect 2014.

84. Geersing GJ, de Groot JA, Reitsma JB, Hoes AW, Rutten FH: The impending epidemic of chronic cardiopulmonary disease and multi-morbidity: the need for new research approaches to guide daily practice. Chest 2015, 148:865-869.

85. Meis JJ, Bosma CB, Spruit MA, Franssen FM, Janssen DJ, Teixeira PJ, Augustin IM, Wouters $\mathrm{EF}$, de Vries NK, Schols AM, Kremers SP: A qualitative assessment of COPD patients' experiences of pulmonary rehabilitation and guidance by healthcare professionals. Respir Med 2014, 108:500-510.

86. Nici L, ZuWallack R: An official American Thoracic Society workshop report: the Integrated Care of The COPD Patient. Proc Am Thorac Soc 2012, 9:9-18.

87. Spruit MA: Pulmonary rehabilitation. Eur Respir Rev 2014, 23:55-63.

88. Spruit MA, Pitta F, Garvey C, ZuWallack RL, Roberts CM, Collins EG, Goldstein R, McNamara R, Surpas $\mathrm{P}$, Atsuyoshi $\mathrm{K}$, et al: Differences in content and organisational aspects of pulmonary rehabilitation programmes. Eur Respir J2014, 43:1326-1337.

89. da Costa CC, de Azeredo Lermen C, Colombo C, Canterle DB, Machado ML, Kessler A, Teixeira PJ: Effect of a Pulmonary Rehabilitation Program on the levels of anxiety and depression and on the quality of life of patients with chronic obstructive pulmonary disease. Rev Port Pneumol 2014, 20:299-304.

90. Dodd JW, Hogg L, Nolan J, Jefford H, Grant A, Lord VM, Falzon C, Garrod R, Lee C, Polkey MI, et al: The COPD assessment test (CAT): response to pulmonary rehabilitation. A multicentre, prospective study. Thorax 2011, 66:425-429.

91. Moullec G, Laurin C, Lavoie KL, Ninot G: Effects of pulmonary rehabilitation on quality of life in chronic obstructive pulmonary disease patients. Curr Opin Pulm Med 2011, 17:62-71.

92. Carreiro A, Santos J, Rodrigues F: Impact of comorbidities in pulmonary rehabilitation outcomes in patients with chronic obstructive pulmonary disease. Rev Port Pneumol 2013, 19:106-113.

93. Franssen FM, Rochester CL: Comorbidities in patients with COPD and pulmonary rehabilitation: do they matter? Eur Respir Rev2014, 23:131-141. 
SUMMARY

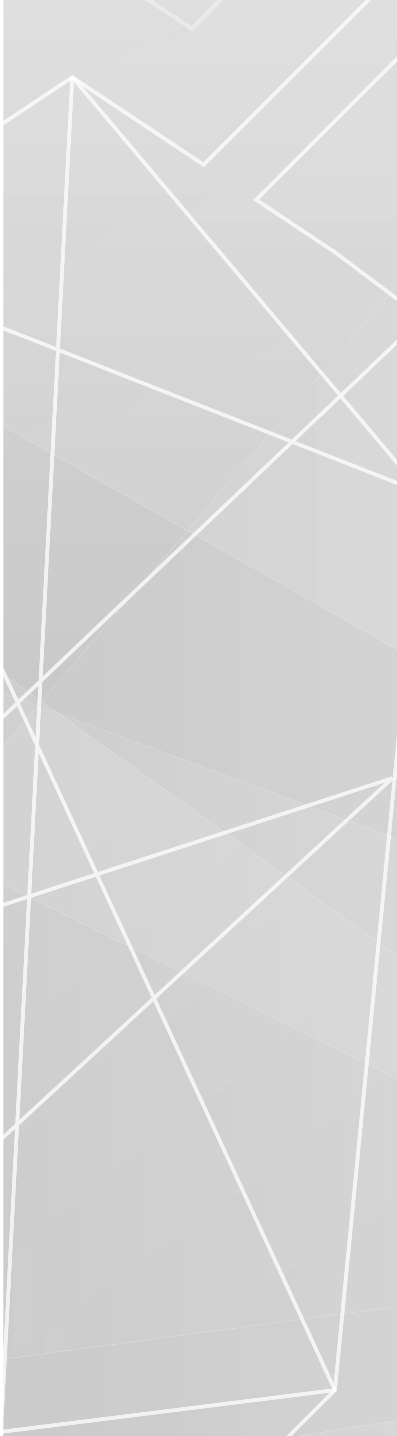



Chronic obstructive pulmonary disease (COPD) is an umbrella term for chronic bronchitis and pulmonary emphysema, both chronic illnesses impairing the airflow in the lungs. Patients with COPD suffer from symptoms like chronic cough, sputum production and/or dyspnoea and report an impaired health status irrespective of the degree of airflow obstruction. Beyond respiratory impairment, patients with COPD often suffer from multiple comorbidities which substantially contribute to the burden of the disease. Since health status and comorbidities are complex concepts in patients with COPD, a better understanding of these concepts will encourage integrated disease management. Therefore, the aim of this thesis is to give an overview of health status measurement as well as determinants of health status and its impact on outcomes in patients with COPD. Further, this thesis will focus on the impact of several comorbidities on health status in patients with COPD (chapter 1).

Numerous questionnaires have been developed in order to assess health status in COPD. Chapter 2 aims to determine whether and to what extent one diseasespecific health status questionnaire correlates with several generic health status questionnaires in patients with advanced COPD. Cross-sectional analyses at baseline, four, eight and 12 months after baseline reveal a moderate to strong correlation between these measures. The correlations between changes over time are weak or even absent which might be explained by the poor or absent agreement in the direction of changes in the different health status questionnaires. Chapter 2 suggests that health care professionals should use diseasespecific as well as generic instruments to gain insight into the disease-specific and general impact of the disease.

Knowledge about determinants of change in health status is scarce. Understanding determinants of change in health status in patients with COPD is crucial to successfully manage COPD and consequently improve health status. Therefore, chapter 3 describes baseline and longitudinal determinants of change in disease-specific health status in patients with advanced COPD and shows that better health status, higher depression scores and worse physical mobility at baseline, as well as a worsening in physical mobility and an increase in dyspnoea during one-year follow-up are predictors of deterioration in diseasespecific health status. This chapter reinforces the stimulation of physical mobility and targeting dyspnoea as components for treatment programs to optimize disease-specific health status in patients with advanced COPD.

Since the impact of changes in health status on outcomes remains unknown, chapter 4 explores the relationship of clinically relevant changes in health status with exacerbation, hospitalization or death in a large cohort of patients with COPD. Patients with stable or improved health status during year 1 have a lower 
likelihood of exacerbation, hospitalization or dying during 2-year follow-up. The current study supports the concept of routine monitoring health and reinforces the clinical importance of improving or at least stabilizing health status in patients with COPD.

Although COPD is a heterogeneous multisystem disease, it is still primarily diagnosed by the degree of airflow obstruction. However, this parameter is only poorly-to-moderately associated with disease activity and progression, extrapulmonary features, comorbidities and prognosis in patients with COPD. Given the importance of health status in COPD, the GOLD document (Global initiative for chronic Obstructive Lung Disease) started to include the assessment of health status as an objective in disease diagnosis and follow-up. Chapter 5 aims to study the impact of the GOLD-recommended symptom measures and the two measures for exacerbation risk on the frequency distribution of GOLD group $A$ to $D$, and their clinical characteristics in patients with COPD. Choice of symptom measure impacts GOLD groups more than choice of exacerbation risk assessment. Health status and psychological symptoms differs between different symptom measures used to identify high and low symptom patients, in particular in GOLD groups A and B. Healthcare professionals should be aware that patients are heterogeneous in terms of health status and symptoms of anxiety and depression based on the outcome measures used.

Beyond respiratory impairment, patients with COPD often suffer from multiple comorbidities which substantially contribute to the burden of the disease. Chapter 6 describes the impact of symptoms of anxiety and depression on health status in patients with COPD referred for pulmonary rehabilitation. Patients without symptoms of anxiety and/or depression have a better health status than patients with symptoms of anxiety, symptoms of depression or both symptoms. Furthermore, symptoms of anxiety and depression are equally distributed across the updated GOLD groups. Accordingly, the assessment of psychological symptoms in patients entering pulmonary rehabilitation, irrespective of the GOLD group, is important.

Because of their direct impact on survival, vascular and cardiovascular diseases are probably the most important coexisting diseases which occur frequently in COPD. Chapter 7 aims to study the prevalence of peripheral artery disease (PAD) and its impact on functional status as well as health status in a large cohort of patients with COPD. PAD was objectively assessed using the anklebrachial index $(\mathrm{ABI})$. Around $9 \%$ of the patients are objectively diagnosed with PAD. Of note, more than two third of these patients did not report PAD in their medical history. Patients affected by comorbid PAD show a worse functional capacity and worse disease-specific health status compared to those without 
PAD. Both differences exceed the thresholds commonly considered as clinically relevant. This chapter suggests that PAD should be considered in studies involving monitoring and interventions in patients with COPD. Moreover, early identification and treatment of comorbid PAD in patients with COPD may mitigate this burden.

Probably due to shared pathophysiological mechanisms, cardiac diseases often remain unrecognized in patients with COPD. The frequency of cardiac diseases as objectively assessed by echocardiography in patients referred for a comprehensive pulmonary rehabilitation (PR) program and the impact on health status is currently unknown. Chapter $\mathbf{8}$ investigates echocardiographic abnormalities and their impact on disease-specific health status in a large cohort of patients with COPD referred for PR. More than half of the patients referred to PR have echocardiographic abnormalities of which two third did not have such abnormalities in their medical history. Most prevalent are left ventricular hypertrophy, increased right ventricular systolic pressure and impaired left ventricular ejection fraction. Although the impact on disease-specific health status in our population is only limited, early identification and treatment are important to understand the effects of concurrent cardiac diseases and may consequently affect the course of the disease.

In conclusion, this thesis demonstrates various concepts of health status in patients with COPD (chapter 10). Comprehensive health status measurement is challenging, but important and necessary to understand the overall effects and the impact of the disease. In addition, health status measurement might play an important role in COPD prognosis. Finally, this theses shows that comorbidities, e.g. symptoms of anxiety and depression, PAD as well as cardiac diseases, even worsen patients' health status. 

SAMENVATTING 

COPD is een afkorting van de Engelse term chronic obstructive pulmonary disease en betekent in het Nederlands chronisch obstructieve longziekte. COPD is een verzamelnaam voor chronische bronchitis en longemfyseem en wordt gekarakteriseerd door een aanhoudende luchtwegvernauwing. Eerste kenmerkende symptomen van COPD zijn hoesten, slijmproductie en/of kortademigheid. Patiënten met COPD ervaren vaak exacerbaties; een tijdelijke, acute verslechtering van de symptomen. Verder rapporteren zij een verminderde kwaliteit van leven, ongeacht de ernst van de luchtwegobstructie. Buiten de respiratoire beperking lijden patiënten met COPD vaak aan bijkomende ziektes, zogenaamde comorbiditeiten, die substantieel bijdragen aan de mate van ziektelast. Kwaliteit van leven en comorbiditeiten zijn complexe concepten binnen het ziektebeeld COPD. Een betere inzicht in deze concepten is belangrijk voor een integraal ziekte management. Het doel van dit proefschrift is om een overzicht te geven van verschillende meetinstrumenten voor kwaliteit van leven, van determinanten van kwaliteit van leven alsook de invloed van verandering in kwaliteit van leven op uitkomsten. Verder bestudeert dit proefschrift de invloed van enkele comorbiditeiten op kwaliteit van leven (hoofdstuk 1).

Talrijke meetinstrumenten werden in het verleden ontwikkeld om de kwaliteit van leven bij patiënten met COPD in kaart te brengen. Het doel van hoofdstuk 2 is om het verband tussen een ziekte-specifieke vragenlijst en vier generieke vragenlijsten te onderzoeken. Cross-sectionele analyses gedurende een jaar follow-up laten een moderaat tot sterk verband zien tussen deze vragenlijsten. Echter, het verband tussen de veranderingen in deze vragenlijsten zijn zwak of zelfs afwezig. Dit is mogelijk te verklaren met het feit, dat er geen of nauwelijks overeenkomst is in de richting van verandering van de verschillende vragenlijsten. Hoofdstuk 2 maakt duidelijk dat zorgverleners en andere health care professionals idealiter ziekte-specifieke als ook generieke instrumenten zouden moeten gebruiken om volledige inzicht te krijgen in de ziekte-specifieke als ook generieke gevolgen van deze ziekte.

Kennis over de determinanten van verandering in kwaliteit van leven is schaars. Begrijpen van deze determinanten is echter cruciaal om COPD succesvol te behandelen en vervolgens de kwaliteit van leven te verbeteren. Daarom beschrijft hoofdstuk 3 de baseline als ook longitudinale determinanten van verandering in ziekte-specifieke kwaliteit van leven bij patiënten met gevorderd COPD. Een betere kwaliteit van leven, hogere depressie scores en een slechtere mobiliteit aan het begin van de studie als ook een verslechtering in fysieke mobiliteit en een toenemende kortademigheid gedurende een jaar follow-up blijken onafhankelijke voorspellers voor een verslechtering in kwaliteit van leven. Hoofdstuk 3 onderstreept het belang van fysieke mobiliteit en dyspneu als componenten 
voor behandelprogramma's om zo de kwaliteit van leven bij patiënten met gevorderd COPD te verbeteren.

Omdat de invloed van klinisch relevante veranderingen in kwaliteit van leven op uitkomsten onbekend is, onderzoekt hoofdstuk 4 het verband tussen een klinisch relevante verandering in ziekte-specifieke kwaliteit van leven en het krijgen van een exacerbatie, hospitalisatie en overlijden in een groot internationaal cohort patiënten met COPD. Patiënten met een stabiele of verbeterde kwaliteit van leven gedurende het eerste jaar hadden een kleinere kans op het krijgen van een exacerbatie, hospitalisatie of overlijden gedurende de volgende twee jaar. Dit hoofdstuk onderstreept het belang om de kwaliteit van leven regelmatig te meten en deze te verbeteren of tenminste te stabiliseren om de prognose te verbeteren.

Hoewel COPD een heterogene ziekte is wordt het vaak primair gediagnosticeerd door de mate van luchtwegobstructie. Echter, deze parameter is maar matig geassocieerd met de ziekteactiviteit en verloop van de ziekte, extra-pulmonaire functies en comorbiditeiten. Gezien het belang van de kwaliteit van leven bij patiënten met COPD, adviseren de GOLD richtlijnen (Internationaal Initiatief voor Chronisch Obstructieve Longziektes) de kwaliteit van leven mee te nemen voor de diagnose van COPD en de follow-up. Het doel van hoofdstuk 5 is om de invloed van de door GOLD aanbevolen instrumenten voor symptomen en de instrumenten voor exacerbatie risico op de verdeling van GOLD groep $A$ tot $D$, en de invloed daarvan op klinische karakteristieken van COPD patiënten te bestuderen. De keuze van het instrument voor symptomen beïnvloedt de verdeling meer dan de keuze van exacerbatie risico assessment. Verder moeten zorgprofessionals zich ervan bewust zijn dat patiënten met betrekking tot kwaliteit van leven, angstige en depressieve symptomen verschillen, afhankelijk van het gebruikte meetinstrument.

Buiten de respiratoire beperking lijden patiënten met COPD ook vaak aan comorbiditeiten die de ziektelast substantieel kunnen beïnvloeden en verergeren. Hoofdstuk 6 beschrijft de invloed van angstige en depressieve symptomen op de kwaliteit van leven bij patiënten met COPD die doorverwezen worden voor longrevalidatie. Patiënten zonder angstige en/of depressieve symptomen hadden een betere kwaliteit van leven vergeleken met patiënten met angstige en/of depressieve symptomen. De proporties patiënten met angstige en/of depressieve symptomen waren niet verschillend tussen de GOLD groepen. Dus, ongeacht de ernst van de ziekte is de evaluatie van psychologische symptomen bij patiënten die starten met longrevalidatie, belangrijk. 
Gezien het direct verband met overleving, zijn vasculaire en cardiovasculaire aandoeningen mogelijk de meest belangrijke en meest voorkomende comorbiditieten bij patiënten met COPD. Hoofdstuk 7 bestudeert de prevalentie van perifeer vaatlijden en de invloed daarvan op functionele status en kwaliteit van leven in een groot cohort patiënten met COPD. Perifeer vaatlijden werd objectief gemeten met de enkel-arm-index. Circa $9 \%$ van de patiënten zijn gediagnosticeerd met perifeer vaatlijden. Meer dan twee derde van deze patiënten heeft geen perifeer vaatlijden in hun medische voorgeschiedenis. Patiënten met perifeer vaatlijden hebben een slechtere functionele status en slechtere kwaliteit van leven vergeleken met patiënten zonder perifeer vaatlijden. Dit hoofdstuk suggereert dat perifeer vaatlijden deel zou moeten uitmaken in studies betreffende monitoring en behandeling van patiënten met COPD. Verder is tijdige identificatie en behandeling van comorbid perifeer vaatlijden belangrijk om de ziektelast te verminderen.

Waarschijnlijk door gemeenschappelijke pathofysiologische mechanismen worden cardiale aandoeningen vaak niet herkend bij patiënten met COPD. Het voorkomen van cardiale aandoeningen, objectief gemeten met echocardiografie bij patiënten die doorverwezen worden voor longrevalidatie en de invloed daarvan op de kwaliteit van leven is op dit moment nog niet bekend. Hoofdstuk 8 onderzoekt echocardiografische afwijkingen en hun invloed op ziekte-specifieke kwaliteit van leven bij patiënten die doorverwezen zijn voor longrevalidatie. Meer dan de helft van deze patiënten heeft een of meer echocardiografische afwijkingen. Ongeveer twee derde van deze patiënten heeft geen afwijking in hun medische voorgeschiedenis. Meest voorkomende afwijkingen zijn linker ventrikel hypertrofie, een verhoogde systolische druk in het rechter ventrikel en een verminderde linker ventrikel ejectiefractie. Hoewel echocardiografische afwijkingen maar een beperkt effect op de kwaliteit van leven hebben, is een vroege opsporing en behandeling belangrijk om de effecten van deze comorbiditeten te begrijpen en uiteindelijk het verloop van de ziekte te beïnvloeden.

Samenvattend demonstreert deze scriptie verschillende concepten van kwaliteit van leven bij patiënten met COPD. Het uitgebreid in kaart brengen van de kwaliteit van leven is uitdagend maar belangrijk en nodig om de volledige effecten en de invloed van de ziekte te begrijpen. Bovendien speelt het meten van kwaliteit van leven een belangrijke rol bij de prognose van COPD. Verder liet dit proefschrift zien dat comorbiditeiten, zoals symptomen van angst en depressie, perifeer vaatlijden en cardiale afwijkingen, de kwaliteit van leven van patiënten met COPD nog kunnen verergeren. 

ZUSAMMENFASSUNG 

Chronic obstructive pulmonary disease (COPD) ist der englische Term für chronisch obstruktive Lungenerkrankung. COPD ist ein Sammelbegriff für Lungenemphysem und chronische Bronchitis; beides sind chronische Erkrankungen, die die Luftströmung in der Lunge beeinträchtigen. Patienten mit COPD leiden unter Symptomen wie chronischem Husten, vermehrter Sputumbildung und / oder Atemnot. Des Weiteren erfahren sie oft eine akute Verschlechterung der Symptomatik, sogenannte Exazerbationen, und berichten über eine beeinträchtigte Lebensqualität unabhängig vom Schweregrad der Atemwegsobstruktion. Neben der Einschränkung der Atemfunktion leiden Patienten mit COPD oft an mehreren Begleiterkrankungen, sogenannten Komorbiditäten, die zu der Krankheitslast beträchtlich beitragen. Lebensqualität und Komorbiditäten sind komplexe Phänomene bei dieser Patientengruppe. Ein ausführliches Verständnis dieser Phänomene können integriertes Krankheits-Management fördern. Folglich ist das Ziel dieser Arbeit, einen Überblick über bestehende Fragebögen zur Lebensqualität zu geben, sowie Determinanten von Lebensqualität und die Auswirkungen der Veränderung von Lebensqualität bei Patienten mit COPD darzustellen. Des Weiteren befasst sich diese Arbeit auf den Einfluss verschiedener Komorbiditäten auf die Lebensqualität bei Patienten mit COPD (Kapitel 1).

Zahlreiche Fragebögen wurden entwickelt, um die Lebensqualität zu messen und zu bewerten. Ziel des 2. Kapitels ist es, festzustellen, ob und in welchem Umfang ein krankheitsspezifischer Fragebogen mit mehreren generischen Fragebögen bei Patienten mit fortgeschrittener COPD korreliert. Querschnittsanalysen beim Studienbeginn, sowie bei vier, acht und 12 Monaten nach Studienbeginn zeigen einen mäßigen bis starken Zusammenhang zwischen diesen Fragebögen. Die Korrelationen zwischen den Veränderungen im Laufe der Zeit waren schwach oder gar nicht vorhanden. Das ist vermutlich durch die schlechte oder nicht vorhandene Übereinstimmung in der Richtung der Veränderungen in den verschiedenen Fragebögen zu erkläre. In Kapitel 2 wird vorgeschlagen, dass krankheitsspezifische sowie auch generische Fragebögen eingesetzt werden sollten, um einen Einblick der gesamten Auswirkung der Krankheit zu gewinnen.

Erkenntnisse zu Determinanten der Veränderung von Lebensqualität bei Patienten mit COPD sind spärlich. Grundlegendes Verständnis zu diesen Determinanten ist entscheidend, um COPD erfolgreich zu behandeln und folglich die Lebensqualität zu verbessern. Daher beschreibt Kapitel 3 Determinanten von krankheitsspezifischer Lebensqualität bei Patienten mit fortgeschrittener COPD: eine bessere Lebensqualität, höhere Depressionswerte und schlechtere physische Mobilität bei Studienbeginn, sowie eine Verschlechterung der physischen Mobilität und eine Zunahme der Atemnot während des nachfolgenden Jahres 
sind Prädiktoren für die Verschlechterung der krankheitsspezifischen Lebensqualität. Diese Studie bekräftigt die Notwendigkeit, die Mobilität von Patienten mit fortgeschrittener COPD zu stimulieren und deren Atemnot zu behandeln. Beides sind demnach wichtige Komponenten für Therapieprogramme zur Verbesserung der krankheitsspezifischen Lebensqualität dieser Patienten.

Da die Auswirkungen einer veränderten Lebensqualität auf die Prognose nicht bekannt ist, untersucht Kapitel $\mathbf{4}$ den Zusammenhang von klinisch relevanten Veränderungen der Lebensqualität mit Exazerbationen, Hospitalisierungen oder Eintritt des Todes in einer großen internationalen Kohorte von Patienten mit COPD. Patienten mit einer stabilen oder verbesserten Lebensqualität im 1. Jahr der Studie haben eine geringere Wahrscheinlichkeit einer Exazerbation, Hospitalisierung oder einer infausten Prognose während der zwei Folgejahre. Diese Studie unterstützt das regelmäßige Erfassen der Lebensqualität und verstärkt die Wichtigkeit der Verbesserung oder mindestens Stabilisierung der Lebensqualität bei Patienten mit COPD .

Obwohl COPD eine heterogene Multisystemerkrankung ist, wird es noch oft hauptsächlich durch das Ausmaß der Atemwegsobstruktion diagnostiziert. Allerdings hängt diese Komponente nur mäßig bis gar nicht mit der Krankheitsaktivität und Progression, sowie extra-pulmonalen Funktionen, Komorbiditäten und Prognose zusammen. Deswegen wurde kürzlich im aktuellsten GOLDReport (globale Initiative für COPD) die Beurteilung der Lebensqualität und der Symptomatik zusätzlich zu den auf der Lungenfunktion basierten Stadien hinzugefügt. Hinzu kommen das Exazerbationsrisiko gemessen an der Häufigkeit von Krankheitsschüben in den vergangenen 12 Monaten (Exazerbationen oder Hospitalisierungen) und die Ausprägung der Symptomatik. Je nach Lebensqualität oder Symptomwahrnehmung, der Lungenfunktion sowie der Anzahl Exazerbationen oder Hospitalisierungen werden Patienten in GOLD Gruppe A (wenig Symptome, niedriges Exazerbationsrisiko) bis GOLD Gruppe D (vermehrte Symptome, hohes Exazerbationsrisiko) klassifiziert. Allerdings werden zur Erfassung der Symptome verschiedene Fragebögen empfohlen. Kapitel 5 zielt darauf $a b$, die Auswirkungen der verschiedenen Instrumente auf die Häufigkeitsverteilung sowie die klinischen Charakteristiken zu untersuchen und zeigt, dass der Fragenbogen zur Symptomatik einen größeren Einfluss auf die GOLDEinteilung hat als die Bewertung des Exazerbationsrisikos. Abhängig vom Fragebogen unterscheiden sich außerdem die Lebensqualität und psychischen Symptome zwischen den verschiedenen GOLD Gruppen. Beschäftigte im Gesundheitswesen sollten sich bewusst sein, dass Patienten, abhängig vom verwendeten Fragebogen, in Bezug auf die Lebensqualität, Angst- und Depressionssymptomen heterogen sind. 
Neben der Einschränkung der Atemfunktion leiden Patienten mit COPD oft an Komorbiditäten, die beträchtlich zur Krankheitslast beitragen. Kapitel 6 beschreibt die Auswirkungen von Angst- und Depressionssymptomen auf die Lebensqualität von Patienten mit COPD, die zu einer pulmonalen Rehabilitation überwiesen wurden. Patienten ohne diese Symptome hatten eine bessere Lebensqualität als die mit Angst- und/oder Depressionssymptomen. Außerdem war die Häufigkeit von Angst- und Depressionssymptomen vergleichbar zwischen allen GOLD-Gruppen. Dementsprechend ist die Beurteilung psychischer Symptome bei den zur Rehabilitation überwiesenen Patienten unabhängig von der GOLD-Gruppe wichtig.

Aufgrund ihrer zentralen Bedeutung sind Gefäß- und Herz-Kreislauf-Erkrankungen wahrscheinlich die wichtigsten Komorbiditäten bei Patienten mit COPD. Kapitel 7 untersucht die Prävalenz der peripheren arteriellen Verschlusskrankheit (pAVK) und deren Einfluss auf die Lebensqualität sowie Leistungsfähigkeit in einer großen Kohorte Patienten mit COPD. Hierbei wurde pAVK objektiv mit dem Knöchel-Arm-Index festgestellt. Bei ungefähr $9 \%$ der Patienten wurde eine pAVK diagnostiziert, wobei bei mehr als zwei Drittel dieser Patienten die Diagnose vorher nicht bekannt war. Verglichen mit Patienten ohne begleitende pAVK, berichteten Patienten mit pAVK eine klinisch relevante schlechtere Lebensqualität sowie Leistungsfähigkeit. Dies sind interessante und wichtige Erkenntnisse für zukünftige Diagnosestellungen und Behandlungen, wie auch das Verständnis des komplexen Krankheitsbildes COPD.

Vermutlich wegen gemeinsamer pathophysiologischen Mechanismen, bleiben Herzerkrankungen bei Patienten mit COPD oft unerkannt. Die Häufigkeit von objektiv festgestellten Herzerkrankungen durch Echokardiographie und die Auswirkungen dieser möglichen Abweichungen auf die Lebensqualität bei Patienten mit COPD ist derzeit nicht bekannt. Kapitel 8 untersucht echokardiographische Anomalien und deren Einfluss auf die krankheitsspezifische Lebensqualität in einer großen Kohorte von Patienten mit COPD, die zur pulmonalen Rehabilitation überwiesen wurden. Mehr als die Hälfte der Patienten hatten echokardiographische Auffälligkeiten, von denen zwei Drittel keinen Befund in ihrer Krankengeschichte hatten. Am häufigsten wird Linksherzhypertrophie, erhöhter rechtsventrikulärer systolischer Druck und eingeschränkte linksventrikuläre Ejektionsfraktion gefunden. Auch wenn der Einfluss dieser Abweichungen auf die Lebensqualität nur klein war, sind Früherkennung und Behandlung wichtig, um die Auswirkungen dieser Komorbiditäten zu verstehen, zu behandeln und folglich den Krankheitsverlauf zu beeinflussen.

Zusammenfassend zeigt diese Arbeit verschiedene Aspekte der Lebensqualität bei Patienten mit COPD (Kapitel 10). Eine umfassende Erfassung der Lebens- 
qualität ist eine Herausforderung, aber wichtig und notwendig, um die Auswirkungen der Krankheit zu verstehen. Darüber hinaus könnte die Erfassung der Lebensqualität eine wichtige Rolle bei der Prognose der Krankheit spielen. Letztlich zeigt diese Arbeit, dass Komorbiditäten, z.B. Angst- und Depressionssymptome, pAVK sowie Herzerkrankungen, die Lebensqualität der Patienten noch zusätzlich beeinträchtigen können. 
VALORIZATION 

Valorization refers to "getting the maximum value and usefulness out of education programs and managed projects, by generalizing what has been learnt from the specialist experiences to other, related fields". Knowledge valorization specifically means the "process of creating value from knowledge, by making knowledge suitable and/or available for social (and/or economic) use and by making knowledge suitable for translation into competitive products, services and new commercial activities".

Given this definition, this chapter will discuss the current findings in the light of the social and economic impact as well as innovative concepts for future health care.

\section{RELEVANCE AND INNOVATION}

This thesis highlighted the importance of health status as an outcome parameter and a target for interventions in patients suffering from the multisystemic, progressive, incurable lung disease COPD. Indeed, as defined in the Global initiative for chronic Obstructive Pulmonary Disease (GOLD) strategy document, one of the goals of COPD management is the enhancement of health status. Furthermore, measuring health status has recently been added to the integrated assessment of COPD, highlighting the importance of understanding this complex concept. This manuscript confirms that health status provides important insights for burden, management and prognosis of COPD. Clear outcomes and hard facts (e.g. lung function, biomarkers, etc.) often play a superior role in COPD diagnosis and treatment, however "health status measurement is a means of quantifying, in a standardized and objective manner, the impact of disease on patients' daily life, health, and wellbeing. It is a process that is essentially similar to a highly structured clinical history [...]. It is no more "soft" [...] than any well taken clinical history" [1]. Of course, it is difficult to make the concept of health status concrete or tangible in clinical practice, but - paying attention to it is a first step in the right direction.

\section{TARGET GROUPS}

Health status can be defined as "the impact of health on a person's ability to perform and derive fulfilment from the activities of daily life" [2]. The key word here is "health"; health has been defined as "the ability to adapt and manage one's own wellbeing, in light of the physical, emotional and social challenges of life" [3]. Promoting patients' health, preventing risk and reducing symptoms are key concepts for COPD management and play an important role for future health care. 


\section{Health care professionals}

Given the fact that both health as well as health status are multidimensional, health care professionals from several disciplines are involved in the appropriate diagnoses and treatment of COPD. Pulmonary rehabilitation, as an individualized, interdisciplinary, cost-effective approach, has been shown to positively impact patients' health. Pulmonary rehabilitation aims "to improve the physical and psychological condition of people with chronic respiratory disease and to promote the long-term adherence to health-enhancing behaviors" [4].

Health care professionals are encouraged to assess health status as an important part for COPD diagnoses and patient classification. However, there is one important condition which needs to be fulfilled: providing time for it. A real challenge in times of time efficiency and cost cuts - but crucial for personalized medicine and understanding the patient and the patient's health status which may allow establishing the right treatment for the best outcome. Furthermore, health care professionals should trust the patients' perception and knowledge; patients are able to identify exacerbations based on several visible as well as invisible symptoms and are able to apply self-management strategies to manage their disease. This facilitates early awareness as well as timely treatment.

This thesis also underlines the importance of objectively assessing cardiovascular comorbidities in COPD. Echocardiography as well as the Ankle-BrachialIndex as non-invasive methods to assess cardiac and peripheral vascular diseases, respectively, should be considered as efficient measures to evaluate the complexity of the disease while timely and appropriate treatment can further improve the course of the disease. Echocardiography as well as the AnkleBrachial-Index might be considered as clinically meaningful instruments for COPD screening and/or pre-rehabilitation assessment.

\section{Patients with COPD}

The patient is currently - and will be in the future - an important member of the interdisciplinary treatment team. Therefore, patients are encouraged to express their health status and to be involved in the process of active information seeking. They are encouraged to be conscious about their feelings, perceptions and symptoms. In this context, self-awareness and self-evaluation are important aspects which may lead to self-control, one of the key concepts of future health care: encouraging the patients' functionality and independency, adaptability and flexibility as well as control, autonomy and self-management. Finally, patients 
are stimulated to be open for multidisciplinary disease management strategies as well as new diagnostic and treatment opportunities.

\section{ACTIVITIES AND PRODUCTS}

A part of valorization is dissemination which includes the process of broadcasting a message to the public. The current findings have been presented during the European Respiratory Society (ERS) Congress in 2012, 2013, 2014 and 2015 as well as during the American Thoracic Society (ATS) Congress in 2015. During the ERS Congress in 2013, the abstract entitled Echocardiographic abnormalities in patients with COPD entering pulmonary rehabilitation has been granted with the Award for "Best Abstracts in Rehabilitation and Chronic Care". Furthermore, the results have led to original articles and a research letter published in scientific international journals and have been presented during workshops and courses organized by CIRO and other institutions.

Given this publicity, the current findings have been distributed and are basis and inspiration for future research questions. The current findings may further provoke discussion about the use of questionnaires and if existing instruments can even be replaced with new and/or alternative ones. 


\section{REFERENCES}

1. Jones PW: Health status measurement in chronic obstructive pulmonary disease. Thorax 2001, 56:880-887.

2. Curtis JR, Patrick DL: The assessment of health status among patients with COPD. Eur Respir $J$ Supp/2003, 41:36s-45s.

3. Huber M, Knottnerus JA, Green L, van der Horst H, Jadad AR, Kromhout D, Leonard B, Lorig K, Loureiro MI, van der Meer JW, et al: How should we define health? BMJ2011, 343:d4163.

4. Spruit MA, Singh SJ, Garvey C, Zuwallack R, Nici L, Rochester C, Hill K, Holland AE, Lareau SC, Man WD, et al: An official american thoracic society/european respiratory society statement: key concepts and advances in pulmonary rehabilitation. Am J Respir Crit Care Med 2013, 188:e13-64. 
ACKNOWLEDGEMENTS 

Alleen was het schrijven van dit boekje mij niet gelukt. Daarom wil ik een aantal personen bedanken die een speciale bijdrage hebben geleverd aan de totstandkoming van dit proefschrift. En ik had nooit gedacht dat dit zo moeilijk zou zijn..., maar laat ik beginnen bij het begin en hopelijk niemand vergeten.

Allereerst wil ik alle vrijwillige deelnemers bedanken die hebben deelgenomen bij de in dit proefschrift beschreven onderzoeken. Zonder hen was het helemaal niet mogelijk geweest, hartelijk dank!

Professor Wouters, hartelijk dank voor uw professionele begeleiding en kritische blik als promotor tijdens mijn promotietraject en bij het schrijven van dit proefschrift. Ook wil ik u en Ingrid Augustin danken voor het vertrouwen en de kans om na mijn promotieonderzoek mijn kennis en vaardigheden binnen de Longcentra Nederland verder uit te breiden en toe te passen.

Beste Frits en Martijn, ik kan jullie als mijn copromotoren niet genoeg danken voor jullie professionele begeleiding, betrokkenheid, aanstekelijke gedrevenheid en enthousiasme. Ondanks de persoonlijke begeleiding hebben jullie mij voldoende ruimte gelaten om me zelf te kunnen ontwikkelen. Dank voor jullie vertrouwen, tijd en geduld.

De tijd tot de goedkeuring van de Chance Studie mocht ik overbruggen met het analyseren van jouw data. Beste Daisy, dank voor je vertrouwen en leerzame begeleiding bij het schrijven van de eerste twee artikelen van dit proefschrift.

Beste Gosia en Nicole, dank voor jullie inzet voor de Chance Studie. Gosia, ik weet dat het verkrijgen van een optimaal echo-venster bij onze onderzoekspopulatie nogal uitdagend was. Dankzij je ervaring en professionaliteit is het je (meestal) toch gelukt. Nicole, dankjewel voor het beoordelen van alle echouitslagen en het scoren van de ECG's. Ik ben je erg dankbaar voor al het extra werk.

Lieber Henrik, danke für die Gastfreundschaft und die lehrsamen Wochen am Pneumologischen Forschungsinstitut an der LungenClinic Grosshansdorf. Danke für das entgegengebrachte Vertrauen und die Möglichkeit, einen kleinen Teil des einzigartigen COSYCONET-Datensatzes analysieren zu dürfen.

Beste coauteurs, dear coauthors, liebe Koautoren, dank voor uw waardevolle feedback, thank you for your useful feedback, danke für Ihr wertvolles Feedback! Dear professor Jones, dear Hana, thank you for the opportunity to analyze a part of the unique and impressive data from the ECLIPSE study. Christina, 
thank you for sharing your data with us. Margarethe, danke für die feine Zusammenarbeit.

Bijzondere dank aan de sponsoren van het onderzoek, het Longfonds en GlaxoSmithKline, die de Chance Studie en mijn promotietraject mogelijk hebben gemaakt.

Lieve Ivy, dank voor het bijwerken van de data. Geen taak was je te veel gevraagd. Nu wens ik jou heel veel succes met jouw promotieonderzoek!

Hartelijk dank aan de leden van de beoordelingscommissie van dit proefschrift, bestaande uit voorzitter prof. Dr. Crijns, prof. Dr. Blasi, prof. Dr. Kooman, prof. Dr. Siafakas en prof. Dr. Smeenk voor hun kritische beoordeling en goedkeuring van het manuscript.

Mijn lieve collega's, roomies en lotgenoten - Anouk, Carmen, Cindy, Coby, Dionne B., Dionne S., Esther, Fiona, Jeannet, Nienke, Rafael, Vasilis, Wai-Yan - wat hebben wij een geweldige en bijzondere tijd met z'n allen (gehad)! Voor jullie sta ik graag vroeg op, voor jullie is geen weg te ver, voor jullie verdraag ik zelfs de geur van de champignonsoep. Ik ben ontzettend dankbaar dat ik deze intense tijd met jullie mocht delen. Bedankt voor jullie betrouwbaarheid, steun, appjes, snoepjes, kaartjes, cadeautjes,... Onwijs bedankt voor alles! Nu wens ik jullie heel veel succes bij het afronden van jullie onderzoeken en proefschriften.

Beste Miriam, dank voor je omvangrijke adviezen en de tijd die je je telkens voor elke statistische vraag nam.

Alle overige CIRO collega's, bedankt voor jullie medewerking en begrip voor wetenschappelijk onderzoek. Ik ben ontzettend blij en trots om mijn promotieonderzoek bij CIRO gedaan te mogen hebben.

Katharina Schmidt, liebe Kaddi, vielen, vielen Dank für das gelungene Cover Design! Nach unzähligen Emails, Ideen, Änderungs- und Extrawünschen ist schlussendlich ein großartiger Entwurf draus geworden. Danke! Lieben Dank an dieser Stelle auch an Beke, die diesen Kontakt gelegt hat.

Meine lieben Maastrichter Mädels, Amrei, Anna, Belle, Bördy, Kraisty, Medi und Suse - als ich vor 8 Jahren mit meinem Koffer nach Maastricht gereist bin, um dort den Sprachkurs und später das Studium anzutreten, habe ich nicht im Entferntesten geahnt, dass ich hier solche fantastischen Freundinnen fürs Leben kennen lernen werde. Die Studienzeit ging mit euch noch viel schneller als schnell vorbei. Danke, dass es euch gibt! 
Meine lieben Mädels aus dem Norden, Anne, Beke und Chrissi - obwohl wir uns leider nur (viel zu) selten sehen können, zehre ich immer lange von unseren Treffen. Oft tut es schon gut, zu wissen, dass ihr da seid. Danke!

Belle und Chrissi, meine beiden Paranimfen (zu Deutsch: Begleiter des Doktoranden), euch gilt ganz besonderer Dank. Ich weiß, dass ihr die Richtigen für diesen Job seid. Mit euch an meiner Seite bzw. hinter mir (jetzt wird mir die Bedeutung der Redewendung "hinter einem stehen" erstmal richtig bewusst), kann nichts mehr schief gehen. Danke für eure treue Freundschaft!

Liebe Mama, lieber Papa, lieber Jonas, danke für eure grenzenlose (im wahrsten Sinne des Wortes) Unterstützung und Liebe, euren Stolz, eure zahlreichen Besuche und vielen, vielen Päckchen aus der Heimat mit den lieben Worten und manchmal wirklich notwendiger Nervennahrung und dem neusten Lesestoff. Obwohl wir uns leider nur selten sehen, seid ihr immer da - und das tut einfach nur gut!

Mijn lieve Rik, waar moet ik beginnen... Met jou is het leven gewoon zo veel mooier! Dankjewel voor je oneindige begrip en geduld. Ik kijk uit naar onze toekomst met onze eigen kleine familie en kan niet wachten totdat ik me heel trots jouw vrouw mag noemen. To love you, again and again... 

CURRICULUM VITAE 

Sarah Wilke werd geboren op 15 maart 1987 in Wippra (Duitsland). In 2006 behaalde ze haar Allgemeine Hochschulreife aan het Niedersächsische Internatsgymnasium te Bad Bederkesa in Duitsland. $\mathrm{Na}$ een jaar werken rondde ze in de zomer 2007 eerst haar talencursus Nederlands af en startte vervolgens met haar studie Gezondheidswetenschappen aan de Universiteit Maastricht. In 2011 behaalde ze haar doctoraal diploma met het predicaat cum laude. In hetzelfde jaar is Sarah gestart met haar promotieonderzoek naar de kwaliteit van leven bij patiënten met COPD onder leiding van prof. dr. Emiel Wouters, dr. Frits Franssen en dr. Martijn Spruit bij CIRO in Horn. Eind 2014 heeft zij een werkbezoek gebracht aan het Pulmonary Research Institute aan de LungClinic Grosshansdorf in Duitsland. Onder leiding van dr. Henrik Watz analyseerde zij een deel van de data van de German COPD and Systemic Consequences-Comorbidities Network (COSYCONET) cohort studie (hoofdstuk 7). Door middel van een travel grant van de Deutsche Lungenstiftung kon ze de resultaten van dit onderzoek tijdens het American Thoracic Society (ATS) Congres in Denver, Colorado, Verenigde Staten, presenteren. De bevindingen van dit promotieonderzoek werden op verschillende nationale en internationale congressen gepresenteerd en resulteerden 2013 in de European Respiratory Society (ERS) Grant for Best Abstracts in Rehabilitation and Chronic Care. 

LIST OF PUBLICATIONS 

Wilke, S., Gubbels, J.S., Mulder, S. \& Kremers, S.P.J. (2012). Pedagogisch medewerkers als rolmodel. Management Kinderopvang, 18(3), 24-25.

Wilke, S., Janssen, D.J., Wouters, E.F., Schols, J.M., Franssen, F.M. \& Spruit, M.A. (2012). Correlations between disease-specific and generic health status questionnaires in patients with advanced COPD: a one-year observational study. Health and Quality of Life Outcomes, 10, 98.

Wilke, S., Opdenakker, C., Kremers, S.P. \& Gubbels, J.S. (2013). Factors influencing childcare workers' promotion of physical activity in children aged 0-4 years: a qualitative study. Early Years, 33(3), 226-238.

Hilmarsen, C.W., Wilke, S., Engan, H., Spruit, M.A., Rodenburg, J., Janssen, D.J., Steinshamn, S., Jones, P., Wouters, E.F., Oldervoll, L. \& Franssen, F.M. (2014). Impact of symptoms of anxiety and depression on COPD Assessment Test scores. European Respiratory Journal, 43(3), 898-900.

Wilke, S., Smid, D.E., Spruit, M.A., Janssen, D.J., Muris, J.W., van der Molen, T., van den Akker, M., Jones, P.W., Wouters, E.F.M. \& Franssen, F.M. (2014). The 2014 Updated GOLD Strategy: A Comparison of the Various Scenarios. Chronic Obstructive Pulmonary Diseases: Journal of the COPD Foundation, 1(2): 212220.

Wilke, S., Spruit, M.A., Wouters, E.F., Schols, J.M., Franssen, F.M. \& Janssen, D.J. (2015). Determinants of 1-year changes in disease-specific health status in patients with advanced chronic obstructive pulmonary disease: A 1-year observational study. International Journal of Nursing Practice, 21(3): 239-248.

Wilke, S., Jones, P.W., Müllerova, H., Vestbo, J., Tal-Singer, R., Franssen, F.M., Agusti, A., Bakke, P., Calverley, P.M., Coxson, H.O., Crim, C., Edwards, L.D., Lomas, D.A., MacNee, W., Rennards, S.I., Yates, J.C., Wouters, E.F.M. \& Spruit, M.A. (2015). One-year change in health status and subsequent outcomes in chronic obstructive pulmonary disease. Thorax, 70(5):420-425.

Cleutjens, F., Triest, F., Wilke, S., Vanfleteren, L.E., Franssen, F.M., Janssen, D.J., Rutten, E.P., Spruit, M.A. \& Wouters, E.F. (2015). New insights in chronic obstructive pulmonary disease and comorbidity. American Journal of Respiratory Critical Care Medicine, 191(9):1081-41082.

Smid, D.E., Wilke, S., Jones, P.W., Muris, J.W., Wouters, E.F.M., Franssen, F.M.E. \& Spruit, M.A. (2015). Impact of cardiovascular comorbidities on COPD Assessment Test (CAT) and its responsiveness to pulmonary rehabilitation in pa- 
tients with moderate to very severe COPD: protocol of the Chance study. BMJ Open, 5(7):e007536.

Wilke S., Spruit, M.A., Uszko-Lencer, N.H.M.K., Otkinsa, G., Vanfleteren, L.E.G.W., Jones, P.W., Wouters, E.F.M. \& Franssen, F.M.E. Echocardiographic abnormalities and their impact on health status in patients with chronic obstructive pulmonary disease referred for pulmonary rehabilitation. Submitted.

Wilke, S., Jörres, R.A., Bals, R., Franssen, F.M.E., Gläser, S., Holle, R., Karch, A., Koch, A., Magnussen, H., Obst, A., Schulz, H., Spruit, M.A., Wacker, M., Welte, T., Wouters, E.F.M., Vogelmeier, C. \& Watz, H. Prevalence of peripheral artery disease and its impact in patients with COPD in the COSYCONET study. Submitted.

Braeken, D.C.W., Wilke, S., Smid, D.E., Rohde, G.G.U., Drijkoningen, J.J.C., Wouters, E.F.M., Spruit, M.A. \& Franssen, F.M.E. Sputum microbiology predicts health status in COPD. Submitted.

Mesquita, R., Franssen, F.M.E, Wilke, S., Uszko-Lencer, N.H.M.K., Vanfleteren, L.E.G.W., Goërtz, Y.M.J., Pitta, F., Wouters, E.F.M. \& Spruit, M.A. Does impaired left ventricular ejection fraction affect patient-related outcomes in COPD after adjusting for confounders? Submitted.

Mesquita, R., Wilke, S., Smid, D.E., Janssen, D.J.A., Franssen, F.M.E., Probst, V.S., Wouters, E.F.M., Muris, J.W.M., Pitta, F. \& Spruit, M.A. Measurement properties of the Timed Up \& Go test in patients with COPD. Submitted.

Wacker, M.E., Jörres, R.A., Karch, A., Wilke, S., Heinrich, J., Karrasch, S., Koch, A., Schulz, H., Watz, H., Leidl, R., Vogelmeier, C. \& Holle, R. for the COSYCONETConsortium. Assessing health-related quality of life in COPD: comparing generic and disease-specific instruments in COPD patients with focus on comorbidities. Submitted. 
